\title{
TÓPICOS EM \\ CIÊNCIAS DA SAÚDE
}

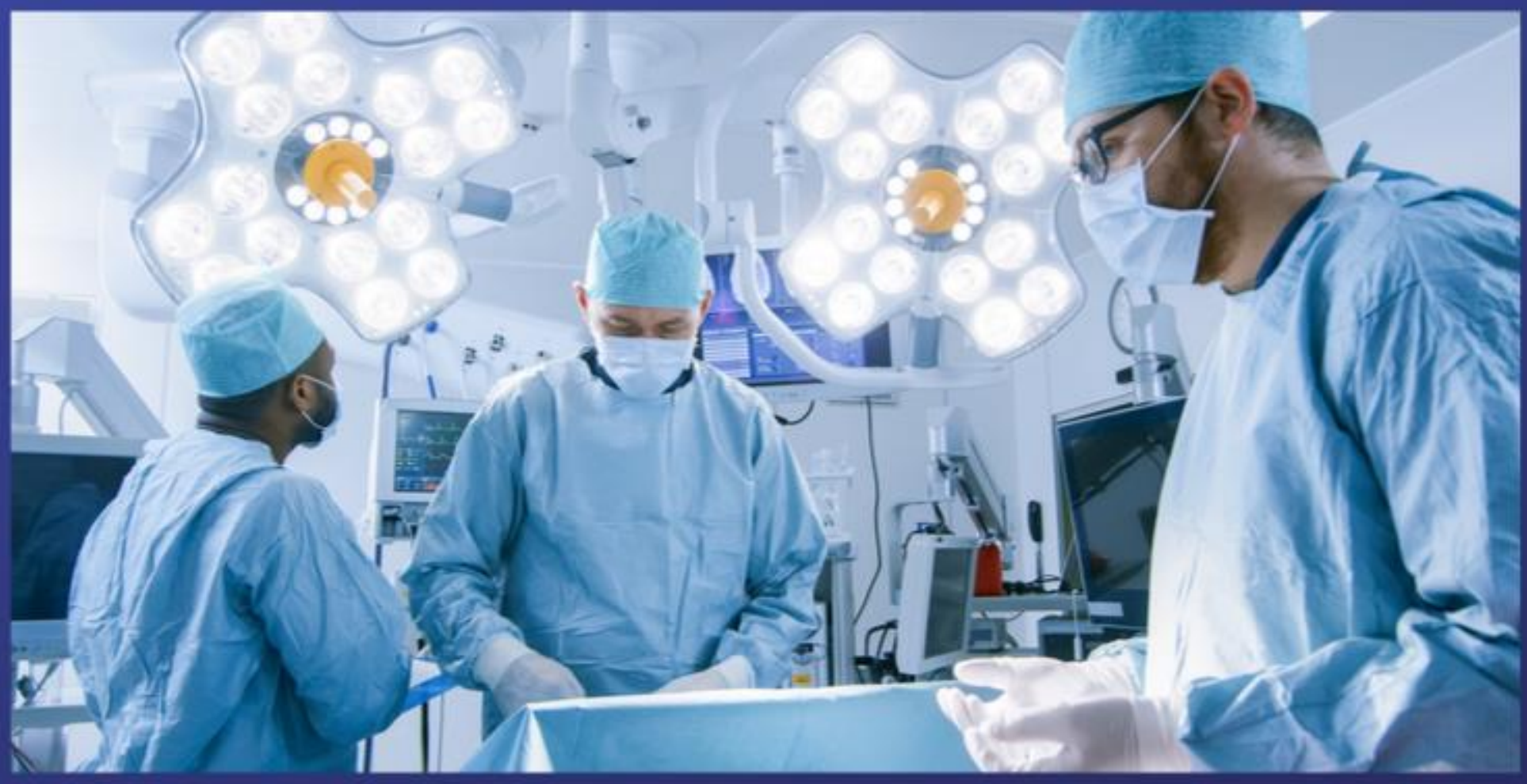

VOLUME 12

口象算回

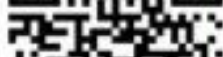

ict?

回陆和

< $>$ Editora Poisson 
Editora Poisson

\section{Tópicos em Ciências da Saúde Volume 12}

1ạ Edição

Belo Horizonte

Poisson

2019 
Editor Chefe: Dr. Darly Fernando Andrade

\section{Conselho Editorial}

Dr. Antônio Artur de Souza - Universidade Federal de Minas Gerais Msc. Davilson Eduardo Andrade

Dra. Elizângela de Jesus Oliveira - Universidade Federal do Amazonas

Msc. Fabiane dos Santos

Dr. José Eduardo Ferreira Lopes - Universidade Federal de Uberlândia

Dr. Otaviano Francisco Neves - Pontifícia Universidade Católica de Minas Gerais

Dr. Luiz Cláudio de Lima - Universidade FUMEC

Dr. Nelson Ferreira Filho - Faculdades Kennedy

Msc. Valdiney Alves de Oliveira - Universidade Federal de Uberlândia

Dados Internacionais de Catalogação na Publicação (CIP)

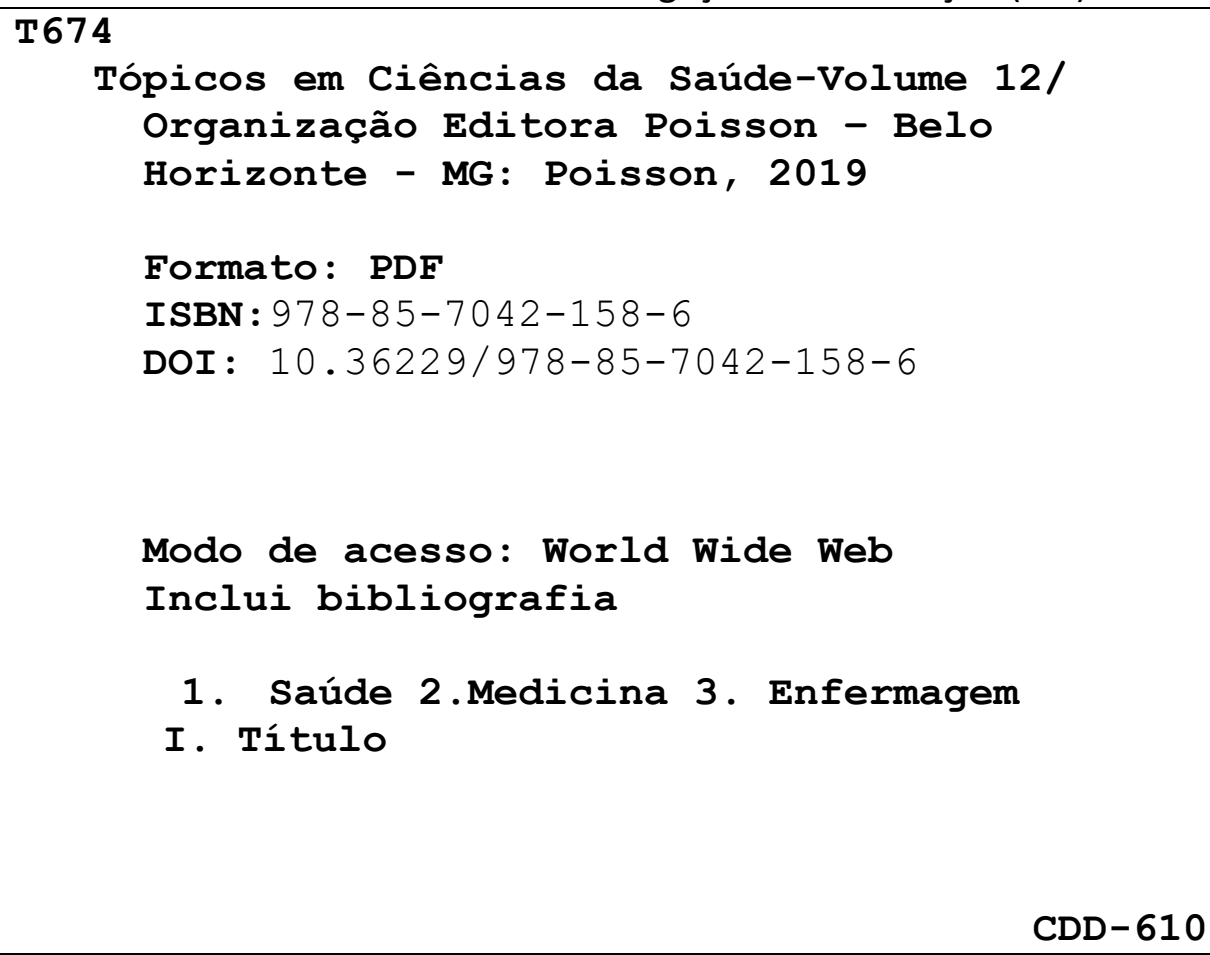

1. Saúde 2.Medicina 3. Enfermagem

I. Título

O conteúdo dos artigos e seus dados em sua forma, correção e confiabilidade são de responsabilidade exclusiva dos seus respectivos autores.

$\underline{\text { www.poisson.com.br }}$

contato@poisson.com.br 


\section{SUMÁRIO}

Capítulo 1: Qualidade de vida na terceira idade: A influência da arquitetura na melhoria das condições de vida dos idosos. 07

Yane Santana de Almeida, Mariana Dominato Abrahão Cury, Emanuel Sá Resende Pedroso DOI: $10.36229 / 978-85-7042-158-6 . C A P .01$

Capítulo 2: Programas de promoção da atividade física de idosos: Efeito na qualidade de vida 12

Fabiana Cristina Scherer, Aline Mendes Gerage, Anderson da Silva Honorato, Bruna Prado Gomes, Camila Pereira, Tânia Rosane Bertoldo Benedetti DOI: $10.36229 / 978-85-7042-158-6 . C A P .02$

Capítulo 3: Realização de um bingo em uma instituição de longa permanência: Um relato de experiência

Álef Lamark Alves Bezerra, Nayara Batista Marques, Vanessa Souto Maior, José Artur de Paiva Veloso DOI: $10.36229 / 978-85-7042-158-6 . C A P .03$

Capítulo 4: Promovendo o lugar de fala: Relato de experiência com idosas da universidade aberta à maturidade em observância dos aspectos biopsicossociais que envolvem o envelhecimento humano. 26

Fabrício Miguel dos Santos, Drielle Barbosa Leal Serafim, Millena Caroline Gomes Rodrigues, Tiago Uriatã de Vasconcelos Costa, Antônio Guedes Rangel Júnior DOI: $10.36229 / 978-85-7042-158-6 . C A P .04$

Capítulo 5: Zooterapia aplicada a melhor idade

Grazielly Diniz Duarte, Milane Sales de Souza, Soraya Abrantes Pinto de Brito, Felipe Eduardo da Silva Sobral

DOI: $10.36229 / 978-85-7042-158-6 . C A P .05$

Capítulo 6: 0 real papel do enfermeiro em suas atribuições ao cuidado do idoso no serviço de atenção domiciliar: Revisão da literatura

Flávio Medeiros Guimarães, Kézia Katiane Medeiros da Silva, Gabriella Souza de Azevedo, Francisco Jalisson de Almeida e Silva, Nádia Rocely Souto de Almeida Lima DOI: $10.36229 / 978-85-7042-158-6 . C A P .06$

Capítulo 7: Conhecimento de idosas de uma unidade da estratégia saúde da família sobre prevenção do câncer cervicouterino.

Augusto Antônio da Fonseca Neto, Antônio de Medeiros Pereira Filho, Alexandre Bezerra Silva DOI: 10.36229/978-85-7042-158-6.CAP.07 


\section{SUMÁRIO}

Capítulo 8: Percepção dos aspectos emocionais em pacientes idosos com doença renal e o fortalecimento pela fé: Um relato de experiência. 51

Josilene Mariz de Brito, Fernanda Alves da Silva Ribeiro, Eduardo José Guerra Seabra, Geralda Jéssica de Araújo Santos, Yraguacyara Santos Mascarenhas

DOI: 10.36229/978-85-7042-158-6.CAP.08

Capítulo 9: Fatores associados à dependência entre idosos com diabetes mellitus e a qualidade de vida nessa idade

Maria Zélia Araújo, Maria Angélica Palmeira da Rocha, Maria Janine Pereira Fernandes, Maria Joselita

Alves, Josiane Costa e Silva

DOI: 10.36229/978-85-7042-158-6.CAP.09

Capítulo 10: 0 latente atrativo gastronômico em Pernambuco para o turista idoso. 66

Lucas Henrique de Barros Portela Campelo, Ívina Albuquerque da Silva, Maria do Rosário de Fátima Padilha, Neide Kazue Sakugawa Shinohara

DOI: 10.36229/978-85-7042-158-6.CAP.10

Capítulo 11: Prevalência da violência contra a pessoa idosa no Estado da Paraíba/Brasil 73

Bianca Fonseca de Araújo, Hosana Barros Capuxú, Lívia Dantas Fragoso, Yngrid Maria Torres Freire, Rodrigo Pinheiro Fernandes de Queiroga

DOI: 10.36229/978-85-7042-158-6.CAP.11

Capítulo 12: Envelhecimento, velhice e morte: 0 conflito entre a experiência de sentido e a finitude numa perspectiva Logoterapêutica 80

Críscia Delancout Lúcio Araújo, Lucas Pereira Lucena, Lucas Brasil Feitosa, Lhais Cabral Martins, Lorena Bandeira Melo de Sá

DOI: 10.36229/978-85-7042-158-6.CAP.12

Capítulo 13: Percepção dos idosos institucionalizados quanto ao enfrentamento e a aceitação da finitude da vida 86

Daiany Maíra Magalhães Franca, Beatriz Cristina Soares Barros, Rafaela Maria Martins Queiroz, Rachel Cavalcanti Fonseca, Maria das Graças Silva DOI: $10.36229 / 978-85-7042-158-6 . C A P .13$

Capítulo 14: Envelhecimento e resiliência: Uma leitura da política nacional de saúde da pessoa idosa 91

Almira Lins de Medeiros, Ayanna Carla de Moraes Gerôncio, Larissa Pontes Carvalho Gomes, Rita de Cassia Dantas Freitas, Emily Souza Gaião e Albuquerque

DOI: $10.36229 / 978-85-7042-158-6 . C A P .14$ 


\section{SUMÁRIO}

Capítulo 15: Utilização das práticas integrativas e terapias complementares no manejo do refluxo Gastroesofágico: Prática baseada em evidências. 99

Thainá Caló Magalhães, João Luis Almeida da Silva

DOI: $10.36229 / 978-85-7042-158-6 . C A P .15$

Capítulo 16: Aromaterapia no manejo da ansiedade: Prática baseada em evidências

Nathália de Azevedo Souza, João Luis Almeida da Silva

DOI: $10.36229 / 978-85-7042-158-6 . C A P .16$

Capítulo 17: Incentivando escolhas alimentares saudáveis: Uma experiencia da utilização de recurso audiovisual em atividade de educação nutricional

Ivana Conceição Porto Moraes , Adriano Bezerra Crispim, Fabiana Santos Silva, Luana de Sousa Pereira DOI: 10.36229/978-85-7042-158-6.CAP.17

Autores: 


\section{Capítulo 1}

Qualidade de vida na terceira idade: A influência da arquitetura na melhoria das condições de vida dos idosos

\section{Yane Santana de Almeida \\ Mariana Dominato Abrahão Cury \\ Emanuel Sá Resende Pedroso}

Resumo: 0 envelhecimento humano é um processo natural, contínuo e irreversível. 0 aumento do número de idosos, principalmente a partir dos anos 1960, modificou a pirâmide etária mundial e tende a alterá-la ainda mais, considerando a diminuição da taxa de natalidade, que vem ocorrendo a cada ano e a melhora na expectativa de vida da maior parte dos países. Este trabalho teve como objetivo compreender o processo de envelhecimento, suas demandas e necessidades, além de entender o quanto a arquitetura local pode interferir e influenciar na qualidade de vida dos idosos. Foi realizado uma revisão sistemática da literatura e à partir desta, projetado um espaço que atendesse as demandas dos idosos residentes em Instituições de Longa Permanência para Idosos. Muito mais do que projetar espaços direcionados aos idosos, seguindo somente as normas de acessibilidade, que contribuem para a amenização de acidentes, dão mais autonomia, segurança e conforto aos usuários, é necessário projetar os espaços, considerando também suas características subjetivas: necessidades e desejos daqueles que irão usufruir dos locais, aprofundando no estudo da qualidade do lugar e procurando entender as necessidades, gostos e demandas dos idosos.

Palavras-chave: Idoso; Instituição de Longa Permanência para Idosos; Qualidade de Vida 


\section{INTRODUÇÃO}

O envelhecimento é considerado um processo natural, que tem como consequência a velhice e, diferentemente do que acontece nas outras fases da vida ele não possui um marcador biofisiológico, tendo a demarcação entre maturidade e envelhecimento fixada arbitrariamente mais por fatores socioeconômicos e legais do que biológicos. 0 crescimento no número de idosos se tornou um fenômeno mundial. 0 número de idosos acima de 80 anos têm aumentado de maneira considerada e tem sido o segmento populacional que mais cresce, embora ainda apresente um contingente pequeno" ${ }^{1}$. 0 avanço na medicina, além das melhorias de condições de infraestrutura e crescimento da maior parte dos países, tem contribuído para o envelhecimento da população.

0 envelhecimento populacional pode ser considerado um paradoxo, pois ao mesmo tempo em que representa um triunfo social, com o aumento da expectativa de vida, é visto também como um problema pela maioria dos governantes, políticos, planejadores e até mesmo pela sociedade, já que envelhecer requer demandas difíceis de serem resolvidas como: a aposentadoria, atenção à saúde, socialização, participação social entre outros ${ }^{2}$. 0 aumento na expectativa de vida é um ganho para a população que viverá mais anos, porém não há garantia de que esses anos vividos a mais terão qualidade, podendo se transformar em anos de sofrimentos, perdas, incapacidades, dependência e exclusão social, conceituando o maior desafio do processo de envelhecimento: envelhecer com qualidade.

A qualidade no envelhecimento está atrelada a diversos fatores como, por exemplo, saúde física e mental, condições de infraestrutura, inserção do idoso com a comunidade e até mesmo a própria satisfação com a vida. Segundo o Instituto Brasileiro de Geografia e Estatística (IBGE), o número de idosos no Brasil e a expectativa de vida tem aumentado cada vez mais, trazendo expectativas de que nos próximos 20 anos a população idosa poderá exceder 30 milhões de pessoas, representando quase $13 \%$ da população brasileira ${ }^{3}$ A modificação no arranjo familiar moderno, com a diminuição no tamanho e conformação das famílias, aliados à saída da mulher para a ocupação no mercado de trabalho, que culturalmente antes era quem assumia a responsabilidade com os mais velhos, além da falta de tempo da vida moderna, contribuiu para o aumento da demanda de Instituições de longa permanência para idosos, além de outras modalidades assistenciais voltadas a esse público, como os centros dia e os centros de convivência. Apesar desse aumento de demanda, a imagem negativa desses locais ainda permanece no imaginário das pessoas. Parte desse preconceito pode ser atribuída ao seu processo histórico, uma vez que essas instituições, antes conhecidas como asilos e surgiram para abrigar pessoas em situações de pobreza, abandono e doentes mentais. Existem algumas modalidades voltadas aos idosos que contribuem para um envelhecimento saudável e com qualidade como: atendimento de saúde básica, atividades de lazer, cultura, social, oficinas de aprendizagem entre outros. A ingressão do idoso em atividades especiais influencia muito na sua saúde física e mental, ajuda na socialização e consequentemente a não exclusão desse idoso na sociedade. No Brasil, existem algumas modalidades assistenciais de atendimento aos idosos como: Centros de Convivência, Centro de Atendimento Básico à Saúde do Idoso, Instituições de Longa Permanência para Idosos, Centros Dia, ILPI entre outros, que buscam trazer melhorias e qualidade de vida aos idosos, assegurando seus direitos. Porém nem todos os idosos são beneficiados, uma vez que essas modalidades estão distribuídas de maneira irregular, onde algumas regiões possuem muitas e outras não possuem nenhuma ou quando possuem, o número de vagas e a disponibilidade das mesmas são reduzidas, atendendo apenas a pequena parcela da população. 0 envelhecimento bem sucedido no Brasil só se tornará uma realidade quando a aplicação intensiva dos métodos já existentes passarem a favorecer uma parcela maior da população do que a que se beneficia atualmente.

Um dos maiores problemas no envelhecimento, além das perdas cognitivas, crônicas e psíquicas que podem ocorrer, é a exclusão do idoso da sociedade. 0 estilo capitalista, onde o lucro é o principal objetivo, faz com que o idoso aposentado perca sua função na sociedade, o colocando como improdutivo e, portanto, fora do sistema. Essa exclusão traz sérios problemas aos idosos, principalmente relacionados à depressão e a falta de vontade de tentar permanecer em sociedade perante todo preconceito que existe. A institucionalização ainda é outro fator que contribui para a exclusão do idoso, onde a partir do momento que é institucionalizado, passa a viver somente na instituição e convivendo apenas com aqueles que estão no mesmo espaço. Nesse sentido, pensar a arquitetura local passa a ser uma necessidade para que os idosos vivam mais e com qualidade.

0 ambiente pode ser definido como um conjunto de atributos físicos, sensoriais, cognitivos, afetivos, espirituais, climáticos e funcionais que nos circundam no dia a dia e do qual fazemos parte ${ }^{4}$. Os ambientes são tradicionalmente planejados visando muito mais a estética do que a funcionalidade e na maioria das vezes desconsiderando o designer universal, ou seja, onde os ambientes possibilitem que todas as pessoas em qualquer estado funcional possam utilizá-lo plenamente. À medida que vão envelhecendo e 
consequentemente se tornando mais frágeis, as pessoas deveriam dispor de um ambiente que seja adequado ao envelhecimento, que contribua para o encorajamento e promova a autonomia e independência. Nesse sentido, deveriam dispor de ambientes acessíveis, que segundo o dicionário, "acessível", é um adjetivo que indica aquilo a que se pode chegar facilmente; que fica ao alcance. Ambientes seguros, bem planejados e projetados voltados diretamente para o público idoso, são capazes de influenciar no modo de vida do idoso, ao permitir que ele circule com segurança pelo espaço, e que pratique suas atividades diárias com maior facilidade e autonomia. Ambientes com barreias ou sem facilitadores restringem o desempenho dos idosos ou, ao contrário, um ambiente com mais facilitadores pode melhorar significativamente seu desempenho.

Muitos idosos não modificam seus ambientes por menosprezarem os riscos que ambientes não planejados e adaptados para eles podem causar, se importando muito mais com a estética dos ambientes do que com a funcionalidade ou como esses ambientes ao sofrerem modificações e adaptações podem contribuir e facilitar suas atividades diárias. Muitos preferem alterar sua rotina, mudando seus hábitos à ter que alterar o ambiente. Ambientes escorregadios, presença de sombras que contribuem para o ofuscamento da visão, ausência de barras auxiliares, degraus não indicados, móveis com quinas, entre outros, são os maiores causadores de acidentes entre os idosos. Modificações simples nos ambientes são capazes de diminuir o risco de acidentes. Os projetos específicos para idosos, muitas vezes atrelados a um pragmatismo para resolver problemas urgentes ou isolados, tendem a discriminar e a subestimar a capacidade dos mesmos 5 . Contudo, projetar um ambiente destinado ao público idoso, não significa retirar ou alterar todas as barreiras físicas, mas sim, dar a possibilidade ao idoso que ainda consegue exercer algumas atividades, que continue exercendo. Um exemplo são as escadas. Não é necessário substituir todas as escadas por rampas, às vezes, simples soluções como corrimãos fixos e em altura adequada e um piso antiderrapante são capazes de trazer mais segurança ao idoso que irá utilizá-la, sem ter a necessidade de privar esse idoso que ainda consegue subir uma escada, de subi-la.

\section{METODOLOGIA}

Para a elaboração desse estudo, foi realizada uma revisão sistemática da literatura e a seguir, a execução da proposta de projetar um espaço que atendesse a demanda dos idosos que residem em Instituições de Longa Permanência para Idosos (ILPI). A seleção do local para a execução do projeto foi pensada a partir de visitas técnicas, realizadas na Instituição de origem onde residem os idosos. Assim, este estudo foi desenvolvido em duas etapas: na primeira foi realizada uma revisão bibliográfica, que significa "aquela que é desenvolvida à partir de material já elaborado, constituído principalmente de livros e artigos científicos" 6 , onde houve o detalhamento da necessidade de adaptações estruturais para que o idoso pudesse viver da melhor maneira possível e, principalmente, com segurança dentro de seu espaço residencial. Para esta etapa, realizou-se um levantamento de dados através da Biblioteca Virtual em Saúde (BVS), onde foi acessada as bases de dados Literatura Latino-Americana e do Caribe em Ciências da Saúde (LILACS), no período de novembro de 2016 à fevereiro de 2017. Os descritores utilizados para a busca de artigos científicos foram: Idoso; Qualidade de Vida e Instituições de Longa Permanência para Idosos. A segunda etapa, compreendeu o período de março à junho de 2017efoi projetado um Lar de Idosos, considerado o ideal, dentro das reflexões que sustentaram a primeira etapa do estudo. Por se tratar de um Trabalho Final de Graduação, considerado pré-requisito para a conclusão do curso de graduação em Arquitetura e Urbanismo da Universidade Federal de Juiz de Fora/MG, o projeto foi apresentado à comunidade acadêmica e a uma banca de especialistas na área.

\section{RESULTADOS E DISCUSSÕES}

A necessidade de considerar os aspectos subjetivos como a percepção e memória em projetos destinados ao público idoso é indispensável, afinal, entender como o idoso se apropria e se identifica com o espaço, contribui para que o mesmo crie uma identificação com o local, podendo influenciar diretamente na sua saúde física e mental.

Os ambientes ideais devem ser seguros e acolhedores, porém mantendo seu caráter desafiador e estimulante, criando conforto e não constrangimento aos idosos. Os ambientes ideais ao público idoso devem ter acessibilidade de uso, facilidade de circulação, especificamente no que diz respeito ao conforto, à conveniência e à possibilidade de escolha, além de segurança e proteção ${ }^{4}$. 0 cuidado com a iluminação deve ser redobrado em projetos destinados aos idosos, visto que o processo de envelhecimento acarreta perdas cognitivas e sensoriais, principalmente em relação à visão, e, a iluminação interfere no campo 
visual dos idosos. Ao se pensarem ambientes destinados aos idosos, é importante que haja uma mescla entre a iluminação natural e artificial, proporcionando ao usuário aproveitar ao máximo a luz natural. Espaços externos que utilizam totalmente a iluminação natural são muito importantes e podem influenciar no aumento da capacidade funcional dos idosos, já que a possibilidade de se sentirem desconfortáveis ou estarem sendo expostos a uma iluminação excessiva ou deficiente é muito menor. A luz solar também estimula os sistemas carcadianos e neuro-endócrinos, e a homeostase do organismo, ou seja, capacitam o organismo a se manter em equilíbrio ${ }^{4}$. A passagem de um ambiente para o outro não deve possuir uma elevada diferença de iluminação, já que essa diferenciação rápida de luminosidade pode causar uma cegueira momentânea nos idosos, trazendo desconforto e até mesmo acidentes.

Outro fato relacionado à interpretação e entendimento do idoso em relação à iluminação é o efeito luz e sombra, que muitas vezes interfere no campo visual do idoso que acaba enxergando a sombra como um buraco e a luz como piso. As cores também são importantes e merecem atenção, principalmente se tratando de ambientes destinados aos idosos. As cores quando utilizadas corretamente, podem proporcionar aos usuários sensação de bem estar, além de melhora na qualidade de vida. É preciso que haja atenção ao utilizar cores em conjunto, já que essas podem causar desconcentração aos idosos que possuem algum déficit cognitivo, considerando que esses não conseguem absorver a quantidade de estímulos desse conjunto ${ }^{4}$. Contudo, não significa que os ambientes devam ser monocolor, até porque irá dificultar para o idoso se orientar no espaço, visto que as cores são muito importantes e contribuem muito para a orientação, já que funcionam como forma de referência. As cores quentes e vibrantes como o vermelho, laranja e amarelo são muito indicadas para ambientes destinados aos idosos, já que os estimulam e os encorajam a serem mais ativos, enquanto as cores frias como o azul e verde, apesar de diminuírem a tensão e o estresse, são contraindicadas, já que são cores de difícil diferenciação e visualização. Mais do que somente manter padrões de habitação e necessidades básicas, as ILPI's devem funcionar como um "lar", um local de aconchego, reconhecimento, afeto e integração do idoso com a sociedade, mantendo a identidade e individualidade dos seus residentes. É necessário a desospitalização dos ambientes e a personificação individual, para que o idoso se reconheça naquele espaço. Oferecer a possibilidade ao idoso, de levar móveis ou outros objetos pessoais com o intuito de contribuir para que eles se sintam realmente em casa e se reconheçam naquele novo espaço, pode contribuir também para uma melhor integração deste com o ambiente.

Ambientes bem planejados têm a capacidade de influenciar positivamente na vida dos seus usuários, principalmente quando esses são idosos e requerem mais cuidados do que os mais jovens, considerando que suas funções e sentidos (tato, olfato, audição, paladar e visão) já não funcionam como antes. As ILPI's devem oferecer além de cuidado especializado, um ambiente familiar, aconchegante, afetuoso e humanizado, já que ela será o lar do idoso, o local onde ele passará a maior parte do dia e até mesmo os últimos anos de vida. É muito importante que a individualidade e identidade dos residentes sejam preservadas, e que suas vontades, quando possível, sejam atendidas.

Outro aspecto importante diz respeito à possibilidade de integração dos idosos residentes em ILPI's com outros idosos não residentes na instituição. A possibilidade dos idosos que residem na comunidade acessarem as ILPI's, quando lhes é ofertado atividades a serem desenvolvidas junto aos idosos residentes, contribui bastante para uma melhor qualidade de vida de ambos. Pensar na atualidade as ILPI's abertas parcialmente ao público em geral, as torna mais prazerosa para o idoso e o incentiva a conviver com o público em geral.

\section{CONCLUSÃO}

Com base nos estudos realizados no decorrer deste trabalho, percebeu-se o quanto os ambientes podem influenciar a vida dos idosos, estejam eles institucionalizados ou não. Além de evitar acidentes e trazer mais conforto e segurança aos usuários, ambientes bem planejados e pensados exclusivamente para atender ao público idoso, são capazes de influenciar na qualidade de vida dos mesmos, principalmente quando se tornam ambientes familiares, acolhedores e protetores. Muito mais do que adaptar os ambientes seguindo somente as normas de acessibilidade, é preciso tornar o ambiente humanizado e acolhedor, sem desvalorizar a individualidade e respeitando os gostos do idoso. Nas modalidades assistenciais destinados ao público idoso, a arquitetura é tão importante quanto à assistência que esses idosos irão receber nesses locais, contribuindo para a melhoria da qualidade de vida. Estratégias consistentes e bem pensadas são capazes de tornar um simples local em locais onde os usuários irão se identificar e consequentemente se apegar. Um dos maiores problemas no envelhecimento, além das perdas cognitivas, crônicas e psíquicas que podem ocorrer, é a exclusão do idoso da sociedade. 
Com o desenvolver da pesquisa, percebeu-se que a partir do momento que locamos outra modalidade assistencial junto com a ILPI, automaticamente o público se mesclaria e, consequentemente haveria uma maior interação dos idosos institucionalizados, melhorando um dos maiores problemas advindos da institucionalização: a exclusão dos idosos. Além da socialização entre idosos institucionalizados e idosos não institucionalizados, é importante a integração dos idosos com as outras faixas etárias. Para isso, mesclar espaços públicos ao espaço privado, a fim de trazer para dentro do espaço destinado aos idosos, um número maior de pessoas de diferentes faixas etárias, pode ser um caminho.

A demanda por modalidades assistenciais destinadas aos idosos só tende a crescer, visto que o número de idosos aumenta a cada ano em todo o mundo. 0 envelhecimento transformou-se em um fenômeno mundial e por isso necessita cada vez mais de estudos e atenção às necessidades a carências desse público. Portanto, espera-se que haja uma maior sensibilização com a situação atual dos idosos no Brasil, entendendo sua importância na sociedade e acabando com esse preconceito que só prejudica as relações dos idosos com a sociedade e interfere inclusive na sua saúde física e mental. A integração com o idoso não fará bem somente a ele, mas a todos os envolvidos, considerando que as trocas de experiências são muito importantes para a formação individual, que sabendo absorver as coisas boas, fará dessas trocas uma oportunidade de crescer como ser humano.

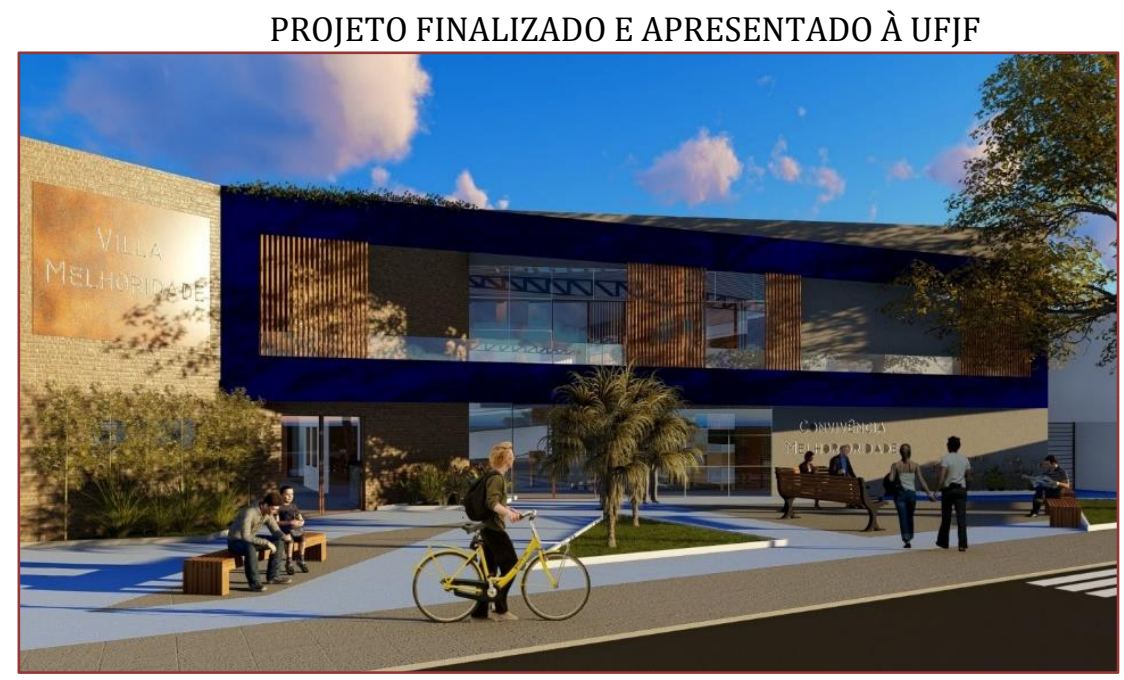

\section{REFERENCIAS}

[1] Camarano, AA.; Kanso, S. As instituições de longa permanência para idosos no Brasil. Revista Brasileira de Estudos de População, v. 27, n. 1, p. 232-235, 2010. Disponível em: http://www.scielo.br/scielo.php?pid=S010230982010000100014\&script=sci_arttext Acesso em 05 Out. de 2017.

[2] Paschoal, SMP.; et al. Tratado de Geriatria e Gerontologia. 3.ed. - [reimpr.]. - Rio de Janeiro: Guanabara Koogan, 2013.

[3] Instituto Brasileiro de Geografia e Estatística(IBGE, 2010). Resultado da amostra características da população. Disponivel em: http://www.cidades.ibge.gov.br/xtras/perfil.php?lang=\&codmun=314080. Acesso em: 28 de setembro de 2016

[4] Perracini, MR.; et al Tratado de Geriatria e Gerontologia. 3.ed. - [reimpr.]. - Rio de Janeiro: Guanabara Koogan, 2013.

[5] Costa, L. Memórias Enclausuradas:AInstitucionalização de Doentes de Alzheimer em Respostas Sociais Não Específicas. IICiclo de Estudos em Gerontologia Social Aplicada, UCP. Braga, 2011. Disponível em: http://repositorio.ucp.pt/bitstream/10400.14/8833/1/Mem\%C3\%B3rias\%20Enclausuradas.pdf. Acesso em novembro de 2016.

[6] Severino, AJ. Metodologia do trabalho científico. 23 ed. São Paulo: Cortez, 2007. Qualidade de vida na terceira idade: a influência da arquitetura na melhoria das 


\section{Capítulo 2}

Programas de promoção da atividade física de idosos: Efeito na qualidade de vida

\section{Fabiana Cristina Scherer \\ Aline Mendes Gerage \\ Anderson da Silva Honorato \\ Bruna Prado Gomes \\ Camila Pereira \\ Tânia Rosane Bertoldo Benedetti}

Resumo: Objetivo: Analisar o efeito de programas de promoção da atividade física na qualidade de vida de idosos usuários de Centros de Saúde de Florianópolis, Santa Catarina, Brasil. Métodos: Participaram do estudo 55 idosos (68,75 $\pm 6,91$ anos), randomizados em três grupos: 1) Mudança de Comportamento, 2) Exercício Físico Tradicional; ambos durante três meses e 3) Controle. Para avaliar a qualidade de vida foram aplicados os questionários WHOQOL-BREF e WHOQOL-OLD no baseline, três, seis e 12 meses após o término dos programas.Resultados: Observou-se efeito isolado do grupo ou do momento em quatro variáveis de qualidade de vida.Conclusões: Os programas testados, da forma como foram aplicados, não foram capazes de promover modificações na percepção da qualidade de vida de idosos.

Palavras-Chave: Promoção da saúde. Atividade motora. Qualidade de vida. Idoso. 


\section{INTRODUÇÃO}

A adoção de hábitos saudáveis, como a prática regular de atividade física (AF), pode melhorar o desempenho funcional nas atividades da vida diária (REZENDE et al., 2015), reduzir as doenças não transmissíveis (HALLAL et al. 2012) e melhorar a percepção do idoso sobre a sua qualidade de vida (QV) (VAGETTI et al, 2014). Apesar disso, os níveis de inatividade física continuam altos entre os idosos (HALLAL et al. 2012).

Na perspectiva de modificar positivamente os hábitos de vida e reduzir os elevados custos para o sistema público brasileiro de saúde, nos últimos anos, houve grande investimento governamental para a criação de programas que incentivam a prática de AF para as comunidades (REIS et al., 2010). A maioria desses programas, que envolvem sessões estruturadas de exercícios físicos ( 3 a 5 vezes/semana, $1 \mathrm{~h} / \mathrm{sessão)}$, promove efeitos positivos, mas tem custo elevado (BENEDETTI et al., 2012), reduzido número de idosos participantes e inconstância na frequência (CARDOSO et al., 2008). Além disso, normalmente, os idosos não adquirem autonomia para a prática quando da participação neste tipo de programa (OPDENACKER et al., 2008).

Uma alternativa são os programas de Mudança de Comportamento (MC), tais como o Active-for-Life (AFL) (WILCOX et al., 2006), o Active Living Every Day (ALED) (GRIFFIN et al., 2010) e o diaBEAT-it (ALMEIDA et al., 2014) aplicados e testados em nível internacional. Dentre eles, merece atenção o penúltimo, pelo índice de retenção de seus participantes (cerca de 70\%) depois de um ano do término da intervenção (GRIFFIN et al., 2010). Assim, com base no programa $A L E D$, foi criado um programa de MC no Brasil, atualmente denominado Vida Ativa Melhorando a Saúde (VAMOS) (BENEDETTI et al., 2012). O programa VAMOS, baseado em encontros teóricos/práticos, objetiva motivar as pessoas para um estilo de vida mais saudável (BENEDETTI et al., 2012).

Paralelamente a isso, identifica-se que, além de existir poucos estudos longitudinais sobre programas de $\mathrm{AF}$ com a avaliação e acompanhamento da QV, no Brasil, não se tem relatos de programas de $\mathrm{MC}$ similares ao VAMOS que acompanham a QV, mas, em nível internacional, há relatos de participantes de programas desse tipo que obtiveram melhoras na QV (WILCOX et al., 2006). Além disso, a qualidade de vida é um indicativo de efetividade dos programas (ALMEIDA et al., 2014).

Assim, o objetivo deste estudo foi analisar o efeito de dois programas de promoção da AF na QV de idosos. Adicionalmente, buscou-se investigar o efeito da assiduidade nos dois programas de promoção de AF na QV de idosos.

\section{MÉTODOS}

O estudo foi desenvolvido em seis centros de saúde localizados em duas Regionais de Saúde (Norte e Leste) de Florianópolis, Santa Catarina, Brasil. Os centros de saúde de cada distrito foram randomizados em grupo de MC (GMC); grupo de exercício físico tradicional (GEFT) e grupo controle (GC), totalizando dois grupos em cada distrito. Para formar os grupos, foram convidados idosos cadastrados nos centros de saúde.

\subsection{AMOSTRA}

Para a composição da amostra, adotou-se os seguintes critérios de inclusão: ter realizado ao menos uma consulta nos seis meses precedentes à realização da pesquisa e ter 60 anos ou mais. Maior detalhamento metodológico foi descrito em estudos prévios (BENEDETTI et al., 2012; BORGES, 2014).

Assim, inicialmente, o estudo contou com 126 idosos ( $69 \pm 7.23$ anos) alocados nos três grupos: GMC ( $\mathrm{n}=$ 35); GEFT ( $\mathrm{n}=38)$; e GC $(\mathrm{n}=53)$.

\subsection{DELINEAMENTO EXPERIMENTAL}

O GMC participou do programa VAMOS (BENEDETTI et al., 2012) (1x/semana, \pm 2 horas), durante 12 semanas, no formato de rodas de conversa, abordando a cada encontro um capítulo do material didático, disponibilizado gratuitamente para os participantes, com conteúdos relacionados à prática de $\mathrm{AF}$ e à adoção de estilo de vida saudável. Os conteúdos abordados em cada encontro foram: 1) VAMOS Preparar, decidir e fazer; 2) VAMOS Encontrar novas oportunidades; 3) VAMOS Superar desafios; 4) VAMOS Estabelecer metas e recompensas; 5) VAMOS Ganhar confiança; 6) VAMOS Reunir Apoio; 7) VAMOS 
Evitando Dificuldades/obstáculos; 8) VAMOS Passo-a-passo; 9) VAMOS Desfazendo o estresse; 10) VAMOS Encontrando novas oportunidades para ser ativo; 11) VAMOS Planejamento positivo; 12) VAMOS Realizando mudanças duradouras. Estes conteúdos eram fundamentados na Teoria Sociocognitiva (BANDURA; AZZI; POLYDORO, 2008), estratégias como aumento da autoeficácia, planejamento, automonitoramento e apoio social, dentre outras, foram utilizadas no decorrer dos encontros.

O GEFT foi submetido a um Programa de Exercício Físico Tradicional (3x/semana, 60 min/sessão), durante 12 semanas. 0 objetivo era desenvolver componentes da aptidão física relacionada à saúde. As intervenções foram conduzidas por profissionais de Educação Física, vinculados ao Núcleo de Apoio à Saúde da Família, do município de Florianópolis, previamente treinados.

Os idosos do GC não participaram de nenhuma intervenção, apenas das avaliações.

A amostra foi caracterizada, no baseline, pelas informações sociodemográficas e dados antropométricos.

Verificou-se a assiduidade a partir de listas de frequência nos GMC e GEFT, utilizando-se a classificação assiduidade $<75 \%$ e assiduidade $\geq 75 \%$ do total de aulas.

\subsection{QUALIDADE DE VIDA}

A QV foi avaliada por meio de entrevista individual no baseline, três, seis e 12 meses após o término das intervenções, por meio dos questionários WHOQOL-BREF (FLECK et al., 2000) e WHOQOL-OLD (FLECK; CHACHAMOVICH; TRENTINI, 2006) ambos traduzidos e validados em português. O WHOQOL-BREF engloba o escore geral e os domínios físico, psicológico, relações sociais $e$ meio ambiente. O WHOQOL-OLD abrange seis domínios funcionamento do sensório; autonomia; atividades passadas, presentes e futuras; participação social; morte e morrer e intimidade. Foi calculado o escore de cada domínio e, especificamente no WHOQOL-OLD, foi realizada a variação do escore transformado (PEDROSO; PILATTI; GUTIERREZ, 2010). Os escores percentuais variam de 0 a 100. Quanto mais próximo de 100, melhor é a QV do avaliado. Para estimativa geral da QV do idoso, foi adotado o que o WHOQOL group sugere, sendo calculado a estimativa de um domínio geral baseado nos 24 itens do questionário (escore geral do WHOQOL-OLD).

\subsection{ANÁLISE DOS DADOS}

Analisou-se os dados pelo sofware Statistical Package for the Social Scienses para Windows, versão 15.0. Na análise descritiva, calculou-se os valores de média e desvio padrão ou frequência absoluta e relativa. Para verificar o efeito dos programas de MC e de Exercício Físico Tradicional nos níveis de QV dos idosos, realizou-se análise de variância (ANOVA) two-way para medidas repetidas, seguido pelo post hoc de Bonferroni. Aplicou-se o teste de qui-quadrado (para associação linear) ou exato de Fisher para comparar os grupos quanto à proporção de participantes que diminuíram/ mantiveram ou aumentaram os escores de QV (delta três, seis ou 12 meses vs. baseline).

0 nível de significância estatística adotado foi de 5\%. A diferença nas magnitudes foi calculada pelo tamanho de efeito ( $\mathrm{ES}=$ effect size). Um ES de até 0,49 foi estabelecido como pequeno, de 0,50 até 0,79 como moderado e de 0,80 ou mais como alto (COHEN, 1988).

Os resultados desse estudo são apresentados considerando os idosos que finalizaram as intervenções e/ou completaram as quatro avaliações $(n=55)$. Adicionalmente, realizou-se a análise por intenção de tratar considerando todos os participantes previamente randomizados, independente se finalizaram ou não as intervenções $(n=126)$. Para tanto, substituiu-se os dados faltantes pela técnica de substituição pelo último valor observado.

\subsection{COMITÊ DE ÉTICA}

O estudo é parte de um projeto maior (BENEDETTI et al., 2012) que investiga o alcance, a efetividade, a adoção, a implementação e a manutenção do programa denominado VAMOS, que foi aprovado na Comissão Nacional de Ética em Pesquisa (no 480.560/2011) e no Comitê de Ética em Pesquisa com Seres Humanos, da Universidade Federal de Santa Catarina (no 2.387/2012). Os participantes assinaram um termo de consentimento livre e esclarecido, após serem informados sobre os objetivos e procedimentos da pesquisa. 


\section{RESULTADOS}

Na tabela 1 estão apresentadas as características gerais dos idosos, de acordo com os grupos.

Tabela 1 - Características sociodemográficas e de saúde dos participantes dos diferentes grupos do estudo (baseline).

\begin{tabular}{|c|c|c|c|c|c|}
\hline Variáveis & $\begin{array}{l}\text { Total } \\
\text { n (\%) }\end{array}$ & $\begin{array}{l}\text { GMC } \\
\text { n (\%) }\end{array}$ & $\begin{array}{l}\text { GEFT } \\
\text { n (\%) }\end{array}$ & $\begin{array}{c}\text { GC } \\
\text { n (\%) }\end{array}$ & $\begin{array}{c}\mathrm{p}- \\
\text { valor }\end{array}$ \\
\hline Faixa etária (\% 60 a 69 anos) & $34(61,82)$ & $7(63,64)$ & $13(56,52)$ & $14(66,67)$ & 0,72 \\
\hline Sexo (\% feminino) & $45(81,80)$ & $8(72,73)$ & $20(86,96)$ & $17(80,95)$ & 0,54 \\
\hline Estado civil (\% casados/juntados) & $31(56,36)$ & $8(72,73)$ & $11(47,83)$ & $12(57,14)$ & 0,53 \\
\hline $\begin{array}{l}\text { Renda familiar mensal ( }<4 \text { salários } \\
\text { mínimos) }\end{array}$ & $40(74,07)$ & $5(45,45)$ & $19(82,60)$ & $16(80,00)$ & 0,03 \\
\hline $\begin{array}{l}\text { Nível de escolaridade (\% } 1 \text { a } 7 \text { anos de } \\
\text { estudo) }\end{array}$ & $31(57,41)$ & $5(45,45)$ & $14(60,87)$ & $12(60,00)$ & 0,01 \\
\hline Situação ocupacional (\% aposentados) & $30(54,55)$ & $6(54,55)$ & $10(43,48)$ & $14(66,67)$ & 0,40 \\
\hline $\mathrm{IMC}^{\dagger}(\%$ excesso de peso $)$ & $33(60,00)$ & $5(45,45)$ & $15(65,22)$ & $13(61,90)$ & 0,58 \\
\hline $\mathrm{PC}^{+\dagger}$ (\% risco muito aumentado) & $32(58,18)$ & $5(45,45)$ & $17(73,91)$ & $10(47,62)$ & 0,10 \\
\hline
\end{tabular}

Fonte: Autoria própria (2012-2013).

Notas: GMC = grupo de mudança de comportamento; GEFT = grupo de exercício físico tradicional; GC = grupo controle; IMC = Índice de Massa Corporal; PC = Perímetro da Cintura; $\mathrm{p}^{*}=$ teste exato de Fisher . Usado por Nutrition Screening Initiative (1992) e adotado por Lipschitz (1994). †† Classificado por World Health Organization (2000).

Na tabela 2 são apresentados os escores da QV, ao longo do estudo, nos três grupos. Foi verificado efeito isolado do grupo para a $\mathrm{QV}$ geral $(\mathrm{F}=4,34 \mathrm{e} \mathrm{p}<0,05$; GMC vs. $\mathrm{GC}-\mathrm{p}=0,02)$ e o domínio meio ambiente (F $=3,51$ e p < 0,05; GMC vs. GC - $\mathrm{p}=0,04$ ) com melhores resultados observados para o GC e efeito isolado do momento para o domínio físico $(\mathrm{F}=5,25$ e $\mathrm{p}<0,05)$, com aumentos do baseline para três meses $(\mathrm{p}=0,00)$ ou 12 meses ( $p=0,04)$, independentemente do grupo.

Notas: GMC = grupo de mudança de comportamento; GEFT = grupo de exercício físico tradicional; GC = grupo controle; $E S$ = tamanho de efeito comparado com as medidas do baseline; Os dados do baseline, três meses, seis meses e 12 meses são mostrados com valores de média $(\overline{\bar{X}})$ e desvio padrão (DP).

$\mathrm{Na}$ análise da influência da assiduidade dos idosos nos programas sobre a QV, nenhum efeito isolado (momento e assiduidade) ou interação foi identificado.

Na análise da QV de acordo com o questionário WHOQOL-OLD, também não se observou interação momento vs. grupo, somente houve efeito isolado do momento $(\mathrm{F}=3,77$ e $\mathrm{p}<0,05)$ no domínio intimidade, sendo verificadas diferenças estatísticas entre o baseline e três meses $(p=0,02)$, e efeito isolado do grupo $(F=5,62$ e $p<0,05)$ com diferenças entre GMC vs. GEFT $(p=0,01)$, sendo observados melhores resultados para o GMC.

Ao verificar o ES encontrou-se resultados de moderado a alto para os seguintes escores e domínios: escore geral, domínio funcionamento do sensório, domínio participação social $e$ domínio intimidade. A princípio, exceto para o domínio funcionamento do sensório, todos os primeiros resultados de cada escore ou domínio que apresentaram ES de moderado a alto são para o momento pós-intervenção - três meses $x$ baseline. Para o escore geral o GMC teve um ES moderado $(E S=0,66)$, no seguimento, o índice decaiu e praticamente manteve o resultado aos 12 meses. No domínio funcionamento do sensório, o GEFT apresentou um ES moderado $(E S=0,50)$, porém, diferente dos demais resultados que apresentaram o primeiro maior valor de ES após a intervenção, aos três meses, este aconteceu aos seis meses. Tal índice decresceu aos 12 meses e quase chegou ao valor do baseline. No domínio participação social, o GMC contou com um ES moderado $(E S=0,75)$ e no follow-up o índice foi decaindo chegando próximo ao valor do baseline. Já, no domínio intimidade, o GMC apresentou ES alto $(E S=1.15)$, aos seis meses, este índice se reduziu, mas aos 12 meses o ES foi moderado $(E S=0,76)$. 0 GEFT, teve tamanho de ES $(E S=0,58)$ e no follow-up houve um decréscimo do índice chegando a valor menor que o baseline. Para este domínio foi verificado ES moderado para o GC $(E S=0,51)$ e no follow-up estes valores decresceram, mas, continuaram maior do que o inicial. 
Tabela 2 - Resultados das medidas da QV geral e dos domínios da QV (WHOQOL-BREF) nos quatro momentos de avaliação (baseline, três meses, seis meses e 12 meses) e nos três grupos (GMC, GEFT e GC) de idosos.

\begin{tabular}{|c|c|c|c|c|c|c|c|c|c|c|}
\hline $\begin{array}{c}\text { Domínios } \\
\text { WHOQOL-BREF }\end{array}$ & $\begin{array}{l}\text { Baseline } \\
\pm \mathrm{DP}\end{array}$ & $\begin{array}{c}\text { Três meses } \\
\text { 土DP }\end{array}$ & $E S$ & $\begin{array}{c}\text { Seis meses } \\
\pm \mathrm{DP}\end{array}$ & & $\begin{array}{l}12 \text { meses } \\
\pm \mathrm{DP}\end{array}$ & $E S$ & Efeitos & F & p \\
\hline \multicolumn{11}{|l|}{ QV Geral } \\
\hline $\mathrm{GMC}(\mathrm{n}=11)$ & $77,27 \pm 9,38$ & $77,27 \pm 7,54$ & 0 & $72,73 \pm 9,38$ & $-0,5$ & $77,27 \pm 13,48$ & 0 & Grupo & 4,3 & 0 \\
\hline GEFT $(n=23)$ & $69,02 \pm 12,43$ & $75,00 \pm 11,31$ & 0,5 & $68,48 \pm 16,37$ & -0 & $68,48 \pm 17,22$ & -0 & Momento & 1,7 & 0,2 \\
\hline $\mathrm{GC}(\mathrm{n}=21)$ & $60,12 \pm 16,11$ & $65,48 \pm 15,26$ & 0,34 & $63,10 \pm 15,04$ & 0,19 & $66,67 \pm 21,41$ & 0,35 & $\begin{array}{l}\text { Grupo vs. } \\
\text { Momento }\end{array}$ & 0,9 & 0,5 \\
\hline \multicolumn{11}{|l|}{ Físico } \\
\hline $\mathrm{GMC}(\mathrm{n}=11)$ & $70,78 \pm 13,25$ & $80,52 \pm 8,20$ & 0,88 & $70,08 \pm 16,00$ & $-0,1$ & $78,90 \pm 16,01$ & 0,55 & Grupo & 1,4 & 0,3 \\
\hline GEFT $(n=23)$ & $65,50 \pm 14,71$ & $72,52 \pm 11,32$ & 0,53 & $71,27 \pm 14,35$ & 0,4 & $68,48 \pm 16,00$ & 0,19 & Momento & 5,3 & 0 \\
\hline $\mathrm{GC}(\mathrm{n}=21)$ & $64,29 \pm 17,64$ & $68,71 \pm 18,45$ & 0,24 & $67,00 \pm 13,41$ & 0,17 & $69,90 \pm 16,15$ & 0,33 & $\begin{array}{l}\text { Grupo vs. } \\
\text { Momento }\end{array}$ & 1,3 & 0,3 \\
\hline
\end{tabular}

Psicológico

\begin{tabular}{|c|c|c|c|c|c|c|c|c|c|c|}
\hline GMC $(\mathrm{n}=11)$ & $75,76 \pm 8,50$ & $78,41 \pm 8,30$ & 0,32 & $72,58 \pm 5,60$ & $-0,4$ & $79,17 \pm 11,64$ & 0,33 & Grupo & 2,3 & 0,1 \\
\hline GEFT $(\mathrm{n}=23)$ & $68,66 \pm 14,04$ & $71,38 \pm 11,47$ & 0,21 & $69,75 \pm 17,10$ & 0,07 & $69,02 \pm 12,68$ & 0,03 & Momento & 2 & 0,1 \\
\hline GC $(\mathrm{n}=21)$ & $65,67 \pm 14,78$ & $71,03 \pm 14,70$ & 0,36 & $67,26 \pm 13,71$ & 0,11 & $69,25 \pm 13,72$ & 0,25 & $\begin{array}{l}\text { Grupo vs. } \\
\text { Momento }\end{array}$ & 0,5 & 0,8 \\
\hline
\end{tabular}

Relações Sociais

\begin{tabular}{|c|c|c|c|c|c|c|c|c|c|c|}
\hline GMC $(\mathrm{n}=11)$ & $70,45 \pm 18,01$ & $70,45 \pm 13,10$ & 0 & $69,32 \pm 11,53$ & $-0,1$ & $73,48 \pm 20,35$ & 0,16 & Grupo & 0,5 & 0,6 \\
\hline GEFT $(\mathrm{n}=23)$ & $72,83 \pm 14,70$ & $77,17 \pm 11,01$ & 0,33 & $73,91 \pm 16,72$ & 0,07 & $75,18 \pm 11,13$ & 0,18 & Momento & 0,2 & 0,9 \\
\hline GC $(\mathrm{n}=21)$ & $75,40 \pm 15,02$ & $72,62 \pm 16,28$ & $-0,2$ & $75,40 \pm 14,31$ & 0 & $74,60 \pm 13,56$ & $-0,1$ & $\begin{array}{c}\text { Grupo vs. } \\
\text { Momento }\end{array}$ & 0,5 & 0,8 \\
\hline
\end{tabular}

Meio Ambiente

\begin{tabular}{|r|c|c|c|c|c|c|c|c|c|c|}
\hline GMC $(\mathrm{n}=11)$ & $74,15 \pm 8,85$ & $74,72 \pm 7,58$ & 0,07 & $71,59 \pm 9,93$ & $-0,3$ & $74,72 \pm 9,42$ & 0,06 & Grupo & 3,5 & 0 \\
\hline GEFT $(\mathrm{n}=23)$ & $63,86 \pm 11,69$ & $70,11 \pm 12,95$ & 0,51 & $66,85 \pm 9,32$ & 0,28 & $66,17 \pm 9,78$ & 0,21 & Momento & 1,9 & 0,1 \\
\hline GC (n=21) & $63,39 \pm 14,12$ & $67,81 \pm 10,87$ & 0,35 & $67,13 \pm 9,78$ & 0,31 & $64,99 \pm 11,44$ & 0,12 & $\begin{array}{c}\text { Grupo vs. } \\
\text { Momento }\end{array}$ & 0,6 & 0,7 \\
\hline
\end{tabular}

Fonte: Autoria própria (2012-2013).

Não foi verificado, para as variáveis do questionário WHOQOL-OLD, efeito da assiduidade $(\mathrm{p}>0,05)$, tanto no GMC quanto no GEFT.

Em relação ao percentual de idosos que diminuíram/ mantiveram ou aumentaram o escore geral de QV (WHOQOL-BREF) (figura 1), não foram identificadas diferenças entre os grupos após três, seis e 12 meses ( $p>0,05$ ). Também não foram encontradas diferenças significantes entre os grupos para os demais domínios do WHOQOL-BREF ( $\mathrm{p}>0$,05). Na análise do WHOQOL-OLD, os resultados foram os mesmos tanto para o escore geral quanto para os diferentes domínios $(\mathrm{p}>0,05)$.

Na análise por intenção de tratar, verificou-se manutenção do efeito isolado do momento para os domínios físico (WHOQOL-BREF) e intimidade (WHOQOL-OLD). Adicionalmente, foi detectado efeito isolado do momento para o domínio participação social (WHOQOL-OLD), sendo observada diminuição dos escores médios da QV entre três e seis meses $(\mathrm{p}=0,04)$, independentemente do grupo. Em relação, ao ES não foram encontrados valores moderados ou altos para nenhuma variável de QV. 
Figura 1 - Percentual de idosos que diminuíram/mantiveram ou aumentaram o escore de QV geral (WHOQOL-BREF), de acordo com o delta dos momentos (três, seis ou 12 meses vs. baseline), nos três grupos (GMC, GEFT e GC).

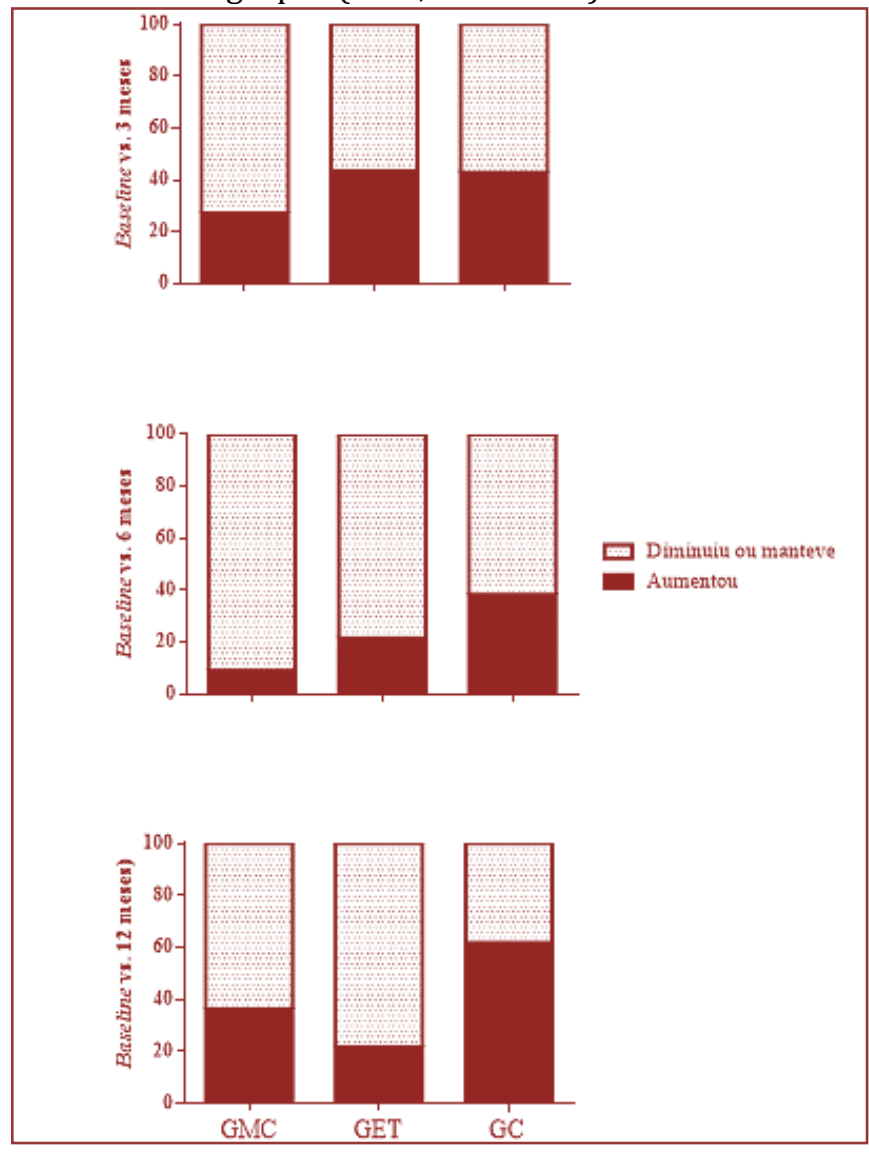

Fonte: Autoria própria (2012-2013).

Notas: GMC = grupo de mudança de comportamento; GEFT = grupo de exercício físico tradicional; GC = grupo controle.

\section{DISCUSSÃO}

Os principais achados do presente estudo foram: a) ao longo do tempo, identificou-se aumento na QV nos domínios físico e intimidade, independentemente do grupo analisado; b) a assiduidade nos dois programas de promoção da AF não influenciou a percepção da QV de idosos.

Antes de analisar, especificamente o aumento significativo no domínio físico da QV, é importante ressaltar que este domínio representa as atividades voltadas para a vida diária, como a presença ou ausência de energia e/ou fadiga, mobilidade, dor e desconforto, sono e repouso, a dependência de medicamentos e capacidade para o trabalho (WORLD HEALTH ORGANIZATION, 1998). Isto reflete a autonomia do idoso e sua independência, ou seja, a sua capacidade funcional. Esperava-se, no presente estudo, que este aumento fosse atribuído aos programas de promoção da AF investigados. Todavia, tendo em vista que o GC também apresentou melhorias neste quesito, tais modificações não se devem às intervenções aplicadas, e sim a outros fatores que merecem melhor investigação, tais como: melhora na percepção de saúde e redução da ingestão de medicamentos. Neste sentido, um estudo verificou que ausência de escolaridade, percepção de saúde negativa, apresentar maior número de morbidades autorreferidas e maior número de classes de medicamentos resultam em baixos escores do domínio físico de QV (PAIVA et al., 2016).

Já, o domínio intimidade está intrinsicamente relacionado a capacidade de ter relacionamentos pessoais e íntimos, ligadas aos sentimentos de amor e companheirismo (GRUPO WHOQOL-OLD, 2005). Assim, parece que a relação com companheiro(a) melhorou no decorrer do tempo ou houve idosos que iniciaram/experienciaram novas relações neste período, o que é esperado nos grupos de intervenção e, principalmente, no GMC, onde é incentivado o apoio de familiares, apoio social (BANDURA; AZZI; POLYDORO, 2008) para a realização de AF e esta relação pode melhorar o afeto. Inclusive, este grupo apresentou ES alto após três meses e, após 12 meses, ES moderado. 0 fato desse aumento ter ocorrido no GC, principalmente após três meses com ES moderado, remete a indagar se não foi o efeito de aprendizado 
do questionário pós-teste, já que estes índices foram diminuindo no follow-up. Em adição, também pode ter ocorrido outras interferências externas que não foram controladas em nosso estudo. Por exemplo, aumento de renda econômica. Paiva et al. (2016) encontrou que a ausência de renda esteve associada a baixos escores de QV, dentre eles, nos domínios físico $e$ intimidade.

Retratando sobre a indiferença dos grupos para os resultados na QV, Dale, Brassington e King (2014) corroboram afirmando que as mudanças reais no estilo de vida e adesão as intervenções podem ser fundamentais para a obtenção de resultados de saúde mental e bem-estar. Contudo, o modo como é entregue as intervenções e as técnicas utilizadas podem não ser essenciais para provocar estas alterações, embora a especificação dos componentes e técnicas sejam necessárias. Porém, os autores sugerem mais estudos em relação às diferenças de efetividade entre as intervenções.

Por outro lado, Kristén et al. (2015), na revisão sistemática, apontam e recomendam que futuros estudos de intervenção devem envolver intervenções comportamentais. Corroborando Conn, Hafdahl e Mehr (2011), na metanálise, encontraram que intervenções de mudança de comportamento (exemplo: atingir metas/objetivos, feedback de atividade física, auto-monitoramento) são mais custo efetivas em se tratando de promoção de atividade física para adultos saudáveis que outras estratégias de intervenções.

Assim, devemos ter cautela sobre custo efetividade das intervenções. Mas, devemos considerar que, de maneira geral, as intervenções de MC e exercício físico tradicional promovem benefícios à saúde e a QV. Em programas de exercício físico tradicional são comprovados os efeitos positivos sobre a capacidade funcional, a saúde mental, a vitalidade e autonomia (BORGES; BENEDETTI; MAZO, 2008; VAGETTI et al, 2014). Semelhante benefícios são reportados em programas de MC direcionados, em parte, à prática de atividade física à idosos saudáveis (MENDOZA-RUVALCABA; ARIAS-MERINO, 2015).

Poucos estudos investigaram se assiduidade resulta em melhores níveis de QV em idosos praticantes de $A F$. Sugere-se que somente aqueles idosos que frequentam assiduamente os programas de AF experimentam melhorias na função cognitiva e funcional (BORGES; BENEDETTI; MAZO, 2008). Nesta direção, Alexandre, Cordeiro e Ramos (2009) sinalizaram que os idosos que praticavam mais AF ou que tinham maior frequência semanal de prática de $\mathrm{AF}$ apresentaram melhores níveis de QV no domínio físico (WHOQOL-BREF). Assim, diante dos resultados controversos e da escassez de estudos, evidencia-se a necessidade de mais estudos para compreender essa relação, envolvendo, principalmente, amostras maiores.

Assim, são necessários mais estudos para entender melhor a relação entre os programas de AF e a QV, uma vez que os poucos estudos apresentam diferenças metodológicas. Poucos estudos usam ambos os questionários para avaliar a QV (WHOQOL-BREF e WHOQOL-OLD) em idosos. Ainda, há uma gama de questionários utilizados para avaliar a QV (VAGETTI et al, 2014), mas não há consenso em relação ao melhor instrumento para ser usado com idosos, o que dificulta indicar um direcionamento seguro da efetividade de programas e compreender mais profundamente esta relação entre a AF e QV. Para reforçar, existem poucos estudos longitudinais envolvendo AF e QV (VAGETTI et al, 2014), principalmente em se tratando de programas de MC e QV de idosos que vivem em comunidade.

Paralelamente, Borges (2014), a partir de informações obtidas em grupos focais, verificou a necessidade de adaptações no Programa VAMOS. Os idosos relataram que o material didático utilizado continha muito texto, poucas figuras e era muito extenso. Ainda, disseram sentir falta de atividades práticas no programa. Tais aspectos, talvez, tenham influenciado nos resultados encontrados minimizando os benefícios esperados a partir da participação no Programa.

O presente estudo apresenta algumas limitações, a citar: alta taxa de desistência ao longo do estudo, tamanho amostral reduzido, o que diminui o poder das análises estatísticas, em especial de variáveis com magnitude de efeito baixo. Nessa perspectiva, é preciso considerar a possibilidade de suporte (envio de mensagens educativas, ligações) após o término da intervenção para uma mudança efetiva nos aspectos ligados à QV, seja pela descrença desta população ou por fatores históricos.

Apesar disso, os pontos fortes merecem destaques, a citar a utilização do WHOQOL-BREF associado ao WHOQOL-OLD. Isto reforça os achados, pois contribui para a identificação da percepção da QV de idosos (GRUPO WHOQOL-OLD, 2005). Outro ponto é o amplo período de acompanhamento dos participantes, em todas as fases e após o término das intervenções, permitindo investigar a causa e efeito das variáveis envolvidas no estudo em longo prazo e também a entrega da intervenção ser realizada face a face. Para Kristén et al. (2015), é essencial aplicar design longitudinais com medidas repetidas (com mínimo de três medidas) em estudos de intervenção que visam compreender comportamentos, como também recomendam as intervenções face a face, onde o participante possa interagir com outras pessoas. Pois, são 
mais efetivas do que outros modos de entrega de intervenção (por telefone, via internet, e-mail) (CONN; HAFDAHL; MEHR, 2011).

\section{CONCLUSÃO}

Conclui-se que os programas de promoção de AF testados (MC e Exercício Físico Tradicional), aplicados em idosos cadastrados em centros de saúde de Florianópolis, não foram capazes de promover modificações nos domínios de QV. Recomenda-se que, antes de reaplicar o Programa VAMOS, sejam realizadas novas adaptações no intuito de maximizar seus efeitos e promover melhorias na QV de seus participantes.

\section{REFERÊNCIAS}

[1] Rezende, A. A. B. et al. Effects of sensory motor training of lower limb in sedentary elderly as part of functional autonomy. Revista Andaluza de Medicina del Deporte, v. 8, n. 2, p. 61-66, 2015. Disponível em: https://reader.elsevier.com/reader/sd/pii/S1888754614000999?token=F026D62D49F20DF596A64E3C628AFFFC9 822CA8C338957AD53F9594C8E13FCF790ACD09271D213BD678EDE92556579AC. Acesso em: 02 maio de 2019.

[2] Hallal PC, Andersen LB, Bull FC, Guthold R, Haskell W, Ekelund U, et al. Global physical activity levels: surveillance progress, pitfalls, and prospects. Lancet. 2012; 380 (9838):247-57.

[3] Vagetti, G. C. et al. Association between physical activity and quality of life in the elderly: a systematic review, 2000-2012. Revista Brasileira de Psiquiatria, v. 36, n. 1, p. 76-88, 2014 . Disponível em: http://www.scielo.br/scielo.php?script=sci_arttext\&pid=S151644462014005020895\&lng=en\&nrm=iso\&tlng=en. Acesso em: 02 maio de 2019.

[4] Reis RS, Hallal PC, Parra DC, Ribeiro IC, Brownson RC, Pratt M, et al. Promoting Physical Activity Through Community-Wide Policies and Planning: Findings From Curitiba, Brazil. J Phys Act Health. 2010; 7[Suppl 2]:S137-45.

[5] Benedetti, T. R. B. et al. Programa "Vamos" (Vida Ativa Melhorando a Saúde): da concepção aos primeiros resultados. Revista Brasileira de Cineantropometria e Desempenho Humano, v. 14, n. 6, p. 723-737, 2012. Disponivel em: http://www.scielo.br/pdf/rbcdh/v14n6/a11v14n6.pdf. Acesso em: 02 de maio de 2019.

[6] Cardoso Asa, Borges LJ, Mazo GZ, Benedetti TB, Kuhnen AP. Fatores influentes na desistência de idosos em um programa de exercício físico. Movimento. 2008; 14(01):225-39.

[7] Opdenacker J, Boen F, Coorevits N, Delecluse C. Effectiveness of a lifestyle intervention and a structured exercise intervention in older adults. Prev Med. 2008; 46(6):518-24.

[8] Wilcox, S. et al. Results of the first year of active for life: translation of 2 evidence-based physical activity programs for older adults into community settings. American Journal of Public Health, v. 96, n. 7, p. 1201-1209, 2006. Disponível em: https://www.ncbi.nlm.nih.gov/pubmed/16735619. Acesso em: 02 de maio de 2019.

[9] Griffin, S. F. et al. Results from the Active for Life process evaluation: program delivery fidelity and adaptations. Health Education Research, v. 25, n. 2, p. 325-342, 2010 . Disponível em: https://academic.oup.com/her/article/25/2/325/668833. Acesso em: 02 de maio de 2019.

[10] Almeida, F. A. et al. Design and methods of "Diabeat-it!": a hybrid preference/randomized control trial design using the RE-AIM framework. Contemporary Clinical Trials, v. 38, n. 2, p. 383-396, 2014. Disponível em: https://www.ncbi.nlm.nih.gov/pubmed/24956325. Acesso em: 02 de maio de 2019.

[11] Borges, R. A. Programa de Promoção de Atividade Física no Sus: Barreiras e Facilitadores Organizacionais. 2014. 125f. Dissertação (Mestrado em Educação Física) - Universidade Federal de Santa Catarina, Florianópolis, Santa Catarina, 2014. Disponível em: https://repositorio.ufsc.br/bitstream/handle/123456789/129327/329527.pdf?sequence=1\&isAllowed=y. Acesso em: 02 de maio de 2019.

[12] Bandura, A.; Azzi, R. G.; Polydoro S. Teoria social cognitiva: conceitos básicos. In: Bandura, A. A evolução da teoria social cognitiva. Porto Alegre: Artmed, 2008.

[13] Fleck, M. P. A. et al. Aplicação da versão em português do instrumento abreviado de avaliação da qualidade de vida "Whoqol-Bref". Revista de Saúde Pública, v. 34, n. 2, p. 178-183, 2000. Disponível em: http://www.scielo.br/pdf/rsp/v34n2/1954.pdf. Acesso em: 02 de maio de 2019.

[14] Fleck, M. P.; Chachamovich, E.; Trentini, C. Development and validation of the Portuguese version of the Whoqol-OLD module. Revista de Saúde Pública, v. 40, n. 5, p. 785-791, 2006. Disponível em: http://www.scielo.br/pdf/rsp/v40n5/07.pdf. Acesso em: 02 de maio de 2019. 
[15] Pedroso, B.; Pilatti, L. A.; Gutierrez, G. L. Cálculo dos escores e estatística descritiva do Whoqol-Old pelo Microsoft Excel. Geriatria \& Gerontologia, v. 4, n. 4, p- 214-219, 2010. Disponível em: http://www.brunopedroso.com.br/whoqol-old.html. Acesso em: 02 de maio de 2019.

[16] Cohen, J. Statistical Power Analysis for Behavioral Sciences. Lawrence Erlbaum Associates, 1988.

[17] Nutrition Screening Initiative (NSI). Nutrition interventions manual for professionals caring for older Americans. Washington DC: Nutrition Screening Initiative, 1992.

[18] Lipschitz, D. A. Screening for nutritional status in the elderly. Prim Care, v. 21, n. 1, p. 55-67, mar. 1994.

[19] World Health Organization (Who). Obesity: preventing and managing the global epidemic. Geneva: Report of WHO a consultation, 2000. Disponível em: https://www.who.int/nutrition/publications/obesity/Who_TRS_894/en/. Acesso em: 02 de maio de 2019.

[20] World Health Organization (Who). Whoqol user manual. Division of mental health and prevention of substance abuse. Geneva: Suíça, 1998.

[21] Paiva, M. H. P. et al. Fatores associados à qualidade de vida de idosos comunitários da macrorregião do Triângulo do Sul, Minas Gerais, Brasil. Ciência \& Saúde Coletiva, v. 21, n. 11, p. 3347-3356, 2016. Disponível em: http://www.scielo.br/pdf/csc/v21n11/1413-8123-csc-21-11-3347.pdf Acesso em: 02 de maio de 2019.

[22] Grupo Whoqol-Old. Whoqol-OLD manual. Tradução de Eduardo Chachamovich e Marcelo Pio de Almeida Fleck. Geneva; 2005.

[23] Dale H.; Brassington L.; King, K. The impact of healthy lifestyle interventions on mental health and wellbeing: a systematic review. Mental Health Review Journal, v. 19, n. 1, p. 1-26, 2014. Disponível em: http://www.emeraldinsight.com/doi/full/10.1108/MHRJ-05-2013-0016. Acesso em: 02 de maio de 2019.

[24] 24. Kristén, L. Future challenges for intervention research in health and lifestyle research-A systematic meta-literature review. International Journal of Qualitative Studies on Health and Well-being, v. 10, n. 1, p. 27326, Ago. 2015. Disponível em: https://www.ncbi.nlm.nih.gov/pubmed/26282869 Acesso em: 02 de maio de 2019.

[25] 25. Conn VS, Hafdahl AR, Mehr DR. Interventions to increase physical activity among healthy adults: metaanalysis of outcomes. American journal of public health. 2011; 101(4):751-58.

[26] 27. Borges LJ, Benedetti TRB, Mazo GZ. Exercício físico, déficits cognitivos e Aptidão funcional de idosos usuários dos Centros de saúde de Florianópolis. Rev bras ativ fís saúde. 2008; 13(3):167-77.

[27] 28. Mendoza-Ruvalcaba, N.; Arias-Merino, E. D. "I am active": effects of a program to promote active aging. Clinical Interventions in Aging, v. 10, p. 829-837, maio. 2015. Disponível em: https://www.ncbi.nlm.nih.gov/pmc/articles/PMC4427596/. Acesso em: 02 de maio de 2019.

[28] 29. Alexandre S, Cordeiro RC, Ramos LR. Factors associated to quality of life in active elderly. Rev Saude Publica. 2009; 43(4):613-21. 


\section{Capítulo 3}

Realização de um bingo em uma instituição de longa permanência: Um relato de experiência

\section{Álef Lamark Alves Bezerra \\ Nayara Batista Marques \\ Vanessa Souto Maior \\ José Artur de Paiva Veloso}

Resumo: A realização de atividades lúdicas melhora a capacidade de entretenimento, socialização, memorização, ao explorar as habilidades dos idosos. Além disso, por ser considerado uma forma de aplicação de Cuidados Paliativos, o momento visou, por meio da dinâmica, a redução dos diversos efeitos advindos da senilidade nos pacientes, que afeta, principalmente, a capacidade cognitiva dos indivíduos acometidos. Objetivo: relatar os efeitos de uma atividade lúdica (bingo) em idosos residentes de uma Instituição de Longa Permanência. Metodologia:. Relato de experiência de uma prática de educação em saúde com um grupo de 20 idosos, vivenciada por estudantes de medicina no dia 24 de novembro de 2018 na Instituição de Longa Permanência Vila Vicentina. Resultados e discussão: Podemos observar que o bingo gerou uma interação entre os idosos que aderiram a atividade, gerando um momento de lazer e descontração. A instituição nos deu apoio e colaborou para que a dinâmica fosse realizada com engajamento dos participantes. Considerações finais: A atividade realizada é um dos exemplos de interações que beneficiam a saúde mental dos idosos instituncionalizados, pois colabora para a socialização e o estímulo cognitivo concomitantemente. Deve- se, portanto, pesquisar outras formas de aumentar a adesão dos idosos nessas atividades.

Palavras-chave: Ludoterapia. Idosos. IPLI 


\section{INTRODUÇÃO}

Segundo o IBGE (2011) a duração média de vida da população brasileira vem mudando mediante às transformações socioeconômicas, políticas e tecnológicas ocorridas na sociedade. Dessa forma, é previsível que até o ano de 2025 o Brasil esteja entre as seis maiores população de idosos no mundo. Além disso, estima-se que esse mesmo número poderá quadruplicar até 2060 , se esse ritmo de crescimento for mantido (Brasil, 2011).

Nesse mesmo cenário, há também o crescimento de idosos vivendo em instituições de longa permanência, sendo a maioria levada pela família por diversos motivos, os quais se destacam razões psicológicas, financeiras e familiares (França, 2006).

No contexto dos idosos que reside em instituição de longa permanência, há características peculiares dentro desse grupo, como a falta de acolhimento familiar, renda e independência funcional, além disso, muitas vezes coexistem fragilidades físicas e mentais que exigem um monitoramento específico pelos cuidadores, por meio de atividades dinâmicas que promovam integração, autonomia e qualidade de vida (Guimaraes et al., 2016).

Percebe-se que é imprescindível a garantia de estimulo à capacidade funcional, mental e cognitiva do idoso, por meio do investimento em ações de cuidado, prevenção e controle de doenças próprias dessa idade, sendo as atividades lúdicas e físicas se constituem como intervenções primordiais nesse processo, com objetivo de promover uma maior qualidade de vida aos gerontes (Guimarães, 2016).

Portanto, é possível notar que a prática de atividades de lazer para idosos influencia suas vidas de forma positiva contribuindo significativamente para o estabelecimento e manutenção dos fatores biológicos, psicológicos e sociais (Fleurí, 2013).

Ações lúdicas visam promover a independência, autonomia, vínculos interpessoais, lazer, bem estar lúdico e mental, afeto, atenção, escuta e evitar solidão, sofrimento psíquico, rebaixamento da autoestima e insegurança e promove a manutenção dos fatores biológicos, psicológicos e sociais e valorização das características do indivíduo (Fleuri, 2013).

Estimulação cognitiva realizada com atividade lúdicas traz benefícios como retardar o quadro de demências mais agravantes, além de estimular a capacidade de raciocínio e socialização do idoso (Pinheiro; Gomes, 2014).

Dentre as práticas de lazer dos idosos viventes em instituição de longa permanência, as mais comuns são as religiosas, relações interpessoais, ginástica, assistir televisão e práticas manuais e artesanais (Moura; Souza, 2013).

Desse modo, atividades lúdicas com idosos são instrumentos de animações, que promovem divertimento, lazer e convívio, bem como proporcionam habilidades e disposição na realização de atividades de vida diária (Metzner, 2012).

0 objetivo deste trabalho é relatar a experiência de estudantes de graduação em desenvolver ações lúdicas, como o bingo, voltadas para o público de idosos institucionalizados, conforme a importância destas para a promoção de saúde mental e qualidade de vida.

\section{METODOLOGIA}

Relato de experiência de uma prática de educação em saúde com um grupo de 20 idosos, vivenciada por estudantes de medicina no dia 24 de novembro de 2018 na Instituição de Longa Permanência Vila Vicentina do bairro Torre localizada na cidade de João Pessoa/PB. Para maior aproveitamento da atividade, realizou-se duas reuniões, sendo a primeira para decidir qual ação iríamos realizar e a segunda para definir as etapas a serem cumpridas para o bom proveito da ação.

Como critério de inclusão, adotou-se o fato de ser idoso institucionalizado no local em questão com capacidade cognitiva em participar do bingo e o critério de exclusão consistiu em idoso que se recusou a participar da ação. Dado que objetivava a maior adesão possível dos idosos, os estudantes que fizeram papel de facilitadores, convidando os idosos a participarem da atividade. 
Na prática foram utilizados um globo de bingo contendo 90 pedras redondas cada qual com um número designado, 20 cartelas de bingo com 25 números correspondentes as pedras, 400 grãos de feijão, seis mesas, 20 cadeiras e 20 prêmios para ser dado aos participantes de acordo com a ordem dos vencedores.

\section{DESENVOLVIMENTO}

0 bingo foi realizado no dia 24 de novembro de 2018 às 08 horas tendo como organizadores sete discentes de medicina que estavam realizando uma Pesquisa na Vila Vicentina e se propuseram a realizar uma ação lúdica no intuito integrar e socializar os idosos entre si, aproximar a relação pesquisadorparticipante e fornecer benefícios a saúde adquiridos com a prática realizada, e 15 discentes do curso de medicina da Faculdade de Ciências Médicas da Paraíba participantes de um Projeto de Extensão cujo tema é a saúde do idoso, convidados pelos pesquisadores. Essa ação teve duração média de aproximadamente duas horas e teve um total de 20 idosos participantes distribuídos em cinco mesas.

O delineamento do presente relato de experiência "Realização de um Bingo em uma Instituição de Longa Permanência: um relato de experiência" foi realizado nas seguintes etapas: 1) - Descrição da experiência; 2) - Resgate das fotografias da atividade;

3) - Busca de artigos sobre o mesmo tema; 4) - Discussão dos resultados.

A pesquisa de bibliografia foi realizada, em abril e maio de 2019, por meio das plataformas de indexação Pubmed, Scielo, Lilacs, e os descritores utilizados foram "atividades lúdicas" And "idosos".

\section{RESULTADOS E DISCUSSÃO}

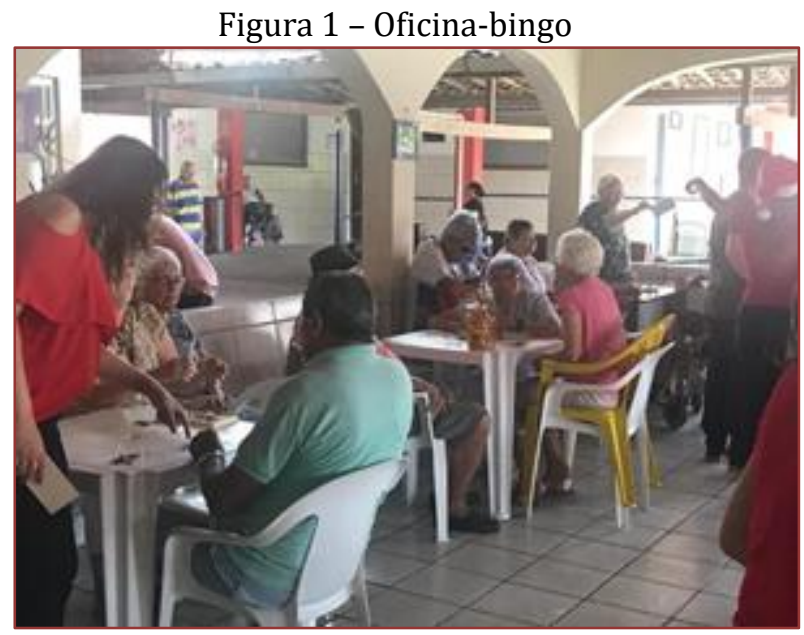

Fonte: Bezerra et al., 2019.

Houve um minucioso preparo para essa oficina, visto que foram feitas reuniões organizativas prévias para definir os brindes, treinar os envolvidos, preparo do ambiente acolhedor e toda a ação e planejamento foi repassada para Instituição de Longa Permanência a fim de que pudéssemos nos prevenir de qualquer eventual infortúnio. Ademais, um pesquisador foi previamente ao local no intuito de confirmar a disponibilidade do local para o dia planejado e conferir se as peças do bingo estavam em estado adequado. É válido citar que Munhoz. et al. (2016) também realizaram uma oficina-bingo semelhante e atribui a eficácia de sua ação ao planejamento prévio. Isso demonstra a importância de planejar previamente as ações.

A fim de facilitar o reconhecimento dos organizadores do evento, todos os organizadores foram vestidos com a camisa vermelha uma vez que a data do evento foi próxima ao data do natal. Outrossim, realizou-se previamente uma decoração natalícia do lugar com o intuito de remeter o evento ao feriado e os prêmios a "um presente de natal". 
Todos os idosos participantes receberam uma cartela, havia um globo para o sorteio dos números e em cada número sorteado os idosos assinalavam a cartela com um grão de feijão. Munhoz. et al. (2016) também utilizaram essa prática em sua ação e relata boa adesão. Ademais, os graduandos foram divididos de acordo com as atividades: rodar a roleta, pegar os números e chamar, auxiliar os idosos com as cartelas e conferir os números

Devido a alguns idosos terem doenças que provocam déficits cognitivos como o Alzheimer e outros possuírem déficits auditivos, em cada mesa havia ao menos um acadêmico a fim de orientar os idosos quanto a marcação dos números e alguns idosos, que necessitavam de mais atenção, dispunham de um aluno exclusivo para orientá-lo. Além mais, cada número era repetido no mínimo duas vezes e relacionado a algum tema. Deste modo, assumindo o compromisso com o princípio da equidade (Figueiredo. et al., 2019).

Oferecer diversas atividades não é condição única para envolver participantes, mas sim o empenho que favoreça suporte às interações (Alves de Moura; de Souza, 2013).

Garces. et al. (2011) realizou atividades físicas, fisioterapêuticas e arteterapia em idosos com Alzheimer e percebeu que essas atividades extras colaboram para a socialização, manutenção da capacidade funcional e percepções de sentimentos, afetos e lembranças dos idosos. Tendo em vista esses benefícios como apoio aos cuidadores para enfrentamento desse momento difícil e pesaroso das suas vidas.

Conforme os idosos completavam a cartela, eles se dirigiam a uma mesa natalina de prêmios e escolhiam um da mesa. A fim de remeter a atividade a algo prazeroso e não apenas competitivo, trouxemos o quantitativo de prêmios igual ao quantitativo de participantes. Assim, os prêmios eram referenciados como "presentes de natal" e a vantagem do integrante que ganhasse primeiro era poder escolher qual presente iria ganhar. A guisa de exemplos, os prêmios iam desde kits de higiene, kits de limpeza, kits de saúde, até kits de beleza.

Figura 2 - Entrega dos prêmios ("presentes de natal")

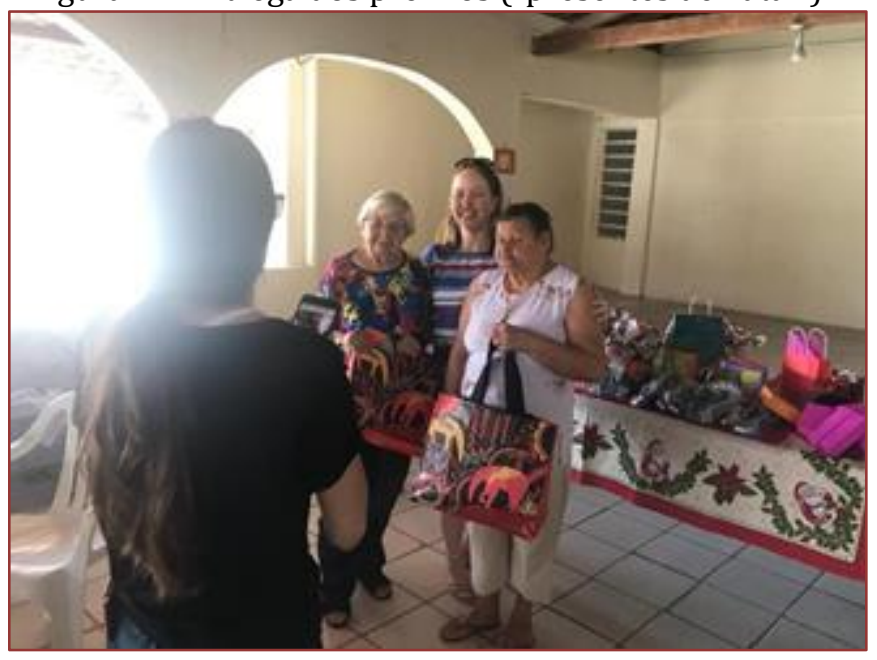

Fonte: Bezerra. et al., 2019.

Ao final da experiência, os autores se reuniram para discutir os pontos positivos e os que poderiam ser melhorados. Enquanto os primeiros foram que o planejamento prévio e o apoio da instituição permitiu uma boa adesão e engajamento por parte dos idosos, os segundos foram que deveríamos ver novas formas de aumentar adesão, visto que embora ela tenha sido satisfatória, acreditamos que poderia ter sido ainda maior.

\section{CONSIDERAÇÕES FINAIS}

É notável o desenvolvimento da futura postura profissional de acordo com as práticas realizadas durante o período de graduação. Dessa forma, é valioso o contato dos discentes com um grupo de pessoas longevas, mais limitadas e com necessidades diferentes, assim como a realização de atividades, que cobram dos alunos uma visão mais ampla sobre equidade e sua aplicação durante todo o aprendizado. 
Acredita-se que o cuidado minucioso auxiliou na repercussão positiva do evento, promovendo participação espontânea dos idosos e a verbalização de satisfação durante após a participação dos mesmos.

Ademais, a experiência foi benéfica para os idosos que puderam se beneficiar de um momento lúdico e interativo que foge da rotina da instituição, proporcionando uma vivência benéfica para a saúde mental, interação social e estímulo ao cognitivo.

\section{REFERÊNCIAS}

[1] Alves de Moura, Giselle; de Souza, Luciana Karine. Práticas de lazer de idosos institucionalizados. Movimento, v. 19, n. 4, 2013. Disponível em <https://www.redalyc.org/html/1153/115328881004/>. Acesso em: 19 de maio de 2019.

[2] Brasil. Instituto Brasileiro de Geografia e Estatística - IBGE. Sinopse do Senso Demográfico de 2010. Rio de Janeiro: IBDE; 2011

[3] Figueiredo, Daniella Santa et al. Health promotion to social determinants: possibility for equity. Journal of Nursing UFPE/Revista de Enfermagem UFPE, v. 13, n. 4, 2019.

[4] Fleurí, Amanda Caroline P. et al. Atividades lúdicas com idosos institucionalizados. Enfermagem Revista, v. 16, n. 1, p. 50-57, 2013.

[5] Garces, Solange Beatriz Billig et al. Relatos de experiências:(com) vivência com idosos que apresentam Alzheimer. Estudos Interdisciplinares sobre o Envelhecimento, v. 16, n. esp, 2011. Disponível em: <https://www.seer.ufrgs.br/RevEnvelhecer/article/view/17919>. Acesso em: 19 de maio de 2019.

[6] Guimaraes, A.C. et al . Atividades grupais com idosos institucionalizados: exercícios físicos funcionais e lúdicos em ação transdisciplinar. Pesqui. prát. psicossociais, São João del-Rei ,v. 11, n. 2, p. 443-452, dez. 2016.

[7] Metzner, A. C. Atividades lúdicas na terceira idade: benefícios para um grupo de mulheres da cidade de Jaborandi. Revista Fafibe On-Line, ano V, n.5, p. 01-06, nov. 2012.

[8] Munhoz, OL. et al. Oficina bingo da saúde: uma experiência de educação em saúde com grupos de idosos. Rev. Min. Enferm, 20:e968, 2016.

[9] Pinheiro, Sarah Brandão; Gomes, Mariana Lima. efeitos das atividades lúdicas no idoso com alteração do cognitivo leve: uma revisão

[10] Sistemática. Revista pesquisa em fisioterapia, v. 4, n. 1, p. 71-77, 2014. Disponível em <https://www5.bahiana.edu.br/index.php/fisioterapia/article/view/369>. Acesso em 19 de maio de 2019. 


\section{Capítulo 4}

Promovendo o lugar de fala: Relato de experiência com idosas da universidade aberta à maturidade em observância dos aspectos biopsicossociais que envolvem o envelhecimento humano

Fabrício Miguel dos Santos

Drielle Barbosa Leal Serafim

Millena Caroline Gomes Rodrigues

Tiago Uriatã de Vasconcelos Costa

Antônio Guedes Rangel Júnior

Resumo: 0 presente estudo tem como objetivo analisar, por meio de um relato de experiência, conteúdos trabalhados a respeito da temática do envelhecer, em especial, a área da Gerontologia a qual tem por base o avanço nas pesquisas da Psicologia do Desenvolvimento, sendo esta contemplada através de uma experiência realizada por estudantes universitários do sétimo período de psicologia da Universidade Estadual da Paraíba - UEPB, em uma visita à Universidade Aberta à Maturidade (UAMA), instalada no Campus I da mesma universidade na cidade de Campina Grande, também no estado da Paraíba. Teve-se como material utilizado a entrevista/escuta de oito idosas. Considerando que a Gerontologia é o estudo dos processos de envelhecimento em suas dimensões biopsicossociais e espirituais. Em face disto, este texto traz uma reflexão sobre as questões que permeiam a vida do idoso, como a autoestima, as suas relações familiares, sociais e intergeracionais, bem como a maneira que lidam com sua autoimagem. Assim, a principal meta a ser observada nesta pesquisa é a de perceber a relevância desse lugar de fala com a finalidade de compreender, analisando conteúdos apresentados em fala, e associando teorias de cunho bibliográfico ao significado que esse processo de envelhecimento tem para esses sujeitos.

Palavras-chave: Envelhecimento, Gerontologia, Autoimagem, Autoestima, Relações sociais. 


\section{INTRODUÇÃO}

As questões inerentes a uma fase muito importante da vida do ser humano - o envelhecer - tem sido o foco de atenção em áreas como medicina, saúde coletiva, psicologia, antropologia, enfermagem, sociologia, entre outras. Em termos cronológicos tomou-se conta do aumento da população de idosos a partir de 1970, década em que se tem uma baixa queda da fecundidade e o aumento, ainda discreto, da população acima dos 60 anos. Hoje, passados quase 50 anos, temos um índice de 650 mil novos idosos incorporados à população brasileira anualmente. Considerando esses números, o Instituto Brasileiro de Geografia e Estatística (IBGE, 2012) divulgou que em 2050 para cada 100 crianças de 0 a 14 anos, haverá 172,7 idosos.

Nas últimas décadas, a velhice alcançou uma maior visibilidade no cenário social, em especial na década de 1980 em que se contribuiu para a produção de conhecimentos e tecnologias destinados a instruir e a gerar práticas de bem viver na velhice (GROISMAN, 2002 -). Apesar dos avanços, ainda há o que se reivindicar e lutar no que tange uma assimilação dos idosos na construção de sua cidadania plena. No campo da psicologia, por exemplo, existem poucas iniciativas sobre o estudo do envelhecimento, em contrapartida, se tem mais visibilidade em pesquisas e teorizações no contexto da infância e adolescência.

Isso se deve ao pensamento que se estabeleceu a partir de 1789 com a Revolução Francesa, nesta época surgiram outros valores que marcaram a psicologia do desenvolvimento. A ideia de que a "personalidade" já vinha inscrita na herança do sujeito passa a ser questionada, e substituída pelo princípio de que a história individual é construída pela interação do ser humano com o ambiente e os acontecimentos cotidianos. Assim, o cenário moderno passa a valorizar o "novo" e o "processo de desenvolvimento" passa a ser entendido como uma construção de caminhos fundamentais para o futuro da sociedade.

Com esse novo olhar sobre a psicologia do desenvolvimento, em especial enaltecendo a fase do envelhecer, pode-se citar a Gerontologia como campo de conhecimento científico que possui como estudo as dimensões biológica, psicológica e social no processo de envelhecimento. A esse processo, dentro do campo da psicologia, dá-se o nome de Psicogerontologia (ou Psicologia do Envelhecimento), uma área de estudo recente em que os estudiosos afins, vêm pesquisando comportamentos ao longo do curso de vida (NOVO, 2003).

Levando em conta esse novo cenário da população brasileira, tornou-se relevante conhecer e compreender o processo de envelhecimento, a realidade do idoso, suas características e potencialidades, assim como sugerir melhorias para esse grupo específico, gerando conhecimento. Com isso, o presente relato visa apresentar um trabalho realizado na UAMA, realizado como atividade complementar da disciplina de Psicologia do Envelhecimento. A referida atividade foi desenvolvida através de um encontro onde fora proposto uma intervenção, empregada através das etapas de acolhimento, troca de experiências por meio do método de escuta grupal e individual, e aplicada pelos referidos alunos de psicologia, junto a idosos devidamente matriculados na Universidade Aberta à Maturidade.

Diante da proposta estabelecida, deu-se ao idoso o lugar da fala, e com esta perspectiva foi possível identificar questões que permeiam suas vidas no que tange à autoimagem, autoestima, relações familiares e intergeracionais. É importante salientar que essas questões não cercam exclusivamente o idoso, mas, suas perspectivas e contextos que podem ser diferentes dos que são vivenciados em outras épocas da vida, pois o olhar que se tem do mundo, de si e do outro se tornam singulares a cada sujeito.

\section{METODOLOGIA}

O trabalho em questão caracteriza-se por uma vivência promovida pela disciplina de Psicologia do Envelhecimento, e denota características que equivalem às necessidades deste estudo, ao buscar analisar a temática da Gerontologia através da análise de questões (relações sociais/familiares/intergeracionais, autoestima e autoimagem) relativas ao envelhecimento, contempladas a partir das entrevistas feitas na Universidade Aberta à Maturidade - UAMA. A instituição está localizada no Campus I da Universidade Estadual da Paraíba (UEPB) e possui como meta, atender à demanda educativa de idosos a partir dos 60 (sessenta) anos de idade, contribuindo na melhoria das capacidades pessoais, funcionais e socioculturais, por meio da formação no curso, bem como a atenção social.

Buscando alcançar o propósito desta pesquisa, foi realizada uma escuta breve com um grupo de 8 (oito) idosas, em que foram ressaltados alguns pontos que contemplam a perspectiva da velhice. 
Atrelado a esta experiência buscou-se artigos para o embasamento teórico nos seguintes bancos de dados online: SciELO (Scientific Electronic Library Online); PePSIC (Periódicos Eletrônicos em Psicologia); BVS (Biblioteca Virtual em Saúde) e Google Acadêmico, usando os seguintes descritores: envelhecimento, gerontologia, autoimagem, autoestima, relações familiares e intergeracionais.

\section{DESENVOLVIMENTO}

Partindo do pressuposto da construção histórica, até o século XIX a velhice era considerada quase como uma doença, pois a pessoa não conseguia se sustentar financeiramente, remetendo o envelhecimento como sinônimo de incapacidade (ARAÚJO E CARVALHO, 2005). Nas primeiras décadas do século XX, alguns autores como Stanley Hall, um estudioso e psicólogo que começa a traçar o perfil da velhice de modo que considera suas transformações físicas e as diferentes perdas sofridas nesta fase da vida, sem deixar de relatar que mesmo as perdas podem ser individuais (NERI, 1995).

Entende-se atualmente que o envelhecimento populacional é um fenômeno que vem ocorrendo de forma gradual em grande parte das populações mundiais. Este aumento da população de idosos advém de diversos fatores, resulta de transformações demográficas ocorridas nas últimas décadas, do aumento da expectativa de vida, do desenvolvimento científico entre outros. De acordo com Chaimowick (2013, p. 16) "está associado a modificações do perfil epidemiológico e das características sociais e econômicas das populações".

Com esse aumento demográfico presenciado nos últimos anos, o campo da Psicogerontologia se destaca enquanto estudo das diferenças que estão dentro do indivíduo, ou seja, em sua subjetividade, e das relações entre as pessoas. Esta relação constitui inúmeros processos psicológicos no envelhecimento, levando em conta os desempenhos de diferentes grupos de idade e sexo e de grupos com experiências culturais e educacionais diversificadas (FALCÃO; CACHIONI, e YASSUDA, 2009).

Dentro dessa perspectiva e considerando que o processo do envelhecimento traz consigo mudanças fisiológicas e autônomas, é salubre refletir sobre algumas ferramentas do viver bem e feliz no envelhecer. Partindo desse pressuposto da autoestima do idoso, pode-se perceber que a relação com entes parentais caminha paralelamente com o bem estar do idoso, sendo evidenciado na Constituição Federal Brasileira, em seu Art. Artigo 3 da Lei no 8.842 de 04 de Janeiro de 1994, quando declara: "a família, a sociedade e o estado têm o dever de assegurar ao idoso todos os direitos da cidadania, garantindo sua participação na comunidade, defendendo sua dignidade, bem-estar e o direito à vida".

0 indivíduo deve acomodar-se em valores internos pessoais como a dignidade, prudência, sabedoria prática e aceitação do modo de viver, esses atributos são influenciados pelo constructo familiar. Caso estes sentimentos não sejam integrados ao Ego, tem-se o desespero, a raiva, amargura, depressão e inadequação (STRAHLER RIVERO ET AL, 2013). Este é um período que se faz regra a ativação do arquétipo do Velho Sábio e da Velha Sábia para abrir espaço na consciência sobre o questionamento a respeito da vida e da morte e proporcionar a sabedoria do envelhecer, o desfrute da vida conforme as limitações a partir da experiência a seu favor e dos outros (ARRUDA, 2012).

São estes arquétipos que possibilitarão o descobrimento da identidade profunda através da ação da libido para o encontro consigo mesmo e a integração com a sombra, ou seja com as qualidades e defeitos, erros e acertos, sombra e luz (GALIÁS, 2012). Strahler Rivero et al (2013) apontam que o fato de o indivíduo acreditar na própria capacidade e ter um alto grau de perseverança leva a diminuição do estresse e da depressão diante da necessidade de adaptação frente às situações ameaçadoras e novos contextos.

Ademais, os contatos com outras pessoas, fora da esfera familiar, tendem a consolidar o sentimento de autoimagem no idoso, uma vez que esse contato exterior é marcado por sentimentos de alegria, autovalorização e aceitação, assim, melhoria no seu estado de saúde (SPIRDUSO, 2005). Outra questão relevante na autoimagem refere-se à reconfiguração do corpo na velhice, após a idade adulta o corpo começa a sofrer modificações se distanciando cada vez mais do corpo idealizado pela sociedade onde se venera a beleza e a juventude. Em semelhança a essa linha de raciocínio Pascual (2012) diz que "é no terreno do corpo [...] que as pessoas de terceira idade mais necessitam crescer em autoestima, defendendo-o dos modelos predominantes que não lhes concedem valor algum" (p. 41). 


\section{RESULTADOS E DISCUSSÃO}

A entrevista foi realizada na Universidade Aberta à Maturidade - UAMA com oito pessoas, todas do sexo feminino na faixa etária de 63 a 84 anos de idade, o que nos leva a refletir sobre como a autoimagem, autoestima, relações familiares e intergeracionais são questões que sobressaem predominantemente o sexo feminino. A seguir serão apresentadas algumas falas ditas pelas idosas entrevistadas, seguidos pelas impressões dos resultados apoiados por uma análise do que foi manifestado. Por questões éticas e de respeito a subjetividade de fala, preconizadas sobretudo sob o crivo do Código de Ética Profissional do Psicólogo (2005), os nomes das idosas não estão sendo mencionados. Tal medida não fragiliza os objetivos colocados, tampouco subverte o intuito principal do trabalho.

Partindo dos relacionamentos familiares e intergeracionais, algumas frases proferidas pelas idosas retratam como o meio pode interferir no percurso de suas vidas e nas tomadas de decisões que influenciam diretamente em como as mulheres são vistas e cobradas na sociedade. A Senhora S. de 70 anos, disse: "Consegui fazer minhas coisas quando fiquei viúva", pode-se notar a submissão feminina, um fenômeno historicamente construído, marcado pelo poder que homem exercia sobre as funções e o corpo das mulheres.

A Senhora S. relatou também que mora com uma pessoa que não é da sua família, mas que a acolheu como filha e hoje é sua companhia diária. No entanto, muitos idosos se deparam, algumas vezes, com o abandono afetivo de seus parentes nessa fase da vida; não sendo generalizante, considera-se também que existem muitos idosos que preferem se reservar, excluindo qualquer tipo de companhia e se sentindo felizes dessa maneira, porém o abandono afetivo é real e doloroso, uma realidade de muitos idosos que se sentem excluídos pela própria família. Essa rejeição pode acarretar sentimento de tristeza e solidão, que se reflete em deficiências funcionais e no agravamento de uma situação de isolamento social. Para Bertolin e Viecil (2014), "a falta de intimidade compartilhada e a pobreza de afetos e de comunicação tendem a mudar estímulos de interação social do idoso e de seu interesse com a própria vida" (p.13).

Outro ponto no tocante aos relacionamentos familiares e intergeracionais, é o relato da Senhora G. de 71 anos, ela diz que se sente muito bem e feliz por estar na UAMA (Universidade Aberta à Maturidade) compartilhando e recebendo experiências dos amigos com quem convive. De acordo com Hinde (1997) pode-se dizer que os amigos, ao lado dos familiares, são, possivelmente, as figuras mais importantes da rede social do idoso. Em seguida, M.E de 63, se dispõe a abrir-se em palavras e diz: "A UAMA pra mim, é conviver, fazer amigos e conversar".

Os novos vínculos criados podem obter um resultado nos relacionamentos já existentes, seja com amigos ou familiares, isso é capaz de exercer um efeito positivo no que tange a autoestima do idoso. "Se, por um lado, os laços familiares são sentidos como significativos mantenedores de segurança emocional, por outro, relações fraternas, sem grau de parentesco, fortalecem a interação social" (ARGIMON; VITOLA, 2009, p. 29).

Com isso, é possível fazer uma ponte com a autoestima do idoso, dentre as entrevistas realizadas a Senhora S. de 70 anos demonstrou bastante orgulho ao falar que fundou um grupo de oração na igreja que funciona há 30 anos, além de se dedicar a outras atividades dentro da sua religião, e afirmou: "Gosto de ser ativa e de participar". Sobre a UAMA, ela disse: "Gosto de dançar, adoro quando tem forró aqui"; "A UAMA mudou minha visão de que idoso é inválido e não pode ter sonhos", nesta última frase dita por ela, me remeteu a visão que a sociedade ainda tem sobre o idoso.

Reiterando ainda sobre a concepção da sociedade sobre o idoso, o envelhecimento ativo é a visão que está em crescimento na atualidade,

Envelhecimento ativo aplica-se tanto a indivíduos quanto a grupos populacionais, permitindo que as pessoas percebam o seu potencial para o bem- estar físico, social e mental ao longo do curso da vida, e que essas pessoas participem da sociedade de acordo com suas necessidades, desejos e capacidades; ao mesmo tempo, propicia proteção, segurança e cuidados adequados, quando necessários. Entre os conceitos envolvidos estão à autonomia, independência, qualidade de vida e expectativa de vida saudável. (WORLD HEALTH ORGANIZATION, 2005, p.14).

A Senhora M. A. de 68, relatou: "Vivi em prol dos meus irmãos, não tive nem como casar, sabe? Fui a pedra fundamental da minha família, vivi em prol dos outros. Com muito sacrifício consegui me formar em pedagogia, mas não tive condições de participar da festa de formatura". 
Referindo-se a experiência na UAMA, M. A. diz que agora irá realizar o sonho de fazer a sua formatura. Finalizando e complementando sua fala, encerra suas palavras com a seguinte frase: "Quero viver cada instante da minha vida, a partir de agora".

Outro relato obtido foi da Senhora M. S. de 70, a mesma conta que criou um grupo chamado de "Divas", composto por mulheres do seu bairro, de diferentes faixas etárias, com intuito de partilhar e viver experiências que possam trazê-las um sentido de liberdade e autonomia na vida. Ela disse: "Vivi histórias bonitas e tristes, não sei se serão contadas a outras pessoas". A senhora E. de 75 anos também relatou como o seu envolvimento em outras atividades mudou sua autoestima, ela disse: "Devido às aulas da UAMA consigo assumir papéis importantes, que quando me aposentei, pensei que não conseguiria. Até minha fé, o meu crer, mudou". Frankl (2017) aponta que a religião tem influências favoráveis nos aspectos que tangem saúde e equilíbrio psíquicos. Assim, a afirmativa de E. sobre fé religiosa, contempla sua justificativa de um possível bem estar quanto ao modo de lidar com questão do credo religioso.

A "velhice" é imperativa no encontro de sentido pelo sujeito, a busca por outras experiências e a realização de desejos não sucumbidos está presente nos relatos obtidos, como um recurso, forma ou chance de se manterem independentes e possuidoras de suas razões e forças motrizes do seu querer. Nessa construção e também resgate de autonomia, é importante para o indivíduo desenvolver meios e técnicas que possam ajudar a formatar habilidades que venham a facilitar sua forma de viver, e ver o mundo.

Sobre a perspectiva da autoimagem continuamos com o relato da Senhora E. de 75 anos, a mesma afirma que não gosta de ser chamada de senhora, ela disse: "É um termo tão pobrinho, porque senhora vem de algo que é velho, sem estilo, sem valor, eu não sou isso, posso ser uma pessoa com muita idade, mas velha não". A idosa lança sua perspectiva que converge com a de Ferreira et al. (2010) quando se lança falando da diferença entre o velho e o idoso. A mesma complementa: "idoso é o indivíduo que possui mais de 60 anos de idade, o velho envolve outras questões subjetivas, inclusive, o modo que encara sua velhice e este processo".

Nessa mesma conjuntura temos o relato de G. de 71 anos, que demonstrou satisfação com a vida, elemento indispensável ao bem-estar emocional, na fase do envelhecimento: "Não me sinto velha é só meu corpo que envelheceu, minha cabeça é do mesmo jeito com vontade de fazer minhas coisas". De acordo com Blessmann (2004, p. 11) "para cada pessoa existe um corpo que envelhece e uma cabeça que se mantém jovem. A cabeça é o lugar de resistência e negação da velhice".

Partindo do gancho da autoimagem, é possível atrelar as mudanças físicas a aceitação desse corpo que passa por grandes modificações. Pode-se notar através do relato da Senhora G. de 71 anos, que indagou: "É preciso cuidar do corpo, para tanto faz caminhadas, preocupa-se com a alimentação e usa maquiagem". A senhora I. de 84 anos também demonstrou um potencial de superação e enfrentamento frente às mudanças no corpo e limitações físicas naturais dessa fase. Ressaltou que mesmo morando sozinha não sente solidão, pois tem muitas amigas. Relembrando Chaimowicz (2013, p. 106) "a solidão e a incapacidade física, a qual leva a perda da independência, os dois principais fatores de riscos para depressão e ansiedade".

\section{CONSIDERAÇõES FINAIS}

A partir do encontro que deu subsídio a essa pesquisa foi possível fomentar uma reflexão sobre o envelhecimento, compreendido como um período do desenvolvimento humano, com características próprias, mas que não necessariamente enfocam o declínio das habilidades, adoecimento e morte, conforme é suposto pelo senso comum da sociedade atual. Foi perceptível, portanto, o resgate do sujeito na sua singularidade, suas condições de sofrimento e ressignificação, além do que, da implantação de estratégias quanto ao posicionamento subjetivo de cada indivíduo perante suas vivências e contendas referentes ao processo de envelhecimento.

Sendo assim, consegue-se concluir que os estudos referentes à Psicologia do Envelhecimento são de grande relevância no que diz respeito a conhecer experiências, para que se compreenda cada vez mais o processo do envelhecer, seus desafios, suas particularidades, as necessidades, bem como as perspectivas que se têm sobre o mesmo, tomando por base que esse percurso faz parte do processo de desenvolvimento humano, sendo, então, tão importante quanto as demais fases da vida. 
É importante ter consciência que o envelhecimento é um dos principais avanços da Humanidade no que tange às condições sanitárias, controle de doenças, questões previdenciárias dentre outras; ademais, é um processo que faz parte da vida de todos os seres humanos, logo, não pode ser visto como peso para o governo e para as famílias, mas como uma conquista, um produto do avanço nas políticas públicas. Assim, pode-se visualizar a velhice como um troféu, pautando-se na premissa que envelhecer é mérito dos vencedores que conquistaram a batalha da vida.

Ainda no conjunto de impressões é importante colocar que, diante da experiência vivida pelos alunos pesquisadores, depreende-se que o projeto da Universidade Aberta à Maturidade, a UAMA, traz para os indivíduos referenciados um lugar de subjetivação e ressignificação diante do processo de envelhecer. 0 estudo aponta que o lugar da fala garante ao sujeito empoderamento na participação ativa nos processos em que ele necessite se implicar. Com o estudo realizado constatamos que é necessário que se desenvolvam políticas públicas mais amplas e mais acolhedoras aos idosos; integralizando-os ao meio social mostrando-os que, de fato, são importantes na conjuntura econômica, subjetiva e afetiva da sociedade.

Por fim, diante dos métodos bibliográficos utilizado, da justificativa de propósito apresentada e dos objetivos elencados, concluímos que por meio da fala garantida aos sujeitos, é possível ter-se um diálogo favorável e respeitoso nos âmbitos intergeracionais, mas sobretudo, que seja oferecido esse lugar indiscriminadamente. Desta feita, concluímos que foram atingidas as metas pretendidas neste trabalho garantia de fala, análise de discurso e confronto da aliança teórica bibliográfica a relatos que tangenciam o processo biopsicossocial do envelhecimento humano.

\section{REFERÊNCIAS}

[1] Argimon, Irani I. de Lima; Vitola, Janice Castilhos. E a família, como vai? In: Bulla, Leonia Capaverde; Argimon, Irani Iracema de Lima (Orgs.). Convivendo com o familiar idoso. Porto Alegre: EDIPUCRS, 2009, p. 25-31.

[2] Bertolin, Giuliana; Viecili, Mariza. Abandono Afetivo do Idoso: reparação civil ao ato de (não) amar?. Revista Eletrônica de Iniciação Científica, Itajaí, v. 5, n. 1, p. 13, mar. 2014.

[3] Blessmann, E. J. Corporeidade e envelhecimento: o significado do corpo na velhice. Estudos interdisciplinares em envelhecimento, v. 6, p. 21-39, 2004.

[4] Conselho Federal de Psicologia, Código de Ética Profissional do Psicólogo. Atualizado em 12 de maio de 2005. Disponível em : <https://site.cfp.org.br/legislacao/codigo-de-etica/>. Acesso em 25 de maio de 2019.

[5] Envelhecimento ativo: uma política de saúde / World Health Organization; tradução Suzana Gontijo. Brasília: Organização Pan-Americana da Saúde, 2005, pg.14.

[6] Falcão, Deusivania Vieira Da Silva; Cachioni, Meire; Yassuda, Mônica Sanches. Contribuições da Psicologia à Gerontologia: reflexões sobre ensino, pesquisa e extensão. Kairós, São Paulo, n. 4, p. 43-58, ago. 2009.

[7] Ferreira, Olívia Galvão Lucena et al. Significados atribuídos ao envelhecimento: idoso, velho e idoso ativo. Psico-USF, v. 15, n. 3, p. 357-364, set./dez. 2010 . Disponível em : <http://www.scielo.br/pdf/pusf/v15n3/v15n3a09.pdf>. Acesso em 25 de maio de 2019.

[8] Frankl, Viktor E. A presença ignorada de Deus / Viktor E. Frankl. Traduzido por Walter O. Schlupp e Helga H. Reinhold. 18. ed . rev. - São Leopoldo : Sinodal; Petrópolis : Vozes, 2017.

[9] Groisman, D. A velhice, entre o normal e o patológico. História, Ciências, Saúde - Manguinhos, Rio de Janeiro, v. 9, n. 1, p. 61-78, 2002.

[10] Jusbrasil. A política nacional do idoso. Disponível em:

<https://www.jusbrasil.com.br/busca?q=art.+3+pol\%c3\%adtica+nacional+do+idoso+-+lei+8842\%2f94>. Acesso em: 15 mai. 2019.

[11] Novo, R. F. (2003). Para além da eudaimonia: o bem-estar psicológico em mulheres na idade adulta avançada. Coimbra, Fundação Calouste Gulbenkian e Fundação para a Ciência e Tecnologia

[12] Pascual, C. P. A sexualidade do idoso vista com novo olhar. Traduzido por Alda da Anunciação Machado. São Paulo: Loyola, 2002,pg, 41. 
[13] Pavarini, Sofia C. I.; Mendiondo, Marisa S. Z. de; Barham, Elizabeth J.; Varoto, Vania A. G.; Filizola, Carmen L. A. A arte de cuidar do idoso: gerontologia como profissão? Nova Estância, São Paulo, v. 14, n. 3, 2005, p. 398-402.

[14] Spirduso, W. W. (2005). Dimensões Físicas do envelhecimento. São Paulo: Manole. Tribess, S; Virtuoso JR, J. S. (2005). Prescrição de Exercícios Físicos para Idosos. Rev. Saúde.Com; 1(2), 163-172.

[15] Transição Demográfica. In: Saúde do Idoso/Flávio Chaimowicz, colaboração de: Barcelos, E.M.,Madureira, M.D.S., Ribeiro, M.T.F. 2a ed. - Belo Horizonte: Nescon UFMG: 2013, p. 16 - 26.

[16] Transição Demográfica. In: Saúde do Idoso/Flávio Chaimowicz, colaboração de: Barcelos, E.M.,Madureira, M.D.S., Ribeiro,M.T.F. 2a ed. - Belo Horizonte: Nescon UFMG: 2013, p. 27 - 31. 


\section{Capítulo 5}

\section{Zooterapia aplicada a melhor idade}

Grazielly Diniz Duarte

Milane Sales de Souza

Soraya Abrantes Pinto de Brito

Felipe Eduardo da Silva Sobral

Resumo: 0 presente trabalho foi realizado com 19 idosos institucionalizados do município de João Pessoa - PB. Teve como objetivo principal realizar uma avaliação dos idosos ao passarem por um período de convívio com animais domésticos, em específicos cães, baseado na zooterapia com o intuito de traçar o índice de satisfação deles e identificar uma forma de melhorar a sociabilização e reduzir os danos comuns no processo de envelhecimento de idosos asilados. A zooterapia foi aplicada com o auxílio de 3 cães, uma vez por semana, por cerca de uma hora, onde os idosos foram estimulados a manter contato direto com os animais a partir de toques, escovação dos pelos, massagens, brincadeiras, oferecimento de alimentos e/ou petiscos, caminhadas entre outros. Antes e após as atividades, os idosos preenchiam uma ficha para obtenção do índice de satisfação. Constatou-se uma interação muito benéfica entre os idosos e os cães, cerca de 95,24\% dos idosos afirmaram ficarem muito felizes após as sessões, superando as expectativas da equipe. Percebeu-se também um aumento de interação entre os idosos que passaram a conversar mais entre si, demonstrando assim tanto os benefícios sociais quanto de bem-estar a partir da zooterapia aplicada a melhor idade.

Palavras-chave: cão, idoso institucionalizado, melhor idade, zooterapia. 


\section{INTRODUÇÃO}

A zooterapia, em sua maioria, enquanto técnica de cuidado humano que se desenvolve no seio do sistema de saúde convencional ocidental, pode ser entendida como sinônimo de terapia animal assistida. Consiste em uma terapia com a presença de animais domésticos e domesticados empregados como coadjuvantes terapêuticos no tratamento e melhoramento de diversos estados patológicos, com o objetivo de promoção da sensibilidade tátil, reações psicológicas e emocionais. Os profissionais mais envolvidos são: fisioterapeutas, fonoaudiólogos, psicólogos, pedagogos juntamente com veterinários e adestradores (Bekker, 2003; Dotti, 2005; Costa Neto, 2011).

Desde que os animais passaram a fazer parte da família, foi criado um laço afetivo entre o animal e seu proprietário e o homem passou a usá-lo para ter benefícios positivos. Nos últimos anos, as experiências com os animais vêm demostrando a capacidade dos animais em auxiliar a recuperação da saúde humana.

A terceira idade é uma das etapas mais importantes da vida, onde precisa-se de maior atenção à saúde, as alterações físicas, psicológicas e até mesmo as mudanças econômicas e sociais (Tavares et al., 2017).

O Brasil vem apresentando um aumento no número de idosos quando comparado a anos anteriores, ganhou 4,8 milhões de idosos desde 2012, superando a marca dos 30,2 milhões em 2017, segundo a Pesquisa Nacional por Amostra de Domicílios Contínua do IBGE, a maioria são mulheres, com 16,9 milhões (56\% dos idosos), enquanto os homens idosos são 13,3 milhões (44\% do grupo). Em João Pessoa também se tem uma maior quantidade de mulheres $(50.59 \%$ de mulheres e $49.41 \%$ de homens), e os idosos representam 4.6\% da população local (IBGE, 2017).

Estudos mostram que a institucionalização do idoso tem como primeira consequência o despertar de um sentimento de perda de autonomia, tornando-os dependentes de terceiros ou das normas da instituição acolhedora. 0 que pode acarretar aumento da susceptibilidade a doenças, tristeza profunda e respostas biológicas de múltiplas origens: física, psíquica ou social trazendo complicações ao processo de envelhecimento (Argimon \& Sten, 2005; Ricci et al., 2014).

As atividades ministradas em asilos e abrigos no município de João pessoa, tem um apoio técnico multiprofissional com diversos serviços: saúde, limpeza, cuidadores, enfermeiros, psicólogos, técnicos da saúde, fisioterapeutas, assistentes sociais e agentes da saúde. Os quais promovem uma melhor qualidade de vida para a saúde dos idosos, mas ainda não encontramos veterinários compondo parte deste quadro de apoio.

0 presente trabalho foi realizado com 19 idosos selecionados do Asilo Vila Vicentina Júlia Freire que abriga atualmente 66 idosos. Teve como objetivo principal realizar uma avaliação dos idosos institucionalizados ao passarem por um período de convívio com animais domésticos, em específicos cães, acompanhados de estudantes de Medicina Veterinária da Faculdade UNINASSAU - JP, baseado na zooterapia com o intuito de traçar o índice de satisfação dos mesmos.

\section{METODOLOGIA}

Foi realizado um estudo descritivo, exploratório e transversal na instituição de idosos Vila Vicentina Júlia Freire, uma instituição de longa permanência para idosos sem fins lucrativos, localizada no Bairro da Torre na cidade de João Pessoa- PB.

Após identificação e seleção dos idosos, eles preencheram um questionário sócio avaliativo aplicado pelos discentes do curso de Graduação em Medicina Veterinária da Faculdade UNINASSAU - JP.

Foram utilizados 03 cães terapêuticos previamente submetidos a avaliação clínica veterinária para constatação da plena saúde dos animais. Os cães selecionados apresentavam um temperamento dócil e a capacidade de interagirem com os idosos sem demonstrar medo ou agressividade, carteira de vacinação e vermifugação atualizadas contra as principais enfermidades (zoonóticas e não zoonóticas) que acometem as espécies envolvidas.

Dezenove idosos entre os 66 asilados foram previamente apontados pela psicóloga da instituição, apresentavam no seu perfil quadros de ansiedade, preocupação excessiva e persistente, medo de situações cotidianas, síndromes depressivas (distúrbio mental caracterizado por depressão persistente ou perda de interesse em atividades, prejudicando significativamente o dia a dia.) e baixa autoestima (dificuldades de se enxergar positivamente). 
As atividades de zooterapia foram aplicadas uma vez por semana, com pelo menos 40 minutos de interação entre os idosos e os animais, durante 3 meses (sendo 1 mês de adaptação dos cães a instituição e dois meses de execução das atividades zooterápicas propriamente dita), com acompanhamento direto dos alunos no manejo dos animais e na avaliação dos idosos.

Em cada visita realizada, foi aplicado, antes e após a atividade de zooterapia, um questionário com a técnica de avaliação baseada na pesquisa de Likert - com escala psicométrica, em seguida os dados foram compilados para a obtenção da média com o índice de satisfação à terapia assistida por animais.

\section{RESULTADOS E DISCUSSÃO}

Dos 19 idosos que participaram da amostra, 42,1\% eram do sexo masculino enquanto, 57,9\% eram do sexo feminino. A faixa etária média era de 80 anos. Cerca de $89,5 \%$ dos idosos, afirmaram já ter contato com animais antes de serem institucionalizados e já tinham criado algum tipo de animal de estimação. Contudo, 94,7\% dos participantes relataram gostar de animais mesmo sem ter tido contado anteriormente, enquanto 5,3\% afirmaram não gostar de animais.

Estudos demonstram que a interação entre idosos e animais de estimação resulta em diversos benefícios que ultrapassam o âmbito da saúde física, como no caso de portadores da doença de Alzheimer que experimentam redução da sensação de solidão, melhora do humor e dos comportamentos sociais (Barker\&Wolen, 2008).

Houve, com as ações de zooterpia aplicadas na instituição Vila Vicentina, uma interação muito benéfica entre os idosos e os animais através de contatos físicos incluindo: colocar no colo, jogar bola, escovação e estímulos táteis, com participação de todos os 19 idosos. (Figura 1).

Figura 1 - Idosos interagindo com os cães através de estímulos de toques, escovação, colocaçãoo no colo, jogo de bola, passeio

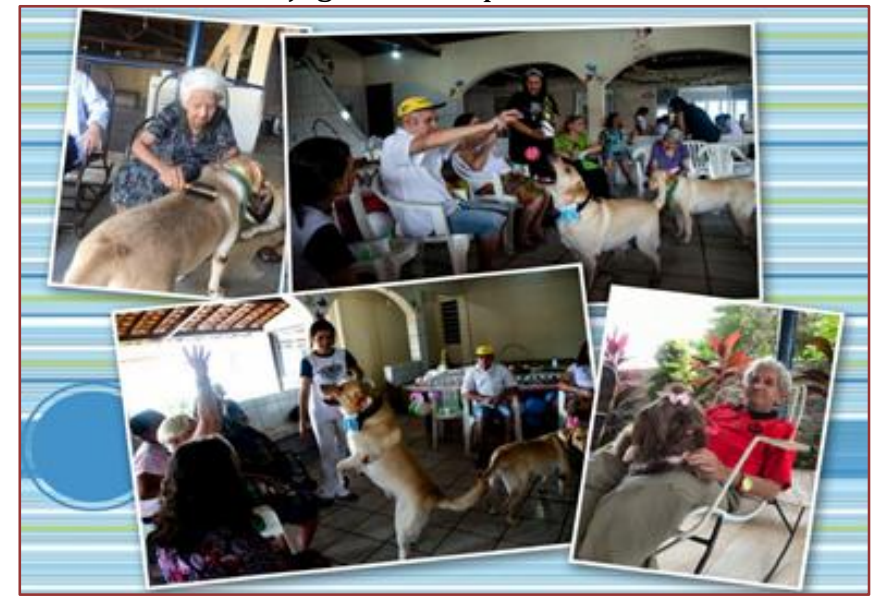

Os participantes demonstraram muito afeto e carinho pelos animais durante as atividades em todas as visitas, estabeleceram um vínculo afetivo com os animais e maior interação entre os próprios idosos (Figura 2). 
Figura 2 - Demonstração de afeto e carinho com os animais e interação entre os idosos, cães e alunas

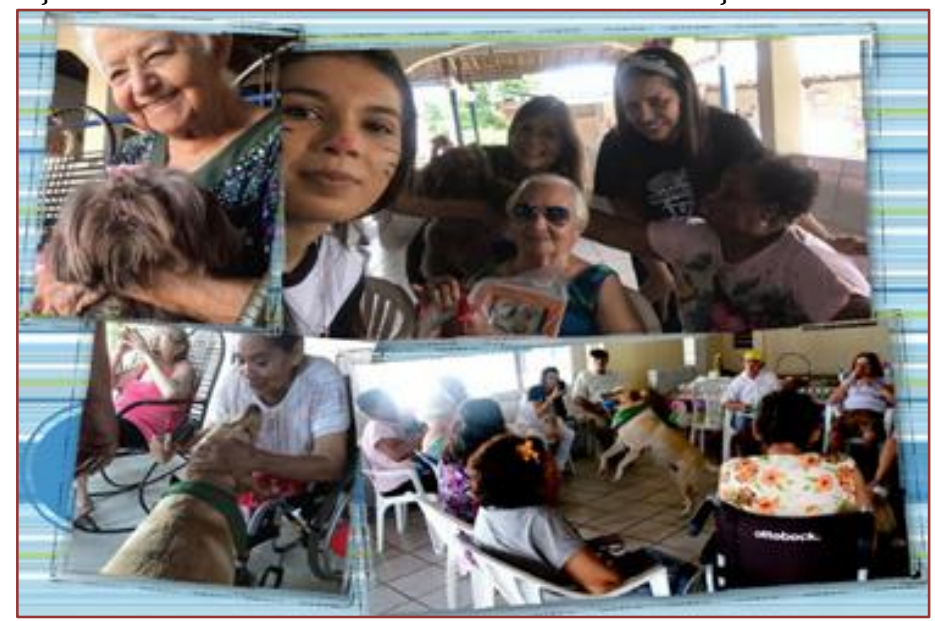

Após análise parcial dos dados registrados podemos perceber que 17,34\% dos idosos afirmaram estar triste antes da atividade de zooterapia, enquanto 67,22\% disseram estar bem e feliz (Gráfico 1).

Após a zooterapia cerca de 75,76\% relataram estarem muito bem e nenhum idoso informou estar triste (Gráfico 2).

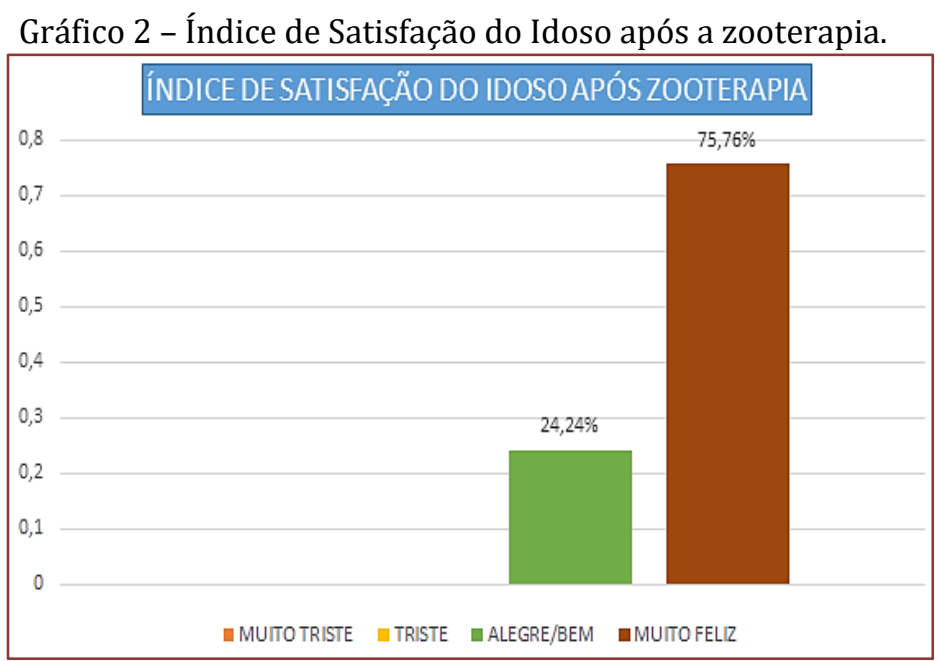

Percebemos que, em tão pouco tempo de inserção do projeto na instituição, a interação dos idosos com os cães trouxe melhora no bem estar e satisfação dos idosos, o que sugere, como apontam diversos estudos, que animais direcionados para os idosos promovem melhora física, no humor e na comunicação pela promoção do contato físico suprindo a necessidade do conforto tátil e de um meio socialmente aceitável de satisfazer a necessidade de tocar e ser tocado, melhorando o bem-estar e a auto-estima (Machado et al., 2008;; Kaiser et al., 2002; Cappote, 2009; Ricci et al., 2014). 


\section{CONSIDERAÇÕES FINAIS}

As atividades realizadas com o projeto de zooterapia aplicada a melhor idade, junto aos 19 idosos institucionalizados na Vila Vicentina Júlia Freire em João Pessoa-PB, mostrou que os idosos interagiram muito bem com os animais e que eles afirmaram satisfação ao estarem em contato semanal com os cães. Ficou clara a alegria, demonstração de afeto e o carinho por parte dos idosos aos animais, além de ocorrer uma interação maior entre os própios idosos que conversavam entre si durante as atividades. Os resultados apurados até o momento superaram as expectativas e demonstram benefícios sociais e de bem estar entre os idosos.

Salienta-se, no entanto, que as atividades do projeto ainda estão em andamento com o objetivo de ampliar o estudo e ajudar a identificar uma forma de melhorar a sociabilização e reduzir os danos comuns no processo de envelhecimento de idosos asilados através da zooterapia.

\section{REFERÊNCIAS}

[1] Argimon, I. L., Sten, L. M. 2005. Habilidades cognitivas em indivíduos muito idosos: um estudo longitudinal. Cadernos de Saúde Pública, Rio de Janeiro. v.21. n.1, p. 64 - 72.

[2] Backer, S. B. \& Wolen, A. R. 2008. The beneftis of human-companion animal interaction. A. Review J. Vet. Med. 35 (4): $487-495$.

[3] Becker, M. 2003. O poder curativo dos bichos: como aproveitar a incrível capacidade dos bichos de manter as pessoas felizes e saudáveis. Tradução: A. B. Pinheiro de Lemos. Rio de Janeiro. Bertrand Brasil.

[4] Capote, P. S. 0.2009. Terapia assistida por animais (TAA) e defici encia mental : análise do desenvolvimento psicomotor (Tese de Doutorado). Universidade Federal de São Carlos, São Carlos, Brasil.

[5] Costa Neto, E. M. 2011. A zooterapia popular no estado da Bahia: registro de novas espécies animais utilizadas como recursos medicinais. Ciência e Saúde Coletiva, p. 639-650.

[6] Dotti, J. 2005. Terapia e Animais : atividade e terapia assistida por animais. São Paulo : Noética.

[7] IBGE - Instituto Brasileiro de Geografia e Estatística. Pesquisa Nacional por Amostra de Domicílio : idosos, Rio de Janeiro, 2017.

[8] Kaiser, L. et al. 2002. A dog and a "happy pearson" visit nursing home residents. Western Journoul of Nursing Reseache. 24 (6) : 671-683.|

[9] Machado, J. A. C. et al. 2008. Terapia assistida por animais (TAA). Revista Científica Eletrônica de Medicina Veterinária, Ano IV, n.10.

[10] Ricci, G. D. et al. 2014 Animais solidários: A zooterapia como extensão universitária para idosos institucionalizados. Revista de Cultura e Extensão USP, n. 11, p. 113-121.

[11] Tavares, R. E. et al. 2017. Envelhecimento saudável na perspectiva de idosos: uma revisão integrativa. Revista Brasileira de Geriatria e Gerontologia, v. 20, n. 6, p. 889-900. 


\section{Capítulo 6}

O real papel do enfermeiro em suas atribuições ao cuidado do idoso no serviço de atenção domiciliar: Revisão da literatura

\section{Flávio Medeiros Guimarães}

Kézia Katiane Medeiros da Silva

Gabriella Souza de Azevedo

Francisco Jalisson de Almeida e Silva

Nádia Rocely Souto de Almeida Lima

Resumo: 0 envelhecimento populacional já se mostra uma realidade em todo o Brasil, sendo o produto da queda nas taxas de fecundidade e de mortalidade, além dos progressos sanitários que ocorreram nas últimas décadas. 0 objetivo do estudo é identificar o real papel do enfermeiro em suas atribuições na atenção e cuidado ao idoso no serviço de atenção domiciliar.

Palavras-chave: Qualidade de vida; Idoso, Pessoa Idosa, Envelhecimento. 


\section{INTRODUÇÃO}

O envelhecimento populacional já se mostra uma realidade em todo o Brasil, sendo o produto da queda nas taxas de fecundidade e de mortalidade, além dos progressos sanitários que ocorreram nas últimas décadas. As modificações na estrutura etária no Brasil ocorreram entre os anos de 1940 e 1960, momento no qual o país experimentou uma diminuição significativa na mortalidade mantendo a fecundidade em níveis altos. Entretanto, foi a partir do final da década de 60, com a estrutura etária que levou a uma população quase estável caracterizado por um perfil envelhecido (CARVALHO, WONG, 2008).

De acordo com os estudos iniciais nessa área, bem como os avanços nos estudos pesquisados no Brasil e da portaria de Serviços de Atendimento Domiciliar do Ministério da Saúde (SAD \MS) № 249, que estabeleceram a assistência domiciliar a ser desenvolvida como modalidade assistencial pelo Centro de Referência a Saúde do Idoso (REHEM; TRAD, 2005).

Mesmo com o crescimento da população idosa tendo se iniciado ao final dos anos 60, foi apenas com a implantação do SAD que se observou um aumento nas visitas domiciliares, o que garante uma maior prevenção de doenças e, consequentemente, o aumento na qualidade de vida dos mesmos e de seus familiares. Dessa maneira, o enfermeiro passa a ser o orientador do idoso e de seus familiares, além de ensiná-los a lidar com as suas dificuldades e a prevenir situações as quais não agravem o seu quadro clínico, reduzindo, assim, a necessidade da ida a uma unidade básica de saúde.

Nesse contexto, o objetivo do estudo é identificar o real papel do enfermeiro em suas atribuições na atenção e cuidado ao idoso no serviço de atenção domiciliar.

\section{METODOLOGIA}

Para viabilizar o desenvolvimento deste estudo, optamos por um estudo de revisão literária, tendo como questões norteadoras para esta pesquisa: os benefícios da implementação do Serviço de Atendimento Domiciliar-SAD e o papel do enfermeiro nessa proposta de trabalho, com abordagem pelo Ministério da Saúde por meio de portarias, e protocolos na rede de serviços públicos dos estados e municípios no Brasil. 0 período da coleta de dados compreendeu entre 19/02/18 a 15/04/2018 e foram utilizados nos critérios de inclusão os artigos completos e de língua portuguesa por meio dos descritores: serviço de atenção domiciliar, enfermeira, paciente e SUS, descritos na língua portuguesa, nas seguintes bases de dados da Biblioteca virtual da Saúde: Lilacs (Literatura Latino Americana e do Caribe em Ciências da Saúde), SciELO (Scientific Eletronic Library Online) e Bdenf (Base de Dados da Enfermagem).

A análise das referências foi baseada nas publicações dos últimos dez anos (de 2008 a 2018) em virtude da grande maioria dos estudos estarem contidos neste período.

Realizamos uma leitura flutuante inicial das referências e, portanto, das 86 referências encontradas na Lilacs, somente 22 referências tiveram aderência ao nosso objetivo; das 18 referências encontradas na SciELO 14 referências tiveram aderência e das seis referências na BDENF, quatro referências foram aproveitadas dentro dos critérios de inclusão estabelecidos.

Na base dados da Scielo das 14 referências selecionadas: duas eram da área de Nutrição; duas da área de Odontologia e 10 referentes a todas as áreas de conhecimento da saúde e da enfermagem. Portanto, ao realizar uma leitura em profundidade selecionamos 10 referências relacionadas que de fato tratavam de políticas públicas desde a sua origem, voltadas ao papel do enfermeiro no serviço de atendimento domiciliar. Na base de dados Bdenf das 04 referências encontradas somente uma foi selecionada porque duas referências se tratavam das políticas públicas da Espanha e que não se adequou a nossa realidade e, uma referência também foi encontrada na Scielo. Na base de dados Lilacs das 24 referências selecionadas foram aproveitadas 15 porque duas referências se repetiram na Bdenf e sete referências se repetiram na SciELO. Portanto, as referências que foram analisadas são 10 sendo 4 na base de dados Scielo, uma na BDENF e 5 na LILACS.

Nessa pesquisa, os indicadores foram recolhidos por meio da leitura exploratória, seletiva, analítica e interpretativa, tendo como premissa a assistência domiciliar ao idoso na perspectiva do papel da enfermeira nesse cuidado domiciliar. 


\section{RESULTADOS E DISCUSSÃO}

De acordo com as buscas nas bases de dados foram selecionados 10 artigos dentre os pré-selecionados para esta revisão, de acordo com os critérios estabelecidos, conforme apresentado no Quadro 1.

Quadro 1 - Síntese das pesquisas e estudos dos artigos analisados segundo as características do tema em estudo

\begin{tabular}{|c|c|c|c|c|}
\hline $\begin{array}{l}\text { BASE DE } \\
\text { DADOS }\end{array}$ & ANO & TÍTULO & OBJETIVOS & PRINCIPAIS RESULTADOS \\
\hline 1. SCIELO & 2007 & $\begin{array}{l}\text { Política nacional de } \\
\text { atenção ao idoso e a } \\
\text { contribuição da } \\
\text { Enfermagem }\end{array}$ & $\begin{array}{l}\text { Descrever e avaliar a } \\
\text { Política Nacional de } \\
\text { Atenção ao Idoso no } \\
\text { Brasil e sua relação com a } \\
\text { enfermagem }\end{array}$ & $\begin{array}{l}\text { Após análise da literatura consultada, } \\
\text { concluiu-se que esta política tem } \\
\text { proporcionado, aos atores sociais } \\
\text { envolvidos, conscientização para } \\
\text { justiça social e garantia plena dos } \\
\text { direitos aos idosos. }\end{array}$ \\
\hline 2. LILACS & 2015 & $\begin{array}{l}\text { Internação domiciliar no } \\
\text { Sistema Único de Saúde }\end{array}$ & $\begin{array}{l}\text { Analisar o funcionamento } \\
\text { dos Programas de } \\
\text { Internação Domiciliar } \\
\text { implantados em três } \\
\text { municípios. }\end{array}$ & $\begin{array}{l}\text { Pôde-se constatar avanços na } \\
\text { implementação de serviços de } \\
\text { Internação Domiciliar, bem como } \\
\text { obstáculos para que a mudança dos } \\
\text { modelos de atenção se processe }\end{array}$ \\
\hline 3. SCIELO & 2017 & $\begin{array}{l}\text { Atuação do enfermeiro } \\
\text { na atenção domiciliar: } \\
\text { Uma revisão integrativa } \\
\text { da literatura }\end{array}$ & $\begin{array}{l}\text { Analisar a produção } \\
\text { científica acerca da } \\
\text { atuação do enfermeiro na } \\
\text { atenção domiciliar em } \\
\text { saúde. }\end{array}$ & $\begin{array}{l}\text { Identificou-se que a atuação do } \\
\text { enfermeiro na atenção domiciliar } \\
\text { possui complexidade e diversidade de } \\
\text { ações com uso de tecnologias leves, } \\
\text { leveduras especialmente, e duras. }\end{array}$ \\
\hline 4. LILACS & 2017 & $\begin{array}{l}\text { Atribuições do } \\
\text { enfermeiro em um } \\
\text { programa de atenção } \\
\text { domiciliar do sistema } \\
\text { único de saúde }\end{array}$ & $\begin{array}{l}\text { Descrever o } \\
\text { funcionamento de um } \\
\text { programa de atenção } \\
\text { domiciliar vinculado ao } \\
\text { Sistema Único de Saúde } \\
\text { (SUS) e apontar as } \\
\text { atribuições } \\
\text { desempenhadas pelo } \\
\text { enfermeiro dentro desse } \\
\text { programa. }\end{array}$ & $\begin{array}{l}\text { Conclui-se que compreender as } \\
\text { atribuições do enfermeiro nesse } \\
\text { programa contribui para delimitar a } \\
\text { atuação profissional com perícia, além } \\
\text { de subsidiar a formação e o } \\
\text { aperfeiçoamento profissional }\end{array}$ \\
\hline 5. SCIELO & 2013 & $\begin{array}{l}\text { Abordagem do idoso em } \\
\text { programas de saúde da } \\
\text { família }\end{array}$ & $\begin{array}{l}\text { Discorre-se sobre a } \\
\text { Política Nacional de } \\
\text { Saúde do Idoso Se analisa } \\
\text { a Estratégia de Saúde da } \\
\text { Família no Brasil em } \\
\text { relação à atenção ao } \\
\text { idoso. }\end{array}$ & $\begin{array}{l}\text { Cuidado do idoso deve basear-se, } \\
\text { fundamentalmente, na família com o } \\
\text { apoio das unidades básicas de saúde } \\
\text { sob a estratégia de saúde da família, as } \\
\text { quais devem representar para o idoso, } \\
\text { o vínculo com o sistema de saúde. }\end{array}$ \\
\hline 6. BVS & 2016 & $\begin{array}{l}\text { A enfermagem na saúde } \\
\text { do idoso com vistas a } \\
\text { atenção primária à saúde: } \\
\text { uma revisão integrativa }\end{array}$ & $\begin{array}{l}\text { Analisar as publicações } \\
\text { acerca das condutas do } \\
\text { profissional de } \\
\text { enfermagem na atenção } \\
\text { primária com vistas à } \\
\text { saúde do idoso }\end{array}$ & $\begin{array}{l}\text { Foi possível perceber através dos } \\
\text { estudos que o cuidado ainda está } \\
\text { direcionado no modelo biológico, } \\
\text { sendo associando a técnicas como } \\
\text { aferir a pressão arterial }\end{array}$ \\
\hline 7. LILACS & 2013 & $\begin{array}{l}\text { A atuação da } \\
\text { enfermagem na atenção à } \\
\text { saúde do idoso: possíveis } \\
\text { ações a serem realizadas } \\
\text { segundo as Diretrizes da } \\
\text { política nacional de saúde } \\
\text { da pessoa idosa }\end{array}$ & $\begin{array}{l}\text { Descrever a atuação da } \\
\text { enfermagem na atenção à } \\
\text { saúde do idoso e as } \\
\text { possíveis ações a serem } \\
\text { realizadas por estes } \\
\text { profissionais, segundo as } \\
\text { diretrizes da Política } \\
\text { Nacional de Saúde da } \\
\text { Pessoa Idosa (PNSPI). }\end{array}$ & $\begin{array}{l}\text { Conclui-se, que a enfermagem pode } \\
\text { atuar em todas as diretrizes existentes } \\
\text { na PNSPI, portanto, torna- se } \\
\text { importante conhecê-las, para que } \\
\text { estes profissionais possam nortear as } \\
\text { suas ações na atenção à saúde do } \\
\text { idoso, com o objetivo de melhorar a } \\
\text { autonomia e a independência dos } \\
\text { mesmos. }\end{array}$ \\
\hline
\end{tabular}


(continuação ...)

Quadro 1 - Síntese das pesquisas e estudos dos artigos analisados segundo as características do tema em

\begin{tabular}{|c|c|c|c|c|}
\hline $\begin{array}{l}\text { BASE DE } \\
\text { DADOS }\end{array}$ & ANO & TÍTULO & OBJETIVOS & PRINCIPAIS RESULTADOS \\
\hline 8. LILACS & 2014 & $\begin{array}{l}\text { As atribuições do } \\
\text { enfermeiro na assistência } \\
\text { domiciliar }\end{array}$ & $\begin{array}{l}\text { A importância da } \\
\text { assistência domiciliar, } \\
\text { um tema cada vez mais } \\
\text { discutido entre os } \\
\text { profissionais da área da } \\
\text { saúde devido aos } \\
\text { benefícios imediatos } \\
\text { proporcionados para o } \\
\text { paciente. }\end{array}$ & $\begin{array}{l}\text { Assistência domiciliar é uma } \\
\text { modalidade cada vez mais utilizada } \\
\text { pela sociedade, devido aos inúmeros } \\
\text { benefícios proporcionados para o } \\
\text { paciente, família e hospital, no qual ela } \\
\text { pode ser indicada para para } \\
\text { indivíduos de qualquer idade. }\end{array}$ \\
\hline 9. LILACS & 2013 & $\begin{array}{l}\text { Idoso no contexto } \\
\text { familiar }\end{array}$ & $\begin{array}{l}0 \text { artigo tem como } \\
\text { objetivo tratar a } \\
\text { importância do idoso no } \\
\text { âmbito familiar, assim } \\
\text { como as políticas } \\
\text { públicas em que estão } \\
\text { envolvidos }\end{array}$ & $\begin{array}{l}\text { Desta forma é necessário que se } \\
\text { estabeleça mudanças no modo de } \\
\text { pensar, formação cultural, econômico } \\
\text { e social, para que o idoso possa } \\
\text { exercer seus direitos integrando-se de } \\
\text { forma articulada nas políticas públicas } \\
\text { existentes. }\end{array}$ \\
\hline 10. SCIELO & 2010 & $\begin{array}{l}\text { A Saúde de Pessoas } \\
\text { Idosas - Relevância do } \\
\text { Lazer e das Redes Sociais }\end{array}$ & $\begin{array}{l}\text { Descrever a relevância do } \\
\text { lazer e das redes sociais } \\
\text { na promoção da saúde e } \\
\text { qualidade de vida da } \\
\text { pessoa idosa. }\end{array}$ & $\begin{array}{l}\text { Dar a conhecer diversos tipos de } \\
\text { atividades de lazer, que podem ser } \\
\text { realizadas com os idosos, } \\
\text { proporcionando momentos de alegria } \\
\text { e convívio e estimulando as suas } \\
\text { capacidades físicas e mentais, } \\
\text { promovendo um envelhecimento } \\
\text { ativo. }\end{array}$ \\
\hline
\end{tabular}

Identificou-se de acordo com os 86 artigos pesquisados, sendo inclusos 10 artigos, que atingiram o objetivo proposto. 0 quadro 1 representa a síntese da revisão bibliográfica, sendo esses que constituíram o estudo e apresentaram os reais resultados sobre a temática.

Como integrante da área de saúde, a enfermagem possui responsabilidade direta no cumprimento do item relacionado ao direito à saúde. É, também, sua responsabilidade assegurar a atenção integral à saúde do idoso, por intermédio do Sistema Único de Saúde (SUS), garantindo-lhe acesso universal e igualitário (PARTEZANI ET AL., 2007).

O Enfermeiro possui as seguintes atribuições na atenção básica no atendimento a pessoa idosa: Realizar atenção integral às pessoas idosas; realizar assistência domiciliar, quando necessário; realizar consulta de enfermagem, incluindo a avaliação multidimensional rápida e instrumentos complementares, se necessário, solicitar exames complementares e prescrever medicações, conforme protocolos ou outras normativas técnicas estabelecidas pelo gestor municipal, observadas as disposições legais da profissão; supervisionar e coordenar o trabalho dos ACS e da equipe de enfermagem; realizar atividades de educação permanente e interdisciplinar junto aos demais profissionais da equipe; orientar ao idoso, aos familiares e/ou cuidador sobre a correta utilização dos medicamentos (BRASIL, 2006A, P.46).

\section{CONSIDERAÇÕES FINAIS}

Com o envelhecimento populacional há necessidade de uma visão mais ampla dos profissionais de saúde em relação ao processo saúde-doença, o que exige da enfermagem uma aproximação e o conhecimento dos campos da promoção de saúde. A sistematização da assistência da equipe de enfermagem pode ser desenvolvida de forma criteriosa, através da formulação de um plano de cuidados, a fim de identificar os idosos com maiores riscos, por exemplo, de dependência, proporcionando assim um melhor atendimento e cuidado ao idoso. 


\section{REFERÊNCIAS}

[1] Andrade AM, Silva KL, Seixas CT, Braga PP. Nursing practice in home care: an integrative literature review. Rev Bras Enferm [Internet]. 2017;70(1):199-208. Doi: http://dx.doi.org/10.1590/0034-7167-2016-0214.

[2] Brasil. Ministério da Saúde. Política Nacional de Atenção básica. 2006. Partezani, R et al. Política nacional de atenção ao idoso e a contribuição da enfermagem. Texto \& Contexto Enfermagem , 2007.

[3] Pitzer, Monique Brito. A enfermagem na saúde do idoso com vistas à atenção primária à saúde:uma revisão integrativa. / Monique Brito Pitzer. - Niterói: [s.n.], 2016.

[4] Ribeiro, Denis Fernandes da Silva; Abreu, Germana Périssé. Atribuições do Enfermeiro em um Programa de Atenção Domiciliar do Sistema Único de Saúde. Rev. Aten. Saúde, São Caetano do Sul, v. 15, n. 52, p. 55-60, abr./jun., 2017.

[5] Rehem, Tânia Cristina Morais Santa Bárbara e Trad, Leny Alves Bomfim. Assistência domiciliar em saúde: subsídios para um projeto de atenção básica brasileira. Ciênc. saúde coletiva [online]. 2005, vol.10, suppl., pp. 231 242. ISSN 1413-8123.

[6] Santos, Gleice Ribeiro; Souza, Jéssica Menezes; Lima, Lara Carvalho Vilela. A atuação da Enfermagem na atenção à saúde do idoso: possíveis ações a serem realizadas segundo as diretrizes da política nacional de saúde da pessoa idosa. Reuni - Revista Unijales / Edição 6 / Ano VII / 2013.

[7] Veiga, Kátia Conceição Guimarães; Menezes, Tânia Maria de Oliva. Produção do conhecimento em enfermagem: a (in) visibilidade da atenção à saúde do idoso. Revista Escola de Enfermagem da USP, v.42, n.4, p.761$768,2008$.

[8] Wong, L.; Carvalho, J. A. M. O rápido processo de envelhecimento do Brasil: sérios desafios para as políticas públicas. Revista Brasileira de Estudos de População, Abep, v.23, n.1,2006. 


\section{Capítulo 7}

Conhecimento de idosas de uma unidade da estrategia saúde da família sobre prevenção do câncer cervicouterino

\section{Augusto Antônio da Fonseca Neto \\ Antônio de Medeiros Pereira Filho \\ Alexandre Bezerra Silva}

Resumo: A elevada incidência e mortalidade por câncer cervicouterino no Brasil justificam a implantação de estratégias de controle da doença, incluindo promoção à saúde, prevenção, detecção precoce, tratamento e cuidados paliativos quando necessários. Objetivou-se analisar os conhecimentos de mulheres idosas sobre o câncer cervicouterino. Estudo exploratório-qualitativo. Projeto aprovado pelo Comitê de Ética em Pesquisa da Universidade Federal do Ceará (protocolo no 660.902), a coleta de dados procedeu-se em fevereiro de 2015. Participaram da pesquisa 10 (dez) mulheres idosas, adscritas no Posto de Saúde do Centro, na Cidade de Assú-RN. Foram incluídas mulheres a partir de 60 (sessenta) anos de idade, que nunca fizeram o exame de Papanicolau, e as que há mais de três anos não o fazem e que já tiveram câncer do colo do útero. Excluiuse da amostragem, mulheres com demência, acamadas ou histerectomizadas. Optou-se pela entrevista individual semiestruturada. Os dados foram analisados através do método de Análise de Contéudo de Bardin. Os principais resultados apontam que a maioria das idosas realizam o exame Papanicolau de forma esporádica e que desconhece a magnitude dessa patologia. Esses achados alertam para a necessidade de restruturação da Atenção Primária à Saúde, com ênfase para o caráter da educação em saúde, sendo instrumento de construção do saber significativo, para que as mulheres se apoderem e tomem consciência do seu papel de atoras no seu processo saúde- doença, aponta-se, também, a construção da necessidade de um olhar holístico à mulher idosa nesses serviços de saúde.

Palavras-chave: Atenção Primária à Saúde, Saúde do Idoso, Saúde da Mulher, Neoplasias do Colo do Útero. 


\section{INTRODUÇÃO}

O câncer Cervicouterino (CCU) representa um importante problema de saúde pública em países em desenvolvimento, chegando a ser em algumas regiões, o tipo mais comum na população feminina. Comparado às outras neoplasias, tal câncer é altamente prevenível, apresentando evolução lenta até atingir o estágio de câncer invasivo, além disso, dispõe de

exame de rastreamento tecnicamente simples e eficaz na sua detecção. Na América Latina, o CCU ocupa o segundo lugar no ranking de neoplasias malignas, sendo o mais comum entre as mulheres, é responsável pelo óbito de aproximadamente 230 mil mulheres por ano, implicando em uma das taxas de incidência mais altas do mundo (ZAPPONI, 2010).

Após os 60 anos, as mulheres que tiveram acesso regular ao longo da vida e estabeleceram uma rotina de exames preventivos, com resultados normais, apresentam risco diminuído para o desenvolvimento do câncer cervical, dada a sua lenta evolução. A continuidade do rastreamento, após os 60 anos, deve ser individualizada e, após os 65 anos, a recomendação é de suspender o rastreamento caso, os últimos exames, tenham apresentado resultados normais (BRASIL, 2010). Dando continuidade à linha de raciocínio, para as mulheres com mais de 65 anos de idade e que nunca realizaram o exame citopatológico ${ }^{1}$, deve- se realizar dois exames com intervalo de um a três anos. Se ambos os exames forem negativos, essas mulheres podem ser dispensadas de exames adicionais (BRASIL, 2011).

Nessa direção, no âmbito da Atenção Básica à Saúde, as ações frente ao câncer do colo do útero visam ao acompanhamento da mulher durante toda a sua existência, por meio das ações de prevenção, consultas ginecológicas e referenciamento para níveis de maior complexidade da assistência, em casos diagnosticados, e até o tratamento paliativo, quando necessário (BRASIL, 2013).

Assim, pode-se afirmar que a efetividade das ações de saúde na Atenção Básica, que têm como foco a atenção integral à saúde da mulher, em especial, o controle do câncer do colo uterino, se revestem de fundamental importância no campo da saúde pública. Entretanto, as medidas de prevenção do CCU ainda se apresentam de forma relativamente frágeis, por diversos fatores, entre eles pode-se citar a desorganização dos serviços de saúde; a baixa qualidade da assistência; a pouca valorização das ações de educação em saúde, por parte dos profissionais, entre outros (MENDONÇA, 2011).

A prevenção do CCU tem um custo relativamente baixo quando comparado aos seus benefícios, não sendo imprescindível a utilização de altas tecnologias para a sua prevenção e controle. Porém, para que isso ocorra torna-se fundamental a responsabilização por parte dos profissionais de saúde, ou seja, que efetivem o vínculo e o cuidado, estabeleçam processos educativos que promovam o empoderamento das mulheres para que estas possam tornar-se corresponsáveis na detecção precoce do câncer cervicouterino, participando, também, dos processos decisórios. Para tanto, faz-se necessário que os profissionais assumam a postura de educador e formador de uma consciência sanitária junto aos usuários da Atenção Básica à Saúde (SOARES; MEINCKE, 2010).

Diante do contexto, este estudo questionou: quais conhecimentos, as mulheres idosas com 60 anos ou mais, possuem a respeito da prevenção do câncer do colo uterino? Essas mulheres participam de alguma atividade educativa, orientada por profissional de saúde, a respeito dessa temática?

Portanto, objetiva-se analisar os conhecimentos de mulheres idosas com 60 anos ou mais, acerca da prevenção do CCU em uma equipe da Estratégia de Saúde da Família.

\section{METODOLOGIA}

Trata-se de um estudo de natureza qualitativa, por se trabalhar com a dimensão subjetiva e simbólica das interações sociais na constituição das redes de sociabilidade, com foco no processo da vida cotidiana dos sujeitos. Essa pesquisa exploratória, proporciona maior familiaridade com o fenômeno, com vistas a torná-lo mais explícito (GIL, 2010).

A pesquisa qualitativa não se atém ao universo numérico, mas valoriza a subjetividade do objeto em estudo, ou seja, trabalha com o universo de significados, motivos, aspirações, crenças, valores e atitudes, o que corresponde a uma dimensão mais profunda das relações, dos processos e dos fenômenos que não

\footnotetext{
1 As expressões: exame contra o câncer cervicouterino, exame citopatológico, Papanicolau, colpocitologia oncótica, cérvico-vaginal, preventivo do colo do útero, citologia oncótica, são utilizadas neste trabalho como sinônimos.
} 
podem ser reduzidos à operacionalização de variáveis (MINAYO, 1994).

Esse estudo foi realizado no município de Assú, estado do Rio Grande do Norte, na mesorregião do Oeste Potiguar e Polo Costa Branca, localizado a $207 \mathrm{~km}$ da capital do estado, Natal, cuja amostra foi constituída por dez mulheres com idade de 60 anos ou mais, adstritas à Unidade Básica de Saúde do Centro de Assú. Inicialmente, 15 idosas aceitaram participar do estudo, entretanto 05 (cinco) não compareceram a entrevista que havia sido agendada, ficando a amostra constituída por 10 mulheres idosas.

O critério de inclusão adotado foi apresentar idade de 60 anos ou mais, ter realizado o exame de Papanicolau há mais de três anos ou que nunca haviam realizado tal exame. Foram excluídas da amostra mulheres com demência, acamadas ou histerectomizadas.

Para as entrevistas, utilizou-se um roteiro composto por cinco questões abertas. Esse instrumento continha duas partes: parte 1- dados de caracterização da amostragem; parte 2- questões relacionadas ao exame de prevenção do câncer cervicouterino.

Trivinõs (2012) afirma que a entrevista é um dos importantes meios de coleta de informações, uma vez que tal técnica ao mesmo tempo em que valoriza a presença do investigador, oferece todas as perspectivas possíveis a liberdade e a espontaneidade necessária, enriquecendo a investigação.

A coleta dos dados foi realizada durante o mês de Fevereiro de 2015, e fez-se a opção por utilizar a entrevista semiestruturada individual, conforme orientações de Triviños (2012), pois apontou que melhores resultados em pesquisas qualitativas são alcançados quando se realizam, inicialmente, entrevistas individuais as quais podem ser complementadas posteriormente por meio de outros instrumentos.

Todas as entrevistas foram pré-agendadas pelo Agente Comunitário de Saúde e realizadas de forma individual dentro das próprias residências das idosas em local reservado. Foi utilizado o sistema de gravação (MP4), e cada uma delas teve duração média de 20 minutos, sendo, as mesmas transcritas, em momento oportuno, após a entrevista. Não obstante, foi utilizado um diário de campo para fazer registros que pudessem corroborar ou fazer contraponto com as falas, especialmente questões relativas à linguagem não verbal, contida nas expressões, interjeições, gestos e emoções.

Segundo Minayo (2007) o diário de campo é um caderno de notas, onde iremos registrar todas as impressões pessoais e os comportamentos contraditórios dos sujeitos pesquisados. 0 diário de campo, também, foi útil para registrar determinadas situações observadas por ocasião das visitas "in loco".

Quanto aos aspectos éticos, foram seguidos os preceitos determinados pela Resolução no 466/2012 do Conselho Nacional de Saúde para pesquisas com seres humanos. A investigação foi aprovada pelo Comitê de Ética em Pesquisa da Universidade Federal do Ceará sob o parecer no 660.902. Todos os participantes leram e assinaram um Termo de Consentimento Livre e Esclarecido (TCLE). Para a preservação do anonimato das mulheres atribuiu-se codinomes representados por pedras preciosas.

Os dados foram analisados com base no método de Análise Temática de Conteúdo, proposto por Bardin (2011) e sistematizado por Minayo (2014), pois permite acessar os núcleos de sentido que compõem uma comunicação, cuja presença ou frequência tenham significado para o objeto de pesquisa.

A técnica de Análise Temática de Conteúdo pressupõe algumas etapas, definidas por Minayo (2014) como: leitura irresoluta do material produzido; organização dos termos em categorias (iniciais, emergentes e significativas); agrupamento e codificação das categorias e consolidação dos resultados do estudo.

Seguindo tais orientações, a análise foi efetivada em três etapas: pré-análise, exploração do material e interpretação dos resultados. Durante a pré-análise foi feita uma leitura exaustiva do material, com o objetivo de obter uma visão do conjunto inicial e identificar as categorias para classificação das falas. Em seguida, durante a exploração do material, realizou-se a análise em si, classificando as falas ou fragmentos de falas selecionadas entre as categorias de análise. Dando continuidade, foram identificados núcleos de sentido - unidades de análise - em cada categoria empírica que, juntamente com os pressupostos teóricos iniciais, apontaram as subcategorias e as inferências em torno dos quais fora realizada a análise interpretativa das falas.

Após a leitura aprofundada dos discursos, foram elaboradas duas categorias de análise. As categorias emergentes: 1) a procura pelo exame Papanicolau, subdividida na subcategoria: (a) Não presença de 
sinais e sintomas; 2) a prevenção do câncer cérvicouterino: o olhar das mulheres, composta pelas subcategorias: (a) a importância do exame Papanicolau e (b) a recusa ao exame.

As categorias e subcategorias estão apresentadas no quadro a seguir, para melhor compreensão dos termos de maior significância do estudo em tela.

Quadro 1- Distribuição das categorias e subcategorias simbólicas da prevenção do câncer cervicouterino. Assú/RN, 2016.

\begin{tabular}{|l|c|c|}
\multicolumn{1}{|c|}{ CATEGORIAS } & SUBCATEGORIAS & 17 \\
\hline A procura pelo exame Papanicolau & Não presença de sinais e sintomas & 15 \\
\hline $\begin{array}{l}\text { A prevenção do câncer cervicouterino: o olhar } \\
\text { das mulheres }\end{array}$ & A importância do exame Papanicolau & 27 \\
\cline { 2 - 3 } & A recusa do exame de Papanicolau. & . \\
\hline
\end{tabular}

Fonte: Pesquisa de campo.

\section{RESULTADOS E DISCUSSÃO}

Na caracterização da população estudada, observou-se que $70 \%$ das mulheres são viúvas, $20 \%$ são solteiras e $10 \%$ casadas. No tocante a faixa etária, 40\% apresentam idade entre 63 e 66 anos, 30\% estão entre 72 e 79 anos de idade e mais de 30\% se encontram na faixa etária entre 80 e 88 anos. Nesse viés, apresentar idade avançada e não ter cônjuge (solteiras, separadas e viúvas), encontra-se entre os fatores mais associados a não realização do exame contra o câncer do colo do útero (MAEDA; ALVES; SILVA, 2012).

Vemos, que existe um pensamento equivocado no exposto anteriormente, onde essas mulheres associam o risco de desenvolver o CCU ao ato sexual, talvez relacionando com possíveis Infecções Sexualmente Transmissíveis (ISTs), é fundamental que os serviços de saúde orientem sobre a importância da realização do exame de prevenção contra o CCU independentemente de se está sexualmente ativa ou não, já que a sua realização periódica permite reduzir a mortalidade por esse tipo de neoplasia na população de risco. Esta estratégia deve ser estendida a mulheres de idade avançada, pois o pico da faixa de risco é 64 anos, e a partir daí sua incidência apenas decresce, embora não desapareça (MAEDA; ALVES; SILVA, 2012).

No grupo de mulheres analisadas foi possível verificar que 50\% possuía renda familiar de um salário mínimo, 30\% recebiam dois salários mínimos e 20\% delas referiu receber mais de dois salários mínimos. Quanto ao nível de escolaridade, 30\% não são alfabetizadas, 20\% sabem ler e escrever, 20\% tiveram até quatro anos de estudo e 30\% apresentavam entre cinco e sete anos de estudo, sendo notória a influência do grau de instrução para um melhor discernimento do sujeito em todos os seus planos de vida, onde está incluso o quesito saúde, essa relação é evidenciada no estudo de Thuler et. al (2012), que revelou a baixa escolaridade e as condições socioeconômicas desfavoráveis sendo fatores contribuintes para a não realização do exame contra o câncer cervicouterino.

\section{A PROCURA PELO EXAME DE PAPANICOLAU}

Essa categoria, discute sobre a periodicidade, com que as mulheres idosas, se submetem ao exame contra o câncer cervicouterino. Observa-se que as respostas variaram entre três e dez anos para a realização do exame Papanicolau. As respostas, de um modo geral, estavam associadas "a descuido", "a não sentir incômodo/alteração/dor", "a nervosismo", como pode ser observado a seguir:

Já vai fazer mais de três anos. Porque descuido mesmo. Mas agora todo ano vou fazer. (Safira).

Há mais de três anos. Porque fiquei nervosa de fazer, por isso nunca mais repeti. (Esmeralda).

Raramente. Agora mesmo em fevereiro vai fazer três anos. Descuido e não tenho tempo. Mas é um dever de todas nós mulheres se cuidar. (Rubi).

Há mais de três anos. Porque não requisitavam. (Pérola).

Como se observa, as mulheres investigadas não realizam com periodicidade o exame contra o câncer cérvicouterino por motivos variados, seja pela falta de cuidado pessoal, seja pelo medo de se submeter ao exame e ainda por não verificarem/sentirem nenhum sinal ou sintoma de anormalidade aparente, onde a dor no ideário popular tem forte significado para uma possível alteração fisiopatológica, outro 
ponto que chama atenção, é a postura passiva do sujeito frente a sua condição de saúde, onde é referido, que o exame só seria realizado se fosse solicitado pelo profissional de saúde.

Tais comportamentos, provavelmente devem-se à falta de uma consciência crítica sobre a importância de detecção da lesão de forma precoce, fator que pode impactar decisivamente o curso de vida dessas idosas, isso faz sugerir, também, que a ação educativa junto a esse público não vem sendo realizada de maneira efetiva, ou se realizada, não está surtindo efeitos positivos, isto é, de corresponsabilização e mudança de comportamento em relação à prevenção do CCU. O CCU apresenta um bom prognóstico quando diagnosticado e tratado precocemente.

A detecção precoce do câncer do colo do útero faz parte das ações de Atenção Secundária, cuja principal estratégia é o rastreamento de mulheres sexualmente ativas por meio do exame citopatológico do colo uterino, a efetividade desse programa está relacionada com taxas de coberturas maiores que $80 \%$, estima-se que essa cobertura possa diminuir em aproximadamente $50 \%$ a mortalidade por câncer cervical (PICCOLI; CASARIN, 2011).

Faz-se importante destacar o impacto epidemiológico do câncer no Brasil e a sua magnitude social. Dessa forma, as condições de acesso da população brasileira à atenção oncológica e os custos cada vez mais elevados devido aos desdobramentos que levam a utilização da alta complexidade demonstram a necessidade de estruturação de uma rede de serviços regionalizada e hierarquizada que garanta uma atenção integral a essa população (BRASIL, 2006).

Portanto, é imperioso que as Unidades de Saúde da Família desenvolvam ações de promoção e educação em saúde, por meio de grupos de debate em saúde, da busca ativa, com vistas a contemplar as mulheres que não realizam o exame de prevenção contra o CCU há mais de três anos, aquelas que nunca o fizeram e as que têm diagnóstico de lesões pré-malignas ou malignas tendo como objetivo o acompanhamento e rastreamento adequado.

\section{A PREVENÇÃO DO CÂNCER CERVICOUTERINO: O OLHAR DAS MULHERES}

Esta categoria foi composta por duas subcategorias: “a importância do exame Papanicolau" e "a recusa ao exame".

Quando foram indagadas sobre a importância de se realizar o exame contra o câncer cérvicouterino, a maioria das idosas sentiram dificuldades em expressar a sua compreensão. Nesse sentido, foram emitidas frases curtas e uma evocação bastante econômica, senão vejamos:

\section{A importância do exame Papanicolau}

Eu creio que é para evitar, para saber se tem doença. (Esmeralda). A importância é que venha sobreviver sem essa doença. (Rubi).

É importante fazer o exame. (Pérola).

É uma prevenção, é contra o câncer para a pessoa viver bem com saúde. (Ametista). É uma doença muito perigosa, é muito perigosa. (Zircônia).

Eu acho que é muito importante para quem quer. Não sei. (Turmalina)

Observa-se o pouco conhecimento das mulheres frente à detecção precoce do câncer do colo do útero. Dessa forma, faz-se necessário, intensificar a ferramenta de educação em saúde adequadamente, por meio de metodologias ativas, visando instigar e estimular as mulheres nessa faixa etária à detecção precoce desse tipo de câncer.

Compreende-se que a prática educativa ensejada pelos profissionais da Atenção Básica, deve oportunizar que os usuários exerçam a sua vocação ontológica de ser sujeito que constrói o mundo, estimulando o poder criador da humanidade. Para tanto, profissionais e usuários não devem ocupar polos opostos no processo da saúde, devem na realidade dialogarem entre si, a partir da ocupação de espaços de diálogo e comunicação (FREIRE, 2011).

No contexto atual dos serviços de saúde, as práticas educativas tendem a ser pouco valorizadas em detrimento do atendimento à demanda espontânea e a produções de outras ações. É perceptível ainda que os serviços de saúde, quando se propõem a realizar ações de educação em saúde, tendem a utilizar a vertente de educação bancária como prioritária, não de modo intencional, mas como um hábito, de modo 
pré-reflexivo, ainda que os discursos sejam em torno de temas como transformação ou educação popular (DAVID; SILVA, 2012).

Ao analisar o arcabouço teórico/prático da educação em saúde, pode-se perceber que nem sempre esta prática é capaz de despertar a criticidade e a reflexão dos sujeitos, sendo utilizadas, hegemonicamente, para perpetuar a subordinação do paciente ao poder científico e político dos profissionais do campo da saúde. Assim, a educação em saúde, a depender de quem e como a pratique, tanto pode possibilitar a construção de sujeitos autônomos nos seus processos de análises e escolhas, quanto pode contribuir para a reprodução de uma população incapaz de refletir criticamente sobre as realidades que as envolvem (MOUTINHO, et. al., 2014).

A educação em saúde, realizada sob a orientação desses pressupostos, permite não só o fortalecimento de vínculos e confiança entre serviços de saúde e usuários, mas também o fortalecimento de espaços de diálogo e construção de saberes, em que usuários e profissionais discutem estratégias de enfrentamento dos problemas de forma conjunta, a fim de que se tenha alternativas capazes de efetivar práticas de saúde integrais e resolutivas, postura que, também, pode ser dedicada na contrução e orientação das idosas, para que essas tenham um conhecimento significativo a respeito do CCU (DEMO, 2005).

Os profissionais que atuam na Estratégia Saúde da Família possuem papel fundamental no tocante à prevenção do câncer do colo do útero, ao incluir na sua prática a articulação entre a prevenção e a promoção da saúde, por meio da expansão e qualificação da Atenção Primária (VALE, et. al., 2010).

Diante do exposto, observa-se que a alta mortalidade por câncer do colo do útero pode ser um indicativo de falhas no diagnóstico precoce de displasias, decorrentes de diversos fatores: dificuldade de acesso ao programa de prevenção ao câncer cérvicouterino, pouca ou nenhuma oferta dessas ações nas Unidades Básicas de Saúde, a não utilização do serviço pela população por questões subjetivas diversas, inadequação das ações de educação em saúde, entre outros fatores(GASPERIN; BOING; KUPEK, 2011).

Desse modo, algumas idosas, quando abordadas sobre o motivo de não procurar os serviços para a realização do exame de prevenção do câncer cérvicouterino, relataram sentir vergonha de expor sua intimidade e o fato de não sentir qualquer tipo de desconforto ou anormalidadeaparente.

\section{A recusa ao exame}

É só descuido mesmo, não está sentindo nada. (Safira). Medo de fazer, pois já faz muito tempo que fiz. (Esmeralda).

Eu não sei, às vezes porque não gostam, porque não acreditam. (Rubi). Se acomodam, têm medo de fazer o exame. (Pérola).

Eu acho que às vezes é vergonha, diz que dói. Acha que não deve fazer porque já está com idade, não vai ter esse problema, não menstrua mais, eu acho que é isso aí (Ametista).

Os discursos deixam clara a necessidade de se investir em práticas educativas direcionadas à problemática do câncer do colo do útero, uma vez que a ausência dessas ações se relaciona ao fato dessas mulheres não apresentarem vida sexualmente ativa, o processo fisiológico da menopausa, não havendo, no imaginário das idosas, pelo captado em seus discursos, necessidade de abordagem do tema. Consequentemente, em consonância com o Sistema Único de Saúde (SUS), torna-se imprescindível que profissionais de saúde desenvolvam ações de prevenção e educação em saúde de forma dialógica junto às mulheres com vistas à redução da mortalidade por câncer de colo uterino (REIS, 2013).

\section{CONSIDERAÇ̃̃ES FINAIS}

A presente pesquisa pretendeu trazer a luz do debate científico e analisar os conhecimentos das mulheres idosas em relação à prevenção do câncer do colo do útero, apontando que o modo como elas significam seu estado de saúde é fator determinante para que estas procurem ou não os serviços de saúde, impactando decisivamente desfechos de saúde com ações preventivas e de promoção da saúde ou de cura e reabilitação quando se tem a doença estabelecida.

Percebeu-se que a maioria das mulheres realiza o exame, objeto desse estudo, de forma esporádica e desconhecem a magnitude dessa doença, portanto, não atribui a importância necessária à realização 
do exame de prevenção, conforme preconiza o Ministério da Saúde.

As práticas educativas, de cunho coletivo, contra o câncer do colo cervicouterino não fazem parte do processo de trabalho dos profissionais de saúde vinculados à Unidade Básica de Saúde em foco. Compreende-se, todavia, que a educação em saúde deva fazer parte do cotidiano de trabalho dos profissionais de saúde, devendo ser de responsabilidade de toda a equipe da ESF. Além disso, esses achados apontam para a necessidade de ressignificação das práticas de saúde, por parte dos profissionais, no que toca a prevenção do câncer do colo do útero, sugerindo um olhar holístico sobre a mulher idosa.

Os resultados aqui apresentados podem instigar reflexões a respeito das práticas educativas em saúde e a adoção de novas posturas profissionais em serviço.

Sabe-se das limitações deste estudo, tendo em vista, o reduzido número de mulheres entrevistadas, sendo necessários outros estudos que possam dar seguimento e aprofundar as investigações acerca da temática em foco, contudo, fica evidenciado direções a serem debatidas.

\section{REFERÊNCIAS}

[1] Brasil. Secretaria de Atenção à Saúde. Departamento de Atenção Básica. Controle dos Cânceres do colo do útero e da mama. Brasília: Ministério da Saúde, 2006.

[2] _. Instituto Nacional de Câncer. Sistema de informação do controle do câncer de mama (Sismama) e do câncer do colo do útero (Siscolo). Rio de Janeiro: INCA, 2011.

[3] Secretaria de Atenção à Saúde. Departamento de Atenção Básica. Controle dos Cânceres do colo do útero e da mama. Brasília: Ministério da Saúde, 2013.

[4] David, Helena Maria Scherlowski Leal; Silva, Maria Rocineide Ferreira da. Educação Popular e saúde e a enfermagem na Atenção Básica. In: Elizabeth, Carmem; Oliveira, Adriano; Ferreira, Darlisom Sousa Ferreira (org.). Programa de Atualização em Enfermagem: Atenção Primária e saúde da Família - Ciclo 2. Porto Alegre: Artmed/ Panamericana, 2012.

[5] Demo, Pedro. A educação do futuro e o futuro da educação. 2. ed. Campinas: Coleção Educação Contemporânea. 2005.

[6] Freire, Paulo. Educação e Mudança. 34. ed. São Paulo: Paz e Terra, 2011.

[7] Gasperin, Simone Iara; Boing, Antônio Fernando; Kupek, Emil. Cobertura e fatores associados à realização do exame de detecção do câncer de colo útero em área urbana no Sul do Brasil: um estudo de base populacional. Cad. Saúde Pública, v. 27, n. 7, p.1312-1322, 2011.

[8] Gil, Antônio Carlos. Como elaborar projetos de pesquisa. 4. ed. São Paulo: Atlas, 2007.

[9] Maeda, Tamie de Carvalho; Alves, Ana Paula; Silva, Sueli Riul da. Conhecimento de mulheres idosas sobre o exame de Papanicolau. Ciência Cuid Saúde, v. 11, n. 2, p. 360-367, 2012.

[10] Mendonça, Francisco Antonio da Cruz et al. Prevenção do câncer de colo uterino. Adesão de enfermeiros e usuárias da Atenção Primária. Revista Rene, v.12 n.2, p. 261-70, 2011.

[11] Minayo, Maria Cecília de Souza (org.). Pesquisa social: teoria, método e criatividade. 2 ed. Petrópolis, RJ: Vozes, 1994.

[12] Moutinho, C. B. et al. Dificuldades, desafios e superações sobre educação em saúde na visão de enfermeiros de Saúde da Família. Trabalho, Educação e Saúde, v. 12, n. 2, p. 253- 272, 2014.

[13] Piccoli, Jaqueline da Costa Escobar; Casarin, Micheli Renata. Educação em saúde para prevenção do câncer do colo do útero em mulheres do município de Santo Ângelo/RS. Ciência e Saúde Coletiva, v. 16, n. 9, p. 3925 -3932, 2011.

[14] Reis, Tatiana Carvalho et al. Educação em Saúde: aspectos históricos no Brasil. J Health Sci Inst, v.31, n. 2, p. 219-23, 2013.

[15] Triviños, A. N. S. Pesquisa qualitativa. In: . Introdução à pesquisa em ciências sociais: a pesquisa qualitativa em educação. São Paulo: Atlas, 2012.

[16] Thuler, Luiz Claudio Santos; Bergmann, Anke; Casado, Letícia. Perfil dos pacientes com câncer do colo do útero no Brasil, 2000-2009: estudo de base secundária. Revista Brasileira de Cancerologia, v. 58, n. 3, p. 351-357, 2012.

[17] Starfield, Bárbara. Atenção Primária: equilíbrio entre necessidades de saúde, serviços e tecnologias. Brasília: Unesco, Ministério da Saúde, 2002. 
[18] Soares, Marilu Correa; Meincke, Sonia Maria Konzgen. Câncer de colo uterino: caracterização das mulheres em um município do Sul do Brasil. Revista Enfermagem, v.14, n. 1, p. 90-96, 2010.

[19] Santos, Marianna Silva dos; Nery, Ines Sampaio. Saberes e Práticas de mulheres idosas na prevenção do câncer cérvico-uterino. Revista Brasileira de Enfermagem, v. 64, n. 3, p. 465-471, 2011.

[20] Vale; Diana Brada Andrade Peixoto et al. Avaliação do rastreamento do câncer do colo do útero na Estratégia Saúde da Família no município de Amparo, São Paulo, Brasil. Cad.Saúde Pública, v. 26, n. 2, p.383-390, 2010.

[21] Vasconcelos, E.M. Educação popular e a atenção à saúde da família. 4. ed. São Paulo: Hucitec, 2010.

[22] Zapponi, Ana Luiza; Melo, Enirtes Caetano Prates. Distribuição da mortalidade por câncer de mama e de colo de útero segundo Regiões Brasileiras. Revista Enfermagem, v.18, n. .4, p. 628-631, 2010. 


\section{Capítulo 8}

Percepção dos aspectos emocionais em pacientes idosos com doença renal e o fortalecimento pela fé: Um relato de experiência

Josilene Mariz de Brito

Fernanda Alves da Silva Ribeiro

Eduardo José Guerra Seabra

Geralda Jéssica de Araújo Santos

Yraguacyara Santos Mascarenhas

Resumo: A insuficiência renal crônica (IRC), é definida como uma condição sem alternativas de melhoras rápidas, de evolução progressiva, ocasionando problemas clínicos, sociais e econômicos. No Brasil, a população com IRC tem aumentado muito nos últimos anos, especialmente devido ao envelhecimento da população geral e ao aumento no número de pacientes com hipertensão arterial e diabetes mellitus. METODOLOGIA: Trata-se de um relato de experiência de caráter descritivo, explanando a vivência de acadêmicos de enfermagem, durante uma coleta de dados para uma pesquisa de mestrado, no período de abril e maio do ano 2016, cujo foco foi avaliar a qualidade de vida de pacientes que fazem hemodiálise na Clínica do Rim, localizado no Hospital Regional do Seridó, em Caicó, Rio Grande do Norte. Cidade da qual atua como um ponto de referência para os serviços de hemodiálise, de modo a atender toda região do Seridó. RESULTADOS E DISCUSSÃO: A partir do diálogo e das observações, foi perceptível o quadro de vulnerabilidade que muitos destes pacientes apresentam, a doença atinge esferas distintas de suas vidas, como trabalho, relações interpessoais, momentos de lazer em viagens, entre outros, alguns inclusive chegam a relatar não ter mais ânimo para enfrentar a vida, e com o sentimento de limitação presente, esse sentido de viver se encontra atrelado somente em função da doença, não havendo mais a capacidade de lidar de forma adequada com a situação, por outro lado, existem pessoas que possuem um melhor aceitação do quadro de saúde, estas mesmo com as restrições seguem sua rotina normalmente e com certos cuidados, ainda trabalham, saem em momentos de lazer, e conseguem manter suas relações e vínculos existentes com pessoas próximas. CONSIDERAÇÕEES FINAIS: 0 apoio e o incentivo da família e amigos são primordiais nesse momento, pois ajuda o indivíduo hemodialítico a lidar melhor com a doença e as mudanças decorrentes da mesma em sua vida. A rejeição e o isolamento encontrados em muitos casos, podem influenciar demasiadamente no quadro do paciente, uma vez que a quebra de vínculo familiar e a solidão nessas circunstâncias, pode desencadear um estado depressivo repercutindo de forma negativa no tratamento. 


\section{INTRODUÇÃO}

A insuficiência renal crônica (IRC) é definida como uma condição sem alternativas de melhoras rápidas, de evolução progressiva, ocasionando problemas clínicos, sociais e econômicos. No Brasil, a população com IRC tem aumentado muito nos últimos anos, especialmente devido ao envelhecimento da população geral e ao aumento no número de pacientes com hipertensão arterial e diabetes mellitus (MARTINS; CESARINO, 2005; KUSUMOTO et al, 2008).

A insuficiência renal é uma síndrome clínica que tem como característica predominante a incapacidade dos rins executarem suas principais funções. Uma disfunção no sistema renal compromete a saúde do indivíduo, dependendo da gravidade, pode desencadear um quadro renal crônico, esta também pode ser uma doença assintomática, a qual os indivíduos chegam a desconhecer sua existência até o momento em que o quadro clínico se apresentar bastante avançado(ALVES; GUEDES; COSTA, 2016; COSTA; COUTINHO; SANTANA, 2014).

A ocorrência e a intensidade dos sinais e sintomas da IRC, dependem do grau de comprometimento da função dos rins e de outras condições subjacentes, próprias do envelhecimento humano, tais como: a presença de outras doenças crônicas e/ou redução da função renal decorrente de alterações anatômicas e fisiológicas (KUSUMOTO et al, 2008).As modalidades de tratamento da IRC consiste na substituição parcial das funções renais, por meio do transplante renal e/ou diálise, que é dividida em: hemodiálise e diálise peritoneal. A hemodiálise é o procedimento mais adotado nesses casos, a qual compreende um processo mecânico e extracorpóreo, que consiste na remoção de substâncias tóxicas e do excesso de líquido do organismo.

De modo geral, esse tratamento é realizado em uma unidade hospitalar, três vezes por semana, em sessões que duram três ou quatro horas, além desses cuidados, a pessoa em tratamento deve fazer restrição na dieta e ingestão de líquidos e também fazer uso de medicamentos que auxiliam na reestruturação do funcionamento renal (KUSUMOTO et al, 2008; COSTA; COUTINHO; SANTANA, 2014).

A doença renal crônica (DRC) e a diálise provocam situações variáveis que afetam tanto o aspecto físico, quanto o psicológico, e também interferem diretamente na participação do indivíduo na sociedade, pois as limitações que acompanham esta doença, repercute no âmbito pessoal, familiar e social. As mudanças no cotidiano do paciente renal trazem enormes perturbações a sua rotina diária, as quais permanecerão durante toda sua vida, tais como: depender de uma máquina para sobreviver, ter sua vida atrelada a um centro de hemodiálise, alterações na percepção da sua imagem corporal, a perda do emprego, entre outros, gerando grande impacto no seu modo de vida(ALVES; GUEDES; COSTA, 2016; MARTINS; CESARINO, 2005).

Este estudo objetiva relatar a experiência de discentes do curso de Enfermagem como colaboradores de uma coleta de dados em uma pesquisa de mestrado, que teve como intuito avaliara qualidade de vida de pacientes que fazem hemodiálise, descrever o seu estado de saúde, as mudanças que ocorreram devido a doença, as dificuldades e formas de enfrentamento, principalmente a população idosa.

\section{METODOLOGIA}

Trata-se de um relato de experiência de caráter descritivo, explanando a vivência de acadêmicos de enfermagem, durante uma coleta de dados para uma pesquisa de mestrado, no período de abril e maio do ano 2016, cujo foco foi avaliar a qualidade de vida de pacientes que fazem hemodiálise na Clínica do Rim, localizado no Hospital Regional do Seridó, em Caicó, Rio Grande do Norte. Cidade da qual atua como um ponto de referência para os serviços de hemodiálise, de modo a atender toda região do Seridó. As coletas foram realizadas por seis discentes do curso de graduação em Enfermagem, por meio da supervisão de uma aluna do programa de mestrado de Saúde e Sociedade da Universidade do Estado do Rio Grande do Norte - UERN. 0 público atingido compreendeu os pacientes que estão em hemodiálise há pelo menos dois meses; maiores de 18 anos de idade; não ter se submetido a transplante renal; apresentar estabilidade clínica/hemodinâmica; ter capacidade de responder o questionário; aceitar participar da pesquisa mediante assinatura do termo de consentimento livre esclarecido. Os critérios que determinaram a exclusão foram: portadores da Síndrome da Imunodeficiência Adquirida (HIV/AIDS); distúrbios osteomusculares; Hepatite B ou C; algum tipo de câncer; sequelas de Acidente Vascular Cerebral. A Clínica do Rim funciona durante os seis dias da semana nos três horários (manhã, intermediário e noturno), atendendo em média 26 pacientes por turno. 
No primeiro momento, o grupo de alunos foi divido em duplas, a fim de haver uma melhor distribuição do horário para a realização da pesquisa, cada um ficou responsável pelo preenchimento de 21 fichas, as quais compreendiam termos livres de consentimento, e questionários com 24 perguntas cada. Cada paciente abordado, caso permitisse a entrevista, tinha que assinar ou colocar sua digital em um termo livre de consentimento, para autorizar a utilização dos dados fornecidos na pesquisa, destacando que essas informações seriam mantidas em sigilo absoluto. Após a autorização, o questionário era aplicado com perguntas sobre a percepção do seu estado de saúde, qualidade de vida e dificuldades enfrentadas por apresentar um quadro de doença renal.

\section{RESULTADOS E DISCUSSÃO}

São diversos os significados que passam pelo imaginário das pessoas afetadas pela IRC, indo desde o impacto do diagnóstico, associado ao reconhecimento da gravidade da doença e do tratamento, até as suas consequências, como os efeitos medicamentosos e os limites nos hábitos alimentares e na vida social, podendo levar os indivíduos a redimensionar tudo o que era vivido anteriormente, em um processo de revisão de si e de suas relações (COUTINHO; COSTA, 2015; COSTA; COUTINHO; SANTANA, 2014). 0 processo desencadeado pela patologia crônica no idoso afeta os aspectos biopsicosocioculturais, provocando mudanças nos hábitos de vida em face a doença, que geram dificuldades associadas ao distanciamento de experiências que proporcionam prazer, à privação do trabalho, às dificuldades financeiras, à incapacidade física para desempenhar as atividades cotidianas, à necessidade do deslocamento para outra cidade para realizar as sessões de hemodiálise, entre outras (COUTINHO; COSTA, 2015;COSTA; COUTINHO; SANTANA, 2014;MACHADO et al, 2014).

Na maior parte dos casos, tais situações adversas provocam medo, dúvidas e insegurança em relação à cura e à possibilidade de viver. Assim, a IRC pode gerar desordens emocionais, emergindo sentimentos negativos que, quando sobrepostos à condição física, atingem diretamente a qualidade de vida dessas pessoas, deste modo, o idoso deverá ser visto de forma holística e não fragmentada, pois cada um possui um grau diferente de resiliência, respondendo de forma distinta às adversidades da vida (COUTINHO; COSTA, 2015; COSTA; COUTINHO; SANTANA, 2014; MACHADO et al,2014).

A partir do diálogo e das observações, foi perceptível o quadro de vulnerabilidade que muitos destes pacientes apresentam, a doença atinge esferas distintas de suas vidas, como trabalho, relações interpessoais, momentos de lazer em viagens, entre outros, alguns inclusive chegam a relatar não ter mais ânimo para enfrentar a vida, e com o sentimento de limitação presente, esse sentido de viver se encontra atrelado somente em função da doença, não havendo mais a capacidade de lidar de forma adequada com a situação, por outro lado, existem pessoas que possuem uma melhor aceitação do quadro de saúde, estas mesmo com as restrições seguem sua rotina normalmente e com certos cuidados, ainda trabalham, saem em momentos de lazer, e conseguem manter suas relações e vínculos existentes com pessoas próximas.

Os idosos com DRC submetidos à hemodiálise têm uma gama de fatores negativos, decorrentes deste declínio fisiológico que ocorre com o processo de envelhecimento, entre eles: risco de isolamento social, depressão, mobilidade física prejudicada, autoimagem prejudicada, restrições alimentares e hídricas, limitações com a presença de procedimentos, rotinas e orientações de profissionais de saúde, que pode limitá-los na realização de atividades da vida diária (MACHADO et al, 2014; KUSUMOTO et al, 2008).

Entre os elementos simbólicos atribuídos à hemodiálise, existe um binômio expressado pela relação ambivalente de vida e morte. Diante disso, as variáveis religiosas são associadas a menores índices de depressão e ansiedade, justificado pela capacidade de lidar realisticamente com os problemas, o que contribui para o desenvolvimento de harmonia, de paz, de força interior e de realizações (COSTA; COUTINHO; SANTANA, 2014; CHAVES et al., 2015; MADEIRO et al,2010).

É possível compreender que o apego a uma força maior, a vontade de viver, a fé e a esperança, se encontram em alguns dos pacientes que vivem nesta condição, o que influencia positivamente no modo de vida dessas pessoas, destacando-se como um fator fundamental para o tratamento, já que possibilitam ânimo e incentivo de viver da melhor forma possível, mesmo que ainda não confiem na cura, sentem-se livres de seus anseios quando suas respostas são encontradas na fé e/ou no fortalecimento da vontade de viver ao lado de pessoas queridas. 
Não apenas a esperança, como também o apoio de familiares e amigos, e a relação com os próprios profissionais de saúde, ajudam demasiadamente a enfrentar esse momento de transição, repercutindo na eficácia do tratamento. Os pacientes encontram fortaleza, apoio e segurança para lidar com essa nova situação quando pessoas se disponibilizam a ajudar e se mostram capazes de entendê-los, uma simples conversa pode ser vista como um instrumento que possibilite conforto, esse tipo de incentivo proporciona uma melhor aceitação da doença e do tratamento, além de trazer uma maior qualidade de vida.

\section{CONSIDERAÇÕES FINAIS}

O quadro da doença renal crônica pode deixar o paciente debilitado em diversos aspectos, e isso evidencia a importância de um acompanhamento abrangente desde o tratamento clínico até a observação das necessidades emocionais. No momento de entrevistas para a coleta de dados surgiu uma grande oportunidade de adentrar, mesmo que superficialmente, na observação de fatores que fazem parte da complexidade humana, e nesse universo de singularidades, principalmente em cada paciente hemodialítico, os sentimentos podem ser expressados de forma distinta em instantes de fragilidades, alguns citam que vivem apenas em função da doença e se autodenominam como um fardo carregado pela sua família, enquanto outros, mesmo com as limitações, se dizem capazes de viverem da melhor forma possível.

O apoio e o incentivo da família e amigos é um fator primordial nesse momento, pois ajuda o indivíduo hemodialítico a lidar melhor com a doença e as mudanças decorrentes da mesma em sua vida. A rejeição e o isolamento encontrados em muitos casos, podem influenciar demasiadamente no quadro do paciente, uma vez que a quebra de vínculo familiar e a solidão nessas circunstâncias, pode desencadear um estado depressivo repercutindo de forma negativa no tratamento.

Essa experiência vivenciada proporcionou um primeiro contato com um centro de hemodiálise e com as pessoas que fazem esse tipo de tratamento, a partir disso, foi possível obter uma ligeira visão do tipo de assistência ofertada aos pacientes, observar o trabalho de uma equipe de saúde integrada, e também houve uma grande troca de saberes, tendo em vista que a aprendizagem sobre o quadro dessa doença foi adquirido nesse momento. Também foi possível observar que o cuidado multiprofissional ofertado pelos profissionais de saúde, abrangendo os aspectos biopsicosocioculturais apresentados no paciente, repercute diretamente na assistência, oferecendo um tratamento humanizado e de qualidade.

\section{REFERÊNCIAS}

[1] Alves, L. O.; Guedes, C. C. P.; Costa, B. G. As ações do enfermeiro ao paciente renalcrônico: reflexão da assistência no foco da integralidade. Revista de Pesquisa: Cuidado é Fundamental Online, [S.l.], v. 8, n. 1, p. 3907-3921, jan. 2016. Disponível em: <http://www.seer.unirio.br/index.php/cuidadofundamental/article/view/3945>. Acesso em: 06 Jul.2016.

[2] Chaves, E. C. L. et al. Associação entre Bem-Estar Espiritual e Autoestima em Pessoas comInsuficiência Renal Crônica em Hemodiálise. Psicol. Reflex. Crit., Porto Alegre, v. 28, n. 4, p.737-743, Dec. 2015. Disponível em:

<http://www.scielo.br/scielo.php?script=sci_arttext\&pid=S0102-79722015000400012\&lng=en\&nrm=iso>. Acesso em: 07 jul. 2016.

[3] Costa, F. G.; Coutinho, M. P. L.; Santana, I. O. Insuficiência renal crônica: representaçõessociais de pacientes com e sem depressão. Psico-USF, Itatiba, v.19, n. 3, p. 387-398, dez. 2014. Disponível em:

<http://www.scielo.br/scielo.php?script=sci_arttext\&pid=S1413-82712014000300003\&lng=pt\&nrm=isso>. Acesso em: 07 jul. 2016.

[4] Coutinho, M. P. L.; Costa, F. G. Depressão e Insuficiência Renal Crônica: Uma Análise Psicossociológica. Psicol. Soc., Belo Horizonte, v. 27, n. 2, p. 449-459, ago. 2015. Disponível em: <http://www.scielo.br/scielo.php?script=sci_arttext\&pid=S0102$71822015000200449 \&$ lng=en\&nrm=iso >. Acesso em: 07 jul. 2016.

[5] Kusumoto, L. et al. Adultos e idosos em hemodiálise: avaliação da qualidade de vidarelacionada à saúde. Acta Paulista de Enfermagem, v.21, n.spe, p.152-159, 2008. Disponível

em:<http://www.producao.usp.br/bitstream/handle/BDPI/3570/art_Kusumoto_Adultos_e_idosos_em_hemodialise_avaliacao_da_20 08.pdf?sequence=1\&isAllowed=y>. Acesso em: 06 jul. 2016.

[6] Machado, F. S. et al. Qualidade de vida de idosos submetidos à hemodiálise: uma revisãosistemática. Revista Kairós Gerontologia, São Paulo (SP), Brasil: FACHS/NEPE/PEPGG/PUC-SP. v. 17 n. 3, p.149-163, set. 2014. Disponível em:<http://revistas.pucsp.br/index.php/kairos/article/view/21914/16111>. Acesso em: 06 Jul. 2016.

[7] Madeiro, A. C. et al., Adesão de portadores de insuficiência renal crônica ao tratamento dehemodiálise. Acta paul. enferm., São Paulo , v. 23, n. 4, p. 546-551, 2010 . Disponível em:<http://www.scielo.br/scielo.php?script=sci_arttext\&pid=S0103$21002010000400016 \& \operatorname{lng}=\mathrm{en} \&$ nrm=iso>. Acesso em: 06 Jul. 2016. 
[8] Martins, M. R. I.; Cesarino, C. B. Qualidade de vida de pessoas com doença renal crônicaem tratamento hemodialítico. Revista Latino-Americana de Enfermagem, [S.l.], v. 13, n. 5, p.670-676, out. 2005. Disponível em: <http://www.revistas.usp.br/rlae/article/view/2134/2225>. Acesso em: 06 jul. 2016. 


\section{Capítulo 9}

\section{Fatores associados à dependência entre idosos com diabetes mellitus e a qualidade de vida nessa idade}

\section{Maria Zélia Araújo \\ Maria Angélica Palmeira da Rocha \\ Maria Janine Pereira Fernandes \\ Maria Joselita Alves \\ Josiane Costa e Silva}

Resumo: Objetivo geral: mostrar os fatores associados à dependência entre idosos com diabetes mellitus e a qualidade de vida na terceira idade. Metodologia: tratou-se de um estudo descritivo feito a partir de uma revisão integrativa da literatura. Este tipo de investigação permite o compêndio de diversos estudos publicados admitindo arremates suscitais a respeito de uma determinada temática. trabalharam-se nove artigos que foram publicados entre 2011 e 2019. Resultados: o estudo mostrou os fatores que são associados ao diabetes mellitus no idoso e o que se pode fazer para proporcionar qualidade de vida na terceira idade. Conclusão: com o estudo verificou-se nas elencadas que são vários os fatores que estão associados ao diabetes mellitus na terceira idade o que fora demonstrado nos conhecimentos de cunho científico com a proposição de apresentar uma parcela de contribuição tanto para a academia como para a sociedade em geral.

Palavras-chave: fatores associados, diabetes mellitus, idoso, doença crônica, qualidade de vida. 


\section{INTRODUÇÃO}

De acordo com pesquisas realizadas por Ramos (2012, p. 13) ela apresentou os dados referendados pela Organização Mundial de Saúde a respeito da população com 60 anos ou mais, arguindo que:

A Organização Mundial de Saúde (OMS) considera uma população envelhecida quando a proporção de pessoas com 60 anos ou mais atinge 7\% com tendência a crescer. De acordo com o Censo Populacional de 2010, a proporção de idosos no país passou de 8,57\% para 11,16\%, ultrapassando 21 milhões de pessoas. 3 Segundo projeções da OMS, o Brasil será o sexto país do mundo com o maior número de pessoas idosas. Quanto a expectativa de vida, em 2050, nos países em desenvolvimento será de 82 anos para homens e 86 para mulheres, ou seja, 21 anos a mais do que hoje, que é de 62,1 e 65,2 anos, respectivamente.

A autora ainda frisou que o Brasil será o sexto país do mundo com o maior número de idosos em 2050.

Rocha et al. (2017) argumentou em sua pesquisa que o processo de envelhecimento populacional provocado pela redução da mortalidade, queda na fecundidade e o aumento da expectativa de vida, nos coloca diante de novos desafios, que exigem respostas urgentes. Para isso, é indispensável que haja uma organização da prestação de serviços de saúde adequado à população idosa, contribuindo para o desenvolvimento de ações educativas, estratégias de prevenção, controle dos principais agravos, medidas de reabilitação e incentivo à participação ativa na melhoria da qualidade de vida.

Ferreira, et al. (2017) enfatizou em seu trabalho que o Estatuto do Idoso dispõe a população idosa o direito assegurado à atenção integral de sua saúde por meio do Sistema Único de Saúde - SUS e este deverá garantir o acesso universal e igualitário, promovendo ações de prevenção, promoção, proteção e recuperação da saúde.

O profissional de saúde que se propõe a atuar na Atenção Primaria de Saúde (APS), na condição de integrante de uma equipe multiprofissional, deve se preparar, desde a Graduação, para lidar com a mudança do perfil da população que busca o serviço, com uma presença crescente de idosos. Pode-se inferir que, para aprimorar uma assistência com qualidade e efetividade, conforme proposto pelo Estatuto do Idoso e pelas políticas o acolhimento e a humanização é um direito garantido ao idoso em qualquer ambiente seja de saúde, lazer ou domiciliar (FERREIRA, et al., 2017).

Nos últimos tempos o envelhecimento da população mundial acontece de forma rápida, em especial nos países em desenvolvimento, como o Brasil. Na medida em que cresce a população idosa, aumenta a prevalência de doenças crônicas, e com isso a morbidade e mortalidade no mundo. Entre estas doenças está o Diabetes Mellitus (DM) que acontece quando o organismo não consegue usar adequadamente a insulina que produz ou não produz insulina suficiente para suprir as necessidades do organismo (SILVA; BRANDÃO; LIMA, 2017).

Ramos (2012, p.13) afirmou que:

0 diabetes mellitus representa uma doença altamente limitante, tendo como consequências em longo prazo, danos, disfunção e falência de vários órgãos, especialmente rins, olhos, nervos, coração e vasos sanguíneos. As pessoas com diabetes têm maior risco de hipertensão arterial, doença coronariana, doença arterial periférica e doença vascular cerebral, podendo, ainda, desenvolver neuropatia, artropatia e disfunção autonômica, inclusive sexual, as quais acometem mais frequentemente os idosos.

Também argumentou Carolino, et al., (2008) que o Diabetes Mellitus (DM) é uma condição crônica, caracterizada por hiperglicemia relacionada à deficiência de insulina, com isso eleva os riscos de danos micro e macrovasculares nos portadores, causando redução da expectativa e da qualidade de vida. Ainda arguiu os autores supracitados que fora considerando o aceleramento do ritmo de envelhecimento populacional, visto que é notável o aumento de mortalidade pela doença, especialmente entre os idosos em função da vulnerabilidade criada pelos efeitos do estilo de vida inadequado de boa parte dessa população, no mundo e no Brasil.

Lima, et al. (2017) enfatizou que o envelhecimento e a velhice, portanto, têm se tornado um grande desafio para o Sistema Único de Saúde, por considerar que um idoso doente promove aumento de internações e reinternações, separação do ambiente familiar e gera dificuldade para ter um familiar como acompanhante neste período de sua vida, além do mesmo enfrentar riscos como infecções hospitalares. Diante de tal fato, pode-se afirmar que os gastos públicos são grandes, sendo assim o presidente pela responsabilidade de aumentar as potencialidades de saúde dos idosos em níveis que lhes permitam 
conservarem-se no contexto familiar com autonomia, autoestima e qualidade de vida, ao sistema de saúde coube criar alternativas para essas situações.

Oliveira; Concone; Souza (2016) em sua pesquisa elas argumentaram que a humanização depende diretamente da capacidade de falar e ouvir das pessoas envolvidas no processo e isto se refere também ao atendimento das demandas biopsicossociais e espirituais dos indivíduos, tanto do profissional, quanto do próprio idoso. Enfatizaram que se faz necessário que haja harmonia nas relações, por ser imprescindível a existência do diálogo de uma forma de comunicação que viabilize as relações e interações entre as pessoas, independentemente das condições que elas tenham. Esta perspectiva se apoia na diretriz da Organização Mundial de Saúde (OMS), órgão da Organização das Nações Unidas (ONU), que define saúde como o "estado de completo bem-estar físico, mental e social, não meramente ausência de doença ou enfermidade". Com esta definição a OMS amplia o modelo estritamente biomédico de saúde para um modelo mais abrangente, partindo da possibilidade de se colocar no lugar de outro que, por vezes vulnerável, encontrará na assistência suporte para enfrentar seus desafios.

Diante do exposto, a pesquisa tem como objetivo mostrar os fatores associados à dependência entre idosos com diabetes mellitus e a qualidade de vida na terceira idade.

\section{METODOLOGIA}

Para a construção desse estudo, desenvolveu-se uma pesquisa de revisão literatura, de cunho exploratório, descritivo com abordagem qualitativa. Em se tratando da revisão de literatura, esta se consistiu em um método de pesquisa que possibilita a síntese do conhecimento de um determinado assunto, ou seja, um método de pesquisa que permite a busca, avaliação crítica e síntese das evidências disponíveis do tema que fora investigado.

Revisão da literatura é o processo de busca, análise e descrição de um corpo do conhecimento em busca de resposta a uma pergunta específica. "Literatura" cobre todo o material relevante que é escrito sobre um tema: livros, artigos de periódicos, artigos de jornais, registros históricos, relatórios governamentais, teses e dissertações e outros tipos. Ela compreende três tipos de revisão da literatura, que são: Narrativa; Sistemática e Integrativa.

Moreira (2004, p. 23-24) descreveu que "a revisão de literatura pode ser organizada para estabelecer nexos no conhecimento existente". Vale ressaltar que a revisão "requer postura crítica, cotejo das diversas opiniões expressadas" a fim de se chegar ao consenso a respeito de um determinado tema. Ainda afirma este autor que a revisão de literatura é uma ferramenta importante para otimização do trabalho de investigação, apoiando o que fora dito por Noronha e Ferreira, que entendem que a revisão de literatura “[...] propicia ao pesquisador tomar conhecimento, em uma única fonte, do que ocorreu ou está ocorrendo periodicamente no campo estudado, podendo substituir a consulta a uma série de outros trabalhos. [...]" (NORONHA; FERREIRA, 2000, p. 192).

Além de Moreira (2004), Silva; Menezes, (2001, p. 37) descreveram que:

A revisão de literatura resultará do processo de levantamento e análise do que já foi publicado sobre o tema e o problema de pesquisa escolhidos. Permitirá um mapeamento de quem já escreveu e o que já foi escrito sobre o tema e/ou problema da pesquisa.

A revisão narrativa de conformidade com Rother (2007, p. v-vi) "os artigos de revisão narrativa são publicações amplas apropriadas para descrever e discutir o desenvolvimento ou o estado da arte de um determinado assunto, sob o ponto de vista teórico ou conceitual".

Ainda afirma Rother (2007, p. ix), a revisão narrativa utiliza-se "da aquisição e atualização de conhecimento sobre um determinado tema em curto período de tempo" [...] "para descrever o estado da arte de um assunto específico, sob o ponto de vista teórico ou contextual". Constitui-se basicamente "da análise da literatura, da interpretação e análise crítica pessoal do pesquisador". No tocante a Revisão Sistemática Galvão e Pereira (2014, p. 183) descreveram que: "As revisões sistemáticas devem ser abrangentes e não tendenciosas na sua preparação. Os critérios adotados são divulgados de modo que outros pesquisadores possam repetir o procedimento".

Ainda afirmaram os autores supracitados que "as Revisões sistemáticas de boa qualidade são consideradas o melhor nível de evidência para tomadas de decisão". Tal posicionamento evidencia-se em 
razão de se seguir um método científico explícito e apresentar resultado novo. Portanto, "a revisão sistemática é classificada como contribuição original na maioria das revistas de pesquisa clínica".

Galvão e Pereira (2014, p. 183) também notificaram que: As revisões sistemáticas diferem das revisões narrativas ou tradicionais. Essas são amplas e trazem informações gerais sobre o tema em questão, sendo comuns em livros-texto. Também se distinguem das revisões integrativas, nas quais se utilizam diferentes delineamentos na mesma investigação, além de expressarem a opinião do próprio autor Mendes; Silveira; Galvão (2008, p. 763) ao descreverem sobre a revisão integrativa afirmaram que ela corresponde a "um método de pesquisa incipiente na enfermagem nacional, porém a sua contribuição na melhoria do cuidado prestado ao paciente e familiar é inegável".

Em se tratando deste trabalho seguiu-se o desempenho dos seguintes passos:

1) Delineamento do tema e da pergunta condutora;

2) Estabelecimento das estratégias de busca e definição dos critérios de elegibilidade, tendo como inclusão, publicações entre 2011 a 2019, escritos na língua portuguesa, com os descritores: Os descritores utilizados foram: "Envelhecimento", "Idoso", "Doenças Crônicas”, “Diabetes Mellitus", “Qualidade de vida”;

3) A busca foi realizada na base de dados da Scientific Eletronic Library Online (SciELO Brasil) e Biblioteca Virtual em Saúde (BVS), entre outros, que serviram de fontes, tanto para a introdução, desenvolvimento e resultados do estudo ora realizado;

4) Avaliação crítica e categorização dos estudos, no que diz respeito ao ano de publicação, a revista publicada, a formação dos pesquisadores e o tema abordado; e

5) Descrição e discussão dos referenciais teóricos tendo como base a análise de conteúdo de Bardin (2015).

A população da pesquisa compreendeu mais de 30 fontes, entre os artigos científicos que abordasse sobre a temática em apreço, e a amostra foi composta de 09 fontes do total supracitado. 0 processo de inclusão deu-se se levando em consideração artigos completos, na língua portuguesa e publicados dentro do intervalo apresentado no item 2.

Para Gerhardt e Silveira (2009) a pesquisa exploratória tem como objetivo proporcionar maior familiaridade com o problema com vistas a torná-lo mais explícito, ou a construir hipóteses referentes ao mesmo.

Para Gil (2008) a pesquisa descritiva tem a proposição de descrever as características de determinadas populações ou fenômenos. Uma de suas peculiaridades está na utilização de técnicas padronizadas de coleta de dados, tais como o questionário e a observação sistemática. Ex.: pesquisa referente à idade, sexo, procedência, eleição etc.

Segundo Minayo (2003) a pesquisa qualitativa trata-se de uma atividade da ciência, que visa à construção da realidade, mas que se preocupa com as ciências sociais em um nível de realidade que não pode ser quantificado, trabalhando com o universo de crenças, valores, significados e outro construto profundos das relações que não podem ser reduzidos à operacionalização de variáveis.

Toda análise dos conteúdos pesquisados nos artigos que compuseram os resultados do estudo foi realizado tomando como base o método de análise de conteúdo com fundamento em Bardin por ser um dos métodos recomendados para análise de pesquisa na área da saúde (BARDIN, 2015).

Embora esteja trabalhando um artigo, vale ressaltar que se colocou um referencial teórico antes dos resultados e discussão para que se tenha um leitor inteirado com a temática em estudo, visto que nem todo leitor da pesquisa tem conhecimento a respeito dos fatores associados à dependência entre idosos com diabetes mellitus e a qualidade de vida nessa idade. 


\section{DESENVOLVIMENTO}

\subsection{BREVE DESCRIÇÃO SOBRE OS FATORES ASSOCIADOS AO DIABETES MELLITUS, DEPENDÊNCIA DOS IDOSOS E A QUALIDADE DE VIDA NESSA IDADE}

\subsubsection{CONCEITO DE DIABETES MELLITUS}

O Diabetes Mellitus (DM) é uma doença crônica que afeta aproximadamente 7,6\% da população brasileira entre 30 e 69 anos. A hiperglicemia persistente em característica da doença atinge de forma significativa os indivíduos, exigindo alterações importantes em seus estilos de vida. Pacientes com diabetes necessitam modificar hábitos alimentares e aderir a esquemas terapêuticos restritivos, tais como aplicações regulares de insulina e monitorização glicêmica diária. Além disso, estes pacientes devem lidar com o fato de ter que conviver durante toda a vida com uma doença que é responsável por complicações clínicas que prejudicam a saúde do indivíduo. Todas essas variáveis poderiam repercutir no estado de humor dos pacientes diabéticos (CÂNDIDO, et al., 2017).

O Diabetes Mellitus (DM) tipo II é compreendido como uma doença crônica em expansão, que provoca alterações na vida cotidiana dos indivíduos, ocasionando sofrimento psicológico e forte impacto familiar e social. Caracteriza-se pelo aumento dos níveis de glicose no sangue e os principais sintomas estão relacionados ao aumento da sede, fome e micção, perda repentina de peso, formigamentos nas mãos e pés, cansaço, entre outros. Além disso, a DM tipo II é responsável por 90\% a 95\% dos diagnósticos, considerando-se a mais comum entre as DM, apresentando como fatores de riscos a obesidade, idade avançada, histórico familiar e sedentarismo (GARCIA, et al., 2017).

Alterações Fisiológicas Para Medeiros et al. (2014) as alterações fisiológicas decorrentes do processo de envelhecimento são extensas, mas incluem uma redução lenta e gradual do bom funcionamento do corpo. Eles enfatizaram que essas alterações quando associadas a algum fator genético e/ou ambiental, proporcionam ao idoso o desenvolvimento de patologias recorrentes e outras manifestações clínicas, que lhes conferem inúmeros prejuízos à saúde. Ainda argumentaram que, dentre as patologias que mais acometem a população idosa, as doenças crônicas se destacam, destacando, portanto, o Diabetes Mellitus.

\subsubsection{TRATAMENTO}

0 tratamento envolve a aceitação da doença, apoio social e familiar, bem como cautela quanto à adesão medicamentosa e não medicamentosa. Na maioria dos casos, as pessoas com DM tipo II necessitam utilizar medicamentos por via oral, injetáveis ou a combinação de ambos, em vista do controle dos níveis de glicose presentes no sangue, caracterizando o tratamento medicamentoso; já o tratamento não medicamentoso está relacionado à associação do controle da glicose no sangue, realização de atividades físicas e hábitos alimentares saudáveis, entretanto, tendo em vista que o DM tipo II é caracterizado como uma doença progressiva, o tratamento farmacológico é imprescindível para o controle glicêmico e prevenção de possíveis complicações da doença (GARCIA, et al., 2017).

O diabetes em idosos está relacionado a um risco maior de morte prematura, a maior associação com outras morbidades e, principalmente, com as grandes síndromes geriátricas, sendo importante destacar os prejuízos em relação à capacidade funcional, autonomia e qualidade de vida, o que a configura como uma doença de alto impacto, com repercussões sobre o sistema de saúde, família e o próprio idoso acometido. Representa uma doença altamente limitante, tendo como consequências em longo prazo, danos, disfunção e falência de vários órgãos, especialmente rins, olhos, nervos, coração e vasos sanguíneos (SOUZA et al., 2012).

As pessoas com diabetes têm maior risco de hipertensão arterial, doença coronariana, doença arterial periférica e doença vascular cerebral, podendo, ainda, desenvolver neuropatia, atroparia e disfunção autonômica, inclusive sexual, as quais acometem mais frequentemente os idosos. Além disso, o idoso diabético, quando comparado ao não diabético, está mais sujeito a ser bastante medicado, apresentar perdas funcionais (dificuldade de locomoção, por exemplo), problemas cognitivos, depressão, quedas e fraturas, incontinência urinária e dores crônicas, devendo, portanto, ser tratado de forma individualizada (RAMOS, et al., 2017).

A adesão terapêutica para tratamento de diabetes mellitus é muito complexa e depende de múltiplos fatores. Por exemplo, a questão financeira, informações acerca da DM, escolaridade e a não ocorrência dos sintomas da patologia interferem consideravelmente. Além disso, a maior parte dos portadores são idosos, e existe uma gama de medicamentos que este público administra para outras co-morbidades e isso 
dificulta a aceitação de mais uma terapia medicamentosa para o manejo do tratamento (DUARTE; et al., 2013).

O envelhecimento e a velhice, portanto, têm se tornado um grande desafio para o Sistema de Saúde no que concerne ao idoso doente por promover o aumento de internações e reinternações, separação do ambiente familiar e dificuldade para ter um familiar como acompanhante neste período, além de riscos como infecções hospitalares. Com isso os gastos públicos são grandes, sendo assim o presidente pela responsabilidade de aumentar as potencialidades de saúde dos idosos em níveis que lhes permitam conservarem-se no contexto familiar com autonomia, autoestima e qualidade de vida, ao sistema de saúde coube criar alternativas para essas situações (LIMA, et al., 2016).

Os riscos da falta de cuidado associado ao portador de DM é muito grave pois o idoso naturalmente já tem suas limitações e portando tal patologia associada a estas limitações aumentam, pois vem os agravos decorrente do problema de saúde que afetam muitos órgãos e podem levar da cegueira ao óbito. 0 cuidado domiciliar é muito importante na prevenção destes agravos, para o cuidador os obstáculos são grandes, mas os profissionais da UBS tem um papel primordial na assistência ao idoso portador de DM como também no apoio ao cuidador e/ou familiar (CAMPOLINA; DINI; CICONELLI, 2011).

Estresse crônico, depressão e ansiedade, decorrentes do cuidado diário ofertado a um idoso dependente, podem contribuir para o prejuízo da saúde e do bem-estar do cuidador. 0 comprometimento na saúde pode exercer um risco sobre a qualidade dos cuidados prestados ao outro e a si mesmo. Os cuidadores, especialmente mulheres e cônjuges, têm níveis mais elevados de depressão e sobrecarga advindos ao compromisso de cuidar e níveis mais baixos de bem-estar subjetivo e saúde percebida. Esses cuidadores na maioria das vezes desenvolvem problemas de comportamento nos receptores de cuidado, provém da quantidade de horas de cuidado e de atribuições. As queixas de saúde mais frequentes entre os cuidadores são dor, hipertensão arterial sistêmica, problemas de coluna, insônia e problemas na visão. Outras queixas de morbidades como anemia, audição prejudicada, câncer, constipação, hipotireoidismo, incontinência urinária/fecal, obesidade, osteoporose e problemas pulmonares estudos afirmam estes fatores (SANTOS; KOETZ, 2017).

\subsubsection{FATORES ASSOCIADOS AO DIABETES MELLITUS}

De acordo com a Organização Mundial de Saúde, ela identificou que os fatores de risco para DM podem ser classificados em três grupos: hereditários; comportamentais; e socioeconômicos. Entre os fatores de risco comportamentais, destacam-se o tabagismo, o consumo excessivo de bebidas alcoólicas, a obesidade, os hábitos alimentares inadequados e a inatividade física. Esse conjunto de fatores responde pela grande maioria das mortes por doenças e agravos não transmissíveis (DANT) e por fração substancial da carga de doenças atribuída a essas enfermidades (OMS, 2001).

Na pesquisa de Menezes et al. (2014) elas afirmaram que, quando se tem o conhecimento dos fatores e características modificáveis que influenciam suas complicações é fundamental para traçar estratégias de mudanças de comportamentos relacionados à saúde dos acometidos com o DM.

Seguindo os resultados estudos realizados e segundo Goulart, em sua pesquisa afirmou que de conformidade com estudos realizados pela Organização Mundial da Saúde, estima-se que no Brasil aproximadamente 11,3 milhões de pessoas serão diabéticas no ano de 2030 e esse aumento ocorrerá, sobretudo, entre os indivíduos dos grupos etários mais avançados (GOULART, 2011), o que não fora diferente na percepção de Menezes et al. (2014) ao apresentarem os resultados da pesquisa realizada em uma das cidades da região nordestina, no que concerne aos cuidados com os fatores de riscos associados ao DM na terceira idade.

\section{RESULTADOS E DISCUSSÃO}

De conformidade com os artigos elencados e a proposição dos pesquisadores a respeito dos fatores que são associados ao diabetes mellitus na terceira idade, conforme mostra o Quatro 1, no qual tem-se a ordem dos artigos, autores, títulos, objetivos, local e ano de publicação, que foram apresentados em ordem do ano mais recente ao ano mais distante para que se pudesse ter uma descrição do estado da arte no que concerne o diabetes mellitus na população idosa. 
Quadro 01 - Identificação dos artigos pesquisados, destacando autores, títulos, objetivos, local e ano de publicação.

\begin{tabular}{|c|c|c|c|c|}
\hline Artigo & Autores & Título & Objetivos & Local e ano de publicação \\
\hline 01 & $\begin{array}{l}\text { MENEZES, T. N.; } \\
\text { OLIVEIRA, E. C. T.. }\end{array}$ & $\begin{array}{l}\text { Validade e concordância } \\
\text { do diabetes mellitus } \\
\text { referido em idosos. }\end{array}$ & $\begin{array}{l}\text { Verificar a validade e a } \\
\text { concordância do relato de } \\
\text { diabetes mellitus (DM) na } \\
\text { população idosa do } \\
\text { município de Campina } \\
\text { Grande/PB. }\end{array}$ & $\begin{array}{l}\text { Ciência \& Saúde Coletiva, v. } \\
\text { 24, n. 1, p.27-34, } 2019 .\end{array}$ \\
\hline 02 & FONSECA, A. D. G., et al. & $\begin{array}{l}\text { Fatores associados à } \\
\text { dependência entre idosos } \\
\text { com diabetes mellitus } \\
\text { tipo } 2 \text {. }\end{array}$ & $\begin{array}{l}\text { Identificar fatores } \\
\text { associados à dependência } \\
\text { entre idosos com Diabetes } \\
\text { Mellitus (DM) tipo } 2 \text {. }\end{array}$ & $\begin{array}{l}\text { Rev Bras Enferm [Internet]. } \\
\text { n. 71, (suppl 2), p. } 922-30 \text {, } \\
2018 .\end{array}$ \\
\hline 03 & RAMOS, R. S. P. S. et al. & $\begin{array}{l}\text { Fatores associados ao } \\
\text { diabetes em idosos } \\
\text { assistidos em serviço } \\
\text { ambulatorial } \\
\text { especializado } \\
\text { gerontogeriátrico. }\end{array}$ & $\begin{array}{l}\text { Identificar a prevalência de } \\
\text { diabetes e sua relação com } \\
\text { os fatores associados em } \\
\text { idosos assistidos em } \\
\text { serviço ambulatorial } \\
\text { especializado geronto- } \\
\text { geriátrico. }\end{array}$ & $\begin{array}{l}\text { Rev. Bras. Geriatr. Gerontol., } \\
\text { Rio de Janeiro, v. 20, n. 3, p. } \\
\text { 364-374, } 2017 .\end{array}$ \\
\hline 04 & SOUSA, E. L., et al. & $\begin{array}{l}\text { Qualidade de vida e } \\
\text { fatores associados à } \\
\text { saúde de idosos } \\
\text { diabéticos. }\end{array}$ & $\begin{array}{l}\text { Avaliar a qualidade de vida } \\
\text { de idosos acometidos por } \\
\text { diabetes mellitus tipo } 2 \text { e } \\
\text { identificar os fatores } \\
\text { associados. }\end{array}$ & $\begin{array}{l}\text { Rev enferm UERJ, Rio de } \\
\text { Janeiro, v. } 24 \text {, n. } 5 \text {, p. } 1-7 \text {, } \\
\text { e8456, } 2016 .\end{array}$ \\
\hline 05 & VITOI, N. C., et al. & $\begin{array}{l}\text { Prevalência e fatores } \\
\text { associados ao diabetes } \\
\text { em idosos no município } \\
\text { de Viçosa, Minas Gerais. }\end{array}$ & $\begin{array}{l}\text { Avaliar a prevalência e os } \\
\text { fatores associados ao } \\
\text { diabetes em idosos, bem } \\
\text { como verificar a } \\
\text { concordância entre o uso } \\
\text { de medicamentos para } \\
\text { diabetes e a informação } \\
\text { referida sobre a doença. }\end{array}$ & $\begin{array}{l}\text { REV BRAS EPIDEMIOL } \\
\text { OUTDEZ, v. 18, n. } 4 \text {, p. 953- } \\
965,2015 .\end{array}$ \\
\hline 06 & MENEZES, T. N. et al. & $\begin{array}{l}\text { Diabetes mellitus } \\
\text { referido e fatores } \\
\text { associados em idosos } \\
\text { residentes em Campina } \\
\text { Grande, Paraíba. }\end{array}$ & $\begin{array}{l}\text { Verificar a prevalência de } \\
\text { diabetes mellitus referido e } \\
\text { fatores associados em } \\
\text { idosos residentes em } \\
\text { Campina Grande-PB. }\end{array}$ & $\begin{array}{l}\text { Rev. Bras. Geriatr. Gerontol., } \\
\text { Rio de Janeiro, 2014. v. 17, } \\
\text { n. 4, p. 829-839, } 2014 .\end{array}$ \\
\hline 07 & MENDES, T. A. B., et al. & $\begin{array}{l}\text { Diabetes mellitus: fatores } \\
\text { associados à prevalência } \\
\text { em idosos, medidas e } \\
\text { práticas de controle e uso } \\
\text { dos serviços de saúde em } \\
\text { São Paulo. }\end{array}$ & $\begin{array}{l}\text { Avaliar a prevalência de } \\
\text { diabetes autorreferida em } \\
\text { idosos, o conhecimento que } \\
\text { estes têm sobre a doença e } \\
\text { os fatores relacionados à } \\
\text { mudança de } \\
\text { comportamento em relação } \\
\text { à prática de controle da } \\
\text { enfermidade e o uso dos } \\
\text { serviços por idosos } \\
\text { diabéticos. Brasil. }\end{array}$ & $\begin{array}{l}\text { Cad. Saúde Pública, Rio de } \\
\text { Janeiro, v. 27, n. 6, p. 1233- } \\
\text { 1243, jun., } 2011 .\end{array}$ \\
\hline 08 & MENEZES, M. C., et al. & $\begin{array}{l}\text { Fatores associados ao } \\
\text { diabetes Mellitus em } \\
\text { participantes do } \\
\text { Programa 'Academia da } \\
\text { Cidade' na Região Leste } \\
\text { do Município de Belo } \\
\text { Horizonte, Minas Gerais, } \\
\text { Brasil, } 2007 \text { e } 2008 .\end{array}$ & $\begin{array}{l}\text { Identificar fatores de risco } \\
\text { associados ao diabetes } \\
\text { Mellitus (DM) entre } \\
\text { usuários de serviço de } \\
\text { promoção da saúde. }\end{array}$ & $\begin{array}{l}\text { Epidemiol. Serv. Saúde, v. } \\
\text { 20, n. 4, p. 439-448. Brasília } \\
\text { dez.2011. }\end{array}$ \\
\hline 09 & MENEZES, M. C., et al. & $\begin{array}{l}\text { Fatores associados ao } \\
\text { diabetes Mellitus em } \\
\text { participantes do } \\
\text { Programa 'Academia da } \\
\text { Cidade' na Região Leste } \\
\text { do Município de Belo } \\
\text { Horizonte, Minas Gerais, } \\
\text { Brasil, } 2007 \text { e } 2008 .\end{array}$ & $\begin{array}{l}\text { Identificar fatores de risco } \\
\text { associados ao diabetes } \\
\text { Mellitus (DM) entre } \\
\text { usuários de serviço de } \\
\text { promoção da saúde. }\end{array}$ & $\begin{array}{l}\text { Epidemiol. Serv. Saúde, v. } \\
\text { 20, n. 4, p. 439-448. } \\
\text { Brasília dez. } 2011 .\end{array}$ \\
\hline
\end{tabular}

Fonte: Elaborado pelas autoras. 
Analisando os objetivos de cada uma das pesquisas elencadas verificou-se que nos últimos nove anos tem havido uma grande preocupação dos pesquisadores da temática em apreço em identificar (03), verificar (03) e avaliar (03), representando 33,3\% cada bloco de pesquisas, nos quais buscaram destacar os fatores associados ao Diabetes Mellitus na população idosa, visto que essa doença crônica tem atingido a grande maioria dos idosos no Mundo e no Brasil, a ponto da Organização Mundial de Saúde-OMS destacar que o Brasil se encontra na sexta posição. Dentre as pesquisas analisadas percebeu-se que será de fundamental importância que se oriente os idosos no que concerne aos fatores relacionados à mudança de comportamento em relação à prática de controle da enfermidade e o uso dos serviços de saúde por idosos diabéticos. Além de fazer uma concordância entre o uso de medicamentos para o diabetes e a informação referida sobre a doença uma vez que ela é uma doença crônica, a qual o idoso precisa conviver bem com ela para que possa usufruir de qualidade de vida.

\section{CONSIDERAÇÕES FINAIS}

Com a realização da pesquisa pode-se afirmar que os fatores que estão associados a doença são aqueles que estão relacionados com seus hábitos alimentares, sedentarismos, o não exercício de atividades físicas, dentre outros que são vilões na vida daqueles que não se dispõem há novos hábitos, os quais lhes proporcionaram uma longevidade com qualidade de vida.

\section{REFERÊNCIAS}

[1] BARDIN, L. Análise de conteúdo. Lisboa: Edições 70, 2015.

[2] CAMPOLINA, A. G.; DINI, P., S.; CICONELLI, R., M. Impacto da doença crônica na qualidade de vida de idosos da comunidade em São Paulo (SP, Brasil). Ciência \& Saúde Coletiva, v. 16, n. 6, p. 2919-2925, 2011. Disponível em: http://www.scielo.br/pdf/csc/v16n6/29.pdf. Acesso em: 19 out. 2017.

[3] CÂNDIDO, J. A. B. F. et al. FINDRISK: estratificação do risco para Diabetes Mellitus na saúde coletiva. Revista Brasileira em Promoção da Saúde, v. 30, n. 3, 2017. Disponível em:

https://periodicos.unifor.br/RBPS/article/view/6118. Acesso em: 18 out. 2017.

[4] CARolino, I. D. R. et al. Fatores de risco em pacientes com diabetes mellitus tipo 2. Rev Latinoam Enfermagem 2008 março-abril, v. 16, n. 6, www.eerp.usp.br/rlae p. 1-72, 2008. Disponível em: http://www.scielo.br/pdf/rlae/v16n2/pt_11.pdf. Acesso em: 19 out. 2017.

[5] DUARTE, R. et al. Recomendações Nacionais da SPD para o Tratamento da Hiperglicemia na Diabetes Tipo 2 (com base na Posição Conjunta ADA/EASD). Revista Portuguesa de Diabetes, v. 8, n. 1, p. 4-29, 2013. Disponível em: www2.spd.pt:8080/wp.../gui_spd_terapeutica_diabetes_tipo2_actualizacao_40-48.pdf. Acesso em: 19 out. 2017.

[6] FERREIRA, L. V. et al. Busca do autocuidado por idosos na rede de Atenção à Saúde. Revista Contexto \& Saúde, v. 17, n. 32, p. 46-54, 2017. Disponível em:

https://www.revistas.unijui.edu.br/index.php/contextoesaude/article/view/5984. Acesso em: 19 out. 2018.

[7] FONSECA, A. D. G. et al. Fatores associados à dependência entre idosos com diabetes mellitus tipo 2. Rev Bras Enferm [Internet]. n. 71, (suppl 2), p. 922-30, 2018. Disponível em: http://www.scielo.br/pdf/reben/v71s2/pt_00347167-reben-71-s2-0868.pdf. Acesso em 10 mar. 2019.

[8] GALVÃO, T. F.; PEREIRA, M. G. Revisões sistemáticas da literatura: passos para sua elaboração. Epidemiol. Serv. Saúde, Brasília, v. 23, n. 1, p. 183-184, jan-mar 2014. Disponível em: http://www.scielo.br/pdf/ress/v23n1/2237-9622-ress-23-01-00183.pdf. Acesso em: 26 abr. 2019.

[9] GARCIA, L. R. S. et al. Conhecimento sobre diabetes mellitus entre profissionais da rede pública de ensino. Revista Brasileira em Promoção da Saúde, v. 30, n. 1, 2017. Disponível em: https://periodicos.unifor.br/RBPS/article/view/5455. Acesso em: 19 out. 2017.

[10] GERHARDT, T. A.; SILVEIRA, D. T. Metodologia de Pesquisa. Disponível em: https://books.google.com.br/books?hl=ptBR\&lr=\&id=dRuzRyEIzmkC\&oi=fnd\&pg=PA9\&dq=pesqui sa+explorat\%C3\%B3ria+pdf\&ots=92Q6XjvLJ\&sig=0z26yZfwnvU90KvwLMJcJnSxi5M\#v=onepage \&q\&f=false. Acesso em: 20 mar. 2018.

[11] GIL, A. C. Como elaborar projetos de pesquisa. 4. ed. São Paulo: Atlas, 2008. Disponível em: https://wp.ufpel.edu.br/ecb/files/2009/09/Tipos-de-Pesquisa.pdf. Acesso em: 13 out. 2018.

[12] GOULART, F.A. A. Doenças crônicas não transmissíveis: estratégias de controle e desafios para os sistemas de saúde. Brasília: OPAS; 2011. 
[13] LIMA, A. A. et al. O cuidado e o autocuidado de clientes com diabetes e seus familiares: uso e administração de insulina na Estratégia da Saúde da Família. 2016. Disponível em: https://repositorio.ufsc.br/handle/123456789/168874. Acesso em: 16 out. 2018.

[14] MEDEIROS, J. et al. D. Aplicabilidade de hidroginástica e musculação em pessoas idosas da comunidade. Revista Interfaces: Saúde, Humanas e Tecnologia, v. 2, n. 6, 2014. Disponível em: http://interfaces.leaosampaio.edu.br/index.php/revista-interfaces/article/view/132/113. Acesso em: 19 out. 2018.

[15] MENDES, T. A. B. et al. Diabetes mellitus: fatores associados à prevalência em idosos, medidas e práticas de controle e uso dos serviços de saúde em São Paulo, Brasil. Cad. Saúde Pública, Rio de Janeiro, v. 27, n. 6, p. 1233-1243, jun, 2011. Disponível em: https://www.scielosp.org/pdf/csp/2011.v27n6/1233-1243/pt. Acesso em: 10 abr. 2019.

[16] MENDES, K. D. S.; SILVEIRA, R. C. C. P.; GALVÃO, C. M. Revisão Integrativa: método de pesquisa para a incorporação de evidências na saúde e na enfermagem. Texto Contexto Enferm, Florianópolis, Out-Dez; v. 17, n. 4, p. 758-64, 2008. Disponível em: http://www.scielo.br/pdf/tce/v17n4/18.pdf. Acesso em: 08 maio 2019.

[17] MENEZES, T. N. et al. Diabetes mellitus referido e fatores associados em idosos residentes em Campina Grande, Paraíba. Rev. Bras. Geriatr. Gerontol., Rio de Janeiro, 2014; V. 17, n. 4, p. 829-839, 2014. Disponível em: http://www.scielo.br/pdf/rbgg/v17n4/1809-9823-rbgg-17-04-00829.pdf. Acesso em 10 abr. 2019.

[18] MENEZES, M. C., et al. Fatores associados ao diabetes Mellitus em participantes do Programa 'Academia da Cidade' na Região Leste do Município de Belo Horizonte, Minas Gerais, Brasil, 2007 e 2008. Epidemiol. Serv. Saúde, v. 20, n. 4, p. 439-448. Brasília dez. 2011. http://dx.doi.org/10.5123/S1679-49742011000400003. Disponível em: http://scielo.iec.gov.br/scielo.php?script=sci_arttext\&pid=S1679-49742011000400003. Acesso em 10 mar. 2019.

[19] MENEZES, T. N.; OLIVEIRA, E. C. T. Validade e concordância do diabetes mellitus referido em idosos. Ciência \& Saúde Coletiva, v. 24, n. 1, p.27-34, 2019. Disponível em: https://www.scielosp.org/pdf/csc/2019.v24n1/27-34/pt. Acesso em 10 abr. 2019.

[20] MENEZES, T. N., et al. Diabetes mellitus referido e fatores associados em idosos residentes em Campina Grande, Paraíba. Rev. Bras. Geriatr. Gerontol., Rio de Janeiro, v. 17, n. 4, p. 829-839, 2014. Disponível em: http://www.scielo.br/pdf/rbgg/v17n4/1809-9823-rbgg-17-04-00829.pdf. Acesso em 10 abr. 2019.

[21] MINAYO, M. C. S. (Org.). Pesquisa Social: teoria, método e criatividade. 22. ed. Rio de Janeiro: Vozes, 2003.

[22] MOREIRA, W. Revisão de Literatura e Desenvolvimento Científico: conceitos e estratégias para confecção. Janus, Lorena, ano 1, nำ 1, 2osestre de 2004. Disponível em:

https://portais.ufg.br/up/19/o/Revis_o_de_Literatura_e_desenvolvimento_cient_fico.pdf. Acesso em: 08 out. 2018.

[23] NORONHA, D. P.; FERREIRA, S. M. S. P. Revisões de literatura. In: CAMPELLO, Bernadete Santos; CONDÓN, Beatriz Valadares; KREMER, Jeannette Marguerite (orgs.) Fontes de informação para pesquisadores e profissionais. Belo Horizonte: UFMG, 2000.

[24] OLIVEIRA, B.; CONCONE, M. H. V. B.; SOUZA, S. R. P. A Enfermagem dá o tom no atendimento humanizado aos idosos institucionalizados? Kairós. Revista da Faculdade de Ciências Humanas e Saúde. ISSN 2176-901X, v. 19, n. 1, p. 239-254, 2016. https://revistas.pucsp.br/index.php/kairos/article/view/31112. Acesso em: 19 out. 2017.

[25] OMS, World Health Organization. Surveillance of risk factors for noncommunicable diseases: the WHO step wise approach. Geneva: World Health Organization; 2001.

[26] RAMOS, R. S. P. S. Diabetes e fatores associados em idosos assistidos em serviço geronto-geriátrico. RecifePE: UFPE, 2012. 112f. Dissertação (Mestrado em Enfermagem) - Programa de Pós- Graduação em Enfermagem, Universidade Federal de Pernambuco, Recife-PE, 2012.

[27] RAMOS, R. S. P. S. et al. Fatores associados ao diabetes em idosos assistidos em serviço ambulatorial especializado geronto-geriátrico. Rev. Bras. Geriatr. Gerontol., Rio de Janeiro, v. 20, n. 3, p. 364- 374, 2017. Disponível em: http://www.scielo.br/pdf/rbgg/v20n3/pt_1809-9823-rbgg-20-03-00363.pdf. Acesso em 10 abr. 2019.

[28] ROCHA, K. B. et al. A visita domiciliar no contexto da saúde: uma revisão de literatura. Psicologia, Saúde e Doenças, v. 18, n. 1, p. 170-185, 2017. Disponível em:

www.scielo.mec.pt/scielo.php?script=sci_arttext\&pid...00862017000100015. Acesso em: 19 out. 2017.

[29] ROTHER, Edna Terezinha. Revisão sistemática X revisão narrativa. Acta paul. Enferm; v. 20, n. 2, p. v-vi, 2007. Disponível em: http://www.scielo.br/pdf/ape/v20n2/a01v20n2.pdf. Acesso em: 08 out. 2018.

[30] SANTOS, B. E.; KOETZ, L. C. E. O Perfil Sócioepidemiológico e a Auto percepção dos Cuidadores Familiares sobre a Relação Interpessoal e o Cuidado com Idosos. Revista Acreditação: ACRED, v. 7, n. 13, p. 115-132, 2017. Disponível em: https://dialnet.unirioja.es/descarga/articulo/6130788.pdf. Acesso em: 19 out. 2017.

[31] SILVA, A. S.; BRANDÃO, E. S. P.; LIMA, L. R. Assistência farmacêutica ao paciente idoso portador de doenças crônicas e arterial sistêmica. Mostra Científica da Farmácia, v. 3, n. 1, 2017. Disponível em: publicacoesacademicas.unicatolicaquixada.edu.br/.../mostracientificafarmacia/.../1214. Acesso em: 19 out. 2017. 
[32] SILVA, Edna Lúcia da: MENEZES, Estera Muszkat. Metodologia da pesquisa e elaboração de dissertação. 3. ed. Florianópolis: Laboratório de Ensino a Distância da UFSC, 2001. Disponível em: http://cursos.unipampa.edu.br/cursos/ppgcb/files/2011/03/Metodologia-da-Pesquisa-3a-edicao.pdf. Acesso em: 05 jun. 2019.

[33] SOUSA, E. L., et al. Qualidade de vida e fatores associados à saúde de idosos diabéticos. Rev enferm UERJ, Rio de Janeiro, v. 24, n. 5, p. 1-7, e8456, 2016. Disponível em: http://www.facenf.uerj.br/v24n5/v24n5a02.pdf. Acesso em 10 mar. 2019.

[34] SOUZA, E. C. S. et al. Avaliação da qualidade de vida de portadores de diabetes utilizando a medida específica B-PAID. Revista Mineira de Enfermagem, Viçosa, v. 16, n. 4, p. 509-514, 2012. Disponível em: http://www.reme.org.br/artigo/detalhes/555. Acesso em: 19 out. 2017.

[35] VITOI, N. C., et al. Prevalência e fatores associados ao diabetes em idosos no município de Viçosa, Minas Gerais. REV BRAS EPIDEMIOL OUT-DEZ, v. 18, n. 4, p. 953-965, 2015. Disponível em: https://www.scielosp.org/article/ssm/content/raw/?resource_ssm_path=/media/assets/rbepid/v18n4/19 805497-rbepid-18-04-00953.pdf. Acesso em 10 mar. 2019. 


\title{
Capítulo 10
}

\section{O latente atrativo gastronômico em Pernambuco para o turista idoso}

\author{
Lucas Henrique de Barros Portela Campelo \\ Ívina Albuquerque da Silva \\ Maria do Rosário de Fátima Padilha \\ Neide Kazue Sakugawa Shinohara
}

Resumo: 0 maior número de turistas que circulam no estado de Pernambuco, ainda se restringe ao público oriundo do próprio estado ou de estados vizinhos. Sabe-se ainda que $23,5 \%$ dos turistas internacionais que escolheram o Brasil como destino em 2017, são indivíduos com idades superiores a 51 anos. Turistas com idades mais avançadas são capazes de reduzir a sazonalidade de atividades turísticas. A gastronomia, por sua vez, constitui um dos importantes aparelhos turísticos para o público idoso. Diante da representatividade gastronômica de Pernambuco, buscou-se verificar se as iguarias locais poderiam constituir um atrativo turístico para os turistas idosos. Para tanto, foram necessários acessos em plataformas de dados de entidades públicas e privadas ligadas direta ou indiretamente ao turismo no Mundo, no Brasil e em Pernambuco. Os descritores utilizados foram: "índice de competitividade do turismo", "inventário turístico", "anuário de estatística", "destino turístico", "emissores", "demanda turística”, "segmentação do turismo", "perfil do turista", "idoso", "terceira idade”, "gastronomia”, "polo gastronômico", "patrimônio", "patrimônio imaterial", "Pernambuco", "Recife". Foi observado que Pernambuco é um destino turístico em potencial no Brasil, capaz de atrair turistas idosos nacionais e internacionais. A gastronomia pode contribuir significativamente para estimular viajantes idosos a escolherem o estado de Pernambuco como destino turístico, devido ao ótimo acervo de possibilidades gustativas e a predisposição inata do grupo em aproveitar a riqueza cultural pernambucana de influências portuguesa, judaica, holandesa, indígena e africana. Todavia, órgãos governamentais devem investir fortemente em acessibilidade e segurança, para que os turistas idosos tenham uma boa vivência em terras pernambucanas.

Palavras-chave: gastronomia, iguarias, Pernambuco, turista idoso, turismo sênior. 


\section{INTRODUÇÃO}

Apesar de Pernambuco dispor de fortes tradições culturais, vasta culinária e uma beleza natural peculiar, o turismo no estado responde por apenas $4 \%$ do Produto Interno Bruto Brasileiro, demonstrando possuir ainda certa carência de investimentos em algumas regiões. (JATOBÁ, 2019). Segundo pesquisa do Fundo de Populações da Organização das Nações Unidas (ONU), o número de idosos no mundo representa um percentual de $12 \%$ da população total, com estimativas de que tal percentual chegue a $22 \%$ até o ano de 2050. Nesse sentido, o setor de turismo para a terceira idade tem se profissionalizado para atender às necessidades e aos cuidados de que os mais experientes necessitam. Devido a isso, o negócio de turismo para a terceira idade tem se tornado cada vez mais promissor, com estimativas de crescimento acentuadas. Atentos à realidade do mercado, os prestadores de serviço têm moldado as propostas turísticas e a gastronomia às necessidades desses clientes especiais (CORREIO BRAZILIENSE, 2017).

No tocante às possibilidades turísticas ofertadas no estado, Pernambuco detém um importante acervo histórico-cultural com influências portuguesa, judaica e holandesa, pelo menos 82 bens tombados e uma gama de delícias regionais que retratam toda a potencialidade da gastronomia local (JAROCKI; CARVALHO, 2009). Mesmo diante da vastidão de opções turísticas disponíveis, as iguarias locais sempre estarão à disposição dos viajantes, podendo conferir memórias gustativas agregadoras das culturas regionais nas quais estão inseridas (PECCINI, 2013). Diante da expressividade e da importância da gastronomia pernambucana, buscou-se verificar se as iguarias locais poderiam constituir um atrativo turístico para os turistas idosos. Após analisar os dados disponíveis entre os anos de 2009 a 2019 nos sites do Ministério do Turismo (MTUR), Confederação Nacional de Turismo (CNTUR), Empresa de Turismo de Pernambuco (EMPETUR), Agência Estadual de Planejamento e Pesquisa de Pernambuco (CONDEPE/FINDEM), Fundação Joaquim Nabuco (FUNDAJ), Serviço Brasileiro de Apoio a Micro e Pequena Empresa (SEBRAE) e a Associação Brasileira de Bares e Restaurantes (ABRASEL), foi possível inferir que a gastronomia pernambucana pode contribuir significativamente para estimular viajantes idosos a escolherem o estado de Pernambuco como destino turístico (GUSMÃo et al., 2018; BRASIL, 2018; EMPETUR, 2017; GASPAR, 2009). Entretanto, órgãos governamentais competentes devem investir massivamente em acessibilidade e em segurança pública para assegurarem que o turista idoso tenha mais conforto e boas experiências ao viajar para Pernambuco (NOVA, 2014).

\section{METODOLOGIA}

Os dados utilizados neste trabalho foram prioritariamente extraídos de órgãos oficiais de caráter público como o Ministério do Turismo (MTUR), Confederação Nacional de Turismo (CNTUR), Empresa de Turismo de Pernambuco (EMPETUR), Agência Estadual de Planejamento e Pesquisa de Pernambuco (CONDEPE/FINDEM), Fundação Joaquim Nabuco (FUNDAJ). Para agregar conhecimentos, foi necessário utilizar dados de importantes instituições de caráter privado como o Serviço Brasileiro de Apoio a Micro e Pequena Empresa (SEBRAE) e a Associação Brasileira de Bares e Restaurantes (ABRASEL). Além desses órgãos públicos e privados, periódicos foram selecionados para a complementação acadêmica das informações necessárias. Os descritores utilizados na pesquisa foram: "índice de competitividade do turismo", "inventário turístico", "anuário de estatística", "destino turístico", "emissores", "demanda turística", "segmentação do turismo", "perfil do turista", "idoso", "terceira idade", "gastronomia", "polo gastronômico", "patrimônio", "patrimônio imaterial", "Pernambuco", "Recife". Os anos de delimitação das informações foram de 2009 a 2019.

\section{DESENVOLVIMENTO}

As populações contemporâneas vivenciam um aumento no número de indivíduos com idade superior a 65 anos cujo índice global pode atingir até 1,5 bilhão de pessoas idosas até o ano de 2050 (WHO, 2011). Essa nova composição etária mundial constitui um mercado consumidor em potencial para muitos segmentos econômicos, sobretudo os da indústria do turismo. Visando atingir o público de idade mais avançada, o setor turístico tem se mobilizado para desenvolver estratégias competitivas de negócios utilizando ferramentas de marketing para estimular a mobilização deste perfil de viajante (KIM et al., 2015), tendo em vista que os turistas idosos são capazes de reduzir a sazonalidade de atividades turísticas em períodos de baixa estação, pois possuem maior tempo disponível e possuem obrigações profissionais e familiares flexíveis. Ao viajar, o idoso busca estabelecer novos convívios sociais, reciclar a mente e adquirir trocas de experiências. Desta forma, os tipos de turismo que mais satisfazem os intentos desse potencial grupo são: o cultural, o religioso, o gastronômico, o rural, o ecoturismo e o de saúde (MARQUES 2018). 
Independente do tipo de turismo escolhido, a gastronomia sempre se fará presente e necessária, atuando como fomentadora cultural do fenômeno turístico (KRAUSE \& BAHLS, 2016). 0 turismo gastronômico caracteriza-se quando a gastronomia constitui a principal motivação da viagem. Geralmente a culinária do destino costuma participar como coadjuvante no turismo, podendo vir a ser o principal atrativo em alguns casos, visto que a gastronomia reforça a identidade cultural do cenário turístico elegido (BARBOSA, 2016).

A arte da cozinha brasileira reúne saberes, sabores e técnicas de preparo que figuram uma memória gustativa agregadora das culturas regionais, integrando fundamentalmente com o conjunto do qual faz parte. Quando um turista consome um acarajé, está também criando vínculos com os baianos e com seu jeito autêntico de ser brasileiro (PECCINI, 2013). Ao optar por um destino turístico no país, contribui, assim, com a movimentação da economia de redes hoteleiras e restaurantes (GUSMÃO et al., 2018).

Diante do importante complexo de iguarias regionais de influências europeias, africanas e indígenas elaboradas ao longo da história brasileira, entendem-se as constantes preocupações a respeito da preservação dos patrimônios gastronômicos, vistos como uma herança da expressão cultural identitária do nosso povo (PECCINI, 2013).

\section{RESULTADOS E DISCUSSÃO}

O litoral pernambucano, assim como várias praias do Nordeste brasileiro, é fruto da transformação do espaço impulsionado pela acentuada movimentação turística, sendo o litoral sul de Pernambuco o maior captador de investimentos relacionado ao turismo por acomodar o maior número de visitantes (CARVALHO, 2009). As perspectivas de crescimento para o setor durante os próximos anos são favoráveis, muito disso, decorrente da contribuição turística dos idosos. Segundo dados do Ministério do Turismo (Mtur), o desejo de viajar aumentou de 23,7\% para 26,9\% em grupos de viajantes com idade superior a 60 anos (CORREIO BRASILIENSE, 2017). Tal crescimento pode, inclusive, contemplar destinos pernambucanos mais situados ao interior do estado, como Gravatá, Triunfo, Garanhuns (regiões serranas), Caruaru (possuidor da maior feira livre do Brasil e maior centro de artes figurativas da América, segundo a UNESCO) e Petrolina (produção de vinhos no Vale do São Francisco). Atualmente, essas cidades interioranas têm despertado o interesse de visitantes situados na Região Metropolitana do Recife ou em cidades circunvizinhas (CARVALHO, 2009). Como a cidade do Recife é o porta de entrada, por possuir o aeroporto que recebe turistas de todas as regiões brasileiras e escala de diversas empresas da aviação internacional, para se conhecer o Estado de Pernambuco é interessante que haja esforços para captar também os turistas internacionais a fim de que conheçam as cidades situadas fora do litoral e gerem renda para esses mesmos destinos.

De acordo com o Ministério do Turismo, em 2017, o turista internacional idoso que escolheu Pernambuco como destino correspondeu a 9,6\% do total de turistas internacionais, o equivalente a 7.513 indivíduos com mais de 60 anos (BRASIL, 2018). Quanto ao turismo doméstico, não se conhece de forma exata essa porcentagem. De acordo com dados oficiais, sabe-se que o turismo de Pernambuco é composto em sua maioria por turistas do próprio estado (60,6\%), seguidos dos estados emissores: São Paulo (11\%), Bahia (5,9\%), Paraíba (4,5\%), Alagoas (3,5\%), Rio de Janeiro (2,4\%) Ceará $(2,2 \%)$, Sergipe $(2,1 \%)$, Distrito Federal $(1,0 \%)$ e outros estados (4,9\%) (BRASIL, 2009). Um estudo da Confederação Nacional de Turismo (CNTUR) em parceria com o Serviço Brasileiro de Apoio a Micro e Pequenas Empresa (SEBRAE) traçou o perfil do turista brasileiro no qual foi percebido que os transeuntes com mais de 55 anos avaliaram como os principais pontos positivos do Nordeste as belas praias e a hospitalidade dos nordestinos (CNTUR; SEBRAE, 2012). Esse mesmo estudo ainda esboça que esse grupo sabe da importância de viajar para a qualidade de vida e estão abertos a experiências e interações que os destinos têm a oferecer. É nesse quesito de viver experiências locais que Pernambuco apresenta grande potencial para impulsionar o setor gastronômico, o que pode tornar o destino turístico mais agradável e até mesmo ser o principal motivo de sua viagem, pois, de acordo com o Ministério do Turismo, 95,5\% dos turistas internacionais avaliaram positivamente a culinária do Estado (BRASIL, 2018).

No Anuário Estatístico de Pernambuco, no ano de 2016, há dados sobre os principais atrativos das cidades litorâneas no que diz respeito à gastronomia em três municípios: no litoral sul o destaque é para Ipojuca; no litoral norte, Itapissuma; e na Região Metropolitana do Recife, Olinda (PERNAMBUCO, 2016). Entretanto a gastronomia de Pernambuco não se restringe apenas ao litoral. Numa análise feita através do Inventário Turístico (INVTUR) de Pernambuco, refinados pelas categorias A, B e C do Mapa do Turismo do Brasil, dos 76 municípios com vocação turística no estado, 22 são pertencentes a essas 3 categorias (BRASIL, 2017) e foi o critério de seleção para a análise da gastronomia típica do estado. Estas são informações que colaboram na tomada de decisões e criam expectativas no turista nacional e estrangeiro, 
no trade turístico e na aparelhagem de cultura local, tendo potencial para servir de rota ou roteiro de Pernambuco.

A categorização desses municípios foi feita pelo Ministério do Turismo baseada em dados extraídos do Instituto Brasileiro de Geografia e Estatística, do Ministério do Turismo e do Ministério do Trabalho e Emprego, portanto só foram contabilizadas as informações regularizadas. As variáveis selecionadas por questões de maior proximidade com a realidade foram: Quantidade de Estabelecimento de Hospedagem, Quantidade de Empregos em Estabelecimentos de Hospedagem, Quantidade Estimada de Visitantes Domésticos e Quantidade Estimada de Visitantes Internacionais. A categorização é um instrumento importante para entender quais são os maiores destinos procurados pelo fluxo de turistas internacionais e nacionais através do preenchimento de leitos da rede de hospedagem do local e ascende de $\mathrm{E}$ à A. Outra característica importante é como o fluxo das categorias A respingam nas categorias $\mathrm{B}$, a $\mathrm{B}$ na $\mathrm{C}$ e assim sucessivamente (BRASIL, 2018).

Os municípios representantes de Pernambuco no Mapa do Turismo Brasileiro pertencem a categoria A e C e 10 estão presentes no Litoral: Ipojuca (A), Recife (A), Cabo de Santo Agostinho (B), Fernando de Noronha (B), Jaboatão dos Guararapes (B) Olinda (B), São José da Coroa Grande (B) Tamandaré (B), Goiana (C), Ilha de Itamaracá (C), e Paulista (C); 9 no Agreste: Arcoverde (B), Caruaru (B), Gravatá (B), Belo Jardim (C), Bezerros (C), Bonito (C), Pesqueira (C), Santa Cruz do Capibaribe e Toritama (C); e 4 no Sertão: Petrolina (B), Serra Talhada (B), Afogados da Ingazeira (C) e Triunfo (C) (BRASIL, 2019).

A título de rota ou roteiro é interessante atentar ao Mapa do Turismo anterior (2017 a 2019), pois houve algumas mudanças: Garanhuns, Araripina, Ouricuri e Salgueiro saíram do mapa; Jaboatão dos Guararapes, São José da Coroa Grande, Paulista, Arcoverde, Bezerros, Santa Cruz do Capibaribe e Toritama subiram uma categoria. Entretanto, é necessário deixar claro que sair ou entrar no mapa do turismo, assim como subir de categoria, são como o Ministério do Turismo ordena suas prioridades de investimento no setor. 0 que não causa tanto impacto na hora de decidir se vale a pena incluir, por exemplo, Garanhuns ao seu roteiro, já que é nesse destino que é realizado, segundo a Secretária de Cultura de Pernambuco e a Fundação do Patrimônio Artístico de Pernambuco, o maior festival de cultura do Brasil: Festival de Inverno de Garanhuns (PERNAMBUCO, 2019). Esse festival é muito importante para o serviço de alimentação, pois de acordo com a prefeitura de Garanhuns houve um aumento de $60 \%$ no movimento da rede alimentícia (GARANHUNS, 2019).

Tendo os números aproximados de município por sub-região do estado, permitiu-se fazer uma análise gastronômica a nível estadual. As cidades litorâneas evidentemente oferecerem um cardápio com grande variedade de peixes e de frutos do mar. Os principais ingredientes são Agulha, Camarão, Lagosta, Polvo, Ouriço, Aratu, Sardinha, Siri, Sururu e Ostra. À medida que o destino vai se interiorizando (Agreste e Sertão) os ingredientes que não faltam nos cardápios são carne de bode (assada, guisada, buchada e sarapatel), carne de boi (charque, carne de sol, chambaril/pirão e mão de vaca), queijo coalho, galinha (de capoeira e cabidela), carne de porco, tilápia, surubim, milho (cuscuz, xerém, canjica, pamonha, munguzá doce e salgado), raizadas (cachaças envelhecida na garrafa com partes de plantas dentro) e doces de Umbu, Caju, Piqui e cana-de-açúcar (EMPETUR, 2017). Além desses ingredientes principais identificados na gastronomia pernambucana, a Assembleia Legislativa do Estado confere os títulos de patrimônio imaterial de Pernambuco a alguns itens gastronômicos como é o caso do Bolo Souza Leão, Bolo de Rolo, Cartola, Tapioca e Cachaça (GASPAR, 2009). FAZER TABELA COM OS PRINCIPAIS ATRATIVOS SEGUNDO 0 INVTUR.

De acordo com a Associação Brasileira de Bares e Restaurantes (ABRASEL):

Recife também pode ser considerado o maior polo gastronômico do Norte e do Nordeste, com opções que vão desde mercados públicos a restaurantes sofisticados, desde a típica tapioca a pratos da mais alta gastronomia (ABRASEL, 2019).

Assim sendo, Pernambuco não só oferece aos turistas serviços de alimentação típica como também uma grande diversidade de opções de outros tipos de cozinha. Com essa variedade gastronômica, boa avaliação internacional da gastronomia, fluxo de turistas idosos internacionais, emissores de turistas domésticos, vontade do turista idoso em experimentar o local em sua totalidade, o sentimento de beleza natural pelas praias e bom acolhimento dos nordestinos para com os turistas acima de 55 anos, fica evidente que Pernambuco é um destino turístico que pode ser escolhido pela oferta de uma rica experiência gastronômica para o público idoso e ainda contribuir para a interiorização do turismo no Estado devido à quantidade de municípios (13) presentes no Agreste e no Sertão. Ademais, a valorização de ingredientes típicos é um dos seis destaques dentro da variável "capacidade dos restaurantes", na dimensão "serviços e 
equipamentos turísticos" e do índice de Competitividade do Turismo Nacional. Esse índice é um importante documento para a gestão do turismo e é definido através de 13 dimensões, na qual cada dimensão possui entre 3 a 7 variáveis. Os resultados são agrupados por pontuações em cinco níveis e Recife pontuou o suficiente para ser um dos oito destinos, dos 65 estudados, que fazem parte do nível máximo na dimensão de "serviços turísticos" (BRASIL, 2015). Por fim, outra ação que pode ser feita para atrair o turista idoso doméstico ou internacional por meio da culinária local é fazer propagandas gastronômicas para esse público nos principais emissores de turistas nacionais e internacionais.

A Constituição Federal Brasileira de 1988 buscou dar dignidade às pessoas, reduzindo as desigualdades sociais e assegurando o tratamento isonômico a cada indivíduo, valorizando as capacidades individuais e garantindo o acesso à cidadania. 0 legislador utilizou suas prerrogativas para a criação de um precioso conjunto de normas que possibilitasse, dentre outros casos, que o cidadão idoso possuísse condições mínimas de participação influente na vida ativa da sociedade brasileira, para assegurar que todos (as) possuam sentimento de pertencimento também nas atividades culturais, de lazer e conveniência, através de ajustes materiais e de recursos humanos às necessidades desse grupo especial (VILA NOVA, 2014). Diante disso, é imprescindível que órgãos governamentais invistam com responsabilidade em acessibilidade e segurança pública, para que os turistas idosos tenham uma boa vivência em terras pernambucanas.

\section{CONSIDERAÇÕES FINAIS}

Pernambuco é um dos principais destinos turístico do nordeste brasileiro, atraindo tanto turistas nacionais quanto turistas internacionais. Dentre os principais atrativos ofertados no estado, a gastronomia contribui de forma significativa devido ao ótimo acervo de possibilidades de sabores, cores e tradições. Sabe-se que uma parcela desses turistas são pessoas idosas com independência financeira e que a tendência mundial é que esse grupo cresça cada vez mais. Assim, muitos deles podem ser turistas em potencial, com boas perspectivas de retorno. Por se tratar de uma atividade extremamente competitiva no mundo globalizado, é imprescindível que os órgãos públicos estejam atentos às necessidades do turista idoso para que o potencial gastronômico do estado possa ser aproveitado ao máximo e possa gerar emprego, renda e qualidade de vida aos envolvidos com a atividade turística. Todavia, Pernambuco necessita se preparar para recepcionar adequadamente esse perfil de turista, já que o número de visitantes de idades mais avançadas tende a ser maior ao longo dos anos, por causa do aumento de expectativa de vida global. Questões como acessibilidade, inclusão, segurança e qualidade dos serviços ofertados são itens indispensáveis, exigidos em normas e acordos internacionais, para que turistas idosos tenham uma boa vivência no destino e possa desfrutar com segurança, para assim retornar com sentimento de saudade.

\section{REFERÊNCIAS}

[1] ABRASEL, ASSOCIAÇÃO BRASILEIRA DE BARES E RESTAURANTES. Guia Abrasel. Disponível em: <http://guia.abrasel.com.br/guiaabrasel/guiaabrasel.php>. Acesso em: 20 mai. 2019.

[2] ABRASEL, ASSOCIAÇÃO BRASILEIRA DE BARES E RESTAURANTES. Pernambuco. Disponível em: < https://pe.abrasel.com.br/noticias/noticias/abrasel-lanca-guia-com-bares-e-restaurantes-de-pernambuco/>. Acesso em: 20 mai. 2019.

[3] BARBOSA, J. 0 turismo cultural e gastronômico para o fortalecimento da identidade e competitividade dos destinos. Entrevista Jordi Tresserras. Caderno Virtual de Turismo, v. 16, n. 2, 2016.

[4] BRASIL, MINISTÉRIO DO TURISMO. Caracterização e Dimensionamento do Turismo Doméstico no Brasil, 2009. Disponível em: <http://www.dadosefatos.turismo.gov.br/2016-02-04-11-54-03/demanda-tur\%C3\%ADsticanacional/item/download/445_fd511d7fc060b614d3d946f693689c77.html> . Acesso em: 30 mai. 2019.

[5] BRASIL, MINISTÉRIO DO TURISMO. Estudo da Demanda Turística Internacional, Fichas Sínteses 20132017, 2018. Disponível em: <http://www.dadosefatos.turismo.gov.br/2016-02-04-11-54-03/demandatur\%C3\%ADstica-internacional.html>. Acesso em: 29 mai. 2019.

[6] BRASIL, MINISTÉRIO DO TURISMO. Índice de competitividade do turismo nacional: relatório Brasil 2015, Brasília, DF, 2015. Disponível

em:<http://www.turismo.gov.br/sites/default/turismo/o_ministerio/publicacoes/downloads_publicacoes/Relatorio _Brasil_2015_WEB.pdf>. Acesso em: 20 mai. 2019.

[7] BRASIL, MINISTÉRIO DO TURISMO. Índice de competitividade do turismo nacional: Recife, 2015. Disponível em: 
<http://www.turismo.gov.br/sites/default/turismo/o_ministerio/publicacoes/Indice_competitividade/2015/Recife_ RA_2015.pdf>. Acesso em: 20 mai. 2019.

[8] BRASIL, MNISTÉRIO DO TURISMO. Mapa do Turismo, 2017. Disponível em:

<http://www.mapa.turismo.gov.br/mapa/init.html\#/home>. Acesso em: 28 mai. 2019.

[9] BRASIL, MINISTÉRIO DO TURISMO. Programa de Regionalização do Turismo, 2018. Disponível em: <http://regionalizacao.turismo.gov.br/images/pdf/PerguntasRespostasCategorizacao2018.pdf>. Acesso em: 29 mai. 2019.

[10] CARVALHO, Adriana Garcia de. Turismo e produção do espaço no litoral de Pernambuco. 2009. Tese de Doutorado. Universidade de São Paulo.

[11] BRASILIENSE, C. Ganhar o mundo depois dos 60: turismo para terceira idade cresce no Brasil. Jornal diário de Pernambuco. 2017. Disponível em

< https://www.diariodepernambuco.com.br/app/noticia/economia/2017/08/09/internas_economia,716983/ganha r-o-mundo-depois-dos-60-turismo-para-terceira-idade-cresce-no-br.shtml> Acesso em 17 abril de 2019.

[12] CNTUR - CONFEDERAÇ̃̃O NACIONAL DE TURISMO; SEBRAE - SERVIÇO BRASILEIRO DE APOIA A MICRO E PEQUENA EMPRESA, Pesquisa: Perfil do Turista e Segmentos de Oferta, 2012. Disponível em:

< http://www.sebrae.com.br/sites/PortalSebrae/bis/pesquisa-o-perfil-do-turista-e-dos-segmentos-deoferta,ce6836627a963410VgnVCM1000003b74010aRCRD>. Acesso em: 30 mai. 2019.

[13] CORREIO BRAZILIENSE. In : DIARIO DE PERNAMBUCO Ganhar o mundo depois dos 60: turismo para terceira idade cresce no Brasil: Setores dedicados ao turismo para maior idade crescem a cada ano e se aprimoram na oferta de serviço para um público especial que exige cuidado e segurança. Disponível em

: https://www.diariodepernambuco.com.br/app/noticia/economia/2017/08/09/internas_economia,716983/ganhar -o-mundo-depois-dos-60-turismo-para-terceira-idade-cresce-no-br.shtml. Acesso: 07.06.2019

[14] EMPETUR - EMPRESA DE TURISMO DE PERNAMBUCO. Inventário Turístico de Pernambuco - INVTURPE, 2017. Disponível em: <https://inventariope.blogspot.com>. Acesso em: 28 mai. 2019.

[15] GARANHUNS. Festival de Inverno de Garanhuns, 2019. Disponívem em: <https://garanhuns.pe.gov.br/29festival-de-inverno-de-garanhuns-aponta-bons-resultados-na-movimentacao-economica/>. Acesso em: 16 set. 2019.

[16] GASPAR, L. Patrimônio imaterial de Pernambuco. Pesquisa Escolar Online,Fundação Joaquim Nabuco, Recife. Disponível em: <http://basilio.fundaj.gov.br/pesquisaescolar/>. Acesso em: 30 mai. 2019.

[17] GUSMÃO, P. A. et al. Turismo na terceira idade: uma análise da percepção do turista sobre os atributos do produto turístico no destino João Pessoa-PB. Observatorio de la Economía Latinoamericana, n.1, 2018.

[18] JAROCKI, Isabella Maria Coelho. Circuito Delícias de Pernambuco: a gastronomia como potencial produto turístico. Revista Turismo em Análise, v. 20, n. 2, p. 321-344, 2009.

[19] JATOBÁ, M. FOLHA DE PERNAMBUCO. Mais municípios de Pernambuco podem entrar na rota do turismo: A Secretaria de Turismo e Lazer de Pernambuco (Setur-PE) que aumentar a quantidade, que hoje é de 103 cidades. Economia. Disponível em:

<https://www.folhape.com.br/economia/economia/economia/2019/04/26/NWS,103110,10,550,ECONOMIA,2373MAIS-MUNICIPIOS-PERNAMBUCO-PODEM-ENTRAR-ROTA-TURISMO.aspx.> Acesso: 07 jun. 2019.

[20] KIM, H. et al. Tourism experience and quality of life among elderly tourists. Tourism management, v. 46, p. 465-476, 2015.

[21] KRAUSE, Rodolfo Wendhausen; BAHLS, AADSM. A gastronomia como fator de influência na escolha de destinações turísticas-base de estudo balneário Camboriú (SC-Brasil). PASOS. Revista de Turismo y Patrimonio Cultural, v. 14, n. 2, p. 433-446, 2016.

[22] MARQUES, L. A. Turismo na Terceira Idade: um olhar geográfico sobre o projeto Trilhas da Longevidade. 2017. MONOGRAFIA UNIVERSIDADE FEDERAL DE UBERLÂNDIA INSTITUTO DE GEOGRAFIA CURSO DE GEOGRAFIA.

[23] ONU. Organização das Nações Unidas. Transformando Nosso Mundo: A Agenda 2030 para o Desenvolvimento Sustentável. Disponível em: <https://nacoesunidas.org/pos2015/agenda2030/>. Acesso em: 29 de maio de 2019.

[24] PECCINI R. Turismo e gastronomia. Revista Rosa dos Ventos. v. 5. n. 2 . Caxias do sul, 2013.

[25] PERNMABUCO, AGÊNCIA ESTADUAL DE PLANEJAMENTO E PESQUISA - CONDEPE/FIDEM. Anuário de Estatística de Pernambuco,2016. Tabela 28.7. Disponível em: <http://www.anuario.pe.gov.br/atividadeseconomicas/turismo>. Acesso em: 28 mai. 2019.

[26] PERNAMBUCO, SECRETARIA DE TURISMO E FUNDAÇÃO DO PATRIMÔNIO ARTÍSTICO DE PERNAMBUCO. Festival de Inverno de Garanhuns, 2019. Disponível em: <http://www.cultura.pe.gov.br/canal/fig2019/fig-2019governo-do-estado-anuncia-as-atracoes-do-maior-festival-de-cultura-do-brasil/>. Acesso em 16 set. 2019. 
[27] NOVA, F. V. Cartilha de acessibilidade urbana: um caminho para todos. $2^{a}$ ed. Recife: Tribunal de Contas do Estado de Pernambuco, 2014. 53p.

[28] WORLD HEALTH ORGANIZATION et al. Global health and ageing. 2011 Disponível em <http://www. who. int/ageing/publications/global_health.pdf.>. Acesso em: 16 abr. 2019. 


\section{Capítulo 11}

\section{Prevalência da violência contra a pessoa idosa no Estado da Paraíba/Brasil}

Bianca Fonseca de Araújo

Hosana Barros Capuxú

Livia Dantas Fragoso

Yngrid Maria Torres Freire

Rodrigo Pinheiro Fernandes de Queiroga

Resumo: A violência contra o idoso é uma temática relevante, pois está presente em diversos níveis sociais e apresenta influência direta na saúde populacional. Este estudo teve como objetivo estimar a prevalência da violência cometida contra a pessoa idosa e sua associação com o sexo no estado da Paraíba/Brasil. Trata-se de um estudo epidemiológico do tipo transversal. A população foi composta por idosos que sofreram atos de violência e foram notificados no período de 2010 a 2016. Os dados - secundários - foram coletados no Sistema de Informação de Agravos de Notificação e no Departamento de Informática do Sistema Único de Saúde. Para análise dos dados, calculou-se a prevalência e a razão de prevalência por sexo para cada tipo de violência, além da frequência dos meios utilizados para provocar a violência. A significância estatística das associações foi determinada pelo cálculo do qui-quadrado e do intervalo de confiança - 95\%. A violência de negligência e abandono foi a que apresentou a maior prevalência do estudo. Em conjunto com a violência psicomoral, sexual e financeira/econômica, foram mais prevalentes em idosas. Enquanto que as violências autoprovocada e física registraram maior prevalência no sexo masculino. No tocante aos meios utilizados para provocar a violência, prevaleceram a força corporal/espancamento e outras formas de agressão com 24,1\% e 52,0\%, respectivamente. Ressalta-se a importância da capacitação e conscientização da sociedade civil para extinguir os preconceitos e respeitar a dignidade do cidadão idoso. Além de reforçar a implementação de políticas públicas para o fortalecimento do cuidado e proteção dessa população.

Palavras-chave: Envelhecimento, Violência, Maus-Tratos ao Idoso. 


\section{INTRODUÇÃO}

No atual contexto, o Brasil vive o aumento da expectativa de vida. Essa realidade iniciou em países desenvolvidos e vem crescendo de forma acentuada em países em desenvolvimento. 0 envelhecimento populacional tem representado um desafio da modernidade, uma vez que os idosos passam a ganhar maior representatividade social por estarem se tornando mais ativos e independentes. Dessa forma, problemas sociais antes suprimidos passam a ser pauta importante de discussão como forma de buscar a melhor qualidade de vida para o longevo (WARMLING, LINDNER, COELHO, 2017).

Nessa perspectiva de problemas sociais, a violência contra o idoso é uma temática relevante, pois está presente em diversos níveis sociais e apresenta influência direta na saúde populacional, podendo ser definida como qualquer ação, única ou repetida, ou ainda, a omissão de providência apropriada, ocorrida dentro de uma relação em que haja expectativa de confiança, que acarrete prejuízo ou aflição a uma pessoa idosa (CASTRO, RISSARDO, CARREIRA, 2017; WHO, 2002).

O cenário se torna mais agravante quando está associado ao ato de reprimir informações, uma vez que devido a velhice carregar consigo o estigma da incapacidade pessoal e total dependência do indivíduo, a vítima poderá vir a omitir por medo de retaliação a violência sofrida (OLIVEIRA et al, 2013; CARMONATORRES, et al, 2017).

A violência contra a pessoa idosa recebe divisões de acordo com tipo da agressão sofrida. A violência física, por exemplo, acontece quando o uso da força física é utilizado com a intenção de causar dor ou lesão; a violência psicológica se destaca pelas atitudes verbalizadas ou não que podem ocasionar angústia ou dor de ordem emocional. No tocante ao abuso sexual, esse tipo de violência envolve qualquer tipo de atividade sexual não consensual; enquanto que o abuso financeiro se refere à exploração ou apropriação indevida de bens de uma pessoa idosa para ganhos pessoais ou monetários (BOND, BUTLER, 2013; CASTRO, RISSARDO, CARREIRA, 2017).

Ainda, a negligência e abandono, formas mais comuns de abuso, relacionam-se à falha, intencional ou não, por parte do cuidador designado, quanto à responsabilidade assumida pelo atendimento às necessidades de saúde física e mental de um idoso (OLIVEIRA et al, 2013; BOND, BUTLER, 2013; CASTRO, RISSARDO, CARREIRA, 2017).

A incidência de maus-tratos contra idosos ainda é desconhecida devido a subnotificação. Estas, podem ocorrer tanto pelo fato do idoso não procurar os serviços de saúde quando sofrem a violência, como também pela ausência de sensibilidade dos profissionais em preencher as notificações no ato do atendimento. 0 Brasil está entre os países da América Latina com estimativas de maiores índices de violência contra a pessoa idosa (CASTRO, RISSARDO, CARREIRA, 2017).

Nessa conjuntura, apesar do Brasil já ter avançado quanto à implementação de políticas públicas que abrangem o combate a violência contra o longevo, com o Plano de Enfrentamento da Violência Contra a Pessoa Idosa e o Estatuto do Idoso, que tornam obrigatória a comunicação, pelos profissionais da saúde, em caso de suspeita ou confirmação de qualquer tipo de violência, o fenômeno ainda é de difícil captação, o que dificulta o conhecimento científico em relação à temática (CASTRO, RISSARDO, CARREIRA, 2017; BRASIL, 2003).

Considerando esse fato, e a escassez de estudos que abordem essa temática no Estado da Paraíba, o presente estudo tem como objetivo estimar a prevalência da violência cometida contra a pessoa idosa e sua associação com o sexo no estado da Paraíba/Brasil.

\section{METODOLOGIA}

Trata-se de um estudo epidemiológico do tipo transversal que utilizou como unidade de análise o estado da Paraíba. Localizado na região Nordeste do Brasil, esse estado conta com 223 municípios e uma população estimada em 2018 de 492.206 idosos (BRASIL, 2019).

A população foi composta por idosos que sofreram atos de violência e foram notificados no período de 2010 a 2016. Os dados - secundários - sobre a violência foram coletados no Sistema de Informação de Agravos de Notificação (SINAN). Além disso, utilizou-se a estimativa da população idosa na Paraíba do ano de 2013 (metade do período do estudo) para o cálculo da prevalência da violência, obtida no Departamento de Informática do Sistema Único de Saúde - DATASUS (BRASIL, 2019).

Para a análise dos dados, calculou-se a prevalência e a razão de prevalência por sexo para cada tipo de violência, além da frequência (absoluta e relativa) da violência e dos meios utilizados para provocar a 
agressão. A significância estatística das associações foi determinada pelo cálculo do qui-quadrado e do intervalo de confiança (IC), com nível de confiança de 95\%.

O estudo dispensa a submissão e avaliação por um Comitê de Ética e Pesquisa por utilizar dados secundários e de domínio público.

\section{RESULTADOS E DISCUSSÃO}

A análise realizada permitiu identificar a ocorrência de alguns tipos de violência nos idosos e que há uma diferença, estatisticamente significativa $(\mathrm{p}<0,05)$, dos acometidos em relação ao sexo.

De acordo com a Tabela 1, a lesão autoprovocada teve uma prevalência de 1,6 casos por 10000 idosos, com uma ocorrência maior no sexo masculino $(57,1 \%)$ e uma prevalência $79 \%$ maior que no sexo feminino.

A violência física foi a que apresentou a segunda maior prevalência do estudo com 13,1 casos por 10000 idosos. Esse tipo de violência também acometeu mais idosos do sexo masculino (56,9\%), com uma prevalência $78 \%$ maior.

Já a violência psico/moral apresentou um comportamento diferente das mencionadas acima, com uma ocorrência maior no sexo feminino $(73,6 \%)$ e uma prevalência duas vezes maior que a do sexo masculino. Ressalta-se que essa violência acometeu 5 por cada grupo de 10000 idosos.

Sobre a violência sexual no idoso, observa-se tratar de um problema quase que exclusivo do sexo feminino, com $95,5 \%$ dos casos e uma prevalência 15,6 vezes maior que a do sexo masculino. Da mesma forma, a violência financeira e econômica também se apresentou como um problema com ocorrência maior nas idosas $(93,3 \%)$ e com uma prevalência 10,4 vezes maior. Por fim, a violência de negligência e abandono foi a que apresentou a maior prevalência do estudo, com 15 casos por 10000 idosos, e uma prevalência $28 \%$ maior no sexo feminino.

Com base nos resultados ora descritos, verificou-se a maior prevalência entre os homens que sofrem violência física, dando o segundo destaque para a negligência e o abandono vivenciado por mulheres idosas. A relação de suporte parcial ou total, e em muitos casos familiar, torna essa fração da população refém do medo e da insegurança em relação aos atos de violência, de modo que estas podem impactar negativamente nas condições de saúde física e psicológica.

Concernente à violência sexual, a população feminina representa o maior alvo, superando em 15 vezes o público idoso masculino. Esse triste fato torna as idosas mais suscetíveis à violência e está relacionado com o ideal enraizado na sociedade civil sobre a fragilidade feminina. Logo, os maus tratos se dão de modo abrupto ou sutil, caracterizando graves danos morais, sociais e psicológicos. Todavia, o fato de se concretizar numa íntima relação, em que há expectativa de confiança entre os parceiros, interfere na subnotificação dos casos, levando à imprecisão das estatísticas, não só na Paraíba, mas em todo o mundo (LINO et al, 2016). 
Tabela 1 - Frequência, prevalência e razão de prevalência de violência no idoso por sexo entre 2010 e 2016, Paraíba.

\begin{tabular}{|c|c|c|c|c|c|c|}
\hline \multicolumn{7}{|c|}{ LESÃO AUTOPROVOCADA } \\
\hline Sexo & $\mathrm{N}$ & $\%$ & Prevalência* & $\mathrm{RP} \mathrm{M} / \mathrm{F}^{* *}$ & p-valor & IC 95\% \\
\hline $\mathrm{M}$ & 40 & 57,1 & 2,2 & & & \\
\hline $\mathrm{F}$ & 30 & 42,9 & 1,2 & 1,79 & 0,02 & $1,11-2,87$ \\
\hline Total & 70 & 100 & 1,6 & & & \\
\hline \multicolumn{7}{|c|}{ VIOLÊNCIA FÍSICA } \\
\hline Sexo & $\mathrm{N}$ & $\%$ & Prevalência* & $\mathrm{RP} \mathrm{M} / \mathrm{F}^{* *}$ & p-valor & IC 95\% \\
\hline $\mathrm{M}$ & 324 & 56,9 & 17,5 & & & \\
\hline $\mathrm{F}$ & 245 & 43,1 & 9,9 & 1,78 & 0,01 & $1,50-2,10$ \\
\hline Total & 569 & 100 & 13,1 & & & \\
\hline \multicolumn{7}{|c|}{ VIOLÊNCIA PSICO/MORAL } \\
\hline Sexo & $\mathrm{N}$ & $\%$ & Prevalência* & $\mathrm{RP} F / \mathrm{M}^{* * *}$ & p-valor & IC 95\% \\
\hline M & 57 & 26,4 & 3,1 & & & \\
\hline $\mathrm{F}$ & 159 & 73,6 & 6,4 & 2,08 & 0,01 & $1,54-2,81$ \\
\hline Total & 216 & 100 & 5,0 & & & \\
\hline \multicolumn{7}{|c|}{ VIOLÊNCIA SEXUAL } \\
\hline Sexo & $\mathrm{N}$ & $\%$ & Prevalência* & $\mathrm{RP} F / \mathrm{M}^{* * *}$ & p-valor & IC 95\% \\
\hline M & 1 & 4,5 & 0,1 & & & \\
\hline $\mathrm{F}$ & 21 & 95,5 & 0,8 & 15,64 & 0,01 & $\ldots$ \\
\hline Total & 22 & 100 & 0,5 & & & \\
\hline \multicolumn{7}{|c|}{ VIOLÊNCIA FINANCEIRA E ECONOMICA } \\
\hline Sexo & $\mathrm{N}$ & $\%$ & Prevalência* & $\mathrm{RP} \mathrm{F} / \mathrm{M}^{* * *}$ & p-valor & IC $95 \%$ \\
\hline M & 2 & 6,7 & 0,1 & & & \\
\hline $\mathrm{F}$ & 28 & 93,3 & 1,1 & 10,43 & 0,01 & $2,48-43,78$ \\
\hline Total & 30 & 100 & 0,7 & & & \\
\hline \multicolumn{7}{|c|}{ VIOLÊNCIA DE NEGLIGENCIA E ABANDONO } \\
\hline Sexo & $\mathrm{N}$ & $\%$ & Prevalência* & $\mathrm{RP} F / \mathrm{M}^{* * *}$ & p-valor & IC $95 \%$ \\
\hline M & 243 & 36,9 & 13,1 & & & \\
\hline $\mathrm{F}$ & 416 & 63,1 & 16,7 & 1,28 & 0,01 & $1,09-1,49$ \\
\hline Total & 659 & 100 & 15,2 & & & \\
\hline \multicolumn{7}{|c|}{$\begin{array}{l}\text { * Por } 10.000 \text { idosos } \\
\text { de prevalência: Masculino/Feminino } \\
\text { de prevalência: Feminino/Masculino } \\
\text { Fonte: SINAN, DATASUS. }\end{array}$} \\
\hline
\end{tabular}

Denota-se, portanto, que as agressões cometidas por parceiros íntimos compreendem qualquer comportamento causador de danos físicos, psíquicos ou sexuais ao idoso, incluindo comportamento controlador e abuso econômico. Além disso, entende-se por parceiro íntimo qualquer pessoa que tenha vínculo com o idoso, podendo ser familiar, amigo ou cuidador (WARMLING, LINDNER, COELHO, 2017).

Em relação à violência psicomoral e financeira, esta é vivida também, em sua densa maioria, pelo segmento do sexo feminino. Notificar os casos de maus tratos mais conhecidos - como o físico, o abandono e a negligência intrafamiliar - já é deveras complicado; reconhecer e identificar as demais variantes de tais agressões é ainda mais difícil, devido à complexidade do relacionamento entre agressor e agredido (CASTRO, RISSARDO, CARREIRA, 2017).

Sobre os meios de agressão, observa-se, na tabela 2, que prevaleceram outras formas de agressão e a força corporal/espancamento com 52,0\% e 24,1\%, respectivamente. Acredita-se que a utilização desses meios para a prática da violência leve à ocorrência de fraturas, hematomas ou outros danos físicos considerados traumas agudos que resultam na procura do indivíduo pelo atendimento de urgência.

A violência cometida por meio enforcamento, estupro e outra forma de agressão teve uma frequência maior nas idosas. As demais formas de agressão listadas na tabela 2, foram mais utilizadas na violência contra os idosos. 
Tabela 2 - Frequência dos meios de agressão utilizados para a violência contra o idoso por sexo, Paraíba, 2010 a 2016.

\begin{tabular}{|l|c|c|c|c|c|c|}
\hline \multirow{2}{*}{ Meio de agressão } & \multicolumn{2}{|c|}{ Masculino } & \multicolumn{2}{c}{ Feminino } & \multicolumn{3}{c|}{ Total } \\
\cline { 2 - 7 } & $\mathrm{N}$ & $\%$ & $\mathrm{~N}$ & $\%$ & $\mathrm{~N}$ & $\%$ \\
\hline Força corporal/espancamento & 170 & 28,3 & 144 & 20,5 & 314 & 24,1 \\
\hline Enforcamento & 4 & 0,6 & 7 & 1,0 & 11 & 0,8 \\
\hline Objeto contundente & 17 & 2,8 & 15 & 2,1 & 32 & 2,4 \\
\hline Objeto perfuro cortante & 59 & 9,8 & 30 & 4,2 & 89 & 6,8 \\
\hline Envenenamento & 18 & 3,0 & 17 & 2,4 & 35 & 2,6 \\
\hline Arma de fogo & 55 & 9,1 & 17 & 2,4 & 72 & 5,5 \\
\hline Estupro & 1 & 0,1 & 19 & 2,7 & 20 & 1,5 \\
\hline Substância ou objeto quente & 7 & 1,1 & 2 & 0,2 & 9 & 0,6 \\
\hline Outra agressão & 249 & 41,5 & 428 & 61,0 & 677 & 52,0 \\
\hline Em branco & 20 & 3,3 & 22 & 3,1 & 42 & 3,2 \\
\hline Total & 600 & 100,0 & 701 & 100,0 & 1301 & 100,0 \\
\hline
\end{tabular}

Fonte: SINAN

Outrossim, diversas variantes estão envolvidas nos atos de violência ao idoso, como enforcamento, objeto perfurante, envenenamento, arma de fogo, estupro e objetos quentes. Os sinais mais comuns do sofrimento podem ser a presença de lesões corporais evidentes, tais como cortes, feridas, mordidas, vergões, escoriações, hematomas e fraturas que, quase sempre, não condizem com a causa atribuída pela vítima quando do atendimento médico (CASTRO, RISSARDO, CARREIRA, 2017).

Os profissionais de saúde são, frequentemente, os primeiros a ter o contato inicial com a pessoa idosa vítima de agressões e, assim, têm o papel intransferível e fundamental na formulação da rede de apoio a essas pessoas, bem como são responsáveis por coletar os dados pertinentes ao banco de informações para serem interpretados pela secretaria de saúde. Tal conjuntura requer a construção de um conjunto de ações, as quais podem levar à intervenção consistente a fim de diagnosticar, prevenir, oferecer cuidados necessários e impedir que a vítima retorne ao ciclo de violência (SANTANA, 2010).

Vale ressaltar que, devido à pressão psicológica, há ocultação de lesões antigas e sem explicação pelo idoso. Constata-se isso não somente através dos dados, quando mostram informações em branco, uma vez que os mais velhos se sentem ameaçados de morte pelos agressores (mesmo os envolvidos dentro da própria família), mas também pelas denúncias anônimas e outros casos praticados e até então não registrados.

Em adição ao exposto, tem-se, ainda, a vertente do descuido e do abandono, práticas massacrantes no psicológico da vítima. A negligência pode ser diferenciada em passiva, ou não intencional, e ativa ou intencional. Quando coexistem ações, como descuido das necessidades vitais, permitindo desnutrição, desidratação e formação de úlcera no idoso, sem a realização de precauções de segurança, estas são formas de negligência passiva (OLIVEIRA et al, 2013).

Por outro lado, a negligência ativa ocorre quando o agressor intimida e insulta o idoso, ignora uma situação de emergência ou deixa a pessoa idosa dependente sozinha por quantidade inadequada de tempo, sem observação e desamparada, privando-a de alimentação e tratamentos importantes, haja vista a maior obtenção de processos doentios experimentada por sua faixa etária suscetível (OLIVEIRA et al, 2013).

$\mathrm{Na}$ literatura, os valores observados nos resultados ora em debate divergem dos apresentados por Warmling, Linder e Coelho (2017), quando este menciona a prevalência da violência psicológica sobre a física. Na Paraíba, observou-se uma maior parcela de agressão física com 13,1 casos para um grupo avaliado de 10.000 idosos - frequência de 36,3\% em relação ao total de casos de violência, enquanto a violência psicológica ou psico/moral foi de 5 casos para 10.000 pessoas (frequência de $13,8 \%$ do total), diferente do quadro observado no Brasil pelo autor, onde houve uma maior frequência da violência psicológica (com 20,9\%) sobre os 5,9\% de violência física. 
Não obstante, é importante ressaltar a possibilidade de inconsistência em muitos dados apresentados devido à discutida subnotificação, visto que, além dos problemas relacionados à dificuldade de notificação pelos serviços de saúde, os idosos sofrem com baixa autoestima, isolamento social e uma insegurança latente que os mantêm reféns da tortura cometida pelos encarregados da missão de protegê-los (WARMLING, LINDNER, COELHO, 2017).

\section{CONSIDERAÇÕES FINAIS}

A violência cometida contra a pessoa idosa no estado da Paraíba/Brasil ocorre em ambos os sexos, sendo a de maior prevalêcia a de negligência e abandono. Destaca-se que a violência psicomoral, sexual e financeiro econômica foram mais prevalentes em idosas, enquanto que as violências autoprovocadas e física aconteceram mais no sexo masculino.

Quanto aos meios de agressão que provocou a violência contra o idoso, formas como a força corporal e espancamento foram frequentes nos idosos do sexo masculino. Em contrapartida, o estupro apareceu com maior representatividade em idosas, reforçando a questão de gênero.

Ressalta-se que, além das dificuldades inerentes aos idosos em procurarem os serviços para notificarem os casos de violência, seja por desconhecimento, vergonha, medo, além de outros fatores que devem ser investigados, ainda temos as subnotificações atribuídas aos profissionais de saúde que são linha de frente nos estabelecimentos de saúde.

Portanto, dada a pertinência da temática, ressalta-se a importância da capacitação e conscientização da sociedade civil para extinguir os preconceitos e respeitar a dignidade do cidadão idoso. Além de reforçar a implementação de políticas públicas para o fortalecimento do cuidado e proteção dessa população.

\section{REFERÊNCIAS}

[1] BRASIL. Lei no ${ }^{\circ}$ 10.741, de 1ํ de outubro de 2003. Dispõe sobre o Estatuto do Idoso e dá outras providências. Diário Oficial da União: Brasília, DF, 03 out 2003.

[2] BRASIL. Lei no. 12.461, de 26 de julho de 2011. Altera a Lei no 10.741, de 1o de outubro de 2003, para estabelecer a notificação compulsória dos atos de violência praticados contra o idoso atendido em serviço de saúde. Diário Oficial da União: Brasília, DF, 27 jul 2011.

[3] BRASIL. Ministério da Saúde. Departamento de informática do SUS (DATASUS). Dados epidemiológicos e sociodemográficos. Disponível em

http://w3.datasus.gov.br/datasus/datasus.php?area=359A1B375C2D0E0F359G19HIJd2L2412M0N\&VInclude=../site /infsaude.php. Acesso: 20 de abril de 2019.

[4] BOND, M. C; BUTLER, K. H. Elder abuse and neglect: definitions, epidemiology, and approaches to emergency department screening. Clin Geriatr Med. 2013. Disponível em: https://www.ncbi.nlm.nih.gov/pubmed/23177610. Acesso em 10 de maio de 2019.

[5] CARMONA-TORRES, Juan Manuel et al . Elder abuse within the family environment in the Azores Islands. Rev. Latino-Am. Enfermagem, v. 25, e2932, 2017. Disponível em:

http://www.scielo.br/scielo.php?script=sci_arttext\&pid=S0104-11692017000100372\&lng=en\&nrm=iso. Acesso em 21 de maio de 2019.

[6] CASTRO V. C, RISSARDO L. K, CARREIRA L. Violence against the Brazilian elderlies: an analysis of hospitalizations. Rev Bras Enferm. v. 71, (supl 2), p. 777-85. Disponível em: http://www.scielo.br/pdf/reben/v71s2/pt_0034-7167-reben-71-s2-0777.pdf. Acesso em 01 de maio de 2019.

[7] LINO, Valéria Teresa Saraiva et al. Prevalência e fatores associados ao abuso de cuidadores contra idosos dependentes: a face oculta da violência familiar. Ciênc. Saúde coletiva. v. 24, n. 1, p. 87-96, Jan. 2019. Disponível em: http://www.scielo.br/scielo.php?script=sci_arttext\&pid=S1413-81232019000100087\&lng=en\&nrm=iso.Acesso em 30 de abril de 2019.

[8] OLIVEIRA, A.A.V; TRIGUEIRO, D.R.S.G; FERNANDES, M.G.M; SILVA, A.O . Maus-tratos a idosos: revisão integrativa da literatura. Rev. bras. Enferm. v. 66, n. 1, p. 128-133.

2013.Disponívelemhttp://www.scielo.br/scielo.php?script=sci_arttext\&pid=S003471672013000100020\&lng=en\&nr m=iso. Acesso em 30 de abril de 2019.

[9] PINA, G. V. E, RODRÍGUEZ, J. P, CANCINO A. D, ENAMORADO, J. E. R. Violencia intrafamiliar contra el adulto mayor en una comunidad de Guinea Bissau. MEDISAN. V. 17, n.7), p 1053, 2013. Disponível em: http://scielo.sld.cu/pdf/san/v17n7/san04177.pd. Acesso em 21 de maio de 2019. 
[10] SANTANA, M. S. Maus-tratos em adultos mais velhos e seus cuidadores familiares: um estudo de revisão. Rev. Interinst. Psicol. v. 3, n. 1, p. 33-41, jul. 2010 . Disponível em

<http://pepsic.bvsalud.org/scielo.php?script=sci_arttext\&pid=S198382202010000100005\&lng=pt\&nrm=iso>. Acesso: 07 de abril de 2019.

[11] WARMLING, D, LINDNER, S. R, COELHO, E. B. S. Prevalência de violência por parceiro íntimo em idosos e fatores associados: revisão sistemática. Ciênc. Saúde coletiva. v. 22, n. 9, p. 3111-3125. 2017. Disponível em: <http://www.scielo.br/scielo.php?script=sci_arttext\&pid=S141381232017002903111\&lng=en\&nrm=iso >. Acesso em 20 de abril de 2019.

[12] World Health Organizations (WHO), INPEA (International Network for the Prevention of Elder Abuse). Missing voices. Views of Older Persons on Elder Abuse. Geneva: World Health Organization; 2002. Disponível em: http://apps.who.int/iris/bitstream/10665/67371/1/WHO_NMH_VIP_02.1.pdf 2. Acesso em 30 de março de 2019. 


\section{Capítulo 12}

Envelhecimento, velhice e morte: o conflito entre a experiência de sentido e a finitude numa perspectiva Logoterapêtica

\section{Críscia Delancout Lúcio Araújo \\ Lucas Pereira Lucena \\ Lucas Brasil Feitosa \\ Lhais Cabral Martins \\ Lorena Bandeira Melo de Sá}

Resumo: 0 envelhecimento, enquanto condição inerente ao homem, compreende perdas físicas e simbólicas que se manifestam de diferentes formas ao longo da vida. Entretanto, o discurso social, na tentativa de distanciar o sentimento de perda, muitas vezes anula o lugar de sujeito aos idosos, podendo gerar sofrimento. Na contramão desse discurso, o presente artigo visa apresentar elementos que possibilitem o entendimento de que a finitude pode operar como um fator impulsionador para vida, favorecendo para que o ser humano dê continuidade a suas realizações mesmo diante das contingências, já que este não é um ser imortal, capaz de adiar suas vivências. Para isso, tendo como base a Logoterapia e Análise Existencial, buscou-se, por meio de uma revisão bibliográfica, atentar para as realizações pessoais que podem ocorrer tanto através de êxitos como de sofrimentos. A elaboração do luto, nesse sentido, se mostra como elemento de grande importância, uma vez que pode gerar uma mudança de posição diante das perdas que ocorrem, possibilitando que o sujeito ressignifique sua existência a partir da vontade de sentido.

Palavras-chave: Velhice, Morte, Luto, Sentido, Logoterapia. 


\section{INTRODUÇÃO}

Envelhecer é processo natural, uma vez que todo àquele que se encontra vivo está submetido à passagem do tempo e aos impactos que o acompanham. Este processo pressupõe transformações graduais e irreversíveis, que vão desde as alterações orgânicas, como a perda da elasticidade da pele e a lentificação do metabolismo, às mudanças na esfera social, como a aposentadoria e o esfacelamento dos laços socioafetivos, uma vez que há o afastamento dos colegas de trabalho e perdas de amigos e entes queridos (ZIMERMAN, 2000).

As vicissitudes que irrompem com a chegada da velhice podem ser percebidas como sinais da morte, provocando medo em quem as vivencia, pois anunciam a proximidade do próprio fim, demandando dos sujeitos a elaboração do luto referente às perdas físicas, psíquicas e sociais. 0 sentimento de morte iminente intensifica-se frente às limitações provocadas pela própria condição de ser idoso, o que pode causar desesperança ante àquilo que representa o que resta da vida.

Uma vez que, para Frankl, o sujeito deve ser concebido como uma totalidade tridimensional (corpo, mente e espírito), o elemento central de sua existência passa a ser a vontade de sentido, que diz respeito à "capacidade de [...] descobrir e realizar valores e significados" (PETER, 1999, p.39). Essa descoberta só se dá através da abertura da pessoa para o mundo, fenômeno caracterizado por Frankl (1991 apud PEREIRA, 2013, p.89) como autotranscendência:

A autotranscendência assinala o fato antropológico fundamental de que a existência do homem sempre se refere a alguma coisa que não ela mesma - a algo ou alguém, isto é, a um objetivo a ser alcançado ou a existência de outra pessoa que ele encontre. Na verdade, o homem só se torna homem e só é completamente ele mesmo quando fica absorvido pela dedicação a uma tarefa, quando se esquece de si mesmo no serviço a uma causa, ou no amor a uma outra pessoa. É como o olho, que só pode cumprir a sua função de ver o mundo, enquanto ele não vê a si próprio.

A morte, consequência final que acompanha o homem por toda a vida, se faz presente nas suas diferentes dimensões, contudo, há uma tendência em mantê-la afastada, a considerando um acontecimento distante, que tardará a se cumprir. Nessa lógica, o ser humano vive como se a morte não existisse, desconsiderando por completo sua finitude até que, de um só golpe, ela se apresenta seja por meio da morte de uma pessoa querida, ou através de um problema de saúde severo, provocando angústias e sofrimentos (BARBOSA; MELCHIORI; NEME, 2011).

Assim, por mais que o sofrimento seja inerente a existência do homem, pode-se notar uma intensificação desse processo em determinadas situações na velhice, como por exemplo nas sucessivas tentativas de elaboração frente ao corpo e as relações que se mostram cada vez mais frágeis. É em cima de situações na qual sentimentos de angústia, desamparo e medo predominam, que Frankl (2003) conceituou sobre o sentido do sofrimento. Para ele essas circunstâncias podem servir como elementos impulsionadores para o crescimento e amadurecimento do ser humano, uma vez que as estratégias de enfrentamento utilizadas revelariam as potencialidades desse sujeito e se mostrariam como elementos-chave para a realização pessoal.

Partindo da relação entre morte e velhice, o presente trabalho visa, através de uma revisão bibliográfica, associar esses conceitos às premissas da Logoterapia, abordagem teórica que compreende a busca do sentido da vida como motivador básico do homem, na tentativa de apresentar elementos que possibilitem o entendimento de que a ideia de finitude pode operar como um fator impulsionador, favorecendo para que o ser humano dê continuidade a suas realizações mesmo diante de um sofrimento, já que este não é um ser imortal, capaz de adiar suas vivências.

\section{ALGUMAS PERSPECTIVAS SOBRE A VELHICE E A FINITUDE DO PONTO DE VISTA DA LOGOTERAPIA E ANÁLISE EXISTENCIAL}

O ser humano, diferente das outras espécies, é consciente da sua própria finitude, tendo de encará-la diariamente através dos incidentes cotidianos, dos relatos midiáticos e dados estatísticos divulgados. Buscando dar conta desse fato, elabora teorias e adota crenças na tentativa de dar um sentido a sua condição de ser mortal. 
O interessante é que nessa morte assistida, sempre é o outro que é acometido, o que, de certa forma, conforta aquele indivíduo em achar que nunca irá ocorrer com ele ou entre os seus (NETO, 2012).

Entretanto, quando isso se aplica a velhice, percebe-se que, se o outro que morre é um velho, acaba por servir como um prenúncio da morte do velho que vive. Questionamentos como "será que serei o próximo? Já que todos do meu tempo estão partindo..." revelam a angústia frente a esse tema que muitos insistem em não pensar, mas que poderiam ser o mote que os levaria a reavaliar a presença de sentido em suas vidas. Uma vez que encarar esse processo não mais como uma sentença, pode servir como um chamado para a vida, para viver o que ainda resta dela em busca da realização de seu sentido tendo consciência que só se vive uma vez (NETO, 2012; VELÁSQUEZ, 2018).

O luto, nesse sentido, seria um elemento importante para a transformação da posição do sujeito frente à finitude. Ele está contido como consequência de toda e qualquer encontro com uma perda/morte física ou simbólica, compreendendo cinco fases. 0 primeiro momento do luto consiste na negação da perda, em que o sujeito se vê incapaz de admiti-la, insistindo em rejeitar o ocorrido. A segunda fase é marcada pela raiva, que se apodera do sujeito e pode ser direcionada a qualquer coisa ou pessoa. A fase seguinte caracterizase pela barganha, na qual o enlutado começa a fazer juramentos de que conduzirá a sua vida de outra maneira, esperando que perdas como essa não voltem a ocorrer (NETTO, 2015).

Em seguida viria a fase da depressão, na qual o sujeito é invadido por uma profunda tristeza, no entanto, esse sentimento não deve ser considerado patológico, mas uma reação normal na ausência do objeto querido. A última fase do luto é a aceitação da realidade vivenciada nesse processo, isso não quer dizer que tudo esteja bem, mas que o sujeito aprendeu a viver com o fato que provocou seu luto, atribuindo a ele um novo sentido (NETTO, 2015).

Esse processo é viabilizado pela dimensão noética (ou espiritual) do sujeito, ou seja, pela vontade de sentido que urge em realizar-se. Assim, ao destacar no sujeito seu âmbito espiritual como orientador e norteador do ser, uma vez que é nele que se encontra o núcleo central do ser humano, Frankl (1985 apud ZAMULÁK, 2015) entende que o ser-espiritual seria sua força motriz, para aquele que se encontra aberto para o mundo, sendo impulsionado pelas realizações dos seus valores na sua busca pelo sentido.

Centrado em torno deste núcleo existencial, pessoal e espiritual, o ser humano não é apenas individualizado, mas também integrado. Desta forma, o núcleo espiritual, e apenas este, é que garante e constitui a unidade e integridade, neste contexto significa a integração dos aspectos somático, psíquico e espiritual (p.134).

Essa abertura para o mundo é o potencial de movimento da vida, sendo direcionada por sua condição de ser-espiritual para conseguir agir sobre as determinadas situações do cotidiano, em que a vida se encarrega de interrogar ao indivíduo sobre sua existência, sua especificidade, e, assim, o sujeito encontra seu sentido, pois, esse fator não está dado, não pode ser criado, apenas buscado.

Entretanto, o discurso social em torno da velhice colabora para a desvalorização da figura do idoso, que, ao ser considerado inapto para exercer as atividades que antes lhe eram reservadas, fica sob a tutela de seus familiares, perdendo, assim, sua autonomia. A pessoa idosa é afastada de sua rotina e percebe sua liberdade ameaçada. Esse cenário leva o sujeito a vivenciar um sentimento de vazio, o distanciando do seu "ser-responsável", pois entende que não há mais sentido em viver nesse não-lugar. Dessa forma, ao passo que o sujeito tem sua autonomia cerceada de maneira que lhe impede de acessar seus valores, está implícita a repressão de sua dimensão espiritual. 0 vazio existencial aí se manifesta pelo caráter insustentável que essa situação traz, sendo uma reação de seu espírito para que o sujeito possa se defender de sua desumanização (CARVALHO, 1993; BARBOSA, MELCHIORI, NEME, 2011).

Nessa conjuntura que a Logoterapia concebe a condição existencial do homem possuindo uma característica trágica, pois é justamente diante desse fator que se encara a existência humana como sendo, de fato, singular, se apresentando como um campo de sentido (NETO, 2012). 
Dá-se, então, o surgimento a "Tríade Trágica" - a dor/sofrimento, a culpa e a morte- colocada como uma premissa da vida, sendo algo inerente ao existir, que o possibilita de agir e se conscientizar de possibilidades diante uma situação limitante. Nas palavras de Xausa (2003, p.84):

A resposta sobre o sentido do trágico é encontrada na atitude mesma que elegemos ante uma situação que se nos apresenta tragicamente. Só o ser humano tem o privilégio de eleger uma atitude frente ao sofrimento que se apresenta como tal.

\subsection{LIDANDO COM A MORTE: A LOGOTERAPIA E SUA PERSPECTIVA TRANSFORMADORA DO SOFRIMENTO EM SENTIDO}

Culturalmente o sujeito envelhecido se depara com uma série de perdas simultâneas atribuídas a posição do idoso, isto porque a representação social de ser velho corresponde a uma imagem de um indivíduo que por não produzir mais é visto como incapaz. Esta colocação de inutilidade coloca a velhice em uma alta desvalorização social que recai sobre si, em se fixar neste lugar de que "agora nada mais pode se fazer", pois além da perda de papéis e posição social, na velhice também há a percepção real de perdas sobre o corpo (ZIMERMAN, 2000).

Ainda assim, o sujeito frankliano é dotado de uma realidade pessoal onde se infere duas premissas básicas: a liberdade e a responsabilidade (PETER, 1999). Essa liberdade se refere ao poder de decisão, que é inerente ao indivíduo, e que por isso mesmo o torna um ser responsável, uma vez que toda decisão implica não só em uma consequência como também em uma renúncia. Ou seja, é somente a partir da ação do sujeito sobre o mundo, através do processo de decisão, que se torna possível a realização de sentido, mas essa ação não deve ser vista apenas como uma intervenção externa, pois, de acordo com Frankl (1978 apud PEREIRA, 2013, p.100), "toda decisão implica autodecisão, e esta redunda, simultaneamente, em autocriação".

Nesse contexto o indivíduo, partindo da atitude, isto é, da disposição de efetuar uma ação que tenha sentido, é capaz de se autodeterminar, "pois o homem não se destina a ser, mas vir a ser" (FRANKL, 1978 apud PEREIRA, 2013, p. 99). Isso pode ser percebido quando pessoas que são acometidas por uma situação de sofrimento começam a olhar aquela circunstância de outro ângulo, conseguindo tirar algum aprendizado de si que ainda não se tinha reconhecimento, podendo até ampliar ou fortalecer o próprio sentido de vida desse sujeito. Outro aspecto, estaria no valor de atitude, nele se encontram as possibilidades do homem intimamente ligada à capacidade do mesmo em converter um sofrimento em superação (NETO, 2012).

Contudo, o sofrimento pode, inicialmente, ser negado, assim como a primeira fase do luto, isso porque entra em contradição com os valores pessoais que foram desenvolvidos durante toda a vida que tinham como intuito melhor direcionamento nas ações do indivíduo. E, baseado nisso, chama-se de sofrimento o momento em que a realidade ataca o núcleo central de cada pessoa, fazendo com que se negue a situação em questão (CÔRREA, 2012). Corroborando essa ideia, Frankl (1992 apud NETO, 2012, p.45) aponta que:

Se sofremos por causa de alguma coisa, é precisamente porque não "a podemos sofrer", isto é, porque não queremos permitir-lhe que vigore. A discussão com os dados fatais do destino é a missão última e rumo genuíno do sofrimento. Se uma coisa nos faz sofrer, é porque interiormente lhe voltamos as costas; é porque criamos distância entre a nossa pessoa e essa coisa.

Diante disso, surge a percepção de que o sofrimento não se caracteriza só como um ponto negativo. 0 sujeito idoso, por estar mais próximo da finitude, pode refletir sobre pontos de si e dos outros que nunca se fez pensar, se deparando com o que de fato é importante para sua própria existência, delineando novas valorações no sentido de atualizar sua dimensão espiritual diante da velhice. Dessa forma, pode-se inferir que o homem é capaz de mudar não a situação, mas sim a si mesmo, aliás, mudar de atitude, dando espaço para se ter uma vida realizada. Até mesmo, pois, diante de uma enfermidade ou sofrimento, o sujeito ainda é capaz de se realizar com ações que podem ser ressignificadas, vivências essas que talvez não teria se mostrado possível antes (CÔRREA, 2012; VELÁSQUEZ, 2018). 
Nesse sentido, a morte não esgota o sentido da existência humana, ao contrário, o potencializa. Se a imortalidade fosse uma realidade possível, o homem poderia adiar suas ações até o infinito, não havendo urgência em realizá-las. Em contrapartida, a consciência da própria finitude leva o homem a aproveitar, ao máximo, seu tempo de vida, vivendo intensamente os instantes únicos de sua existência e podendo, a partir deles, alcançar o seu sentido (FRANKL, 2003).

\section{CONSIDERAÇõES FINAIS}

Estando o homem ciente não só de suas realizações positivas, mas também de situações diretamente ligadas com o sofrimento, as experiências emergentes na vida de cada um não estão presentes apenas em uma classificação de sucesso ou fracasso, mas sim na vivência significativa que o homem pode dar a essas situações, encontrando sentido não só frente a seus êxitos, mas também nos momentos mais dolorosos (VELÁSQUEZ, 2018). Neste ensejo, Pereira (2015) mostra que é por ser um ser espiritual que o sujeito pode transcender o caráter reducionista dos condicionamentos a partir de cada decisão sobre as exigências concretas de cada momento.

O sofrimento, perante a morte, estaria se manifestando diante da negação da realidade que o sujeito se encontra, a partir do momento que ele se sente com os valores "renegados" por pressupor que não existe mais as possibilidades de vivenciá-los. Ou seja, sente-se com os seus valores e sentidos agredidos pela sua condição existencial, durante esse momento. Sendo assim, morrer não é um fato negativo. É antes de um fato positivo, uma vez que estabelece o fim do futuro e define as fronteiras das possibilidades humanas (KROEFF; REVERTÉ, 2018).

Assim, os valores de atitudes e o suprasentido estariam atuando frente a essas situações de sofrimento, no intuito de fazer com que o indivíduo saiba lidar com a sua finitude, não entrando em sofrimento extremo quando se deparar com sua condição de ser mortal. Com isso, fica evidente que há neste sujeito um algo a mais: uma força de obstinação que não se deixa domar. Esse processo, que Frankl vai chamar de antagonismo noogênico, implica acima de tudo um tensionamento para que o sujeito não sucumba às dificuldades que lhe são impostas, mas ao contrário, use delas para se afirmar (PEREIRA, 2015).

A prática logoterapêutica, partindo da noção que os seres humanos são livres e responsáveis para se posicionar frente ao próprio destino, se mostra como aliada para fomentar uma compreensão mais natural da condição de ser finito, diminuindo os estigmas associados a velhice. Dessa forma, pode contribuir para a promoção de reflexões acerca dessa temática através de espaços abertos de discussão nos diversos campos da sociedade, de maneira que esses debates possam ultrapassar visões estereotipadas, impactando diretamente no sofrimento por elas causado.

\section{REFERÊNCIAS}

[1] Barbosa, Caroline Garpelli; Melchiori, Lígia Ebner; Neme, Carmen Maria. A família e a morte: reflexões sobre as vivências de adolescentes, adultos e idosos. In: Valle, Tânia Gracy Martins do; Maia, Ana Cláudia Bortolozzi (Orgs.). Psicologia do desenvolvimento humano e aprendizagem. São Paulo: Cultura Acadêmica, 2011, p. 189-203.

[2] Carvalho, José Mauro Romer de. 0 vazio existencial e o sentido da vida. In: Informação Psiquiátrica. v.12, n.3. p. 111-115, 1993.

[3] Côrrea, Diogo. Do luto ao sentido: aportes da logoterapia no espaço psicoterapêutico. Mogi das Cruzes: Psicol. teor. prat. vol.14 no.3 São Paulo dez. 2012. Disponível em

<http://pepsic.bvsalud.org/scielo.php?script=sci_arttext\&pid=S1516-36872012000300015\&lng=pt\&nrm=iso>. acessos em 15 jun. 2019.

[4] Frankl, Viktor. Psicoterapia e sentido da vida: fundamentos da Logoterapia e análise existencial. 4 ed. São Paulo: Quadrante, 2003.

[5] Kroeff, Paulo; Reverté, Maria Antonia Lacasta. Biblioterapia em grupo de idosos em luto. In: Oliveiros, Olga; Kroeff, Paulo. In: Finitude e Sentido da Vida: A logoterapia no embate com a tríade trágica. Porto Alegre: Editora Evangrav, 2018, p. 191-202.

[6] Neto, Barbosa. Tanatologia e Logoterapia: um diálogo ontológico. Ceará: Revista Logos \& Existência: Revista da associação brasileira de Logoterapia e análise existencial, 1 (1), 38-49, 2012. Disponível em:<https://pt.scribd.com/document/402636022/Tanatologia-e-Logoterapia-um-Dialogo-Ontologico-pdf> Acesso em: 10 de maio. 2019.

[7] Netto, José Valdecí Grigoleto. As fases do luto de acordo com Elisabeth Kübler-Ross. In: Encontro Internacional de Produção Científica Unicesumar, 9., 2015, Paraná. Anais... Paraná: UniCesumar, 2015. p. 4-8. 
Disponível em: <http://www.cesumar.br/prppge/pesquisa/epcc2015/anais/Jose_Valdeci_Grigoleto_Netto_2.pdf>. Acesso em: 2 maio. 2019.

[8] Pereira, Ivo Studart. O Homem e a Vontade de Sentido. In: ___ A ética do sentido da vida: fundamentos filosóficos da logoterapia. São Paulo: Ideias \& Letras, 2013.

[9] ___ A ontologia dimensional de Viktor Frankl: O humano entre corpo, psiquismo e espírito. In: Logos e Existência. v.4, n.1.p. 2-13, 2015. Disponível em: <http://periodicos.ufpb.br/ojs/index.php/le/article/view/21725/13056>. Acesso em: 10 de maio.2019.

[10] Peter, Ricardo. Viktor Frankl: a antropologia como terapia. Trad. Thereza Christina Stummer. São Paulo: Paulus, 1999.

[11] Velásquez, Luiz Fernando. Os valores logoterapêuticos: sua importância ao final da existência. In: Oliveiros, Olga; Kroeff, Paulo. Finitude e Sentido da Vida: A logoterapia no embate com a tríade trágica. Porto Alegre: Editora Evangrav, 2018, p. 43-69.

[12] Xausa, Izar Aparecida de Moraes. (2003). 0 sentido dos sonhos na psicoterapia em Viktor Frankl. São Paulo: Casa do Psicólogo.

[13] Zamulak, Juliana. Autotranscedência: caminho para superação do individualismo. Curitiba: Revista da associação brasileira de Logoterapia e análise existencial, 4 (2), 130-142, $2015 . \quad$ Disponível em:<https://pt.scribd.com/document/382545803/Autotranscendencia-Caminho-Para-a-Superacao-DoIndividualismo> Acesso em: 12 de maio. 2019.

[14] Zimerman, Guite I. Velhice: aspectos biopsicossociais. Porto Alegre: Artmed, 2000. 


\title{
Capítulo 13
}

Percepção dos idosos institucionalizados quanto ao enfrentamento e a aceitação da finitude da vida

\author{
Daiany Maíra Magalhães Franca \\ Beatriz Cristina Soares Barros \\ Rafaela Maria Martins Queiroz \\ Rachel Cavalcanti Fonseca \\ Maria das Graças Silva
}

Resumo: 0 aumento da expectativa de vida muitas vezes é acompanhado pelo processo de adoecimento inerente ao envelhecimento. Essa realidade pode refletir na dependência dos idosos para a realização de atividades cotidianas, ocasionando a institucionalização dos mesmos pelos familiares. Percebendo, dessa forma, a necessidade de uma abordagem interdisciplinar e integral, promovidas pelos cuidados paliativos, os quais visam a melhoria da qualidade de vida de pacientes com doenças sem possibilidades de cura e auxiliam no enfrentamento das suas limitações. Assim, esse estudo objetiva conhecer a percepção dos idosos em relação ao embate da finitude humana. Trata-se de uma pesquisa de campo de caráter exploratório e descritivo com abordagem qualitativa. Foram avaliados 6 idosos institucionalizados de ambos os sexos residentes na instituição de longa permanência Vila Vicentina Júlia Freire no município de João Pessoa-PB, seguindo alguns critérios de inclusão. 0 instrumento utilizado para coleta de dados foi um roteiro de entrevista semiestruturado elaborado pelas pesquisadoras, envolvendo aspectos sociodemográficos dos idosos e informações relacionadas ao enfrentamento e a aceitação da terminalidade. Todo estudo respeitou a Resolução 466/12 do Conselho Nacional de Saúde a qual trata de pesquisa envolvendo seres humanos. Por fim, foi observado que a espiritualidade é uma questão muito presente na aceitação da finitude da vida e enfrentamento de momentos difíceis para os idosos institucionalizados. Ela, além de refletir em como os pacientes lidam com algumas doenças, possibilita uma melhora na qualidade de vida no geral.

Palavras-chave: Instituição de longa permanência. Espiritualidade. Idoso. Cuidados Paliativos. 


\section{INTRODUÇÃO}

Tendo em vista a dinâmica da transição demográfica e epidemiológica, é perceptível que o Brasil vive um período de acelerado envelhecimento, o que torna o aumento da expectativa de vida um fenômeno real no país. De acordo com dados do IBGE (Instituto Brasileiro de Geografia e Estatística), essa população dispõe de uma taxa de crescimento de cerca de 4\% ao ano no período de 2012-2022, o que acarretará em um acréscimo de aproximadamente 1 milhão de idosos por ano em um período de 10 anos. Isso traz importantes inferências para a sociedade como um todo, visto que população acima de 60 anos cresce em ritmo mais acelerado do que qualquer outro grupo etário (IBGE, 2015).

Nessa linha, compreende-se que esse processo envolve algumas mudanças de naturezas epidemiológicas, pois com o transcurso da longevidade humana, as doenças crônicas não-transmissíveis tornaram-se mais frequentes. Essa modificação no perfil de saúde resulta em mudanças no paradigma desses tipos de serviços, dado que é preponderante o surgimento complicações em idosos, que manifestam maior carga de doenças e incapacidade decorrentes do processo de cronicidade (SCHRAMM et al, 2004).

Entre as consequências desse processo, está o aparecimento das fragilidades e das vulnerabilidades humanas, ocasionando a dependência do outro, que estimula o processo de institucionalização, gerado pela necessidade de apoio. Em consequência, quaisquer ações destinadas aos idosos devem levar em conta a competência cognitiva, a autossuficiência e a necessidade de cuidado, confirmando, assim, a importância de uma abordagem multidisciplinar e integral, motivadas pelos cuidados paliativos, os quais, tendo em vista o contexto biopsicossocial de idosos inseridos em instituição de longa permanência, se dispõem em oferecer melhorias na qualidade de vida de pessoas com doenças incuráveis apesar das suas limitações (VERAS, 2009).

Com isso, é comum que muitas pessoas recorram a outros meios como forma de enfrentamento de determinadas questões. A espiritualidade pode ser definida como tudo aquilo que atribui um sentido à vida. Esse conceito difere da religião por abordar um significado mais amplo e abranger o sentimento individual capaz de fazer com que se suporte momentos difíceis e se supere emoções, como a culpa, raiva e ansiedade, através de crenças pessoais. Muitos pacientes utilizam desse meio para lidar com suas doenças, conseguindo enfrenta-las de uma melhor forma (SAAD, 2001).

A compreensão de que a convivência com a morte está mais presente entre os idosos institucionalizados fundamentou a pertinência desse estudo, a fim de abordar as suas percepções quanto ao enfrentamento da finitude humana.

\section{METODOLOGIA}

A pesquisa em questão é caracterizada como um estudo descritivo e transversal, de abordagem qualitativa. Com a finalidade de compreender a importância dos cuidados paliativos e identificar a percepção dos idosos institucionalizados quanto ao enfrentamento e a aceitação da finitude da vida. Segundo Minayo (2012), o estudo qualitativo tem o objetivo de buscar entender determinadas questões através de motivos, crenças, valores, significações e atitudes, possibilitando o estudo de certo grupo de acordo com a interação entre suas variáveis.

Foram realizadas entrevistas com 6 idosos, de ambos os sexos, residentes na instituição de longa permanência Vila Vicentina Júlia Freire no município de João Pessoa-PB, obedecendo os critérios de inclusão: ter idade igual ou superior a 60 anos; residir na instituição; concordar com os termos da pesquisa; responder com coerência. Como critérios de exclusão, foram analisados integrantes que não reunissem todos os parâmetros dos critérios de inclusão. A coleta de dados foi feita por meio de um questionário, o qual caracterizava o perfil sociodemográfico e uma entrevista semiestruturada com roteiro previamente estabelecido. 0 roteiro da pesquisa foi composto por 7 perguntas que buscavam esclarecer quais eram os sentimentos dos idosos diante da morte, como eles lidavam com aceitação da finitude da vida e o papel da espiritualidade nesse processo. Em seguida, realizou-se a escuta e a transcrição material coletado.

Os dados qualitativos foram interpretados através da técnica de análise de conteúdo por meio das entrevistas que abordem os temas elucidados a partir das respostas dos entrevistados. 
Tal análise terá como base aquilo que foi dito durante a entrevista ou também observado, buscando compreender o pensamento do entrevistado pelo que foi expresso no texto. A Pesquisa foi submetida a Plataforma Brasil de acordo com as exigências da Comissão Nacional de Ética em Pesquisa (CONEP), com o CAAE 94741218.2.0000.5178. Para manter o sigilo das informações e preservar os idosos, suas falas foram apresentadas por I1, I2, I3... (idosos 1, 2, 3...).

\section{RESULTADO E DISCUSSÕES}

0 estudo foi realizado com 6 idosos institucionalizados, sendo $4(66,7 \%)$ do sexo feminino e 2 (33,3\%) do sexo masculino, com idade superior a 60 anos. Dentre os integrantes, o nível de escolaridade varia desde pessoas que nunca estudaram ou que possuem ensino fundamental incompleto. Os entrevistados mostraram-se bastante religiosos diante das perguntas.

Após a análise das falas dos idosos participantes emergiram as seguintes temáticas:

\section{MORTE E OS SEUS SENTIMENTOS}

A morte é uma fase do ciclo da vida humana que sempre foi interpretada de forma diferente quando comparada a sua definição e o seu significado em culturas, períodos e religiões. Nesse sentido, a finitude da vida também pode assumir conceitos intrínsecos, gerando sentimentos como medo ou aceitação grata. Assim, tendo como fato a terminalidade, o simbolismo da morte deve ser valorizado, junto com a problematização da questão existencial de cada ser (SILVA, 2017). Frente a essa temática, percebeu-se na maioria desses idosos que a morte é abordada como a atenuação de um fardo que a vida lhes trouxe.

"A morte é um descanso do mundo, é uma lição que todos têm que passar". (I3)

"A morte é uma realidade [...] é uma passagem para a outra vida, que eu sei que é muito boa, pois lá estará o nosso salvador e redentor". (I6)

"Morte é reviver, voltar a vida eterna de acordo com sua obediência, sua fé, sua crença. Crendo no Deus verdadeiro e que Jesus é filho de Deus [...]” (I4).

Além disso, a maioria mostrou ter poucas inquietações quanto à finitude, referindo-se preparados para tal momento, aspecto percebido pelos marcantes traços da fé nas suas falas.

"Não penso sobre a morte, mas não tenho medo, aprendi isso com o tempo e as experiências vividas pelo mundo. Hoje estou preparado". (I3)

"Não tenho medo, antes eu tinha, mas passou. Antes eu tinha medo de morrer sem me confessar, mas hoje estou preparada". (I6)

Frente a essas respostas, evidencia-se que a particularidade em relação à morte é expressa em sentimentos que não se constroem apenas enquanto o cérebro realiza conexões para responder perguntas, mas durante o transcorrer da existência, a partir de experiências e de saberes acumulados.

\section{ENFRENTAMENTO E ESPIRITUALIDADE}

Levando em consideração a delicadeza do assunto "morte", buscou-se conhecer a forma como se comportavam diante de uma situação conflituosa do cotidiano, pois o valor que cada pessoa dá aos momentos de sofrimento é fruto das crenças pessoais. Nesse âmbito, foram coletadas respostas concernentes ao que eles utilizavam (ou o que faziam) para enfrentarem momentos difíceis das suas vidas, e as respostas foram:

"[...] refletindo, lendo a Bíblia e os Salmos que nos encorajam, ouvindo e aprendendo, pois somos eternos aprendizes. E, quando não nos sentimos capazes, Deus nos capacita". (I4)

“Quando estou triste e chorando, Deus me anima e eu não fico adoecendo e sem comer por isso". (I5) 
Diante desse cenário, nota-se que a espiritualidade é uma ferramenta utilizada para o enfrentamento das dificuldades da vida, pois possibilita vislumbrar o propósito da existência para solucionar conflitos, fato que promove que resistência ao estresse (ROCHA, 2014).

\subsection{ESPIRITUALIDADE E FINITUDE}

Ao entender a utilização da espiritualidade no enfrentamento e no auxílio das adversidades, é indiscutível a importância que ela assume diante do enfrentamento da morte. Com isso, buscou-se entender a percepção dos idosos quanto a contribuição da espiritualidade diante da aceitação da finitude humana.

"A espiritualidade me ajuda muito. $O$ que mais quero alcançar na minha vida é contemplar a face de Deus e receber a minha coroa, o meu galardão". (I4)

"Se houver fé, Deus é capaz de nos livrar de muita coisa e pode nos ajudar a ter uma passagem tranquila da vida para a morte". (I3)

"A nossa relação com Deus ajuda a enfrentar a morte, porque esperamos Nele e confiamos, pois Ele é o criador de todas as coisas". (I6)

Nesse contexto, é válido ressaltar que o cotidiano desses idosos que fazem uso da espiritualidade é caracterizado pela presença de questões existenciais positivas. Essas características explícitas nas suas respostas servem como de ponto de apoio para a busca do sentido verdadeiro da vida e de tudo que já é memória, trazendo esperança e contentamento diante das possíveis angústias relacionadas à finitude (GOMES, 2010), possibilitando a manifestação de emoções positivas (NASCIMENTO et al., 2010).

\subsection{ESPIRITUALIDADE E CUIDADO}

A partir do entendimento do valor da espiritualidade na vida dos idosos institucionalizados, é válido apresentar a prática biopsicossocial e espiritual dos cuidados em saúde como uma atenção integral ao homem, pois essa abordagem coloca em evidência as suas crenças diante das circunstâncias sociais, psicológicas e biológicas.

Tendo em vista os benefícios que a relação com o transcendente traz ao homem, identificou-se nas falas dos idosos o desejo quanto a uma abordagem profissional que valorizasse suas dimensões espirituais, característica voltada ao cuidado integral e multidimensional do indivíduo.

"Esse tema é pouco abordado [...]. É importante que os profissionais preparem mais os pacientes para a morte com a ajuda da espiritualidade, pois pelo vestibular passa pouca gente, mas pela morte passam todos". (I3)

"Acho muito importante conversar sobre isso. [...] ajuda a não ter medo da morte [...]. Eu mesmo já estou esperando o dia que vou a presença do Deus Todo Poderoso". (I6)

Com isso, é possível afirmar que o conhecimento sobre as crenças e os desejos dos idosos é um fator facilitador do cuidado, visto que aproxima o profissional da realidade de cada ser, proporcionando confiança na relação e eficiência no processo do cuidar (PERES, 2007).

\section{CONSIDERAÇÕES FINAIS}

Diante desse estudo constatou-se que o processo de institucionalização é um fator do aumento da expectativa de vida. Desse modo, estudos que visem abordar a percepção de idosos institucionalizados quanto ao enfrentamento e a aceitação da morte são necessários, pois a vivência deles com a finitude da vida é real e marcante, além de ser um tema de grande valor social, visto que perpassa todos os indivíduos.

A utilização das perguntas sobre os sentimentos em relação à morte fundamenta a possibilidade da abordagem da terminalidade ligada à espiritualidade, utilizada como um apoio pela maioria dos idosos da amostra para aceitação de questões existências. Nas falas dos idosos, constatou-se o desejo quanto a obtenção de um cuidado multidimensional, que deve ser realizado por profissionais capazes de reconhecer aspectos únicos em cada idoso institucionalizado, a fim de utilizá-los como potencializadores desse cuidado. 


\section{REFERÊNCIAS}

[1] Fornazari, S. A; Ferreira, R. E. R. Religiosidade/espiritualidade em pacientes oncológicos: qualidade de vida e saúde. Psicologia: Teoria e Pesquisa, v. 26, n. 2, p. 265-272, 2010.

[2] Gomes R. Espiritualidade e cuidados paliativos: Alguns pontos para reflexão. Espaço, Instituto São Paulo de Estudos Superiores, v. 18, n. 2, p.187-196, 2010.

[3] IBGE - Instituto Brasileiro de Geogrsfis e Estatística. Mudança demográfica no Brasil no início do século XXI: subsídios para projeções da população. Rio de Janeiro, 2015, 156p.

[4] Minayo, M. C.S. Análise Qualitativa: Teoria, Passos e Fidedignidade. Ciênc. saúde coletiva, Rio de Janeiro, v. 17, no $3,2012$.

[5] Nascimento, L.C. et al. Cuidado espiritual: componente essencial da prática da enfermeira pediátrica na oncologia. Acta Paulista de Enfermagem, v. 23, n. 3, p. 437-440, 2010.

[6] Peres, J.P.P.; Simão, M.J.P.; Nasello, A.G. Espiritualidade, religiosidade e psicoterapia. Revista de Psquiatria Clínica, v. 34, n. 1, p. 136-145, 2007.

[7] Rocha, A.C.A.L. da; Ciosak, S.I. Doença Crônica no Idoso: Espiritualidade e Enfrentamento. Revista da Escola de Enfermagem da USP, v. 48, n. 2, p. 92 - 98, 2014.

[8] Schramm, J. M. A. et al . Transição epidemiológica e o estudo de carga de doença no Brasil. Ciênc. saúde coletiva, Rio de Janeiro, v. 9, n. 4, p. 897-908, Dec. 2004

[9] Silva, F.R.S da.; BARBOSA, J.T.C.; Júnior, J.J.A. de. Espiritualidade em cuidados paliativos: reflexões acerca da terminalidade e da atuação/formação do enfermeiro. Disponível em: http://www.convibra.com.br/upload/paper/2017/156/2017_156_13948.pdf Acesso em: 22/05/2019 às 16:45

[10] Veras, Renato. Envelhecimento populacional contemporâneo: demandas, desafios e inovações. Rev. Saúde Pública, São Paulo , v. 43, n. 3, p. 548-554, jun. 2009. 


\title{
Capítulo 14
}

Envelhecimento e resiliência: Uma leitura da política nacional de saúde da pessoa idosa

\author{
Almira Lins de Medeiros \\ Ayanna Carla de Moraes Gerôncio \\ Larissa Pontes Carvalho Gomes \\ Rita de Cassia Dantas Freitas \\ Emily Souza Gaião e Albuquerque
}

"Os acidentes individuais, tudo o que pode acontecer na vida de alguém, seja a doença, seja esta coisa que chega de todo modo, que é a velhice, não podem constituir um perigo nem para os indivíduos nem para a sociedade." (FOUCAULT, 2008b, p. 89).

Resumo: 0 presente estudo realiza uma leitura da Política Nacional de Saúde da Pessoa Idosa tomando como base conceitos-chave como envelhecimento, vulnerabilidade e resiliência. A partir da análise desta legislação, objetiva-se verificar como nela se encontram previstas as condições de existência de fatores de proteção que contribuem para condutas próprias de pessoas resilientes. 0 método utilizado foi uma revisão de literatura associada à análise documental. No texto da legislação em estudo, os fatores de proteção encontrados relacionam-se a redes de apoio social, suporte familiar e atributos disposicionais positivos. Concluiu-se que os fatores de proteção que podem favorecer o lidar com problemas e superar obstáculos na velhice não possuem estratégias específicas por meio das quais a proteção possa ser efetivada; atribuem-se ao idoso responsabilidades do Estado; e favorece-se a inserção do idoso no sistema de pares, mas se "desconhece" a importância das relações intergeracionais. 0 estudo indicia a possibilidade de pesquisas outras que aprofundem as análises, por isso constitui-se enquanto suporte para o desenvolvimento destas.

Palavras-chave: Envelhecimento, Políticas públicas, Vulnerabilidade, Resiliência. 


\section{INTRODUÇÃO}

Baseado no Censo de 2010, o Instituto Brasileiro de Geografia e Estatística (IBGE) estima que a população de idosos deve passar de 14,9 milhões (7,4\% do total), em 2013, para 58,4 milhões (26,7\% do total), em 2060. Neste período, a expectativa média de vida do brasileiro deve aumentar dos atuais 75 anos para 81 anos.

O aumento da população de idosos tem sido festejado como um ganho de vida desejado. Entretanto, este traz consigo um aumento da ocorrência de problemas de saúde em função das modificações próprias do corpo idoso, das mudanças de seus papéis sociais e da forma como eles aprenderam a lidar com as limitações da velhice. Este fenômeno tem sido tratado como um problema social em função da sobrecarga que pode gerar ao sistema de saúde e aos indivíduos que têm sob sua responsabilidade um idoso que não consegue se manter ativo/saudável.

Para além de prováveis problemas derivados desse fenômeno, espera-se que os idosos, como qualquer outro segmento da sociedade, não sejam colocados à margem dos direitos universais à saúde, da inclusão em redes de apoio social e de condições de participação social efetiva. Do mesmo modo que não lhes seja negada a promoção de suporte familiar e de condições de manutenção da autoestima, em um nível que não lhes traga prejuízo ao seu desempenho funcional. Posto serem estas garantias que predeterminam a sua capacidade adaptativa, de recuperação e superação de adversidades, apesar das fragilidades próprias da velhice.

A existência de legislação, diretrizes, orientações que estruturam as políticas públicas de saúde e dão forma a sua efetivação ; a verificação de que os idosos constituem-se em grupo de risco, no qual incidem as diferentes dimensões de vulnerabilidade; o reconhecimento da influência de fatores de proteção na maneira como os indivíduos respondem aos processos adaptativos, requeridos na presença de eventos estressores, nos levam a perguntar sobre como as condições favoráveis à existência desses fatores têm sido contempladas nas estruturações, acima referidas.

Ainda que identifiquem, no cenário nacional, a existência de Diretrizes para o cuidado das pessoas idosas no SUS, enquanto proposta de modelo de atenção integral elaborada, em maio de 2014, no XXX Congresso Nacional de Secretarias Municipais de Saúde e de Orientações técnicas para a implementação de Linha de Cuidado para Atenção Integral à Saúde da Pessoa Idosa no Sistema Único de Saúde, estabelecidas, em 2018, pelo Ministério da Saúde, neste estudo elegeu-se como objeto de análise a Política Nacional de Saúde da Pessoa Idosa, em função desta se constituir em marco referencial e porque a condição de funcionalidade, nela, é tratada como importante indicador de saúde desta população. Fazendo-nos crer que a promoção de fatores que predisponham a comportamentos resilientes, nela, sejam contemplados.

Alinhando-se às discussões sobre estratégias de promoção de saúde e prevenção de doenças de idosos, este artigo tem como objetivo analisar o texto da Política Nacional de Saúde da Pessoa Idosa, no sentido de identificar como, nela, se encontram previstas as condições de existência de fatores de proteção que contribuem para condutas resilientes.

\section{METODOLOGIA}

Para a análise proposta, utilizou-se de revisão de literatura associada à análise documental. A revisão de literatura permitiu mapear os condicionantes de fatores de proteção ao idoso. A análise documental deuse no movimento de descrição e problematização dos trechos da Política Nacional de Saúde da Pessoa Idosa, anexo da Portaria do Ministério da Saúde no 2.528 de 19 de outubro de 2006, que se referem, direta ou indiretamente, à estes fatores.

\section{DESENVOLVIMENTO}

O envelhecimento não é um processo unitário. 0 organismo não envelhece, como um todo, simultaneamente, apesar de se entender que haja uma finitude geneticamente programada na capacidade das células de regenerarem-se. Os déficits físicos, cognitivos e comportamentais decorrem de um conjunto de alterações biológicas com eventos em nível de moléculas e células (SANTOS; ANDRADE; BUENO, 2009). 
Se uns teóricos admitem que os genes predeterminam a velocidade com que se envelhece, encontram explicações para o processo em fatores genéticos; outros entendem que as alterações de ordem fisiológica dependem, sobremaneira, do estilo de vida da pessoa desde a infância. Além do envelhecimento em nível biológico, que diz respeito às modificações dos órgãos, ao seu funcionamento e à capacidade de autorregulação, pode se referir ao envelhecimento social, relativo aos papéis sociais, e o psicológico referente às competências condutuais, as respostas à mudança de ambiente que envolvem inteligência, memória e motivação (CANCELA, 2007).

0 envelhecimento social encontra-se diretamente relacionado à maneira como diferentes culturas tratam a pessoa idosa. Um indivíduo é considerado idoso, em uma sociedade particular, dependendo de como se comporta em relação aos papéis determinados para a sua idade. Estes, por sua vez, variam no tempo histórico de acordo com critérios estabelecidos para agrupar as diferentes faixas etárias. Assim, a velhice é uma experiência heterogênea, vivida como um desengajamento da vida social ou o início de uma vida social prazerosa (SCHNEIDER; IRIGARAY, 2008).

O envelhecimento psicológico diz respeito a várias características (aprendizagem, memória, inteligência e controle emocional, entre outras), que permitem que os indivíduos se adaptem ao meio (CANCELA, 2007). De acordo com tal capacidade de adaptação, adultos podem ser considerados jovens ou velhos psicologicamente (SCHNEIDER; IRIGARAY, 2008).

Na velhice são intensificados os riscos para o desenvolvimento de vulnerabilidades de natureza biológica, socioeconômica e psicossocial. A vulnerabilidade pode ser entendida como uma junção de fatores individuais e coletivos que resulta em uma baixa possibilidade de enfrentamento perante as circunstâncias da vida e uma alta suscetibilidade ao adoecimento e à morte, ou seja, é um estado em que o indivíduo tem sua capacidade de autodeterminação reduzida, podendo apresentar dificuldades para proteger seus próprios interesses (RODRIGUES; NERI, 2012).

Ayres et al. (2003) compreendem a vulnerabilidade como sendo um produto da interação de três distintos planos, denominados de individual, social e programático. A primeira englobaria os fatores biológicos, emocionais, cognitivos atitudinais e referentes às relações sociais. 0 idoso, devido às alterações biológicas, torna-se menos capaz de manter a homeostase quando está sujeito a um estresse fisiológico. Tais mudanças provocam maior suscetibilidade à ação de doenças, crescente vulnerabilidade e maior probabilidade de morte (PAZ, 2006). Desta forma, a vulnerabilidade individual é observada no declínio da capacidade funcional que com frequência conduz a pessoa idosa à limitação ou perda total da capacidade de desempenhar, de forma independente, suas atividades cotidianas.

A vulnerabilidade social é caracterizada por aspectos culturais, sociais e econômicos que indicam a possibilidade de acesso a bens e serviços, como a disponibilidade de recursos materiais, poder de influenciar decisões políticas, oportunidade de enfrentar barreiras culturais, defender-se de coerções violentas, bem como os aspectos que envolvem a estrutura, a organização e a dinâmica familiar. No Brasil, o baixo valor das aposentadorias contribui para a vulnerabilidade social, pois expõe não apenas a pessoa idosa, mas todo seu seio familiar que sobrevive com esse recurso.

A vulnerabilidade programática remete aos recursos sociais necessários para proteger o indivíduo de riscos à integridade e ao bem-estar físico, psicológico e social. 0 plano programático engloba o acesso e a forma de organização dos serviços de saúde, abarca programas voltados à prevenção, à assistência e ao controle. Seu funcionamento ocorre em nível nacional, regional ou local, e os responsáveis pela execução são os governos federal, estadual e municipal ou até mesmo as organizações não-governamentais. Esse plano sugere que o acesso à qualidade dos programas e o compromisso das instituições são determinantes importantes para a distribuição das condições de saúde e bem-estar.

Em maior ou menor influência, aspectos individuais, coletivos, contextuais e históricos das experiências de desenvolvimento e do envelhecimento produzem possibilidades de adoecimento e dificuldades de acesso aos recursos de proteção disponíveis na sociedade. Observa-se espaços de violência no que se refere à omissão do Estado na oferta e na avaliação de instituições que promovem assistência aos idosos. 0 plano da vulnerabilidade programática sugere que o acesso à qualidade dos programas e o compromisso das instituições são determinantes importantes para a distribuição das condições de saúde e bem-estar. 
Conhecer a vulnerabilidade desse grupo possibilita mobilizar a sociedade através de um processo educativo construtivista, para transformações sociais. Estas devem ser alicerçadas nas relações entre setores e na ação comunicativa entre os sujeitos sociais. Vê-se, portanto, a importância de diferentes formas de enfrentamento, em termos assistenciais, de tratamento clínico e de reabilitação, e também na implementação de políticas públicas e de ações de prevenção de doenças, bem como promoção de saúde da população de forma integral e eficaz. Diante dos riscos e desafios nesta etapa da vida, para que o funcionamento adaptativo do idoso possa ser mantido, formas de enfrentamento podem colaborar para um aumento da resiliência na velhice (SCHAIE; HOFER, 2001 apud FORTES et al., 2009).

A resiliência é a "capacidade universal que possibilita a pessoa, grupo ou comunidade prevenir, minimizar ou superar os efeitos nocivos das adversidades, inclusive saindo dessas situações fortalecida ou até mesmo transformada, porém não ilesa"(GROTBERG, 1995 apud ANGST, 2009, p. 254).

Sendo os idosos um grupo vulnerável por sua própria condição e a resiliência "uma resposta aos diferentes tipos de vulnerabilidade, definida como a capacidade de adaptação às situações adversas ligadas aos recursos internos (intrapsíquicos) e externos (ambiente social e afetivo)" (RINCO, LOPES \& DOMINGUES, 2012, p. 88), essa competência pode vir a possibilitar uma construção psíquica adequada à inserção social.

O comportamento resiliente pode permitir que os indivíduos estabeleçam ou mantenham o seu nível de bem-estar mesmo perante situações adversas, ou seja, compreender que não são os fatos que importam, mas o significado dado a estes fatos. Fatores de proteção auxiliam a pessoa a atenuar eventuais efeitos negativos ou disfuncionais na presença de risco "modificam ou melhoram a resposta de uma pessoa a algum perigo que predispõe a um resultado não adaptativo, e que parecem mudar ou reverter circunstâncias potencialmente negativas" (MOTA et al., 2006 apud ANGST, 2009, p. 255). Torna-se importante não apenas a identificação de possíveis fatores de proteção, mas também a compreensão da forma como eles atuam na redução dos impactos das dificuldades enfrentadas (RUTTER, 1987).

No tocante da resiliência, três classes principais de fatores de proteção foram identificadas: disponibilidade de redes de apoio social que encorajem o indivíduo a lidar com as adversidades; atributos disposicionais, como autoestima; coesão familiar e ausência de conflitos (MASTEN; GARMEZY, 1985). Para Brito e Koller (1999), rede social é uma interconexão entre o indivíduo e o sistema social que ele está inserido. Fornece subsídios para definir as formas como a pessoa percebe seu ambiente e se orienta nele, bem como suas estratégias e capacidades para estabelecer relações e enfrentamento dos problemas, colabora diretamente com o bem-estar do idoso, não obstante também pode provocar sofrimento e dor. 0 apoio social pode também agir como um mecanismo de auxílio a terceira idade para lidar e enfrentar situações estressantes, auxiliando em seu manejo e proporcionando apoio emocional.

Rutter (1987) afirma que a autoestima causa no sujeito o bem-estar favorecendo a construção de vínculos afetivos, aumento da competência, reforça o senso de pertencimento, o fortalecimento da imagem pessoal e a promoção do senso de auto-eficácia. Assim sendo, quanto mais satisfatória for a percepção da pessoa em relação a si mesma, mais fortes serão seus sentimentos de satisfação com a vida

A família e os amigos constituem esferas da vida potencialmente capazes de fornecer apoio às pessoas nas relações sociais e diante dos eventos experimentados. A coesão familiar e a ausência de conflitos nas relações podem caracterizar-se como fatores de proteção para o desenvolvimento e a qualidade de vida das pessoas. A influência desses fatores se constitui como suporte importante no processo de envelhecimento, especialmente, pela pessoa idosa experienciar modificações biológicas, psicológicas e de papéis sociais, predispondo o indivíduo a vulnerabilidades.

\section{RESULTADOS E DISCUSSÕES}

No texto da Política Nacional de Saúde da Pessoa Idosa, ainda na introdução, observa-se o registro de que o direito universal e integral à saúde, garantido na Constituição de 1988 e reafirmado com a criação do Sistema Único de Saúde (SUS), se traduz como acesso universal e equânime a serviços e ações de promoção, proteção e recuperação da saúde. Também a reiteração de direitos sociais assegurados à pessoa idosa, como: a promoção de sua autonomia, a integração e participação efetiva na sociedade e o direito à saúde, nos diversos níveis de atendimento do SUS. 
Quando da definição das finalidades da política, a promoção de autonomia e de independência de indivíduos idosos é renovada, indicando-se que ela deva se efetivar por meio de medidas coletivas e individuais de saúde, que devem estar em consonância com os princípios e diretrizes do SUS. Nos considerandos, que antecedem a justificativa da política, se iguala saúde à autonomia e independência; ressaltam-se a participação ativa dos idosos na sociedade, a promoção do envelhecimento saudável e a criação de um entorno favorável ao envelhecimento. Dentre as diretrizes da política, no que diz respeito a assegurar as condições de existência de fatores de proteção, sobressaem-se a promoção do envelhecimento ativo e saudável, a atenção integral, integrada à saúde da pessoa idosa, o provimento de recursos capazes de assegurar qualidade da atenção à saúde da pessoa idosa, o estímulo à participação e fortalecimento do controle social e a articulação intersetorial.

Ao se discorrer sobre a promoção do envelhecimento ativo e saudável, destaca-se a sua definição, a partir de componentes que envolvem o engajamento social ativo com a vida. Evidencia-se a menção de que essa forma de envelhecimento requer, além do cuidado consigo mesmo, a existência de ambientes amistosos e a solidariedade entre as gerações. Requerendo, outrossim, que os indivíduos e a família se preparem para a velhice. 0 sujeito idoso, nessas orientações, é considerado como um agente das ações a ele direcionadas, que deve valorizar os aspectos da vida em comunidade e identificar-se com o potencial para o bem-estar físico, social e mental ao longo do curso da vida.

Como promoção do envelhecimento ativo e saudável, se pode sublinhar a orientação de que não se despreze as oportunidade de, baseado em critérios de risco, desenvolver e valorizar o atendimento acolhedor e resolutivo à pessoa idosa; estimular a solidariedade para com esse grupo etário; facilitar a participação das pessoas idosas em equipamentos sociais, onde o idoso possa ser ouvido e apresentar suas demandas e prioridades; promover a participação nos grupos operativos e nos grupos de convivência, com ações de promoção, valorização de experiências positivas e difusão dessas na rede, nortear e captar experiências.

Reza o texto da Política, que a atenção integral, integrada à saúde da pessoa idosa, deve ser estruturada nos moldes de uma linha de cuidados, ter como foco o usuário, e a consideração de seus direitos, necessidades, preferências e habilidades. Enquanto práticas de cuidados exige abordagem global, interdisciplinar e multiprofissional, que se leve em conta a influência recíproca de fatores físicos, psicológicos e sociais na saúde dos idosos e a importância do ambiente no qual está inserido. Todos níveis da atenção deve ter por meta a preservação da autonomia e da independência funcional dos idosos e como eixos norteadores o enfrentamento de fragilidades da pessoa idosa, da família e do sistema de saúde e a promoção de saúde e da integração social.

No provimento de recursos capazes de assegurar qualidade da atenção à saúde da pessoa idosa se assinala que os fluxos de financiamento devem ter por base as programações ascendentes de estratégias que possibilitem a valorização e o cuidado humanizado ao indivíduo idoso. Como estímulo à participação e fortalecimento do controle social se indica a inclusão, nas Conferências Municipais e Estaduais de Saúde, de temas relacionados à atenção à população idosa, compreendendo-se que esta inclusão possibilita que idosos participem da elaboração das deliberações referentes à saúde e do posterior controle do cumprimento destas.

Tratando-se da articulação intersetorial, destaca-se a educação e a previdência social. A primeira com a indicação de que currículos e programas possam ser discutidos e readequados, nas instituições de ensino superior abertas para a terceira idade. A segunda, quando se trata do SUS, e se prevê implantação e implementação de Centros de Convivência e Centros-Dia, conforme previsto no decreto no1948/96.

A leitura do texto da Política Nacional de Saúde da Pessoa Idosa nos permite tecer considerações sobre como, nesta, as condições de existência de fatores de proteção se encontram expressas. Como, a partir de seus determinantes, das estratégias previstas, a capacidade de condutas resilientes possam vir a ser desenvolvidas pela população idosa.

A alusão à previsão de proteção em vários pontos do texto da política, claramente explícita, quando se trata de direitos universais à saúde, talvez em função da maneira que convém as expressões na introdução do texto, não especifica as estratégias por meio das quais deva se efetivar. Conforme formulada, se alinha aos moldes como, utopicamente, se define atualmente a saúde a partir da própria OMS; enquanto "estado de completo bem-estar físico, mental e social, não somente a ausência de infecções e doenças" (REMOR, 1999, p. 206). 
Nas diretrizes, no seu enunciado geral e no tópico referente à promoção do envelhecimento ativo e saudável, encontramos indicação favorável à inclusão de idosos em redes de apoio social, seja pelo estímulo à participação e fortalecimento do controle social, pela valorização do atendimento acolhedor e resolutivo à pessoa idosa ou pela participação em equipamentos sociais, em grupos operativos e de convivência.

Entendemos que o favorecimento à participação em diferentes grupos, instâncias e fóruns enseja integrar o idoso em redes capazes de lhe dá o suporte na ocorrência de diversidade, enquanto meios de amparo externos à sua família. À primeira vista, a descentralização do controle com a efetiva participação do idoso, neste, nos parece desejável. Entretanto, não podemos deixar de reconhecer que esta poderá vir a se constituir como estratégia de "estado mínimo" que busca se retirar da vida dos cidadãos, atribuindo a estes a responsabilidade que em princípio seria sua. Esta possibilidade poderá a vir se configurar como vulnerabilidade programática, uma vez que se refere a uma ausência de recursos sociais necessários para proteger o indivíduo de riscos a integridade psicológico, social e físico.

A integração e participação efetiva de idosos na sociedade, mencionada na introdução do texto da Política, tem sua promoção indicada quando, nos seus itens 5.1 e 5.2, se discorre sobre articulação intersetorial, no tocante a educação e a previdência social. A interconexão entre o indivíduo e o meio social no qual está inserido, num sistema de pares, poderia se efetivar por meio de instituições de ensino superior abertas à terceira idade e pela implantação e implementação de centros de convivência para idosos. Entendemos que a inserção em um sistema de pares favorece o encontro com o outro "igual", mas não promove as relações intergeracionais.

É possível entrever, nas finalidades da Política, a intenção de promoção de suporte familiar na medida em que se faz alusão a criação de um entorno propício e favorável ao envelhecimento. Intenção reiterada, no discurso das diretrizes, quando se adverte sobre os requisitos de um envelhecimento saudável, sobre este requerer além do cuidado consigo mesmo, a existência de ambiente amistosos e a solidariedade entre as gerações. Somos levados a supor que este envolva coesão no âmbito da família, ausência de conflitos e relações parentais satisfatórias. Todavia, não conseguimos vislumbrar a previsão de ações que os efetivem.

Ao se tratar de "atenção integral, integrada à saúde da pessoa idosa", nos chama atenção o registro de que esta deva ter como foco o usuário, suas preferências e habilidades. Esperávamos, entretanto, que estes atributos individuais não fossem apenas referidos nas recomendações relativas ao trato com o idoso, mas como objetivos de metas a serem alcançadas, no sentido do incentivo ao cultivo da autoestima e autoimagem.

Ademais, nos causou estranhamento o fato de que, ao se tratar de provimento de recursos capazes de assegurar qualidade da atenção à saúde da pessoa idosa, não se fizesse menção, entre os itens considerados prioritários, àqueles relativos a condições de existência de fatores proteção que favoreçam uma conduta resiliente. Também nos sobreveio uma incerteza sobre ser viável se requerer que os indivíduos idosos e a sua família se preparem para a velhice. Nesse sentido, aguardamos que a solicitação implícita na assertiva, seja provida do suporte necessário para que o idoso, ainda que em condições de vulnerabilidades, possa ultrapassar seus limites, conduzindo a vivência de sua velhice de forma satisfatória; ser capaz de passar por eventos estressores e retomar seu cotidiano de maneira resiliente.

\section{CONSIDERAÇÕES FINAIS}

Na Política Nacional de Saúde da Pessoa Idosa, quando se trata de fatores de proteção capazes de favorecer o lidar com problemas e superar obstáculos entre aqueles que vivem a velhice, não são especificadas as estratégias por meio das quais se efetive a proteção enunciada. Além disso, atribuem-se ao idoso responsabilidades que seriam a priori do Estado. Outrossim, na medida que favorece a inserção do idoso no sistema de pares, se "desconhece" a importância das relações intergeracionais.

A ideia de saúde enquanto completo bem-estar, ainda que na presença de enfermidades, guarda certa similaridade com a ideia de uma resiliência utópica, que não requeresse a existência de fatores que a condicionam. Tal similaridade parece incidir no texto da Política, uma vez que nela figura a ideia de proteção atribuindo a esta um status de um horizonte que se repõe sem que possamos identificar as vias pela qual iremos alcançá-la. 
Quando, a partir da leitura do texto da Política, sobrevêm dúvidas sobre a possibilidade de se providenciar as condições favoráveis aos fatores condicionantes de condutas resilientes entre idosos, teme-se que esse grupo etário possa vir a apresentar uma baixa possibilidade de enfrentamento perante as circunstâncias da vida, que cada vez mais se distanciam da capacidade de passar por uma situação adversa, conseguir superá-la e sair dela fortalecido.

Questiona-se sobre a responsabilidade do Estado frente à garantia de direitos constitucionais às populações em risco, no tocante à saúde; à redução do risco de doença e de outros agravos aos indivíduos nessas condições; bem como o acesso universal e igualitário às ações e serviços para sua promoção, proteção e recuperação, tal como reza o texto da lei - garantia conseguida por meio de muitas lutas, pelo envolvimento de muitos atores sociais.

Sem as condições de efetivação dessas garantias, somos levados a admitir que, numa perspectiva de governança dos sujeitos idosos, as políticas que a eles dizem respeito, da maneira como se constituem, parecem não conseguir atingir o objetivo de salvaguardar os indivíduos e a sociedade, como um todo, dos perigos advindos desta coisa que chega de todo modo, que é a velhice.

A análise do conjunto de medidas legais que regem a implementação da política poderá ser mais proveitosa quanto à identificação de condições de existência de fatores de proteção que favoreçam as condutas resilientes. A verificação da prática desenvolvida nos diferentes equipamentos de saúde que atendem idosos poderão contribuir para a visualização de estratégias, em curso, que visem garantir condições de existência de fatores condicionantes de resiliência. Pesquisas desenvolvidas nesse sentido contribuirão para dirimir dúvidas sobre a persistência/desdobramentos das omissões identificadas no texto analisado.

\section{REFERÊNCIAS}

[1] ANGST, Rosana. Psicologia E Resiliência: Uma revisão de literatura. Psicol. Argum., Curitiba, v. 27, n. 58, p. 253-260, jul./set. 2009. Disponível em https://periodicos.pucpr.br/index.php/psicologiaargumento/article/view/20225/0. Acesso em: 18 de novembro de 2018.

[2] Ayres, José Ricardo de Carvalho Mesquita; FrançA Junior, Ivan; Calazans, Gabriela Junqueira; Saletti Filho, Heraldo César. C. O conceito de vulnerabilidade e as práticas de saúde: novas perspectivas e desafios. In: Czeresnia, Dina; Freitas, Carlos Machado de. Promoção da saúde: conceitos, reflexões, tendências. Rio de Janeiro: Fiocruz, 2003. p. 117-139.

[3] Brasil. Congresso Nacional, Lei no 8.842. Dispõe sobre a política nacional do idoso, cria o Conselho Nacional do Idoso e dá outras providências. Brasília, 04 de janeiro de 1994.

[4] _ Constituição (1988). Constituição da República Federativa do Brasil. Brasília, DF: Senado Federal: Centro Gráfico, 1988.

[5] Brito, Raquel Cardoso; Koller, Silvia Helena. Desenvolvimento humano e redes de apoio social e afetivo. In: Carvalho, Alysson Massote (Org.). 0 mundo social da criança: natureza e cultura em ação. São Paulo: Casa do Psicólogo, 1999.

[6] Cancela, Diana Manoela Gomes. O processo de envelhecimento. 2007. Disponível em http://www.psicologia.pt/artigos/textos/TL0097.pdf. Acesso em: 10 de setembro de 2018.

[7] Fortes, Tatiane Favarin Rech.; Portuguez, Mirna Wetters; Argimon, Irani Iracema de Lima. A resiliência em idosos e sua relação com variáveis sociodemográficas e funções cognitivas. Estud. psicol. (Campinas) [online], v. 26, n. 4, p.455-463, 2009.

[8] Foucault, Michel. Nascimento da Biopolítica. São Paulo: Martins Fontes, 2008.

[9] Masten, Ann S.; Garmezy, Norman. Risk, vulnerability, and protective factors in developmental psychopathology. In: Larey, Benjamin B.; Kazdin, Alan E. (Eds). Advances in clinical child psychology, v. 8, New York: Plenum, 1985.

[10] Paz, Adriana Aparecida.; Santos, Beatriz Regina Lara; EIDT, Olga Rosaria. Vulnerabilidade e envelhecimento no contexto da saúde. Acta Paul Enferm., v. 19, n. 3. p. 338-342, 2006. Disponível em: http://www.scielo.br/pdf/ape/v19n3/a14v19n3.REMOR, Eduardo Augusto. Psicologia da saúde: apresentação, origens e perspectivas. Revista Psico, Porto Alegre, v. 30, n.1, p. 205-217, 1999.

[11] Rinco, Michelle; Lopes, Andrea; Domingues, Marisa Accioly. Envelhecimento e Vulnerabilidade Social: discussão conceitual à luz das políticas públicas e suporte social. Rev. Temática Kairós Geront., São Paulo, v. 15, n. 6, p. 79-95, 2012. Disponível em: http://revistas.pucsp.br/index.php/kairos/article/view/17288/12828 
[12] Rodrigues, Natália Oliveira; Neri, Anita Liberalesso. Vulnerabilidade social, individual e programática em idosos da comunidade: dados do estudo Fibra, Campinas, SP, Brasil. Ciênc. saúde coletiva, Rio de Janeiro, v. 17, n. 8, p. 2129-2139, 2012. Disponível em: http://taurus.unicamp.br/bitstream/Reposip/97460/1/2-s2.0-84865239402.pdf.

[13] Rutter, Michael. Psychosocial resilience and protective mechanisms. American Journal of Orthopsychiatric, v. 57, n. 3, p. 316-331, 1987.

[14] Santos, Flávia Heloisa dos Santos; Andrade, Vivian Maria; BUENO, Orlando Francisco Amodeo. Envelhecimento: um processo multifatorial. In: Psicologia em Estudo, Maringá, v. 14, n. 1, p. 3-10, jan./mar. 2009. Disponível em http://dx.doi.org/10.150/S1413-73722009000100002. Acesso em 18 de setembro de 2018.

[15] Schneider, Rodolfo Herberto; Irigaray, Tatiana Quarti. 0 envelhecimento na atualidade: aspectos cronológicos, biológicos, psicológicos e sociais. Estudos em Psicologia. Campinas, v. 25, n. 4, p. 585-593, out./dez. 2008. Disponível em http://www.scielo.br/pdf/estpsi/v25n4/a13v25n4.pdf. Acesso em 16 de setembro de 2018. 


\section{Capítulo 15}

Utilização das práticas integrativas e terapias complementares no manejo do refluxo Gastroesofágico: Prática baseada em evidências

\section{Thainá Caló Magalhães}

João Luis Almeida da Silva

Resumo: A doença do refluxo gastroesofágico (DGRE) é uma das patologias do sistema digestório mais prevalentes no mundo que afeta, substancialmente, a qualidade de vida do indivíduo. Embora o tratamento farmacológico seja comum, a busca por tratamentos não farmacológicos adicionais tem crescido amplamente. Nesse contexto, as Práticas Integrativas e Terapias Complementares surgem como uma possibilidade terapêutica e funcionam como tecnologias do cuidado não invasivas, que ao considerar a multidimensionalidade do indivíduo buscam a saúde através do equilíbrio das diversas dimensões do ser humano. 0 presente estudo objetivou identificar o método terapêutico alternativo considerado mais eficaz no manejo da DGRE. Trata-se de uma pesquisa utilizando a metodologia da Prática Baseada em Evidências. Foi realizada uma busca nas bases de dados PubMed, Cochrane, Medline e Lilacs, utilizando como descritores "Gastroesophageal Reflux" e "Complementary Therapies" e, seus equivalentes em português e espanhol, selecionando publicações do período de 2014 a 2018 que estivessem com o resumo ou o arquivo completo disponíveis na íntegra. Foram selecionados 8 estudos para a realização da avaliação crítica da melhor evidência, concluindo-se que uma consulta expandida moldada a partir das consultas da medicina integrativa e complementar é a ferramenta mais eficaz para a redução dos sintomas da DGRE.

Palavras-chave: Prática Baseada em Evidências; Refluxo Gastroesofágico; ProfissionalPaciente; Terapias Complementares. 


\section{INTRODUÇÃO}

A doença do refluxo gastroesofágico (DRGE) é uma condição muito comum na população e sua etiologia é multifatorial. Pode ser definida como o retorno do conteúdo gástrico para o esôgago ao invés de dar seguimento ao fluxo. É uma patologia caracterizada por sintomas típicos, como a pirose e a regurgitação, e atípicos, localizados em outros aparelhos que não são, necessariamente, o digestório, tais como sintomas orais, pulmonares e otorrinolaringológicos (RIBEIRO, et al, 2016).

Levando em consideração a diversidade de fatores que contribuem para a patogênese da DRGE, a anamnese é fundamental para suscitar as causas envolvidas no acometimento de cada indivíduo e como as mesmas podem promover a piora do quadro (HO, et al, 2016). Desse modo, a necessidade de procura por tratamentos adicionais ao farmacológico vem crescendo, e assim, surge como possibilidade a utilização das Práticas Alternativas para redução dos sintomas do refluxo, com o intuito de melhorar a condição de saúde tanto física quanto emocional, além de promover o bem-estar.

0 termo Práticas Integrativas e Terapias Complementares em Saúde (PICS) é uma denominação brasileira utilizada pela Organização Mundial de Saúde (OMS) para corresponder à Medicina Tradicional/Alternativa e Complementar (Contatore, 2015). Essas terapêuticas podem ser definidas como conjunto de práticas no cuidado baseadas em diferentes racionalidades de saúde que visam estimular mecanismos naturais de prevenção, promoção e cura. Por considerar o ser humano de forma integral, propõe atuar em todas as esferas da saúde, são elas, física, emocional, mental, espiritual e social.

Por não se encaixarem no campo da medicina convencional alopática, as PICS são utilizadas de modo complementar ao invés de substitutivas (Lima; Silva; Tesser, 2014). Seu enfoque baseia-se no entendimento da relação do homem com o todo que o cerca, essa visão holística tem um caráter muito amplo na medida em que transpõe as barreiras entre corpo, mente, espírito e cultura.

Tais terapias enfocam no alívio dos sintomas, recuperação do bem-estar e restabelecimento do equilíbrio global, visto que, o processo de adoecimento é tido como um desequilíbrio em alguma esfera do ser humano. Por serem práticas voltadas para os processos de autocura, seu foco encontra-se no tratamento do indivíduo e não da doença propriamente dita. Segundo Contatore et al (2015) "embora nem todas as práticas englobadas no rol das PICs sejam validadas cientificamente ainda, sua utilização tem crescido de maneira alarmante".

Sendo assim, esse estudo é oportuno e relevante, pois as pesquisas realizadas no Brasil sobre a aplicabilidade das PICS ainda representam um número incipiente. Desse modo, os resultados desse estudo poderão fornecer subsídios para os profissionais de saúde na escolha da abordagem terapêutica. E, ainda, impulsionar a realização de estudos para encontrar evidências de segurança e efetividade de tais prática, a fim de validá-las e ampliar sua utilização.

Por conseguinte, esse artigo teve como objetivo identificar o método terapêutico alternativo considerado mais eficaz no manejo da doença do refluxo gastroesofágico.

\section{METODOLOGIA}

Trata-se de uma revisão sistemática com embasamento na Prática Baseada em Evidências (PBE), que segundo Polit e Beck (2011) corresponde à "utilização das melhores evidências científicas aliadas ao saber tácito obtido através da experiência clínica e as preferências do paciente". A PBE é hoje uma ferramenta fundamental para a prática profissional da enfermagem. Ela fornece subsídios para a tomada de decisões clínicas, do diagnóstico até a melhor intervenção.

A melhor evidência científica advém da pesquisa clínica relevante, centrada no paciente para avaliar a precisão das medidas de diagnóstico, a força de indicadores de prognóstico e a segurança e eficácia das intervenções. A experiência clínica corresponde à habilidade de usar o know-how proveniente do conhecimento, experiências e julgamento profissional para identificar o estado de saúde e diagnóstico de um dado paciente, considerando os riscos e benefícios de uma intervenção. A preferência do paciente indica que as expectativas, vivências e preocupações do cliente devem ser levadas em consideração, deixando a cargo do profissional incorporá-los às escolhas clínicas (Pedrolo, et al, 2009).

0 percurso metodológico de tal metodologia perpassa as seguintes fases: elaboração de um problema, busca de evidências, a averiguação e análise crítica das evidências disponíveis, a implementação destas na prática e apreciação dos resultados (Pedrolo, et al, 2009). 0 presente artigo é construído com o propósito de encontrar a evidência mais eficaz, portanto, as fases seguintes não serão abordadas. 
A questão deve ser formulada utilizando a estratégia Pico (Paciente ou problema; Intervenção ou indicador; Comparação de intervenções ou controle, se houver; Outcomes ou desfecho) (Larabee, 2011). Nesse sentido, esse estudo é centrado na questão: Qual Prática Integrativa ou Terapia Complementar (I) possui maior eficácia e mais efeitos benéficos (C) na redução dos sintomas (O) em pacientes com a doença do refluxo gastroesofágico $(\mathrm{P})$ ?

Com base na questão norteadora, é realizada a busca de evidências, estas advêm de pesquisas com maior rigor científico e que utilizam indicadores de medidas de diagnóstico, tratamento, reabilitação e prevenção de agravos (OCEBM, 2011). A avaliação dos estudos quanto ao nível de evidência (NE) seguiu a Oxford Centre Evidence-Based Medicine, como mostra o Quadro 1.

\begin{tabular}{|c|c|}
\hline $\begin{array}{l}\text { Nível de } \\
\text { Evidência }\end{array}$ & Tipo de Estudo \\
\hline Level I & Systematic review of randomized trials or n-of- 1 trials \\
\hline Level II & Randomized trial or observational study with dramatic effect \\
\hline Level III & Non-randomized controlled cohort/follow-up study \\
\hline Level IV & Case-series, case-control studies, or historically controlled studies \\
\hline Level V & Mechanism-based reasoning \\
\hline
\end{tabular}

Adaptado de: OCEBM Levels of Evidence Working Group. "The Oxford 2011 Levels of Evidence". Oxford Centre for Evidence-Based Medicine. Disponível em: http://www.cebm.net/index.aspx?o=5653

A busca das evidências foi realizada no período de março a abril de 2018, na National Library of Medicine National Institutes of Health (PubMed), Medical Literature Analysis and Retrieval System Online (Medline), Cochrane Database of Systematic Reviews (CDSR) e Literatura Latino-Americana e do Caribe em Ciências da Saúde (Lilacs) utilizando os Descritores em Ciências da Saúde (DeCS): Gastroesophageal Reflux e Complementary Therapies e, seus equivalentes em português e espanhol (Reflujo Gastroesofágico, Terapias Complementarias, Refluxo Gastroesofágico e Terapias Complementares). A interação desses descritores foi realizada pelo operador booleano AND.

Além disso, a pesquisa foi limitada a humanos (população de interesse) e não houve limitação de idioma. Finalmente, os limites adicionais foram utilizados: revisão sistemática, ensaio clínico randomizado, publicações entre 2014 e 2018. A pesquisa nas bases de dados foi realizada durante os meses de março a abril de 2018. A seleção de estudos ocorreu segundo o quadro de Níveis de Evidências de Oxford, selecionando apenas publicações dos níveis I e II.

As publicações encontradas foram confrontadas com o objetivo de identificar possíveis duplicidades intra e entre as bases de dados, posteriormente foram analisadas pelo título e resumo. Para a seleção dos estudos foram utilizados como critérios de inclusão: publicações com o objetivo primário relacionado à aplicação das PICS no manejo da DGRE; revisões sistemáticas e ensaios clínicos randomizados; artigos disponíveis online para leitura na íntegra ou resumos.

Enquanto que, como critérios de exclusão foram: revisões de literatura não sistemáticas, ensaios clínicos não randomizados, estudos que fossem de coorte, transversal, quase experimental, caso-controle, caso clínico, estudo descritivo, estudo quantitativo, estudo ecológico e artigos relacionados à opinião de especialistas. Além de artigos que não relacionassem as práticas integrativas e terapias complementares ao refluxo gastroesofágico e artigos que trouxessem resultados relacionados à redução dos sintomas do refluxo como secundários.

A trajetória referente à busca, seleção, elegibilidade e inclusão das evidências científicas relacionadas à aplicação das práticas integrativas e terapias complementares na doença do refluxo gastroesofágico pode ser visualizada no fluxograma (Figura 1). 
Figura 1 - Fluxograma da seleção de evidências

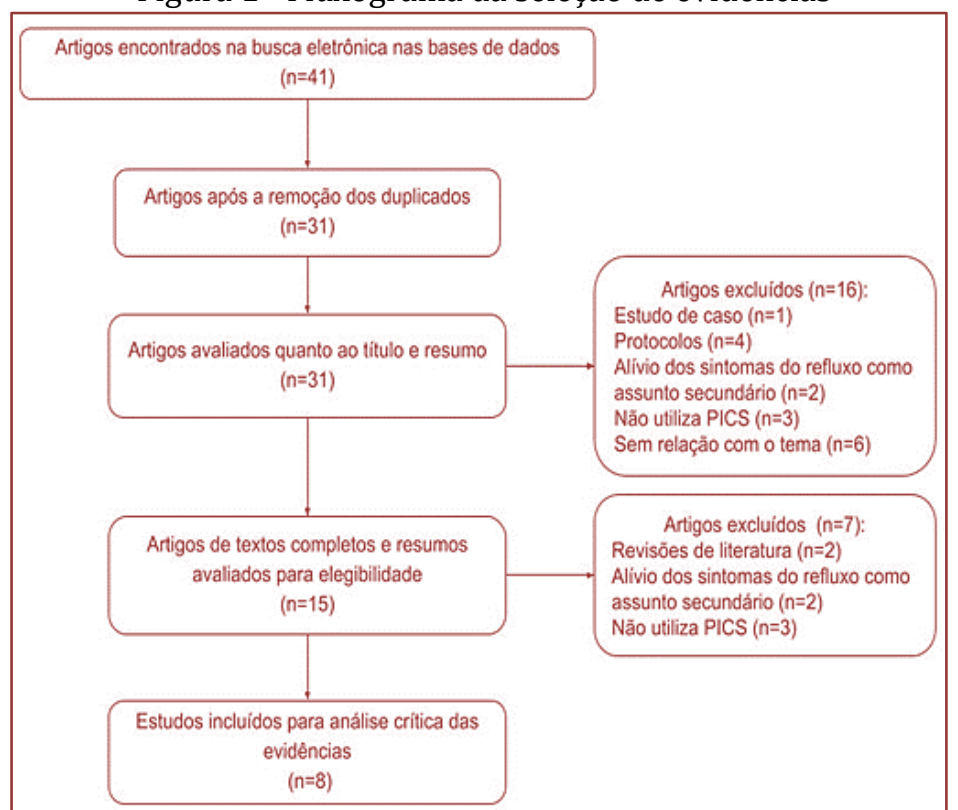

Com estratégia de busca, foram encontradas 9 publicações na base Cochrane, 16 na base MedLine, 16 na PubMed e nenhum na Lilacs, totalizando 41 achados. Posteriormente, foi investigada a existência de duplicidade entre os achados, sendo encontradas 10 duplicidades entre as bases. Após a leitura dos títulos e resumos, foram excluídas 16 publicações por não se encaixarem nos critérios de inclusão. Enquanto que das 15 publicações selecionados para avaliação completa, 7 foram excluídas por não atenderem aos critérios de elegibilidade citados no fluxograma (Figura 1). Concluído o processo de elegibilidade, 8 estudos foram incluídos para avaliação crítica quanto à validade de relevância das evidências. Alguns dos estudos consistem apenas nos resumos pois os artigos na íntegra não estavam disponíveis abertamente ou eram em chinês.

\section{PRÁTICA BASEADA EM EVIDÊNCIAS}

\subsection{RESPOSTA À QUESTÃO CLÍNICA}

Para responder à questão clínica proposta pelo presente artigo, através da análise dos artigos selecionados foi possível elaborar um quadro contendo título, referência, o tipo de paciente envolvido no ensaio clínico, amostra, método de intervenção utilizado e o método de controle (Quadro 2).

Com relação aos desfechos, em Dosset et al (2015) não houve melhoras significativas do Acidil sobre o placebo nos sintomas do refluxo gastroesofágico, no entanto, este estudo não foi desenvolvido para detectar um efeito significativo dessa substância. Apesar disso, foi observado que indivíduos que passaram por uma consulta ampliada demonstraram uma maior probabilidade de melhora dos sintomas de DRGE em comparação aos indivíduos que receberam a consulta médica padrão, independentemente dos tipos de intervenções oferecidas.

Em Eherer (2014) houve resultado positivo quanto à melhora dos sintomas da DRGE através do uso de PICS, nesse estudo a intervenção se deu através de exercícios de respiração específico aliados à musicoterapia. Tanto em Dosset et al (2015) quanto em Eherer (2014) foi percebida uma redução na utilização de medicações para melhora dos sintomas da DRGE.

Em Zohalinezhad et al (2015) não houve melhoras significativas no uso do xarope de marmelo em comparação ao xarope de omeprazol na redução dos sintomas da DGRE na pediatria, sendo ambas escolhas terapêuticas eficazes. Entretanto, a recorrência dos sintomas do refluxo foi mais lenta no grupo que utilizou o xarope de marmelo apontando para a probabilidade de uma maior duração do efeito de tal substância. 
Quadro 2: Distribuição dos artigos por título, referência, método de intervenção e intervenção controle.

\begin{tabular}{|c|c|c|c|}
\hline Título & Referência & $\begin{array}{l}\text { Método de } \\
\text { intervenção }\end{array}$ & $\begin{array}{l}\text { Intervenção } \\
\text { controle }\end{array}$ \\
\hline $\begin{array}{l}\text { Patient-Provider Interactions Affect } \\
\text { Symptoms in Gastroesophageal } \\
\text { Reflux Disease: A Pilot Randomized, } \\
\text { Double-Blind, Placebo-Controlled } \\
\text { Trial }\end{array}$ & $\begin{array}{l}\text { DOSSET, M. L.; MU, L.; DAVIS, R. B.; BELL, } \\
\text { I. R.; LEMBO, A. J.; KAPTCHUK, T. J.; YEH, } \\
\text { G. Y. Patient } \\
\text { Provider Interactions Affect Symptoms in } \\
\text { Gastroesophageal Reflux Disease: A Pilot } \\
\text { Randomized, Double-Blind, Placebo- } \\
\text { Controlled Trial. PLoS ONE, v. 10, n. 9, p. } \\
\text { e 0136855, } 2015 .\end{array}$ & $\begin{array}{l}\text { Composto } \\
\text { homeopático } \\
\text { chamado Acidil }\end{array}$ & Placebo \\
\hline $\begin{array}{l}\text { Management of gastroesophageal } \\
\text { reflux disease: lifestyle modification } \\
\text { and alternative approaches }\end{array}$ & $\begin{array}{l}\text { EHERER, A. Management of } \\
\text { Gastroesophageal } \\
\text { Reflux Disease: Lifestyle Modification } \\
\text { and Alternative Approaches. Digestive } \\
\text { Diseases. v. 32, n.1-2, p. 149-151, } 2014\end{array}$ & $\begin{array}{l}\text { Exercícios } \\
\text { respiratórios com } \\
\text { treinamento }\end{array}$ & $\begin{array}{l}\text { Exercícios } \\
\text { respiratórios } \\
\text { sem } \\
\text { treinamento }\end{array}$ \\
\hline $\begin{array}{l}\text { Effects of Quince syrup on clinical } \\
\text { symptoms of children with } \\
\text { symptomatic gastroesophageal } \\
\text { reflux disease: A double-blind } \\
\text { randomized controlled clinical trial }\end{array}$ & $\begin{array}{l}\text { ZOHALINEZHAD, M. E.; IMANIEH, M. H.; } \\
\text { SAMANI, S. M.; MOHAGHEGHZADEH, A.; } \\
\text { DEHGHANI, S. M.; HAGHIGHAT, M.; } \\
\text { SALEHJ, A.; FARIDJ, P.; AKBARZADEH, A. } \\
\text { R. Effects of Quince syrup on clinical } \\
\text { symptoms of children with symptomatic } \\
\text { gastroesophageal reflux disease: A } \\
\text { double-blind randomized controlled } \\
\text { clinical trial. Complement Ther Clin } \\
\text { Pract. v. 21, n.4, p. } 268-76,2015 \\
\end{array}$ & $\begin{array}{l}\text { Xarope de } \\
\text { marmelada }\end{array}$ & $\begin{array}{l}\text { Xarope de } \\
\text { omeprazol }\end{array}$ \\
\hline $\begin{array}{l}\text { Acupuncture for the treatment of } \\
\text { gastro-oesophageal reflux disease: a } \\
\text { systematic review and meta-analysis }\end{array}$ & $\begin{array}{l}\text { ZHU, J.; GUO, Y.; LIU, S.; SU, X.; LI, Y.; } \\
\text { YANG, Y.; HOU, L.; WANG, G.; ZHANG, J.; } \\
\text { CHEN, J. J.; WANG, Q.; WEI, R.; WEI, W. } \\
\text { Acupuncture for the treatment of gastro- } \\
\text { oesophageal reflux disease: a systematic } \\
\text { review and meta-analysis. Acupuncture } \\
\text { in Medicine. V. 35, n. 5, p. 316-323, } 2017\end{array}$ & $\begin{array}{l}\text { Acupuntura manual } \\
\text { ou } \\
\text { Eletroacupuntura } \\
\text { isoladas ou em } \\
\text { associação à } \\
\text { Medicina Ocidental }\end{array}$ & $\begin{array}{l}\text { Métodos da } \\
\text { medicina } \\
\text { ocidental }\end{array}$ \\
\hline $\begin{array}{l}\text { Clinical Trial of Acupuncture } \\
\text { Treatment of Gastro-esophageal } \\
\text { Reflex Disease by Needling Dorsal } \\
\text { Segment of the Governor Vessel. }\end{array}$ & $\begin{array}{l}\text { GAO, L. J.; BAI, X. H.; Clinical Trial of } \\
\text { Acupuncture Treatment of Gastro- } \\
\text { esophageal Reflex Disease by Needling } \\
\text { Dorsal Segment of the Governor Vessel. } \\
\text { Zhen Ci Yan Jiu. v.41, n. 2, p. 150-153, } \\
2016\end{array}$ & Acupuntura & Omeprazol \\
\hline $\begin{array}{l}\text { Comparative clinical evaluation on } \\
\text { herbal formulation Pepsil, Safoof-e- } \\
\text { Katira and Omeprazole in gastro } \\
\text { esophageal reflux disease }\end{array}$ & $\begin{array}{l}\text { TOSEEF, M. U.; SAEED, A.; MOHI-UH-DIN, } \\
\text { E.; USMANGHANI, K. NAZAR, H.; NAWAZ, } \\
\text { A.; AHMAD, I.; SIDDIQUI, F. A. } \\
\text { Comparative clinical evaluation on herbal } \\
\text { formulation Pepsil, Safoof-e-Katira and } \\
\text { Omeprazole in gastro esophageal reflux } \\
\text { disease. Pak J Pharm Sci. v. 28, n. 3, p. } \\
\text { 863-70, } 2015\end{array}$ & $\begin{array}{l}\text { Fitoterápicos Unani } \\
\text { Pepsil e Safoof-e- } \\
\text { katira }\end{array}$ & Omeprazol \\
\hline $\begin{array}{l}\text { Benefits of massage therapy for } \\
\text { infants with symptoms of } \\
\text { gastroesophageal reflux disease }\end{array}$ & $\begin{array}{l}\text { NEU, M.; PAN, Z.; WORKMAN, R.; } \\
\text { MARCHEGGIANI-HOWARD, C.; FURUTA, } \\
\text { G.; LAUDENSLAGER, M. L. Benefits of } \\
\text { massage therapy for infants with } \\
\text { symptoms of gastroesophageal reflux } \\
\text { disease. Biol Res Nurs. v. 16, n. 4, p. 387- } \\
\text { 97, } 2014\end{array}$ & $\begin{array}{l}\text { Massagem } \\
\text { terapêutica }\end{array}$ & $\begin{array}{l}\text { Tratamento } \\
\text { simulado de } \\
\text { toque / } \\
\text { método não- } \\
\text { massagem }\end{array}$ \\
\hline $\begin{array}{l}\text { Consistent Efficacy of Wendan } \\
\text { Decoction for the Treatment of } \\
\text { Digestive Reflux Disorders. }\end{array}$ & $\begin{array}{l}\text { LING, W.; HUANG, Y.; XU, J. H.; LI, Y.; } \\
\text { HUANG, Y. M.; LING, H. B.; SUI, Y.; ZHAO, } \\
\text { H. L. Consistent Efficacy of Wendan } \\
\text { Decoction for the Treatment of Digestive } \\
\text { Reflux Disorders. Am J Chin Med. v. 43, n. } \\
\text { 5, p. 893-913, } 2015\end{array}$ & $\begin{array}{l}\text { Fórmula de } \\
\text { Wendan contendo } \\
\text { gengibre (WWD) }\end{array}$ & $\begin{array}{l}\text { Não houve } \\
\text { intervenção } \\
\text { controle }\end{array}$ \\
\hline
\end{tabular}


Zhu et al (2017) apontaram efeitos benéficos no uso da acupuntura manual ou da eletroacupuntura tanto isoladas quanto em associação à medicina ocidental. Ao serem utilizadas isoladamente não apresentam resultados significativos em relação à medicina ocidental, entretanto, como adjuvantes apresentaram melhoras significativas na redução dos sintomas do refluxo do refluxo gastroesofágico. Vale ressaltar que, foi identificada uma melhora nas taxas de recorrência dos sintomas ao utilizar eletroacupuntura ou acupuntura manual em comparação à medicina ocidental.

Gao e Bae (2015) obtiveram resultados, significativamente, superiores no uso de acupuntura para a redução dos sintomas da DRGE em comparação ao omeprazol.

Tossef et al (2015) apontaram para resultados significativos no uso de alguns fitoterápicos para a redução dos sintomas da doença do refluxo gastroesofágico, sendo tanto os fitoterápicos Unani Pepsil e Safoof-ekatira quanto o Omeprazol eficazes. A maior diferença foi que o Unani Pepsil não apresentou efeitos colaterais.

Neu et al (2014) não apresentaram resultados significativos na melhora dos sintomas do refluxo gastroesofágico, havendo uma redução dos sintomas globais da DRGE nos dois grupos. Um achado importante desse estudo foi a redução nos níveis de estresse e diminuição da irritabilidade através da massagem terapêutica. Foi possível observar nesse estudo que, a massagem abdominal também aumentou a irritabilidade da criança, assim, é importante que o profissional de saúde oriente os pais quanto à possibilidade do aumento do incômodo ao realizar massagem em bebês com DGRE.

Ling et al (2015) encontrou resultados positivos, não necessariamente siginificativos, no alívio dos sintomas da DGRE através do uso da fórmula de Wendan contendo gengibre. Além disso, foram identificadas menores taxas de recaída em relação as terapias convencionais.

\subsection{BUSCA DE EVIDÊNCIAS}

O Quadro 2 também apresenta as características dos estudos segundo título e referência (autores, ano de publicação, periódico) e tipos de intervenções realizadas. A pesquisa foi composta por 8 estudos, sendo 5 artigos completos na íntegra e 3 resumos. Todos os artigos e resumos foram traduzidos para melhor identificação e análise em relação aos achados.

Com relação ao tipo de estudo, 6 são ensaios clínicos randomizados e 2 são revisões sistemáticas e metaanálises. Pode ser constatar que não houveram publicações em todos os anos do intervalo pesquisado, ocorrendo somente nos anos de 2014, 2015 e 2017. A maior concentração de pesquisas ocorreu no ano de 2015 com 5 publicações, seguido do ano de 2014 com 2 publicações e 2017 com 1 publicação.

Dos artigos selecionados, todos são alusivos à saúde e estão publicados em periódicos internacionais, sendo que sua distribuição nas diferentes áreas da saúde foi variada. Dos 8 estudos definidos, 2 pertencem à revistas de acupuntura (Zhu et al., 2017; Gao; Bai, 2016); 1 pertence à uma revista de enfermagem (NEU et al., 2014); 1 faz parte de uma revista farmacêutica (Toseef et al. 2015); 3 pertencem à revistas médicas, dentre eles, 1 pertence à uma revista de medicina complementar e integrativa (Dosset et al., 2015; Eherer, A. 2014; Ling et al., 2015) e 1 pertence à uma revista de terapias complementares e integrativas (Zohalinezhad et al., 2015). Com apenas uma publicação em chinês, os demais em inglês.

Os descritores identificados nos estudos incluíram um total de 24 termos, sendo que apenas 15 estão presentes no DeCS. Dentre eles podem ser citados os de maior recorrência: Gastroesophageal Reflux e Gastroenterology. Quanto ao local dos estudos, 3 artigos são provenientes da China, 2 são dos Estados Unidos, 1 do Irã, 1 da Áustria, e 1 do Paquistão.

Os autores das pesquisas totalizaram 54 pesquisadores. No que diz respeito aos primeiros autores das 8 publicações, 7 deles são médicos(as) e apenas em 1 dos estudos a primeira autora é enfermeira. No que diz respeito aos demais autores, a maioria se encontra na área da medicina. 


\subsection{AVALIAÇÃO CRÍTICA DAS EVIDÊNCIAS ENCONTRADAS}

A avaliação crítica das evidências é o ponto chave para garantir a qualidade da pesquisa e não impactar de forma danosa no paciente. Para isso, é preciso avaliar criteriosamente todos estudos definidos para determinar a força da evidência e sua validade, sendo os ensaios clínicos randomizados (ECR) e as revisões sistemáticas os estudos que oferecem as melhores evidências. Segundo Pedrolo et al (2009), a utilização de evidências irrelevantes ou a utilização de opiniões pessoais pode implicar em uma análise crítica ineficiente, que poderá ser ilusória e deficiente impactando de forma negativa no paciente.

Nesse sentido, Pedrolo et al (2009, p. 762) salientam que:

Para avaliar um estudo ou diretriz publicado quanto a relevância devemos considerar os seguintes pontos: questão clara; usuários bem definidos; busca abrangente de evidências; descrição dos critérios de seleção e combinação da evidência; descrição dos métodos de formulação da recomendação; consideração dos riscos e efeitos colaterais na sua formulação; registro de identificação das principais recomendações; registro de conflito de interesse dos organizadores; e atualização da diretriz.

Para a avaliação crítica das evidências encontradas no presente estudo foram levados em consideração apenas os ECR, a partir dos seguintes aspectos: tamanho da amostra, descrição do método de intervenção utilizado, a PICS utilizada e os desfechos encontrados pelos autores (Quadro 3).

A partir da análise do quadro 3, pode-se verificar que nem todos os estudos selecionados apresentam uma amostra bem definida de acordo com critérios de inclusão e exclusão (Eherer, 2014; Toseef et al, 2015). Com relação aos estudos utilizados na íntegra, nem todos apresentam uma ampla busca de evidências mediante a escolha da intervenção utilização e o decorrer de suas discussões (Eherer, 2014)

No que diz respeito aos métodos de formulação da recomendação, verificou-se que, com exceção de Eherer (2014), todos os demais autores admitiram o intervalo de confiança de $95 \%(\mathrm{P}<0,05)$ para o cálculo de amostras e para os testes estatísticos desenvolvidos.

Para a análise estatística, somente 3 dos ECR forneceram dados sobre tal quesito. Os softwares utilizados por cada um dos estudos foram: SAS v9.4, Statistical Package for the Social Sciences (SPSS V. 22.0) e SAS 9.2. Dentre os testes estatísticos utilizados, a análise de covariância foi a mais utilizada (3 estudos), seguida dos testes $\mathrm{t}$ ( 2 estudos) e testes qui-quadrados ( 2 estudos), também estiveram presentes o teste $\mathrm{w}^{2}$ (1 estudo), teste de Shapiro-Wilk (1 estudo) e teste de Wilcoxon (1 estudo). 0 cálculo do desvio padrão comum (SD) e a estimativa de mínimo quadrado também foram utilizados em um dos estudos.

Para a coleta de dados sobre os sintomas do refluxo gastroesofágico, todos os estudos utilizaram instrumentos diferentes, são eles: Questionário de Refluxo Gastroesofágico Infantil Revisado (I-GERQ-R), Questionário da Doença do Refluxo (RDQ), Consenso sobre Diagnóstico e Tratamento da DRGE da Medicina Tradicional Chinesa, Questionários de Sintomas da doença do refluxo gastroesofágico para crianças de 1 a 11 meses (GSQ-I), Questionários de Sintomas da doença do refluxo gastroesofágico para crianças jovens de 1 a 4 anos (Gsqyc) e Questionário de avaliação dos sintomas pediátricos do refluxo gastroesofágico para crianças de 5 a 18 anos (GASP-Q), Instrumento Qualidade de Vida Relacionada à Saúde da Doença do Refluxo Gastroesofágico (Gerd-Hrql) e a Escala de Avaliação do Sintoma Gastrointestinal (GSRS). Além disso, dois estudos fizeram uso de um diário para registro dos sintomas (Neu et al, 2014; Doseet et al, 2015).

Para além da coleta de dados sobre os sintomas do refluxo gastroesofágico, alguns estudos fizeram análises sobre outros dados envolvendo os sujeitos da pesquisa. Em Neu et al (2014), foram avaliados a ansiedade e a depressão materna através do Inventário de Ansiedade Traço-Estado (Idate) e da Escala de Depressão Pós-Parto de Edimburgo (Epds), respectivamente. Enquanto que em Doseet et al (2015) foram utilizados o Inventário de Crenças de Medicina Complementar e Alternativa para avaliar crenças sobre as PICS, a medida Consulta e Empatia Relacional (Care) para avaliar as percepções dos sujeitos sobre a empatia relacional durante a consulta e o questionário de credibilidade de Borkevec e Nau para mensurar as expectativas e crenças dos sujeitos sobre o tratamento a que foram submetidos.

Com relação aos aspectos éticos, somente Zohalinezhad et al (2015) e Doseet et al (2015) mencionam a aprovação das pesquisas no Comitê de Ética. Nenhum dos trabalhos mencionam conflitos de interesses, entretanto, somente Neu et al. (2014) aponta para a existência de um viés de atrito. 
Quadro 3: Distribuição dos ECR por autor, amostra, método de intervenção, óleo essencial utilizado e desfecho.

\begin{tabular}{|c|c|c|c|c|}
\hline AUTOR (ANO) & AMOSTRA & $\begin{array}{c}\text { MÉTODO DE } \\
\text { INTERVENCC̃̃O }\end{array}$ & PICS UTILIZADA & DESFECHO \\
\hline $\begin{array}{l}\text { DOSEET et al. } \\
\text { (2015) }\end{array}$ &  & 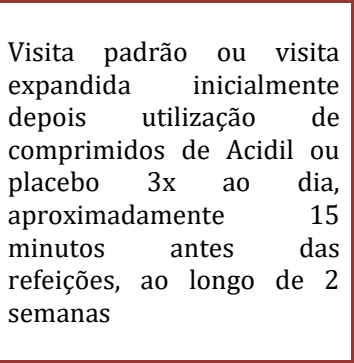 & $\begin{array}{l}2 \text { comprimidos } \\
\text { dissolvidos sob a } \\
\text { língua }\end{array}$ & $\begin{array}{l}\text { Não houve diferença significativa na } \\
\text { gravidade dos sintomas do refluxo } \\
\text { gastroesofágico entre os grupos Acidil } \\
\text { e placebo do início ao seguimento (p = } \\
0,41) \text {, no entanto, os indivíduos que } \\
\text { receberam a visita expandida } \\
\text { apresentaram uma maior } \\
\text { probabilidade de reportar uma } \\
\text { melhoria de } 50 \% \text { ou mais na gravidade } \\
\text { dos sintomas sujeitos que receberam a } \\
\text { visita padrão }(p=0,01) \text {. }\end{array}$ \\
\hline $\begin{array}{l}\text { EHERER, A. } \\
\text { (2014) }\end{array}$ & $\begin{array}{l}\text { Não delimita a } \\
\text { quantidade de sujeitos } \\
\text { dos grupos controle e } \\
\text { intervenção }\end{array}$ & 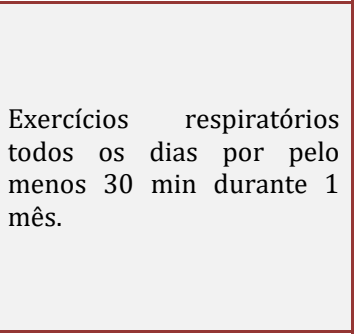 & $\begin{array}{l}\text { Exercícios } \\
\text { respiratórios e } \\
\text { musicoterapia } \\
\text { utilizando música } \\
\text { calma e relaxante } \\
\text { para indicar por } \\
\text { quanto tempo } \\
\text { cada exercício } \\
\text { deveria ser } \\
\text { realizado }\end{array}$ & $\begin{array}{l}\text { Pacientes do grupo de treinamento } \\
\text { tiveram as pontuações dos sintomas } \\
\text { melhoradas em relação ao grupo } \\
\text { controle. }\end{array}$ \\
\hline $\begin{array}{l}\text { ZOHALINEZHAD } \\
\text { et al. (2015) }\end{array}$ & 80 sujeitos & $\begin{array}{l}\text { Doses de xarope de } \\
\text { marmelo durante quatro } \\
\text { semanas consecutivas }\end{array}$ & $\begin{array}{c}\text { Xarope de } \\
\text { marmelo 0,6 } \\
\text { ml/kg/dia em } \\
\text { doses divididas }\end{array}$ & $\begin{array}{l}\text { Em crianças e bebês pequenos, o } \\
\text { escore cumulativo de sintomas médio } \\
\text { foi diminuído em cada grupo de } \\
\text { tratamento (p }=0,07) \text {, sem diferenças } \\
\text { significativas entre os grupos de } \\
\text { tratamento. Em crianças mais velhas e } \\
\text { adolescentes, o escore cumulativo de } \\
\text { sintomas médio foi diminuído em } \\
\text { todos os grupos de tratamento (p = } \\
0,001) \text { sem diferenças significativas } \\
\text { entre os grupos de tratamento. Em } \\
\text { ambos srupos, a frequência média e a } \\
\text { gravidade média de cada sintoma } \\
\text { diminuíram durante e após o } \\
\text { tratamento. }\end{array}$ \\
\hline \multirow{5}{*}{$\begin{array}{l}\text { GAO, L. J.; BAI, X. } \\
\text { H. (2016) }\end{array}$} & $\begin{array}{c}\text { Grupo Xarope de } \\
\text { omeprazol }(n=40)\end{array}$ & & & \\
\hline & $\begin{array}{c}\text { Grupo Xarope de } \\
\text { marmelada }(n=39)\end{array}$ & & & \\
\hline & 60 sujeitos & \multirow{3}{*}{$\begin{array}{l}\text { Acupuntura no segmento } \\
\text { dorsal com agulhas } \\
\text { filiformes, } 1 \mathrm{x} \text { a cada dois } \\
\text { dias durante } 8 \text { semanas. }\end{array}$} & \multirow{3}{*}{$\begin{array}{l}\text { Foram utilizados } \\
\text { os acupontos } \\
\text { [Shenzhu (GV 12), } \\
\text { Shendao (GV 11), } \\
\text { Lingtai (GV 10), } \\
\text { Zhiyang (GV 9), } \\
\text { Jinsuo (GV 8)] e } \\
\text { não-acupontos } \\
\text { (T4, T8). }\end{array}$} & \multirow{3}{*}{$\begin{array}{l}\text { Redução dos escores RDQ e escores da } \\
\text { escala de sintomas do refluxo } \\
\text { gastroesofágico, de } 70,0 \%(21 / 30) \text { e } \\
93,3 \%(28 / 30) \text {, após a intervenção no } \\
\text { grupo de estudo, em comparação com } \\
\text { o grupo controle }[43,3 \% 30) \text { e } 66,7 \% \\
(20 / 30)(P<0,05)\end{array}$} \\
\hline & $\begin{array}{l}\text { Grupo Acupuntura } \\
(n=30)\end{array}$ & & & \\
\hline & $\begin{array}{l}\text { Grupo Omeprazol } \\
\qquad(\mathrm{n}=30)\end{array}$ & & & \\
\hline $\begin{array}{l}\text { TOSEEF et al. } \\
\text { (2015) }\end{array}$ & $\begin{array}{c}\text { Não delimita a } \\
\text { quantidade de sujeitos } \\
\text { dos grupos N sujeitos } \\
\text { dos grupos Pepsil, } \\
\text { Safoof-e-Katira e } \\
\text { Omeprazol } \\
\end{array}$ & $\begin{array}{lcr}\text { Não foi } & \text { explicado } & \text { no } \\
\text { resumo a } & \text { duração } & \text { da } \\
\text { intervenção } & \text { nem } & \text { a } \\
\text { quantidade de fitoterápicos } \\
\text { por administração }\end{array}$ & $\begin{array}{l}\text { Fitoterápicos } \\
\text { Unani Pepsil e } \\
\text { Safoof-e-katira }\end{array}$ & $\begin{array}{l}\text { O valor p dos resultados dos sintomas } \\
\text { foi de } 0,000 \text {, exceto a flatulência, em } \\
\text { que o valor foi de } 0,001 \text {. Todas as } \\
\text { drogas estudadas (Pepsil, Safoof-e- } \\
\text { katira e Omeprazol) são altamente } \\
\text { significativas. }\end{array}$ \\
\hline \multirow[b]{3}{*}{$\begin{array}{l}\text { NEU et al. } \\
\text { (2014) }\end{array}$} & 36 sujeitos & \multirow[b]{3}{*}{ 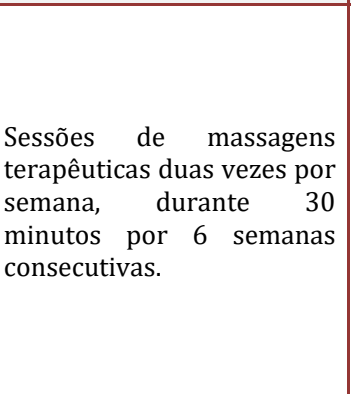 } & \multirow{3}{*}{$\begin{array}{l}\text { Os terapeutas } \\
\text { usaram pressão } \\
\text { moderada da mão, } \\
\text { administrando } \\
\text { cada uma das seis } \\
\text { etapas da sessão } \\
\text { (rosto e cabeça, } \\
\text { tórax, abdômen, } \\
\text { pernas e pés, } \\
\text { braços e mãos e } \\
\text { costas) por } 5 \text { min. }\end{array}$} & \multirow{3}{*}{$\begin{array}{l}\text { Não foram encontradas diferenças } \\
\text { entre os grupos através da avaliação } \\
\text { dos sintomas de refluxo } \\
\text { gastroesofágico pelo I-GERQ-R, usando } \\
\text { o ajuste de ANCOVA para o valor de } \\
\text { referência (p=0.58). Os escores médios } \\
\text { no grupo de massagem foram 22,0 (DP } \\
=4 \text { ), } 15,0 \text { (DP = 4) e } 14,4 \text { (DP = 5) no } \\
\text { início e } 4 \text { e } 6 \text { semanas, } \\
\text { respectivamente; no grupo sem } \\
\text { massagem, foram 23,5 (DP }=4), 15,1 \\
\text { (DP = 5) e } 13,7(D P=6) \text {. }\end{array}$} \\
\hline & $\begin{array}{l}\text { Grupo massagem } \\
\text { terapêutica }(n=18)\end{array}$ & & & \\
\hline & $\begin{array}{l}\text { Grupo não-massagem } \\
\qquad(\mathrm{n}=18)\end{array}$ & & & \\
\hline
\end{tabular}


Para a coleta de dados, somente Doseet et al (2015) utilizaram uma ferramenta para armazenando de dados, tal estudo utilizou o Redcap (Research Electronic Data Capture). Com exceção dos estudos de Eherer (2014), Seef et al (2015) e Gao; Bai (2016), os demais ICR citam as limitações identificadas, foram elas, tamanho da amostra, design, e tamanho do período da intervenção.

Os ECR expuseram de forma clara e objetiva, sempre relacionadas e embasadas por outras evidências da literatura, as recomendações a respeitos das PICS conforme os resultados encontrados nas pesquisas realizadas. Somado a isso, os estudos sugeriram a realização de pesquisas prospectivas na área com amostras maiores e outros métodos de avaliação da redução dos sintomas do refluxo gastroesofágico.

Além dos ECR apresentados no Quadro 3, também foram coletadas evidências por meio dos artigos de Ling et al (2015) e Zhu et al (2017), que consistem em duas revisões sistemáticas e meta-análises sendo. Com relação a publicação de Ling et al. (2015), dos 33 estudos selecionados somente 13 eram específicos sobre refluxo gastroesofágico, os demais eram sobre outro tipo de refluxo também considerados na pesquisa. Foi identificada uma eficiência terapêutica no uso da fórmula de Wendan contendo gengibre no manejo do refluxo gastroesofágico, entretanto, como tal estudo não foi disponível na íntegra, não é possível saber se houve uma avaliação de risco dos estudos incluídos na publicação confirmando a força da evidência identificada.

Zhu et al (2017) utilizaram o instrumento de avaliação do risco de Colaboração Cochrane para analisar os vieses dos percursos metodológicos das pesquisas selecionadas. A partir da utilização dessa ferramenta observa-se que, dos doze estudos incluídos pelos pesquisadores, todos foram classificados como risco pouco claro por causa ausência de informações de registos, exceto no viés de atrito em que todos foram classificados como baixo risco. Além disso, 11 dos 12 ensaios foram feitos na China e 10 estudos foram publicados em chinês, por conseguinte, existe um alto risco de viés de publicação. Sendo assim, não é possível concluir algo em definitivo devido aos tamanho de amostra geralmente pequeno e má qualidade metodológica dos estudos selecionados fazendo-se de grande importância a realização de estudos com amostras maiores, design melhorado e períodos mais longos.

Em termos gerais, no que concerne à validade da evidência encontrada, não é possível julgar os trabalhos selecionados que não estão disponíveis na íntegra devido à ausência de informações a respeito da validade do percurso metodológico. Entretanto, levando em consideração apenas as publicações completas, somente o artigo de Eherer (2014) foi considerado pela presente pesquisa como evidência fraca, visto que a descrição do percurso metodológico está incompleto devido à ausência de descrição da amostra, critérios de inclusão, design no estudo, randomização dos sujeitos, descrição criteriosa da intervenção, descrição dos métodos de avaliação, software de análise estatística, avaliação de atrito e limitações.

\subsection{TOMADA DE DECISÃO A PARTIR DA MELHOR EVIDÊNCIA ENCONTRADA}

A partir de uma análise crítica dos estudos incluídos nessa pesquisa, verificou-se que no que corresponde ao manejo e redução dos sintomas do refluxo gastroesofágico diversas são as PICS que podem ser utilizadas. Entretanto, quando comparados seus efeitos com relação ao grupo controle, não houve melhora significativa na redução dos sintomas da doença do refluxo gastroesofágico em relação aos grupos controles em nenhum dos estudos analisados na íntegra.

Pode-se sugerir que a acupuntura seria o método terapêutico mais adequado no manejo da DGRE a partir dos resultados estatísticos apontados pelo estudo de Gao; Bai (2016). Contudo, como a análise da validade de tal publicação restringiu-se apenas ao seu resumo, já que o trabalho não estava disponível na íntegra, tal achado deve ser considerado com cautela.

Diante desse panorama, Doseet et al (2015) identificaram que não é, necessariamente, uma terapêutica no rol das PICS a intervenção mais eficaz e que traz mais benefícios no manejo da DGRE e sim, um elemento transversal a qualquer prática integrativa, uma consulta expandida, modelada a partir de consultas de medicina complementar.

Tais consultas são mais longas e contém mais questionamentos do que as consultas médicas padrão, contudo, devidos as suas limitações, o estudo não foi capaz de confirmar se o tempo utilizado nas consultas, o tipo de pergunta, algum aspecto da relação profissional-paciente ou uma combinação desses fatores seriam os responsáveis pelos resultados positivos. Desse modo, realizar pesquisas que aprofundem esse tipo de interação são necessárias para descobrir o modo pelo qual uma consulta expandida é tal eficaz no manejo do refluxo gastroesofágico. 
Pode-se especular que, devido ao fato de as consultas de PICS estarem fundamentadas nos preceitos da integralidade, globalidade do processo-saúde e doença e multidimensionalidade do indivíduo e, a DGRE consistir em uma doença multifatorial, daí decorra a efetividade de tal prática. Nesse sentido, a escuta terapêutica apresenta-se como ferramenta para uma assistência qualificada e salubre.

\section{CONCLUSÃo}

O presente trabalho apresentou como evidência considerável para o manejo da doença do refluxo gastroesofágico a consulta expandida moldada a partir de consultas da medicina integrativa e complementar. Embora não seja, necessariamente, uma das práticas designadas na Política Nacional de Práticas Integrativas e Terapias Complementares em Saúde (PNPIC), esse tipo de consulta antecede a escolha e aplicação das PICS, desse modo, o objetivo pode-se afirmar que o objetivo do presente trabalho foi alcançado.

Ao considerar as diversas dimensões do indivíduo, esse tipo de consulta permite ao profissional identificar os desequilíbrios e direcionar o manejo das terapêuticas mais indicadas. Nessa linha, a escuta acolhedora demanda apenas de tecnologia leve para ser executada, desse modo, a utilização de seus componentes objetivando o remodelamento das consultas médicas convencionais configura-se como algo simples.

Sua utilização como ferramenta de intervenção na saúde pode ser adaptada por qualquer profissional da equipe, possibilitando o desenvolvimento do vínculo terapêutico. Como a DGRE é uma das patologias mais frequentes mundialmente, o profissional que está apto a realizar esse tipo de consulta possibilita uma assistência humanizada e acolhedora.

A realização de mais estudos para aprofundar o conhecimento sobre os efeitos da consulta expandida, as PICS de modo geral e seus efeitos no manejo da DGRE são fundamentais, visto que, a quantidade de estudos sobre o tema foi pequena e nem todos estavam disponíveis na íntegra. Ademais, uma consideração presente constantemente nos trabalhos analisados foi a sugestão de realizar trabalhos futuros, com amostras maiores a fim de garantir resultados mais eficazes.

Nenhum trabalho encontrado e/ou selecionado foi realizado no Brasil bem como, não havia nenhuma publicação em português, isto, somado à quantidade limitada de artigos disponíveis na íntegra sobre o tema, representa uma grande limitação, pois, ao analisar artigos de outras línguas pode haver um viés de comunicação impedindo que uma análise fiel seja realizada. Destarte, é fundamental que a pesquisa científica brasileira se aprofunde no campo das PICS para ampliar o escopo teórico-prático dessa área.

\section{REFERÊNCIAS}

[1] Contatore, O. A.; Barros, N. F. de,; Durval, M. R.; Barrio, P. C. C. da C.; Coutinho, B. D.; Santos, J. A.; Nascimento, J. L. de,; Oliveira, S. de L.; Peres, S. M. de P. Uso, cuidado e política das práticas integrativas e complementares na Atenção Primária à Saúde. Ciênc. saúde coletiva. Rio de Janeiro, v. 20, n. 10, p. 3263-3273, outubro, 2015

[2] Dosset, M. L.; Mu, L.; Davis, R. B.; Bell, I. R.; Lembo, A. J.; Kaptchuk, T. J.; Yeh, G. Y. Patient-Provider Interactions Affect Symptoms in Gastroesophageal Reflux Disease: A Pilot Randomized, Double-Blind, PlaceboControlled Trial. Plos One, v. 10, n. 9, p. e 0136855, 2015.

[3] Eherer, A. Management of Gastroesophageal Reflux Disease: Lifestyle Modification and Alternative Approaches. Digestive Diseases. v. 32, n.1-2, p. 149-151, 2014

[4] Gao, L. J.; BAI, X. H.; Clinical Trial of Acupuncture Treatment of Gastro-esophageal Reflex Disease by Needling Dorsal Segment of the Governor Vessel. Zhen Ci Yan Jiu. v.41, n. 2, p. 150-153, 2016

[5] Ho, C. E.; Goh, Y. L.; Zhao, X. X.; YU, C. Y.; Zhang, C. Gerd: An Alternative Perspective. Psychosomatics. v. 57, n. 2, p.142-151, mar-apr, 2016

[6] Larrabee, J. H. Nurse to nurse [recurso eletrônico]: prática baseada em evidências em enfermagem / June H. Larrabee; tradução: Marcela Zanatta; revisão técnica: Lúcia Mana Giunta da Silva. - Dados eletrônicos. - Porto Alegre, AMGH, 2011

[7] Lima, K. M. S. V.; Silva, K. L.; Tesser, C. D. Práticas integrativas e complementares e relação com promoção da saúde: experiência de um serviço municipal de saúde. Interface (Botucatu), Botucatu, v.18, n. 49, p. 261-272, junho, 2014.

[8] Ling, W.; Huang, Y.; XU, J. H.; LI, Y.; Huang, Y. M.; Ling, H. B.; SUI, Y.; Zhao, H. L. Consistent Efficacy of Wendan Decoction for the Treatment of Digestive Reflux Disorders. Am J Chin Med. v. 43, n. 5, p. 893-913, 2015 
[9] Neu, M.; Pan, Z.; Workman, R.; Marcheggiani-Howard, C.; Furuta, G.; Laudenslager, M. L. Benefits of massage therapy for infants with symptoms of gastroesophageal reflux disease. Biol Res Nurs. v. 16, n. 4, p. 387-97, 2014

[10] Pedrolo, E.; Danski, M. T. R.; Mingorance, P.; Lazzari, L. S. M. de,; Méier, M. J.; Crozeta, K. A prática baseada em evidências como ferramenta para prática profissional do enfermeiro. Cogitare Enferm. v. 14, n. 4, p. 760-3, out-dez, 2009

[11] Oxford Centre for Evidence-Based Medicine. Levels of evidence [Internet] 2011 [acesso em 27 abril 2018]. Disponível:https://www.cebm.net/wp-content/uploads/2014/06/Cebm-Levels-of-Evidence-2.1.pdf

[12] Polit, D. F.; Beck, C. T. Fundamentos de Pesquisa em Enfermagem: Avaliação de evidências para a prática da enfermagem. 7aㅡ edição, Porto Alegre, Artmed, 2011

[13] Ribeiro, M. C. B.; Araújo, A. B. de,; Terra-Júnior, J. A.; Crema, E.; Andreollo, N. A.. Late evaluation of patients operated for gastroesophageal reflux disease by nissen fundoplication. Abcd, arq. bras. cir. dig., São Paulo, v. 29, n. 3, p. 131-134, setembro, 2016

[14] Toseef, M. U.; Saeed, A.; Mohi-Uh-Din, E.; Usmanghani, K. Nazar, H.; Nawaz, A.; Ahmad, I.; Siddiqui, F. A. Comparative clinical evaluation on herbal formulation Pepsil, Safoof-e-Katira and Omeprazole in gastro esophageal reflux disease. Pak J Pharm Sci. v. 28, n. 3, p. 863-70, 2015

[15] Zhu, J.; Guo, Y.; Liu, S.; Su, X.; Li, Y.; Yang, Y.; Hou, L.; Wang, G.; Zhang, J.; Chen, J. J.; Wang, Q.; Wei, R.; Wei, W. Acupuncture for the treatment of gastro-oesophageal reflux disease: a systematic review and meta-analysis. Acupuncture in Medicine. V. 35, n. 5, p. 316-323, 2017

[16] Zohalinezhad, M. E.; Imanieh, M. H.; Samani, S. M.; Mohagheghzadeh, A.; Dehghani, S. M.; Haghighat, M.; Salehj, A.; Faridj, P.; Akbarzadeh, A. R. Effects of Quince syrup on clinical symptoms of children with symptomatic gastroesophageal reflux disease: A double-blind randomized controlled clinical trial. Complement Ther Clin Pract. v. 21, n.4, p. 268-76, 2015 


\section{Capitulo 16}

\section{Aromaterapia no manejo da ansiedade: Prática baseada em evidências}

\section{Nathália de Azevedo Souza \\ João Luis Almeida da Silva}

Resumo: A ansiedade é um estado emocional o qual pode acarretar diversos efeitos físicos e psicológicos sobre o corpo, resultando em um autocuidado menos eficiente. Os tratamentos não farmacológicos têm tido maior notoriedade para o alívio desses sintomas. A partir disso, a Aromaterapia surge como uma das principais opções de Terapias Complementares utilizadas pelas equipes de saúde no manejo da ansiedade; ela consiste no uso de óleos essenciais que podem ser administrados por inalação ou associados com massagem, compressa ou em banhos aromáticos. Esse estudo objetivou determinar de forma confiável a melhor evidência da intervenção e óleo essencial no uso da aromaterapia para manejo da ansiedade. Para conferir maior fidedignidade aos resultados, foi utilizada a metodologia de Prática Baseada em Evidências. Foi realizada uma busca de evidências na base de dados PubMed, utilizando como descritores: Aromatherapy; Anxiety, selecionando publicações dos últimos cinco anos e disponíveis em texto completo. Como resultado foram selecionados 14 estudos que atendiam aos critérios de inclusão e exclusão. Seguindo os passos da prática baseada em evidência, realizou-se a análise crítica das publicações que compreenderam o estudo, a qual determinou que a melhor evidência de uso da aromaterapia no manejo da ansiedade é a inalação do óleo essencial de lavanda, por 20 minutos. Logo, essa terapia complementar pode ser uma aliada eficaz e de menor custo para reduzir os níveis de ansiedade de indivíduos com diversos estados de saúde associados.

Palavras-Chave: Aromaterapia, ansiedade, prática baseada em evidências, terapias complementares 


\section{INTRODUÇÃO}

Com o passar dos anos, o corpo humano deixou de ser visto como uma máquina composta apenas de aspectos fisiológicos e passou a ser contemplado como uma totalidade complexa que abrange outras esferas de saúde e bem-estar. Dentre as transformações das concepções dos indivíduos, o cuidado considera o processo de adoecimento como uma perturbação energética, em que os sintomas são reflexo das questões assimiladas pelo ser. Esse crescente paradigma é chamado Vitalista ou Holístico, e é justificado pela física quântica quando esta afirma a existência de uma força vital (energia) associada às forças físicas conhecidas (QUEIROZ, 2000).

Diante dessas modificações, a Organização Mundial de Saúde passou a reconhecer técnicas que abordassem um cuidado biopsicossocial. Por conseguinte, no ano de 2006, foi instituída a Política Nacional de Prática Integrativas e Complementares (PNPIC) no Brasil, a fim de promover ainda mais o princípio de integralidade do Sistema Único de Saúde (SUS) e atender às demandas de conhecer, apoiar, implementar e agregar experiências e terapias que já são conhecidas e aplicadas em diversos municípios do país (BRASIL, 2015). A Portaria № 849/2017, amplia as práticas integrativas e complementares oferecidas pelo SUS e, dentre elas, a Naturopatia que inclui aromaterapia como recurso terapêutico componente (BRASIL, 2017).

A aromaterapia parte do pressuposto que o uso de óleos essenciais gera mudanças no sistema límbico parte do cérebro associada às memórias e emoções - desencadeando respostas fisiológicas nos sistemas nervoso, endócrino e/ou imune. 0 estímulo resulta na melhora da pressão sanguínea, da frequência cardíaca, e atua no sono, respiração e regulação hormonal. Além disso, alivia sintomas emocionais negativos, como a ansiedade, depressão e estresse, consequentemente, melhorando o humor (STEA et al., 2014; TANG et al., 2014; SEYYED-RASOOLI et al., 2016).

A ansiedade afeta cada vez mais a população mundial devido aos novos estilos de vida adotados. Trata-se de um estado emocional que causa tensão ou desconforto antes da ocorrência de algo que seja perigoso, estranho ou desconhecido. Possui componentes psicológicos e fisiológicos; e envolve sentimentos de medo, insegurança, apreensão e alteração dos estados de vigília ou alerta. Quando há interferência na funcionalidade do indivíduo, torna-se uma patologia, podendo desencadear os mais diversos distúrbios. As terapias complementares vêm ganhando força como método de tratamento para esse tipo de estado emocional (GNATTA et al., 2014).

Devido a possibilidade de ampliar a atuação do enfermeiro frente às alterações dos estados físicos, emocionais, psíquicos e espirituais daqueles a quem presta o cuidado, a aromaterapia pode ser uma grande aliada no controle da ansiedade, intervindo nos desequilíbrios dessas dimensões dos sujeitos.

Contudo, é imperativo que esse profissional se apoie em estudos científicos que possibilitem uma atuação segura, precisa, com eficácia e qualidade. Dessa forma, o objetivo do presente trabalho é determinar de forma confiável a melhor evidência científica de intervenção e óleo essencial com o uso da aromaterapia para manejo da ansiedade. Para tanto, a fim de que haja maior fidedignidade quanto aos parâmetros estabelecidos, foi utilizada a metodologia de Prática Baseada em Evidências (PBE) já que esta oferece uma conexão entre os resultados de pesquisa e sua aplicação prática, de forma a promover uma tomada de decisão legítima e bem fundamentada (PEDROLO et al., 2009)

\section{METODOLOGIA}

A PBE apresenta passos a serem desenvolvidos a fim de promover a tomada de decisão a partir das melhores evidências. Dentre elas estão: a elucidação de um problema, a avaliação crítica das evidências encontradas, a implementação dessa prática e apreciação dos resultados (PEDROLO et al., 2009).

Inicialmente, é imprescindível a formulação de uma questão clínica possível de ser respondida. Para tanto, dentro da sistematização da PBE, adota-se a metodologia PICO - entendendo P referente ao paciente, I relacionando-se à intervenção ou indicador a ser avaliado, C para controle ou comparação entre as intervenções (caso necessário) e, O para outcomes ou desfechos (PEDROLO et al., 2009).

No presente estudo, como paciente ou problema foram definidos: pacientes com ansiedade auto relatada ou definida por questionário aos quais foi aplicada Aromaterapia como intervenção, considerando-se os estudos com controle ou comparação com outros tratamentos e possível melhora dos níveis avaliados ou não. A pergunta da qual parte o estudo em questão é: Qual o método de aplicação da Aromaterapia e óleo essencial mais eficazes para redução dos níveis de ansiedade? 
Em seguida, foi realizada a busca das melhores evidências que são provenientes de pesquisas clínicas pertinentes, as quais são focadas no paciente e em indicadores de medidas de diagnóstico, tratamento, reabilitação e prevenção de agravos (PEDROLO et al., 2009). O Centro de Medicina Baseada em Evidências da Universidade de Oxford estabelece uma hierarquia para identificar as melhores evidências de acordo às metodologias dos trabalhos científicos encontrados. Segundo esta determinação, ao procurar resposta sobre a eficácia de tratamentos, está estabelecida a hierarquia presente na Figura 1.

Figura 1: Hierarquia para Evidências em Resposta a Benefícios de Tratamentos.

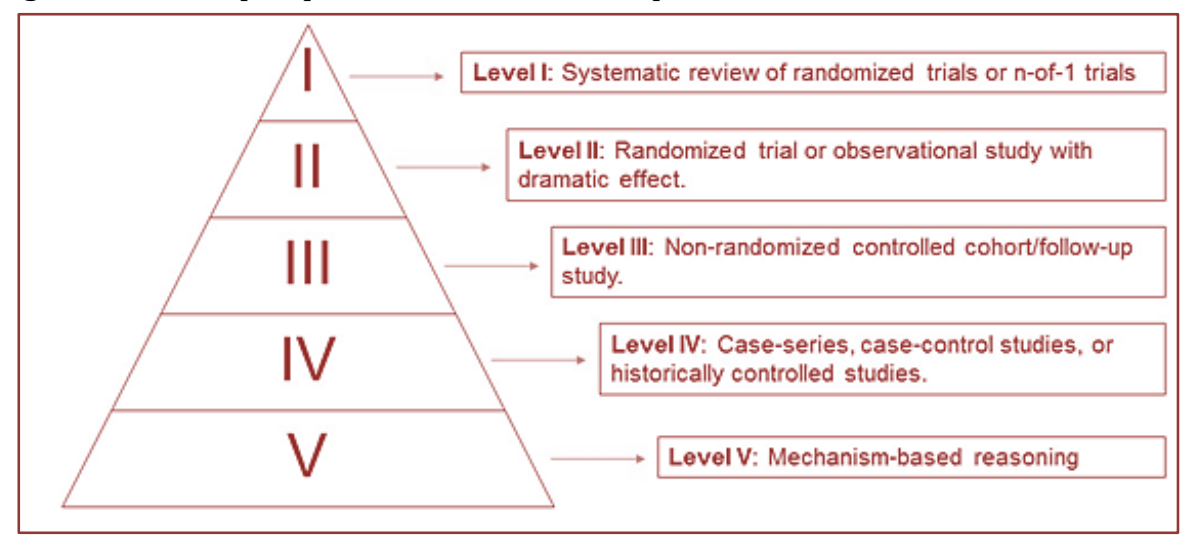

Fonte: Adapatado de OCEBM Table of Evidence Working Group = Jeremy Howick, Iain Chalmers (James Lind Library), Paul Glasziou, Trish Greenhalgh, Carl Heneghan, Alessandro Liberati, Ivan Moschetti, Bob Phillips, Hazel Thornton, Olive Goddard and Mary Hodgkinson. The Oxford 2011 Levels of Evidence. Disponível em: http://www.cebm.net/index.aspx?o=5653

A coleta de evidências se deu na base de dados online PubMed. O PubMed pertence a U.S. National Library of Medicine National Institutes of Health, amplamente utilizada na área da saúde, formada por mais de 26 milhões de citações bibliográficas com estudos produzidos desde 1940; portanto, com uma dimensão ampla e atualizada sobre os estudos mais importantes gerados no mundo.

Para buscar as informações da PBE foram pesquisados os descritores Aromatherapy and Anxiety; a partir de então, foi realizada seleção dos estudos conforme Hierarquia de Evidências de Oxford, as evidências de nível I e II.

Os critérios de inclusão abrangem ainda as seguintes características: artigos que se tratassem de revisões de literatura sistemáticas ou integrativas, artigos de estudos randomizados, estudos realizados com humanos, textos disponíveis online para leitura na íntegra e que tivessem sido publicados entre os anos de 2013 e 2017 - período de tempo definido por ser considerado satisfatório para conter os estudos mais atuais acerca do tema e preconizados na metodologia PBE.

Já os critérios de exclusão foram: artigos de revisões de literatura que não sistemática ou integrativa, artigos que não relacionassem a aromaterapia com os níveis de ansiedade, artigos que trouxessem resultados relacionados à ansiedade como secundários, textos que não estivessem disponíveis para leitura completa, além de estudos que fossem de coorte, transversal, quase experimental, caso-controle, estudo descritivo, estudo quantitativo e estudo ecológico. Foram excluídos também artigos relacionados a opinião de especialistas e fontes secundárias de dados.

Entre um período de três meses, ao pesquisar os descritores Aromatherapy and Anxiety na PubMed, foram encontrados 203 artigos, dos quais 80 estavam disponíveis em texto completo e atendiam ao período de publicação pré-determinado. Após a leitura dos resumos, foram selecionados 42 artigos para leitura na íntegra, os demais, apesar de apresentarem os descritores elencados, não correspondiam a aromaterapia ou ansiedade especificamente. Dos 42, apenas 14 atendiam completamente aos critérios de inclusão e exclusão supracitados.

A partir da leitura dos trabalhos, foi realizada a avaliação crítica da validade e relevância da evidência encontrada, analisando-se os estudos que se tratavam de ensaios clínicos controlados randomizados - por se tratarem da abordagem quantitativa que oferece melhor evidência possível para avaliar a eficácia de intervenções de saúde - e revisões integrativas e sistemáticas de literatura, por apresentarem uma estrutura de construção mais rigorosa. 
Esses estudos são considerados melhor evidência para PBE por serem provenientes de pesquisa clínica relevante, onde o indivíduo é o foco (PEDROLO et al., 2009).

As provas mais encontradas foram avaliadas e comparadas para que fosse sugerida uma tomada de decisão baseada na melhor evidência comprovada por esse estudo.

\subsection{RESPOSTA À QUESTÃo CLÍNICA}

\section{PRÁTICA BASEADA EM EVIDÊNCIAS}

Em busca da resposta à questão clínica proposta pelo presente trabalho, e após a análise dos artigos selecionados em revisão prévia, elaborou-se um quadro contendo título, referência, o tipo de paciente envolvido no ensaio clínico, qual método de intervenção foi utilizado (incluindo o óleo essencial) e qual o método de controle (Quadro 1).

Quanto aos desfechos, todos os ensaios clínicos randomizados (ECR) encontraram resultados positivos quanto à redução dos níveis de ansiedade através do uso da aromaterapia, com exceção de Seifi et al (2014) que não obteve resultados estatísticos significantes na redução dos níveis de ansiedade do seu grupo de intervenção.

Em suma, os autores defenderam a aplicação de aromaterapia por enfermeiros, médicos e outros membros da equipe de tratamento com base nos resultados de seus estudos e também porque o uso de métodos complementares reduz os efeitos colaterais dos medicamentos.

Quadro 1: Distribuição dos artigos por título, referência, paciente, método de intervenção e intervenção controle.

\begin{tabular}{|c|c|c|c|c|}
\hline Título & Referência & Paciente & $\begin{array}{l}\text { Método de } \\
\text { intervenção }\end{array}$ & $\begin{array}{l}\text { Intervenção } \\
\text { controle }\end{array}$ \\
\hline $\begin{array}{l}\text { The Effect of } \\
\text { Aromatherapy on Anxiety } \\
\text { in Patients. }\end{array}$ & $\begin{array}{l}\text { BARATI, F.; NASIRI, A.; AKBARI, N.; } \\
\text { SHARIFZADEH, G. The Effect of } \\
\text { Aromatherapy on Anxiety in Patients. } \\
\text { Nephro-urology monthly, v. 8, n. 5, p. } \\
\text { e38347, } 2016 .\end{array}$ & $\begin{array}{l}\text { Pacientes em } \\
\text { diálise }\end{array}$ & $\begin{array}{l}\text { Inalação de óleo } \\
\text { essencial de Água de } \\
\text { Rosas }\end{array}$ & $\begin{array}{l}\text { Não houve } \\
\text { intervenção }\end{array}$ \\
\hline $\begin{array}{l}\text { Aromatherapy for the } \\
\text { relief of symptoms in burn } \\
\text { patients: A systematic } \\
\text { review of randomized } \\
\text { controlled trials. }\end{array}$ & $\begin{array}{l}\text { CHOI, J.; LEE, J. A.; ALIMORADI, Z.; LEE, } \\
\text { M. S. Aromatherapy for the relief of } \\
\text { symptoms in burn patients: A } \\
\text { systematic review of randomized } \\
\text { controlled trials. Burns : journal of the } \\
\text { International Society for Burn Injuries, } \\
\text { p. 0-7, 2017. Elsevier Ltd and } \\
\text { International Society of Burns Injuries. }\end{array}$ & $\begin{array}{l}\text { Pacientes } \\
\text { queimados }\end{array}$ & $\begin{array}{l}\text { Inalação de óleo } \\
\text { essencial Lavanda e } \\
\text { Rosa }\end{array}$ & $\begin{array}{l}\text { Placebo, } \\
\text { musicoterapia e } \\
\text { sem intervenção }\end{array}$ \\
\hline $\begin{array}{l}\text { The effect of cold } \\
\text { application and lavender } \\
\text { oil inhalation in cardiac } \\
\text { surgery patients } \\
\text { undergoing chest tube } \\
\text { removal. }\end{array}$ & $\begin{array}{l}\text { HASANZADEH, F.; KASHOUK, N. M.; } \\
\text { AMINI, S.; et al. The effect of cold } \\
\text { application and lavender oil inhalation } \\
\text { in cardiac surgery patients undergoing } \\
\text { chest tube removal. EXCLI Journal, v. } \\
\text { 15, p. } 64-74,2016 .\end{array}$ & $\begin{array}{l}\text { Pacientes em } \\
\text { remoção de tubo } \\
\text { torácico }\end{array}$ & $\begin{array}{l}\text { Inalação de óleo } \\
\text { essencial de Lavanda }\end{array}$ & $\begin{array}{l}\text { Não houve } \\
\text { intervenção }\end{array}$ \\
\hline $\begin{array}{l}\text { Effect of lavender essence } \\
\text { inhalation on the level of } \\
\text { anxiety and blood cortisol } \\
\text { in candidates for open- } \\
\text { heart surgery }\end{array}$ & $\begin{array}{l}\text { HOSSEINI, S.; HEYDARI, A.; VAKILI, M.; } \\
\text { MOGHADAM, S.; TAZYKY, S. Effect of } \\
\text { lavender essence inhalation on the } \\
\text { level of anxiety and blood cortisol in } \\
\text { candidates for open-heart surgery. } \\
\text { Iranian Journal of Nursing and } \\
\text { Midwifery Research, v. } 21 \text {, n. } 4 \text {, p. } 397 \text {, } \\
2016 .\end{array}$ & $\begin{array}{l}\text { Pacientes a } \\
\text { realizar cirurgia } \\
\text { de peito aberto }\end{array}$ & $\begin{array}{l}\text { Inalação de óleo } \\
\text { essencial de Lavanda }\end{array}$ & $\begin{array}{l}\text { Água destilada } \\
\text { (placebo) }\end{array}$ \\
\hline $\begin{array}{l}\text { Aromatherapies using } \\
\text { Osmanthus fragrans oil } \\
\text { and grapefruit oil are } \\
\text { effective complementary } \\
\text { treatments for anxious } \\
\text { patients undergoing } \\
\text { colonoscopy: A } \\
\text { randomized controlled } \\
\text { study. }\end{array}$ & $\begin{array}{l}\text { HOZUMI, H.; HASEGAWA, S.; } \\
\text { TSUNENARI, T.; et al. Aromatherapies } \\
\text { using Osmanthus fragrans oil and } \\
\text { grapefruit oil are effective } \\
\text { complementary treatments for anxious } \\
\text { patients undergoing colonoscopy: A } \\
\text { randomized controlled study. } \\
\text { Complementary Therapies in } \\
\text { Medicine, v. 34, n. February, p. 165- } \\
169,2017 .\end{array}$ & $\begin{array}{l}\text { Pacientes que } \\
\text { iriam realizar } \\
\text { colonoscopia }\end{array}$ & $\begin{array}{l}\text { Inalação de óleo } \\
\text { essencial de Toranja, } \\
\text { Lavanda e Osmanthus } \\
\text { fragrans }\end{array}$ & $\begin{array}{l}\text { Não houve } \\
\text { intervenção }\end{array}$ \\
\hline
\end{tabular}


(continuação)

Quadro 1: Distribuição dos artigos por título, referência, paciente, método de intervenção e intervenção controle.

\begin{tabular}{|c|c|c|c|c|}
\hline TÍTULO & REFERÊNCIA & PACIENTE & $\begin{array}{l}\text { MÉTODO DE } \\
\text { INTERVENÇÃO }\end{array}$ & $\begin{array}{l}\text { INTERVENÇÃO } \\
\text { CONTROLE }\end{array}$ \\
\hline $\begin{array}{l}\text { The Effects of Inhalation } \\
\text { Aromatherapy on Anxiety } \\
\text { in Patients With } \\
\text { Myocardial Infarction: } \\
\text { Randomized Clinical Trial. }\end{array}$ & $\begin{array}{l}\text { NAJAFI, Z:; TAGHADOSI, M.; SHARIFI, } \\
\text { K.; FARROKHIAN, A.; TAGHARROBI, Z. } \\
\text { The Effects of Inhalation } \\
\text { Aromatherapy on Anxiety in Patients } \\
\text { With Myocardial Infarction: } \\
\text { Randomized Clinical Trial. Iranian Red } \\
\text { Crescent Medical Journal, v. 16, n. 8, p. } \\
\text { 1-7, } 2014 .\end{array}$ & $\begin{array}{l}\text { Pacientes com } \\
\text { infarto do } \\
\text { miocárdio }\end{array}$ & $\begin{array}{l}\text { Inalação com aroma } \\
\text { de Lavanda }\end{array}$ & $\begin{array}{l}\text { Não houve } \\
\text { intervenção }\end{array}$ \\
\hline $\begin{array}{l}\text { Investigating the effects of } \\
\text { aromatherapy with citrus } \\
\text { aurantium oil on anxiety } \\
\text { during the first stage of } \\
\text { labor. }\end{array}$ & $\begin{array}{l}\text { NAMAZI, M.; AKBARI, S. A. A.; MOJAB, } \\
\text { F.; et al. Investigating the effects of } \\
\text { aromatherapy with citrus aurantium } \\
\text { oil on anxiety during the first stage of } \\
\text { labor. Iranian Journal of Obstetrics, } \\
\text { Gynecology and Infertility, v. } 17, \mathrm{n} . \\
\text { 111, p. } 20-29,2014 .\end{array}$ & $\begin{array}{l}\text { Mulheres em } \\
\text { primeiro estágio } \\
\text { de trabalho de } \\
\text { parto }\end{array}$ & $\begin{array}{l}\text { Inalação de destilado } \\
\text { de } C \text {. aurantium }\end{array}$ & $\begin{array}{l}\text { Solução salina } \\
\text { (placebo) }\end{array}$ \\
\hline $\begin{array}{l}\text { The anxiolytic effect of } \\
\text { aromatherapy on patients } \\
\text { awaiting ambulatory } \\
\text { surgery: a randomized } \\
\text { controlled trial. }\end{array}$ & $\begin{array}{l}\text { NI, C.-H.; HOU, W.-H.; KAO, C.-C.; et al. } \\
\text { The anxiolytic effect of aromatherapy } \\
\text { on patients awaiting ambulatory } \\
\text { surgery: a randomized controlled trial. } \\
\text { Evidence-based complementary and } \\
\text { alternative medicine : eCAM, v. } 2013 \text {, } \\
\text { p. } 927419,2013 .\end{array}$ & $\begin{array}{l}\text { Pacientes em pré- } \\
\text { operatório de } \\
\text { cirurgias eletivas }\end{array}$ & $\begin{array}{l}\text { Inalação de óleo } \\
\text { essencial de } \\
\text { Bergamota }\end{array}$ & $\begin{array}{l}\text { Vapor d'água } \\
\text { (placebo) }\end{array}$ \\
\hline $\begin{array}{l}\text { Effect of Inhalation of } \\
\text { Aroma of Geranium } \\
\text { Essence on Anxiety and } \\
\text { Physiological Parameters } \\
\text { during First Stage of Labor } \\
\text { in Nulliparous Women: a } \\
\text { Randomized Clinical Trial. }\end{array}$ & $\begin{array}{l}\text { RASHIDI FAKARI, F.; } \\
\text { TABATABAEICHEHR, M.; KAMALI, H.; } \\
\text { RASHIDI FAKARI, F.; NASERI, M. Effect } \\
\text { of Inhalation of Aroma of Geranium } \\
\text { Essence on Anxiety and Physiological } \\
\text { Parameters during First Stage of Labor } \\
\text { in Nulliparous Women: a Randomized } \\
\text { Clinical Trial. Journal of Caring } \\
\text { Sciences, v. 4, n. 2, p. 135-141, 2015a. }\end{array}$ & $\begin{array}{l}\text { Mulheres em } \\
\text { primeiro estágio } \\
\text { de parto }\end{array}$ & $\begin{array}{l}\text { Inalação óleo essencial } \\
\text { de Gerânio }\end{array}$ & $\begin{array}{l}\text { Água destilada } \\
\text { (placebo) }\end{array}$ \\
\hline $\begin{array}{l}\text { The effect of lavender } \\
\text { essential oil on anxiety } \\
\text { level in patients } \\
\text { undergoing coronary } \\
\text { artery bypass graft } \\
\text { surgery: A double-blinded } \\
\text { randomized clinical trial. }\end{array}$ & $\begin{array}{l}\text { SEIFI, Z.; BEIKMORADI, A.; OSHVANDI, } \\
\text { K.; et al. The effect of lavender } \\
\text { essential oil on anxiety level in } \\
\text { patients undergoing coronary artery } \\
\text { bypass graft surgery: A double-blinded } \\
\text { randomized clinical trial. Iranian } \\
\text { journal of nursing and midwifery } \\
\text { research, v. } 19, \text { n. } 6, \text { p. } 574-580,2014 .\end{array}$ & $\begin{array}{l}\text { Pacientes que } \\
\text { realizaram } \\
\text { cirurgia cardíaca }\end{array}$ & $\begin{array}{l}\text { Inalação de óleo } \\
\text { essencial de Lavanda }\end{array}$ & $\begin{array}{l}\text { Água destilada } \\
\text { (placebo) }\end{array}$ \\
\hline $\begin{array}{l}\text { Comparing the effects of } \\
\text { aromatherapy massage } \\
\text { and inhalation } \\
\text { aromatherapy on anxiety } \\
\text { and pain in burn patients: } \\
\text { A single-blind randomized } \\
\text { clinical trial. }\end{array}$ & $\begin{array}{l}\text { SEYYED-RASOOLI, A.; SALEHI, F.; } \\
\text { MOHAMMADPOORASL, A.; et al. } \\
\text { Comparing the effects of aromatherapy } \\
\text { massage and inhalation aromatherapy } \\
\text { on anxiety and pain in burn patients: A } \\
\text { single-blind randomized clinical trial. } \\
\text { Burns, v. } 42, \text { n. 8, p. } 1774-1780,2016 .\end{array}$ & $\begin{array}{l}\text { Pacientes } \\
\text { queimados }\end{array}$ & $\begin{array}{l}\text { Massagem } \\
\text { aromaterápica e } \\
\text { inalação de óleo } \\
\text { essencial de Lavanda }\end{array}$ & $\begin{array}{l}\text { Não houve } \\
\text { intervenção }\end{array}$ \\
\hline $\begin{array}{l}\text { Effects of geranium aroma } \\
\text { on anxiety among patients } \\
\text { with acute myocardial } \\
\text { infarction: A triple-blind } \\
\text { randomized clinical trial. }\end{array}$ & $\begin{array}{l}\text { SHIRZADEGAN, R.; GHOLAMI, M.; } \\
\text { HASANVAND, S.; BIRJANDI, M.; } \\
\text { BEIRANVAND, A. Effects of geranium } \\
\text { aroma on anxiety among patients with } \\
\text { acute myocardial infarction: A triple- } \\
\text { blind randomized clinical trial. } \\
\text { Complementary Therapies in Clinical } \\
\text { Practice, v. 29, p. 201-206, } 2017 .\end{array}$ & $\begin{array}{l}\text { Pacientes com } \\
\text { infarto agudo do } \\
\text { miocárdio }\end{array}$ & $\begin{array}{l}\text { Inalação de óleo } \\
\text { essencial de gerânio }\end{array}$ & Óleo de girassol \\
\hline $\begin{array}{l}\text { Aromatherapy with two } \\
\text { essential oils from } \\
\text { Satureja genre and } \\
\text { mindfulness meditation to } \\
\text { reduce anxiety in humans. }\end{array}$ & $\begin{array}{l}\text { SOTO-VÁSQUEZ, M. R.; ALVARADO- } \\
\text { GARCÍA, P. A. A. Aromatherapy with } \\
\text { two essential oils from Satureja genre } \\
\text { and mindfulness meditation to reduce } \\
\text { anxiety in humans. Journal of } \\
\text { Traditional and Complementary } \\
\text { Medicine, v. 7, n. 1, p. } 121-125,2017 .\end{array}$ & $\begin{array}{l}\text { Indivíduos com } \\
\text { ansiedade }\end{array}$ & $\begin{array}{l}\text { Inalação de óleo } \\
\text { essencial de S. } \\
\text { brevicalyx e S. } \\
\text { boliviana, e ambas } \\
\text { combinadas com } \\
\text { mindfulness }\end{array}$ & $\begin{array}{l}\text { Não houve } \\
\text { intervenção }\end{array}$ \\
\hline
\end{tabular}

Fonte: dados de pesquisa na PubMed. 


\subsection{BUSCA DE EVIDÊNCIAS}

Na busca de evidências, foram encontrados 203 artigos com potencial relevância para estudo, mas apenas 14 atenderam todos os critérios de inclusão e exclusão estabelecidos.

Após análise dos artigos selecionados e ao se observar o Quadro 1 anteriormente apresentado, pode-se constatar que houve publicações sobre o tema em todos os anos do intervalo pesquisado: 4 publicações nos anos de 2017 (Choi et al, 2017; Hozumi et al., 2017; Shirzadegan et al., 2017; Soto-Vásquez; AlvaradoGarcía, 2017) e 2016 (Barati et al, 2016; Hasanzadeh et al., 2016; Hosseini et al., 2016; Seyyed-Rasooli et al., 2016), 2 ensaios clínicos do mesmo autor publicados em 2015 (Rashidi-Fakari et al., 2015a; RashidiFakari, 2015b), 3 trabalhos publicados no ano de 2014 (Najafi et al., 2014; Namazi et al., 2014; Seifi et al., 2014) e apenas 1 no ano de 2013 (Ni et al., 2013). Pode-se observar que ao longo dos anos as pesquisas sobre o tema têm se tornado mais constantes e melhor estruturadas. Todas as publicações selecionadas foram publicadas em inglês.

Quanto aos periódicos, nota-se que todos são alusivos à saúde, dentre eles, o assunto mais frequente é o de terapias complementares (quatro periódicos com uma publicação cada), e cinco dos 14 estudos selecionados foram publicados em periódicos iranianos, dois quais o Iranian Journal of Nursing and Midwifery Research é o mais frequente, com três publicações (Hosseini et al., 2016; Rashidi-Fakari et al., 2015a; Seifi et al., 2014).

Ao que se refere aos primeiros autores, 10 dos estudos utilizados nesse trabalho têm pesquisadores relacionados à área de Enfermagem. No que diz respeito aos restantes, se dividem entre a área de medicina e farmácia.

\subsection{AVALIAÇÃO CRÍTICA DA EVIDÊNCIA ENCONTRADA}

Pedrolo et al. (2009) afirmam que a avaliação crítica das evidências é primordial, uma vez que se a evidência não for relevante ou se aquele que a está avaliando influencie os resultados por opinião pessoal, a recomendação clínica torna-se ineficaz, podendo gerar danos ao paciente.

Para avaliar um estudo ou diretriz publicado quanto a relevância devemos considerar os seguintes pontos: questão clara; usuários bem definidos; busca abrangente de evidências; descrição dos critérios de seleção e combinação da evidência; descrição dos métodos de formulação da recomendação; consideração dos riscos e efeitos colaterais na sua formulação; registro de identificação das principais recomendações; registro de conflito de interesse dos organizadores; e atualização da diretriz (PEDROLO et al., 2009, p. 762).

Para avaliação crítica da evidência encontrada foram levados em consideração os seguintes aspectos dos estudos que foram Ensaios Clínicos Randomizados (ECR): o tamanho da amostra, a descrição do método de intervenção utilizado, o óleo essencial usado e os desfechos encontrados pelos autores, esses dados estão discriminados no Quadro 2 apresentado na sequência.

A partir da leitura dos ensaios e das informações discriminadas no quadro 2, pode-se verificar que em todos os estudos selecionados, a questão clínica e os usuários estão bem definidos de acordo com os critérios de inclusão e exclusão estabelecidos na determinação da amostra. Além disso, todos os estudos trazem uma ampla busca de evidências a partir da justificação mediante referências do uso de sua metodologia e de suas discussões. 
Quadro 2: Distribuição dos ECR por autor, amostra, método de intervenção, óleo essencial utilizado e desfecho.

\begin{tabular}{|c|c|c|c|c|}
\hline Autor (ano) & Amostra & Método de intervenção & $\begin{array}{l}\text { Óleo essencial } \\
\text { utilizado }\end{array}$ & Desfecho \\
\hline $\begin{array}{l}\text { BARATI et al., } \\
(2016)\end{array}$ & $\begin{array}{l}46 \text { pacientes em diálise } \\
\text { randomizados em dois } \\
\text { grupos }\end{array}$ & $\begin{array}{l}\text { Inalação durante } 15-20 \\
\text { minutos ao longo de } 4 \\
\text { semanas }\end{array}$ & $\begin{array}{l}\text { Água de Rosas } \\
\text { (3 gotas) }\end{array}$ & $\begin{array}{l}\text { Intervenção reduziu o estado } \\
(\mathrm{P}<0,001) \text { e o traço }(\mathrm{P}<0.001) \text { médio } \\
\text { de ansiedade de antes da intervenção } \\
\text { para na semana } 4 \text { após a intervenção. }\end{array}$ \\
\hline $\begin{array}{l}\text { HASANZADEH et } \\
\text { al. (2016) }\end{array}$ & $\begin{array}{l}80 \text { sujeitos } \\
\text { Grupo I }(n=20) \\
\text { Grupo II }(n=20) \\
\text { Grupo III }(n=20) \\
\text { Grupo IV }(n=20)\end{array}$ & $\begin{array}{l}\text { Inalação ( } 20 \text { minutos) } \\
\text { sozinha ou acompanhada de } \\
\text { aplicação de bolsa fria. }\end{array}$ & $\begin{array}{l}\text { Lavanda } \\
\text { (1-2 gotas) }\end{array}$ & $\begin{array}{l}O \text { índice de ansiedade diminuiu em } \\
\text { todos os grupos de estudo }(\mathrm{P}<0,001) \text {. }\end{array}$ \\
\hline $\begin{array}{l}\text { HOSSEINI et al. } \\
\text { (2016) }\end{array}$ & $\begin{array}{l}90 \text { candidatos } \\
\text { Grupo de intervenção }(n=45) \\
\text { Grupo controle }(n=45)\end{array}$ & Inalação durante 20 minutos & $\begin{array}{l}\text { Lavanda } \\
\text { (2 gotas) }\end{array}$ & $\begin{array}{l}\text { Redução do índice médio de ansiedade } \\
\text { de } 56,73(5,67) \text { para } 54,73(5,42) \text { após } \\
\text { a intervenção no grupo de estudo, em } \\
\text { comparação com o grupo controle } \\
{[1,11(1,17)](P<0,001) \text {. }}\end{array}$ \\
\hline $\begin{array}{l}\text { HOZUMI et al. } \\
(2017)\end{array}$ & $\begin{array}{l}365 \text { pacientes } \\
\text { Grupo controle }(n=74) \\
\text { Grupo veículo }(n=72) \\
\text { Grupo toranja }(n=71) \\
\text { Grupo Lavanda }(n=72) \\
\text { Grupo OF }(n=75)\end{array}$ & $\begin{array}{l}\text { Inalação por tempo não } \\
\text { especificado }\end{array}$ & $\begin{array}{l}\text { Lavanda } \\
(0,05 \mathrm{ml}) \\
\\
\text { Osmanthus } \\
\text { fragrans } \\
(0,05 \mathrm{ml}) \\
\\
\text { Toranja } \\
(0,30 \mathrm{ml})\end{array}$ & $\begin{array}{l}\text { No grupo de alta ansiedade, houve uma } \\
\text { melhora significante do desconforto } \\
\text { abdominal nos grupos Toranja e OF. } \\
\text { No grupo Lavanda não houve diferença } \\
\text { significativa tanta na ansiedade quanto } \\
\text { no desconforto abdominal. }\end{array}$ \\
\hline $\begin{array}{l}\text { NAJAFI et al. } \\
(2014)\end{array}$ & $\begin{array}{l}70 \text { pacientes Grupo } \\
\text { Aromaterapia }(n=35) \\
\text { Grupo controle }(n=35) \text {. }\end{array}$ & $\begin{array}{l}\text { Inalação durante } 20 \text { minutos } \\
\text { durante dois dias } \\
\text { subsequentes }\end{array}$ & $\begin{array}{l}\text { Lavanda } \\
\text { (3 gotas) }\end{array}$ & $\begin{array}{l}\text { Os resultados das medidas repetidas } \\
\text { ANOVA para o fator entre indivíduos } \\
\text { do grupo revelaram que os grupos de } \\
\text { estudo diferiram significativamente } \\
\text { entre os cinco pontos de tempo de } \\
\text { medição em relação ao nível de } \\
\text { ansiedade (Greenhouse-Geisser } \mathrm{F}= \\
21.635 \text {, P-Value }<0.001 \text { ). }\end{array}$ \\
\hline $\begin{array}{l}\text { NAMAZI et al. } \\
(2014)\end{array}$ & $\begin{array}{l}113 \text { primíparas } \\
\text { Grupo Aromaterapia }(n=57) \\
\text { Grupo controle }(n=56) \text {. }\end{array}$ & $\begin{array}{l}\text { Inalação por tempo não } \\
\text { especificado }\end{array}$ & $\begin{array}{l}\text { C. aurantium } \\
(4 \mathrm{ml})\end{array}$ & $\begin{array}{l}\text { Os níveis de ansiedade em dilatação de } \\
3-4 \mathrm{~cm}(\mathrm{P}<0.001) \text { e } 6-8 \mathrm{~cm}(\mathrm{P}<0,001) \\
\text { foram significativamente menores no } \\
\text { grupo de aromaterapia em } \\
\text { comparação com o grupo controle. }\end{array}$ \\
\hline NI et al. (2013) & $\begin{array}{l}109 \text { pacientes, grupo } \\
\text { Bergamota }(n=53) \\
\text { Grupo controle }(n=56)\end{array}$ & Inalação durante 30 minutos & Bergamota & $\begin{array}{l}\text { Doss } 75 \text { pacientes com experiência } \\
\text { cirúrgica incluíram } 30 \text { no grupo } \\
\text { bergamota e } 45 \text { no grupo controle, o } \\
\text { escore STAI diminuiu mais no grupo } \\
\text { bergamota do que no grupo controle } \\
(-4,0 \text { versus }-1,0, P=0,005) \text {. }\end{array}$ \\
\hline $\begin{array}{l}\text { RASHIDI } \\
\text { FAKARI et al. } \\
(2015 b)\end{array}$ & $\begin{array}{l}100 \text { mulheres } \\
\text { Grupo Aromaterapia }(n=50) \\
\text { Grupo Controle }(n=50)\end{array}$ & Inalação durante 20 minutos & $\begin{array}{l}\text { Gerânio } \\
\text { ( } 2 \text { gotas) }\end{array}$ & $\begin{array}{l}\text { No grupo experimental, os valores } \\
\text { médios de ansiedade antes e após a } \\
\text { intervenção foram de } 56,75(9,9) \text { e } \\
52,73(11,7) \text {, respectivamente, o que } \\
\text { mostrou uma diminuição significativa } \\
(\mathrm{P}=0,001) \text { no estado de ansiedade. }\end{array}$ \\
\hline
\end{tabular}


(continuação)

Quadro 2: Distribuição dos ECR por autor, amostra, método de intervenção, óleo essencial utilizado e desfecho.

\begin{tabular}{|c|c|c|c|c|}
\hline Autor (ano) & Amostra & Método de intervenção & $\begin{array}{c}\text { Óleo essencial } \\
\text { utilizado }\end{array}$ & Desfecho \\
\hline $\begin{array}{l}\text { RASHIDI- } \\
\text { FAKARI et al. } \\
(2015 a)\end{array}$ & $\begin{array}{l}98 \text { mulheres } \\
\text { Grupo aromaterapia }(n=48) \\
\text { Grupo controle }(n=50) \text {. }\end{array}$ & Inalação durante 20 minutos & $\begin{array}{l}\text { Casca de } \\
\text { Laranja } \\
\text { (2 gotas) }\end{array}$ & $\begin{array}{l}0 \text { nível de ansiedade das mulheres em } \\
\text { ambos grupos de intervenção }(\mathrm{P}= \\
0,03 \text { ) e controle }(\mathrm{P}=0,003) \text { diminuiu } \\
\text { após a intervenção. No entanto, a } \\
\text { redução foi maior no grupo de } \\
\text { intervenção (pontuação = }-3,08 \text { ) em } \\
\text { comparação com o grupo controle } \\
\text { (pontuação }=-1,14) \text {. }\end{array}$ \\
\hline $\begin{array}{l}\text { SEIFI et al. } \\
(2014)\end{array}$ & $\begin{array}{l}60 \text { pacientes } \\
\text { Grupo aromaterapia }(n=30) \\
\text { Grupo controle }(n=30) \text {. }\end{array}$ & $\begin{array}{l}\text { Inalação durante } 20 \text { minutos } \\
\text { em dois dias }\end{array}$ & $\begin{array}{l}\text { Lavanda } \\
\text { ( } 2 \text { gotas) }\end{array}$ & $\begin{array}{l}\text { O escore médio de ansiedade reduziu } \\
\text { após a intervenção para } 42,73 \pm 7,30 \\
\text { após intervenção }(\mathrm{P}=0,541) \text {. Nos } 3 \\
\text { dias após a cirurgia, o índice médio de } \\
\text { ansiedade reduziu após a intervenção } \\
\text { para } 41,33 \pm 3,65(\mathrm{P}=0.672) \text {. }\end{array}$ \\
\hline $\begin{array}{l}\text { SEYYED- } \\
\text { RASOOLI et al. } \\
(2016)\end{array}$ & $\begin{array}{l}90 \text { pacientes Grupo } \\
\text { massagem } \\
(n=30) \\
\text { Grupo Inalação }(n=30) \\
\text { Grupo Controle }(n=30) .\end{array}$ & $\begin{array}{l}\text { Inalação e massagem, ambas } \\
\text { durante } 30 \text { minutos }\end{array}$ & $\begin{array}{l}\text { Lavanda } \\
\text { ( } 3 \text { gotas) }\end{array}$ & $\begin{array}{l}\text { Os escores médios de ansiedade na } \\
\text { massagem aromática e grupos de } \\
\text { aromaterapia por inalação reduziram } \\
\text { de } 46,36+-6.39 \text { e } 44.73+-9.83 \text { antes } \\
\text { da intervenção para } 40.03+-11.13 \text { e } \\
38.30+-10,51 \text { após a intervenção, e } \\
\text { ambas as intervenções reduziram a } \\
\text { ansiedade do estado. (P=0,007) }\end{array}$ \\
\hline $\begin{array}{l}\text { SHIRZADEGAN } \\
\text { et al.(2017) }\end{array}$ & $\begin{array}{l}80 \text { pacientes } \\
\text { Grupo gerânio }(n=40) \\
\text { Grupo placebo }(n=40) \text {. }\end{array}$ & $\begin{array}{l}\text { Inalação durante } 20 \text { minutos, } \\
\text { duas vezes ao dia, em dois } \\
\text { dias consecutivos }\end{array}$ & $\begin{array}{l}\text { Gerânio } \\
\text { ( } 3 \text { gotas) }\end{array}$ & $\begin{array}{l}\text { O grupo do gerânio mostrou uma } \\
\text { redução significativa no índice médio } \\
\text { de ansiedade após cada sessão de } \\
\text { aromaterapia }(\mathrm{P}<0,001) \text {. Os, dois } \\
\text { grupos não foram significativamente } \\
\text { diferentes em termos de pontuação } \\
\text { média de ansiedade na linha de base } \\
(\mathrm{P}>0,05) .\end{array}$ \\
\hline $\begin{array}{l}\text { SOTO-VÁSQUEZ; } \\
\text { ALVARADO- } \\
\text { GARCÍA (2017) }\end{array}$ & $\begin{array}{l}108 \text { participantes } \\
\text { Grupo Controle }(n=14) \\
\text { Grupo experimental } 1 \text { (EG1; } \\
n=18) \\
\text { Grupo experimental } 2 \text { (EG2; } \\
n=18 \text { ) } \\
\text { Grupo experimental } 3 \text { (EG3; } \\
n=18 \text { ) } \\
\text { Grupo experimental } 4 \text { (EG4; } \\
n=18 \text { ) } \\
\text { Grupo experimental } 5 \text { (EG5. } \\
\text { N=18) }\end{array}$ & $\begin{array}{l}\text { Inalação durante } 30 \text { minutos } \\
\text { em } 12 \text { sessões }\end{array}$ & $\begin{array}{l}\text { S. brevicalyx } \\
(2 \text { gotas }) \\
\text { S. boliviana } \\
(2 \text { gotas) }\end{array}$ & $\begin{array}{l}\text { Os escores de ansiedade de estado e } \\
\text { traço mostram uma diminuição na fase } \\
\text { de estudo pós-teste em todos os } \\
\text { grupos experimentais (EG1, EG2, EG4 e } \\
\text { EG5: p<0,005; EG3: p <0,05), } \\
\text { mostrando uma alteração nos escores } \\
\text { STAI após a intervenção. }\end{array}$ \\
\hline
\end{tabular}

Fonte: dados de pesquisa na PubMed.

Em relação à descrição dos métodos de formulação da recomendação, constatou-se que todos os autores admitiram o intervalo de confiança de $95 \%(\mathrm{P}<0,05)$ para o cálculo de amostras e para os testes estatísticos realizados. Para a análise estatística, 11 estudos escolheram o software Statistical Package for the Social Sciences (SPSS), um estudo usou o software Stata 11 e o outro não deu informações a respeito do programa utilizado. Dentre os testes estatísticos mais escolhidos estão o Test T (7 estudos) e a análise de variância - ANOVA (4 estudos), entre outros.

O método para coleta de dados sobre ansiedade, na maior parte das pesquisas (12 estudos) foi realizada através do Inventário de Traço-Estado de Ansiedade de Spielberger (STAI). O STAI tem sido amplamente utilizado desde 1966. Consiste em 20 declarações (por exemplo, "Estou tenso", "Estou relaxado") e os entrevistados classificam a intensidade de seus sentimentos sobre cada um, no presente momento, de 1 (nenhum) para 4 (muito). Os escores variam de 20 a 80, sendo que as maiores pontuações indicam maior ansiedade (baixa ansiedade: 20-39, ansiedade moderada: 40-59 e alta ansiedade: 60-80) (NI et al., 2013).

Se tratando do registro de conflito de interesse dos pesquisadores, somente Barati et al. (2016) e Najafi et al.(2014) não forneceram informações acerca do quesito. 
Ao que diz respeito ao registro de identificação das principais recomendações, os estudos apresentaram de forma clara nas suas discussões, sempre comparada a outras evidências da literatura, quais suas recomendações de acordo com os resultados encontrados nas pesquisas realizadas. Além disso, houve sugestões de novas pesquisas e de uso da aromaterapia para os grupos com estado de saúde associado de acordo com os usuários do ensaio realizado.

Além dos ensaios clínicos randomizados citados no Quadro 2, também foi coletado como fonte de evidência o artigo de Choi et al. (2017) que se trata de uma revisão sistemática que literatura sobre o uso da aromaterapia para o alívio de sintomas de pacientes queimados, entre eles a ansiedade. Os autores do trabalho fizeram a análise das publicações para risco de parcialidade através da ferramenta de avaliação do risco de colaboração Cochrane (ROB). A partir do estudo concluiu-se, após análise qualitativa, que dos quatro estudos selecionados pelos pesquisadores que a evidência sobre os efeitos da aromaterapia sobre os sintomas de pacientes queimados foi moderada e que são necessários novos estudos melhores estruturados para investigar os mecanismos potenciais subjacentes aos efeitos da aromaterapia.

De modo geral, ao que se refere à validade da evidência encontrada, somente o estudo de Hozumi et al. (2017) foi considerado pela autora do presente trabalho como evidência moderada, visto que a descrição de sua metodologia estava incompleta - ausência de software de análise estatística e ausência do tempo de duração da intervenção - além disso, como método de coleta de níveis de ansiedade utilizou-se de Escala de classificação numérica, que se trata de um meio de coleta menos específico e detalhado do que o usado pelos demais estudos.

\subsection{TOMADA DE DECISÃO A PARTIR DA MELHOR EVIDÊNCIA ENCONTRADA}

Diante da análise crítica dos estudos selecionados nessa pesquisa, constata-se que ao que diz respeito ao manejo da ansiedade em diversos grupos de pacientes com diversos estados de saúde associados (queimados, condições cardíacas, gestação, diálise, entre outros) o método de inalação é considerado unânime para a aplicação da aromaterapia. Seyyed-Rasooli et al. (2016) ao comparar esse método com a massagem ao uso de óleo essencial em pacientes queimados, encontrou resultados positivos na diminuição dos níveis de ansiedade em ambas intervenções, porém concluiu, fundamentado em valores estatísticos, que a inalação ainda é preferencial no que diz respeito à redução dos níveis de ansiedade.

De todos os estudos selecionados, somente Seifi et al.(2014) não encontrou resultados de valor estatístico significante na redução da ansiedade a partir da inalação do óleo essencial de lavanda.

No que concerne ao óleo essencial utilizado, percebe-se que o óleo essencial de Lavanda foi o mais citado entre os estudos (sete citações), seguido pelo óleo essencial de Gerânio, citado duas vezes.

Dentre os sete estudos que utilizaram o óleo de Lavanda, com exceção de Seifi et al.(2014), os resultados foram estatisticamente significantes na redução dos níveis de ansiedade dos indivíduos do grupo de intervenção quando comparados ao grupo controle ou com si mesmos antes e depois da aromaterapia. Os autores utilizaram uma quantidade que variou entre 2 e 3 gotas do óleo, porém ambas apresentaram resultado estatístico positivo na redução da pontuação de ansiedade.

O efeito ansiolítico da Lavanda já havia sido comprovado e explicado em estudos, como o de Schuwald et al.(2013) que utilizou de experimento controlado com camundongos para provar o efeito da lavanda sobre o hipocampo, uma região do cérebro importante para transtornos de ansiedade, mostrando que a inibição pelo óleo de lavanda é principalmente mediada por canais de cálcio dependentes da tensão.

Quanto ao tempo de duração da intervenção, dos 14 estudos, 9 utilizaram o intervalo de tempo de 20 minutos. A escolha foi justificada por Rashidi-Fakari et al. (2015b) porque os receptores olfativos dos participantes tornaram-se insensíveis a inalar o aroma dos óleos essenciais não diluídos 20 minutos após o início da intervenção.

Logo, a sugestão para tomada de decisão a partir da melhor evidência encontrada nesse estudo é de que para o manejo da ansiedade dos mais diversos grupos de pacientes, pode-se utilizar o óleo essencial de Lavanda, entre 2-3 gotas, por inalação durante o período de 20 minutos. 


\section{CONCLUSÃO}

O estudo mostrou evidência considerável de que para o manejo da ansiedade através do uso da aromaterapia, esta deve ser aplicada por inalação e o óleo essencial mais recomendado é o de Lavanda, o que preencheu as questões levantadas por esse trabalho.

Devido a simplicidade e ao baixo custo dessa abordagem terapêutica, sua aplicação na prática clínica pode ser sugerida à equipe de enfermagem como um cuidado não invasivo e estimulado como ferramenta de autocuidado para indivíduos com diferentes níveis de ansiedade e variadas condições de saúde associadas.

Por conseguinte, é importante estimular a realização de mais estudos estruturados sobre o tema para subsidiar uma prática prolongada de tratamento. Isso também deve ser estimulado nos espaços acadêmicos de formação do enfermeiro ou nos serviços de saúde para outras práticas terapêuticas complementares, haja vista que todas envolvem a noção de sujeito holístico multidimensional, mas necessitam de evidências seguras e eficazes de aplicabilidade.

\section{REFERÊNCIAS}

[1] barati, F.; Nasiri, A.; Akbari, N.; Sharifzadeh, G. The Effect of Aromatherapy on Anxiety in Patients. Nephrourology monthly, v. 8, n. 5, p. e38347, 2016. Disponível em:

<http://www.ncbi.nlm.nih.gov/pubmed/27878109\%0Ahttp://www.pubmedcentral.nih.gov/articlerender.fcgi?artid= PMC5111093>. Acesso em: 9/10/2017.

[2] Brasil. Ministério da Saúde. Política nacional de práticas integrativas e complementares no SUS : atitude de ampliação de acesso. - 2. ed. - Brasília : Ministério da Saúde, 2015. 96 p. : il. Disponível em: < http://bvsms.saude.gov.br/bvs/publicacoes/politica_nacional_praticas_integrativas_complementares_2ed.pdf >. Acesso em: 8/10/2017

[3] Brasil. Ministério da Saúde. Portaria No- 849, DE 27 DE Março DE 2017. Inclui a Arteterapia, Ayurveda, Biodança, Dança Circular, Meditação, Musicoterapia, Naturopatia, Osteopatia, Quiropraxia, Reflexoterapia, Reiki, Shantala, Terapia Comunitária Integrativa e Yoga à Política Nacional de Práticas Integrativas e Complementares. Brasília. 2017. 7p. Disponível em: < http://dab.saude.gov.br/portaldab/biblioteca.php?conteudo=legislacoes/pnpics>. Acesso em: 8/10/2017

[4] Choi, J.; Lee, J. A.; Alimoradi, Z.; Lee, M. S. Aromatherapy for the relief of symptoms in burn patients: A systematic review of randomized controlled trials. Burns : journal of the International Society for Burn Injuries, p. 0-7, 2017. Elsevier Ltd and International Society of Burns Injuries. Disponível em:

<http://linkinghub.elsevier.com/retrieve/pii/S0305417917305636\%0Ahttp://www.ncbi.nlm.nih.gov/pubmed/291 69701>. Acesso em: 9/10/2017.

[5] Gnatta, J. R.; Piason, P. P.; Lopes, C. de L. B. C.; Rogenski, N. M. B.; Silva, M. J. P. DA. Aromaterapia com ylang ylang para ansiedade e autoestima: Estudo piloto. Revista da Escola de Enfermagem, v. 48, n. 3, p. 492-499, 2014. Disponível em: <http://www.scielo.br/pdf/reeusp/v48n3/pt_0080-6234-reeusp-48-03-492.pdf>. Acesso em: 9/10/2017.

[6] Hozumi, H.; Hasegawa, S.; Tsunenari, T.; et al. Aromatherapies using Osmanthus fragrans oil and grapefruit oil are effective complementary treatments for anxious patients undergoing colonoscopy: A randomized controlled study. Complementary Therapies in Medicine, v. 34, n. February, p. 165-169, 2017. Elsevier. Disponível em: <http://dx.doi.org/10.1016/j.ctim.2017.08.012>. Acesso em: 9/10/2017.

[7] Najafi, Z.; Taghadosi, M.; Sharifi, K.; Farrokhian, A.; Tagharrobi, Z. The Effects of Inhalation Aromatherapy on Anxiety in Patients With Myocardial Infarction: Randomized Clinical Trial. Iranian Red Crescent Medical Journal, v. 16, n. 8, p. 1-7, 2014. Disponível em: <http://ircmj.com/en/articles/16185.html>. Acesso em: 9/10/2017.

[8] NI, C.-H.; HOU, W.-H.; KAO, C.-C.; et al. The anxiolytic effect of aromatherapy on patients awaiting ambulatory surgery: a randomized controlled trial. Evidence-based complementary and alternative medicine : eCAM, v. 2013, p. 927419, 2013. Disponível em:

<http://www.pubmedcentral.nih.gov/articlerender.fcgi?artid=3877597\&tool=pmcentrez\&rendertype=abstract $>$. Acesso em: 9/10/2017.

[9] Pedrolo, E.; Danski, M. T. R.; Mingorance, P.; Lazzari, L. S. M.; Méier, M. J. C. K. Evidence-Based Practice As a Tool for Professional Practice of Nurses. , v. 14, n. 4, p. 760-763, 2009. Disponível em: <http://revistas.ufpr.br/cogitare/article/view/16396>. Acesso em: 15/9/2017.

[10] Queiroz, M. O itinerário rumo às medicinas alternativas: uma análise em representações sociais de profissionais da saúde The trajectory towards alternative medicines: an analysis of health professionals. Cad. Saude Publica, v. 16, n. 2, p. 363-375, 2000. Disponível em: <http://www.scielosp.org/pdf/csp/v16n2/2086.pdf>. Acesso em: 10/10/2017. 
[11] Rashidi-Fakari, F.; Tabatabaeichehr, M.; Mortazavi, H. The effect of aromatherapy by essential oil of orange on anxiety during labor: A randomized clinical trial. Iranian journal of nursing and midwifery research, v. 20, n. 6, p. 661-4, 2015a. Disponível em: <http://www.ncbi.nlm.nih.gov/pubmed/26793249\%0Ahttp://www.pubmedcentral.nih.gov/articlerender.fcgi?artid= PMC4700683>. Acesso em: 9/10/2017.

[12] Rashidi Fakari, F.; Tabatabaeichehr, M.; Kamali, H.; Rashidi Fakari, F.; Naseri, M. Effect of Inhalation of Aroma of Geranium Essence on Anxiety and Physiological Parameters during First Stage of Labor in Nulliparous Women: a Randomized Clinical Trial. Journal of Caring Sciences, v. 4, n. 2, p. 135-141, 2015b. Disponível em: <http://journals.tbzmed.ac.ir/JCS/Abstract/JCS_71_20150531124630>. Acesso em: 9/10/2017.

[13] Schuwald, A. M.; Nöldner, M.; Wilmes, T.; et al. Lavender Oil-Potent Anxiolytic Properties via Modulating Voltage Dependent Calcium Channels. PLoS ONE, v. 8, n. 4, p. 1-9, 2013. Disponível em: <https://www.ncbi.nlm.nih.gov/pmc/articles/PMC3639265/>. Acesso em: 9/10/2017.

[14] Seifi, Z.; Beikmoradi, A.; Oshvandi, K.; et al. The effect of lavender essential oil on anxiety level in patients undergoing coronary artery bypass graft surgery: A double-blinded randomized clinical trial. Iranian journal of nursing and midwifery research, v. 19, n. 6, p. 574-580, 2014. Disponível em: <https://www.ncbi.nlm.nih.gov/pmc/articles/PMC4280720/>. Acesso em: 9/10/2017.

[15] Seyyed-Rasooli, A.; Salehi, F.; Mohammadpoorasl, A.; et al. Comparing the effects of aromatherapy massage and inhalation aromatherapy on anxiety and pain in burn patients: A single-blind randomized clinical trial. Burns, v. 42, n. 8, p. 1774-1780, 2016. Elsevier Ltd and ISBI. Disponível em: <http://dx.doi.org/10.1016/j.burns.2016.06.014>. Acesso em: 9/10/2017.

[16] Stea, S.; Beraudi, A.; Pasquale, D. DE. Essential oils for complementary treatment of surgical patients: State of the art. Evidence-based Complementary and Alternative Medicine, v. 2014, p. 1-6, 2014. Hindawi Publishing Corporation. Disponível em: <https://www.hindawi.com/journals/ecam/2014/726341/>. Acesso em: 9/10/2017.

[17] Tang, S. K.; TSE, M. Y. M.; Tang, S. K.; TSE, M. Y. M. Aromatherapy: does it help to relieve pain, depression, anxiety, and stress in community-dwelling older persons? BioMed research international, v. 2014, p. 430195, 2014. Disponível em: <http://www.ncbi.nlm.nih.gov/pubmed/25114901\%5Cnhttp://www.pubmedcentral.nih.gov/articlerender.fcgi?artid $=$ PMC4119713>. Acesso em: 9/10/2017. 


\title{
Capítulo 17
}

\section{Incentivando escolhas alimentares saudáveis: Uma experiencia da utilização de recurso audiovisual em atividade de educação nutricional}

\author{
Ivana Conceição Porto Moraes \\ Adriano Bezerra Crispim \\ Fabiana Santos Silva \\ Luana de Sousa Pereira
}

Resumo: Atualmente na maioria dos países os padrões de alimentação estão se modificando, onde as principais mudanças envolvem a substituição de alimentos in natura ou minimamente processados de origem vegetal por produtos industrializados prontos para consumo. Essas transformações, observadas com grande intensidade no Brasil, determinam, entre outras consequências, o desequilíbrio na oferta de nutrientes e a ingestão excessiva de calorias, bem como o aparecimento de doenças, como: obesidade, diabetes, hipertensão e outras doenças crônicas. (BRASIL, 2014). Essa realidade presente também no município de Mossoró-Rn exige a implantação de estratégias efetivas para a redução da morbimortalidade relacionada à alimentação inadequada e ao sedentarismo (BRASIL,2012). Partindo dessa preocupação surge a ideia da elaboração de um instrumento áudio visual criativo para utilização em atividades de educação alimentar e nutricional, objetivando incentivar a adoção de escolhas alimentares mais saudáveis, bem como o esclarecimento aos participantes dos malefícios do consumo de alimentos ultraprocessados e dos benefícios da ingestão de alimentos regionais in natura, destacando seu valor nutricional. Para tanto, a pesquisa de informação nutricional dos alimentos selecionados foi realizada com o auxilio da Tabela de Composição dos Alimentos TACO e de rótulos dos alimentos. Assim, o presente painel consta de informações sobre alguns vilões da alimentação como temperos industrializados, macarrão instantâneo, refrigerante, pipocas amanteigadas, entre outros, demonstrando o quantitativo de açúcar, gordura e sal, e em contrapartida inclui também a sugestão de substituição por alimentos regionais in natura, como batata doce, milho verde, ovo cozido incluindo também algumas preparações como sal de ervas, fanta caseira e macarrão com sardinha. As atividades de EAN realizadas com o apoio do painel apresentam algumas etapas compreendendo: dinâmica de acolhida aos participantes, apresentação interativa das informações nutricionais dos alimentos ultraprocessados, dinâmica de escolha de alimentos substitutos, oficina de sal de ervas, degustação de suco, panfletagem e avaliação da ação. A primeira apresentação foi realizada na Secretaria do Desenvolvimento Social e Juventude para os beneficiários do Programa Bolsa Família e as ações estão seguindo nos espaços de educação em saúde dos equipamentos da rede municipal, com proposta da reprodução desse recurso áudio visual para todas as Unidades Básicas de Saúde através de oficinas. 0 apoio desse instrumento nas atividades de EAN está sendo bastante significativo, ao gerar discussões sobre a importância que a alimentação tem ou pode ter na vida dos participantes, concedendo maior valor ao processo de adquirir, preparar e consumir alimentos. Nesse sentido sua utilização pode representar uma estratégia de comunicação e educação em saúde para apoio aos indivíduos e coletividades na decisão por práticas promotoras da saúde, como também nas atividades dos profissionais de saúde com vistas a melhorias nas condições nutricionais da população.

Palavras-Chave: Alimentos Ultraprocessados, Alimentos in Natura, Guia Alimentar para População 


\section{INTRODUÇÃO}

Atualmente na maioria dos países os padrões de alimentação estão se modificando, onde as principais mudanças envolvem a substituição de alimentos in natura ou minimamente processados de origem vegetal (arroz, feijão, mandioca, batata, legumes e verduras) e preparações culinárias à base desses alimentos por produtos industrializados prontos para consumo. Essas transformações, observadas com grande intensidade no Brasil, determinam, entre outras consequências, o desequilíbrio na oferta de nutrientes e a ingestão excessiva de calorias, bem como o aparecimento de doenças, como: obesidade, diabetes, hipertensão e outras doenças crônicas. (BRASIL, 2014).

Essa realidade presente no município de Mossoró-RN exige a implantação de estratégias efetivas para a redução da morbimortalidade relacionada à alimentação inadequada e ao sedentarismo (BRASIL,2012). Partindo dessa preocupação surge a ideia da elaboração de um instrumento áudio visual criativo para utilização em atividades de educação alimentar e nutricional, objetivando incentivar a adoção de escolhas alimentares mais saudáveis, bem como o esclarecimento aos participantes dos malefícios do consumo de alimentos ultraprocessados e dos benefícios da ingestão de alimentos regionais in natura, destacando seu valor nutricional. Com apresentações interativas partindo de metodologias ativas este projeto está aliado à meta assumida pelo Brasil (2017) em reduzir o consumo regular de refrigerante e suco artificial em pelo menos $30 \%$ na população adulta, e ampliar em no mínimo $17,8 \%$ o percentual de adultos que consomem frutas e hortaliças regularmente até 2019.

Seguindo princípios da Politica Nacional de Alimentação e Nutrição (2014), o referido projeto reforça o respeito á diversidade e cultura alimentar difundindo a riqueza de alguns alimentos regionais, fortalecendo à identidade e cultura alimentar da população. Nesse sentido, a utilização desse recurso áudio visual representa uma estratégia de comunicação e educação em saúde para apoio aos indivíduos e coletividades na decisão por práticas promotoras da saúde, servindo também de base para socialização do conhecimento e da informação sobre alimentação e nutrição por parte dos profissionais de saúde.

\section{METODOLOGIA}

Inicialmente foi realizada a pesquisa de informação nutricional dos alimentos selecionados, incluindo os que já foram mencionados consumo em algumas atividades de educação alimentar e nutricional desenvolvida e outros que fazem parte da cultura regional, com o auxilio da Tabela de Composição dos Alimentos TACO e de rótulos dos alimentos. Assim, o presente painel consta de informações sobre alguns vilões da alimentação como temperos industrializados, macarrão instantâneo, pipocas amanteigadas, biscoito recheado, refrigerante e suco industrializado demonstrando o quantitativo de açúcar, gordura e sal, e em contrapartida inclui também a sugestão de substituição por alimentos regionais in natura, como batata doce, milho verde, ovo cozido incluindo também algumas preparações como sal de ervas, fanta caseira, macarrão com sardinha, entre outros. Na sua confecção priorizou-se o uso de materiais artesanais como palha, tecidos, exaltando a cultura manufaturada, a originalidade expondo o açúcar, o sal e a gordura, como também a durabilidade plastificando as imagens dos alimentos.

As atividades de EAN realizadas com o apoio do painel apresentam algumas etapas compreendendo: dinâmica de acolhida aos participantes, apresentação interativa das informações nutricionais dos alimentos ultraprocessados, dinâmica de escolha de alimentos substitutos, oficina de sal de ervas, degustação de suco, panfletagem com folder sobre o Guia Alimentar para População Brasileira e receita do sal de ervas e avaliação da ação, através de um diálogo constante, instigando a participação ativa dos envolvidos. Isso tudo considerando que o processo educativo para ser efetivo necessita provocar e estimular a subjetividade, na perspectiva de proporcionar prazer no ato de aprender, de conhecer e de saber, e se consolida no ato de retornar o já conhecido, de considerar informações, de revisar e investigar dados disponíveis numa busca constante de novos significados (BRASIL,2009).

\section{RESULTADOS E DISCUSSÃO}

0 apoio desse instrumento nas atividades de EAN está sendo bastante significativo, ao gerar discussões sobre a importância que a alimentação tem ou pode ter na vida dos participantes, concedendo maior valor ao processo de adquirir, preparar e consumir alimentos. A primeira apresentação foi realizada na Secretaria do Desenvolvimento Social e Juventude para os beneficiários do Programa Bolsa Família e as ações estão seguindo nos espaços de educação em saúde dos equipamentos da rede municipal, com 
proposta da reprodução desse recurso áudio visual para todas as Unidades Básicas de Saúde através de oficinas.

Assim, utilizando metodologias ativas que como afirma Mitre et all (2008) estão alicerçadas em um princípio teórico significativo: a autonomia, estamos realizando apresentações respeitando o conhecimento prévio dos participantes e despertando-os para uma participação ativa nas discussões e dinâmicas realizadas. Como destaque observou se o interesse dos participantes em adquirir as receitas sugeridas, principalmente do sal de ervas como opção para substituição dos temperos industrializados, confirmando o que reforça Garcia e Castro (2011) ao colocarem que saber preparar o próprio alimento gera autonomia e permite ampliar o conjunto de possibilidades dos indivíduos, e mesmo quando o preparo dos alimentos não é viável nas ações educativas, é necessário refletir com as pessoas sobre a importância e o valor da culinária como recurso para alimentação saudável. Nesse sentido, alertando sobre os perigos dos alimentos ultraprocessados conseguimos incentivar os participantes para escolhas alimentares saudáveis, despertando o interesse para o consumo de alimentos que fazem parte da nossa cultura local e para valorização da culinária enquanto instrumento para adoção de uma alimentação saudável. Observou se ainda que a aplicação de dinâmicas de grupo facilitou o envolvimento e a participação de todos, atendendo a proposta da pedagogia ativa, onde o participante é o protagonista central e o profissional de saúde é o facilitador das experiências de aprendizagem (BRASIL,2009).
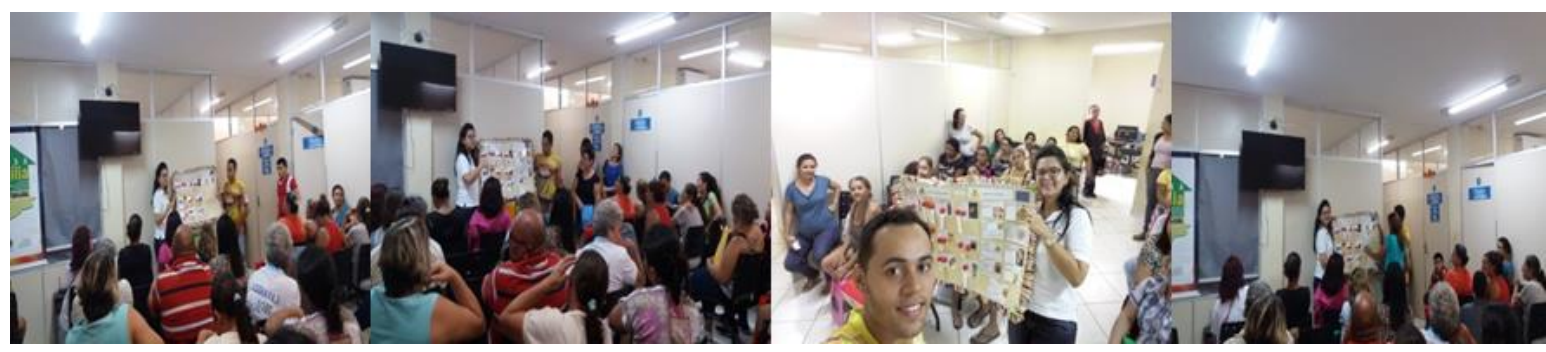

\section{CONCLUSÕES}

Consideramos de grande valia a divulgação desse recurso áudio visual, visto que como afirma Garcia (2003) os costumes regionais/locais estão sendo descaracterizados com o processo de globalização, exigindo estratégias dinâmicas e criativas para o resgate da cultura alimentar local, e além disso é uma necessidade urgente coibir as consequências do consumo de alimentos ultraprocessados para saúde da população, aumentando as estatísticas das doenças crônicas não transmissíveis. Assim sendo, a utilização desse recurso pode representar uma estratégia de comunicação e educação em saúde para apoio nas atividades dos profissionais de saúde com vistas a melhorias nas condições nutricionais da população.

Reconhecendo como reforça Carvalho (2014) que as pessoas farão sempre sua própria análise, pessoal ou compartilhada com o grupo, dos fatos e situações e tomarão suas decisões baseadas em muitos fatores, e não apenas na informação recebida, essa proposta de educação nutricional representa muito mais do que transmissão de conhecimentos, mas apresenta diversos elementos para atribuição de novos significados ao ato de comer e aos hábitos de vida das participantes.

\section{REFERÊNCIAS}

[1] BRASIL, Ministério da Saúde, Política Nacional de Alimentação e Nutrição, Brasília, 2012.

[2] BRASIL, Ministério da Saúde. Secretaria de Atenção à Saúde. Departamento de Atenção Básica. Guia Alimentar para a População Brasileira, 2ª ed., Brasília, 2014.

[3] BRASIL, Ministério da Saúde. Secretaria de Gestão do Trabalho e da Educação na Saúde. Departamento de Atenção Básica. Estratégia Nacional para Educação em Saúde para o Autocuidado em Diabetes Mellitus. Florianópolis, 2009.

[4] CARVALHO, Maria Cláudia da Veiga Soares, Reflexões sobre a construção de um Plano de Ação de EAN IN: Educação Alimentar e Nutricional no Programa Bolsa Família, Rio de Janeiro:ead/ ensP, 2014.

[5] GARCIA, R. W. D; CASTRO, R. R. A culinária como objeto de estudo e de intervenção no campo da Alimentação e Nutrição, Ciência e Saúde Coletiva, RJ, V.16, n.1, 2011. 
[6] GARCIA, Rosa Wanda Diez, Reflexos da globalização na cultura alimentar: considerações sobre as mudanças na alimentação urbana, Campinas, SP, 2003.

[7] MITRE, Sandra Minardi, et all, Metodologias ativas de ensino-aprendizagem na formação profissional em saúde: debates atuais, Revista Ciência e Saúde Coletiva, RJ, 2008. 


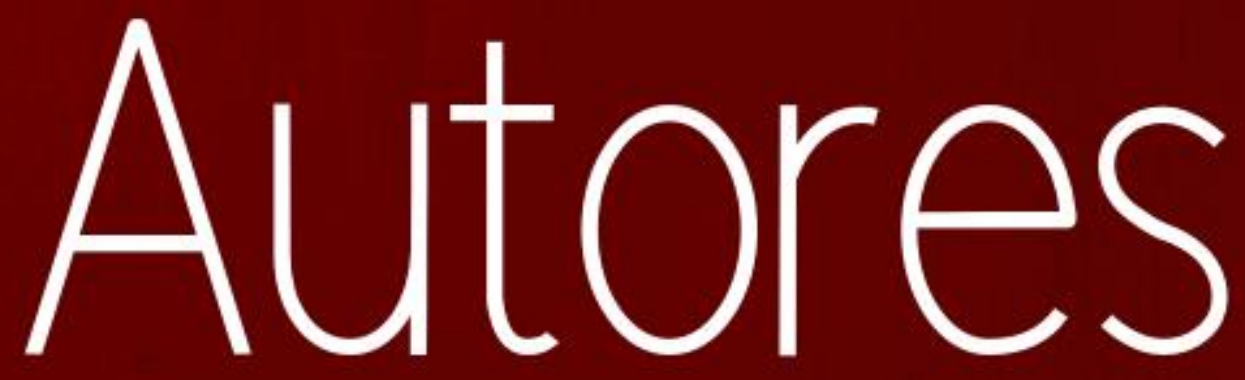




\section{ADRIANO BEZERRA CRISPIM}

Graduado pela Universidade Potiguar desde 2013, possui especialização em Auditoria em Serviços de Saúde pela FVJ, Extensão Universitária pela UFRN com ênfase em Hanseníase. Atuou como nutricionista no Hotel Thermas, atuou também na Prefeitura Municipal de Mossoró, como Supervisor em Saúde da Família e na mesma gestão como Diretor de Unidade. Tem Artigo publicado em Nutrição Social com o tema Desmistificando o Programa Bolsa Família: impactos no estado nutricional da vida dos Beneficiários. Atualmente é de grupo gestor da empresa TD Prestcom. E está se especializando em MBA em Nutrição Organizacional.

\section{ÁLEF LAMARK ALVES BEZERRA}

Médico formado pela Faculdade de Ciências Médicas da Paraíba

\section{ALEXANDRE BEZERRA SILVA}

Professor orientador: Mestre em Saúde da Família, professor do departamento de Ciências Biomédicas da Universidade do Estado do Rio Grande do Norte - UERN.

\section{ALINE MENDES GERAGE}

Finalizou sua graduação em Educação Física pela Universidade Estadual de Londrina (UEL), em 2006, o mestrado pelo Programa de Pós-Graduação Associado em Educação Física UEM/UEL, em julho de 2009, e o doutorado pelo Programa de Pós-Graduação em Educação Física da Universidade Federal de Santa Catarina (UFSC), em abril de 2016. Atualmente, é docente (adjunto A) do Departamento de Educação Física da UFSC, atuando na graduação e na pós-graduação. Participa do Núcleo de Pesquisa em Atividade Física e Saúde (NuPAF - UFSC), do Grupo de Estudo e Pesquisa em Exercício Físico e Doenças Crônicas não Transmissíveis (GEPEFID - UFSC) do Grupo de Estudo e Pesquisa em Metabolismo, Nutrição e Exercício (GEPEMENE - UEL), concentrando seus estudos na linha de atividade física e saúde, principalmente, no que diz respeito às respostas e adaptações cardiovasculares à atividade física e ao exercícios físico.

\section{ALMIRA LINS DE MEDEIROS}

Licenciada em Pedagogia pela UFRN, Mestre em Psicologia l pela UFPB, Doutora em Ciencias Sociais pela UFCG. Professora aposentada do Departamento de Educação da UEPB e Graduanda de Psicologia na UEPB.

\section{ANDERSON DA SILVA HONORATO}

Licenciatura Plena em Educação Física pela Universidade Estadual de Londrina (UEL), Especialização em Biologia Aplicada à Organização do Ambiente Escolar e do Trabalho, Mestrado em Ciências da Saúde pela Universidade Estadual de Maringá (UEM) e Doutorando no Programa de Pós-Graduação em Educação Física (UEM-UEL). Professor do Ensino Básico, Técnico e Tecnológico do Instituto Federal de Santa Catarina - Campus Gaspar. É membro do grupo de Pesquisa Metodologia de Ensino, Saberes e Práticas Educativas (MESPE) do Instituto Federal de Santa Catarina - Campus Gaspar e membro do Grupo de Estudo e Pesquisa em Metabolismo, Nutrição e Exercício (GEPEMENE), no Centro de Educação Física e Esporte, na Universidade Estadual de Londrina. Tem experiência na área de Educação Física Escolar, Educação Física Adaptada, Atividades Rítmicas e Expressivas, Dança e Envelhecimento.

\section{ANTÔNIO DE MEDEIROS PEREIRA FILHO}

Graduando do Curso de Bacharelado em Medicina da Universidade do Estado do Rio Grande do Norte - UERN. 


\section{ANTÔNIO GUEDES RANGEL JÚNIOR}

Doutor em Educação no PROPEd/UERJ. Mestre em Educação pela UFC. Graduado em Psicologia pela URNe/UEPB. Leciona desde 1988 no Departamento do Psicologia da Universidade Estadual da Paraíba - UEPB. Tem experiência na área de Educação, com ênfase em Fundamentos da Educação.

\section{AUGUSTO ANTONIO DA FONSECA NETO}

Graduando do Curso de Bacharelado em Medicina da Universidade do Estado do Rio Grande do Norte - UERN.

\section{AYANNA CARLA DE MORAES GERÔNCIO}

Graduanda em Psicologia pela Universidade Estadual da Paraíba (UEPB). Extensionista do projeto vinculado à PROEX/UEPB "Brinquedoteca Hospitalar: "Brinquedoteca Hospitalar: Espaço de aprendizagem, desenvolvimento psicossocial e qualidade de vida". Pesquisadora no Programa de Iniciação Científica "Cuidados em saúde mental na Atenção Primária em Saúde".

\section{BEATRIZ CRISTINA SOARES BARROS}

Graduanda em Medicina na Faculdade de Ciências Médicas da Paraíba - FCMPB. Integrante do projeto de extensão e pesquisa sobre Cuidados Paliativos.

\section{BIANCA FONSECA DE ARAÚJO}

Discente da Graduação em Medicina do UNIFIP - Centro Universitário

\section{BRUNA PRADO GOMES}

Graduada em Fisioterapia pela Universidade Estadual do Norte do Paraná (UENP) no ano de 2012, onde foi integrante do Grupo de Estudos de Biomecânica e Intervenção Musculoesquelética, entre os anos de 2009 a 2012. Especialização em Osteopatia Estrutural, Osteopatia Visceral e Posturologia pelo Instituto Docusse de Osteopatia e Terapia Manual, Presidente Prudente/SP e, também em Fisioterapia Dermatofuncional e Cosmetologia pela Faculdade Inspirar, Curitiba/PR. Atualmente é mestranda na linha de pesquisa em Atividade Física Relacionada à Saúde pelo Programa de Pós-Graduação Associado em Educação Física da Universidade Estadual de Londrina e Maringá - UEL/UEM. Bolsista da Coordenação de Aperfeiçoamento de Pessoal de Nível Superior (CAPES) entre os anos de 2018-2019. Integrante do Grupo de Estudo e Pesquisa sobre Envelhecimento Humano e Atividade Física (GEPEHAF).

\section{CAMILA PEREIRA}

Graduada em Fisioterapia no ano de 2012 pela Universidade Estadual do Norte do Paraná (UENP), bolsista de Iniciação Científica pela Fundação Araucária. Especialização em Terapia Manual e Técnicas Osteopáticas pelo Instituto Docusse de Osteopatia e Terapia Manual - UENP (2012 2015). Mestra em Exercício Físico na Promoção da Saúde pela Universidade Norte do Paraná (UNOPAR) em Londrina. Doutoranda em Educação Física no Programa de Pós-Graduação Associado em Educação Física UEL/UEM, com período sanduíche na University of Queensland (Brisbane-Austrália) com financiamento da CAPES. Tem experiência na área de Anatomia Humana, Cinesiologia e Biomecânica, Controle Postural, Neurologia Aplicada à Fisioterapia. Integrante do Grupo de Estudo e Pesquisa sobre Envelhecimento Humano e Atividade Física (GEPEHAF).

\section{CRÍSCIA DELANCOUT LÚCIO ARAÚJO}

Acadêmica de Psicologia na Universidade Estadual da Paraíba (UEPB). No momento, integrante do Grupo de Estudos e Pesquisas em TCC com ênfase em terapia do esquema de Jeffrey Young. 


\section{DAIANY MAÍRA MAGALHÃES FRANCA}

Graduanda em Medicina na Faculdade de Ciências Médicas da Paraíba - FCMPB. Integrante do projeto de extensão e pesquisa sobre Cuidados Paliativos

\section{DRIELLE BARBOSA LEAL SERAFIM}

Graduanda do $8^{\circ}$ período no curso de Psicologia pela Universidade Estadual da Paraíba- UEPB. Atuou no grupo de pesquisa: Laboratório de Ciências e Tecnologia em Saúde (LCTS) com foco na Oncologia e participou do projeto de extensão" Serviço de atenção psicossocial no Cras". Atualmente participa do projeto de extensão intitulado "O Abuso sexual infantil: caracterizando o mal" e atua no Programa saúde da família, no projeto "Escuta e Encaminhamento Psicológicos em usuários da UBS"

\section{EDUARDO JOSÉ GUERRA SEABRA}

Professor adjunto IV - UERN Mestre em Clínicas Odontológicas - UFRN. Doutor em Ciências da Saúde - UFRN

\section{EMANUEL SÁ RESENDE PEDROSO}

Possui Graduação em Arquitetura e Urbanismo pela Universidade Federal de Juiz de Fora - UFJF (1999-2004), Mestrado em Arquitetura e Urbanismo pela Universidade Federal de Santa Catarina UFSC (2005-2007) e Doutorado em Ciências em Arquitetura pela Universidade Federal do Rio de Janeiro - UFRJ (2014-2018). É Professor Adjunto do Departamento de Projeto, Tecnologia e Representação em Arquitetura e Urbanismo da Faculdade de Arquitetura e Urbanismo da Universidade Federal de Juiz de Fora - FAU/UFJF e líder do Grupo do Pesquisa ID - Grupo de Estudos sobre o Indivíduo Idoso. Tem experiência na área de Arquitetura e Urbanismo, com ênfase em Projeto de Arquitetura, Percepção e Comportamento, Idoso, Acessibilidade, Desenho Universal, Memória e Apropriação do espaço.

\section{EMILY SOUZA GAIÃO E ALBUQUERQUE}

Psicóloga e Supervisora em Psicologia Clínica - ACP (CFP no 13/6368). Professora substituta da Universidade Estadual da Paraíba. Mestre e Doutoranda em Psicologia Cognitiva pela Universidade Federal de Pernambuco (UFPE). Graduada e licenciada em Psicologia pela Universidade Estadual da Paraíba (UEPB), com formação em psicologia clínica na Abordagem Centrada na Pessoa (ACP). Especialista em Saúde Mental e Dependência Química. Atualmente, é pesquisadora do Núcleo de Estudos em Avaliação Psicológica (NEAP/UFPE). Possui experiência de atuação profissional em psicologia clínica, educacional/escolar, avaliação psicológica e saúde mental, bem como de ensino em psicologia clínica, psicologia organizacional e do trabalho, cognitiva e avaliação psicológica.

\section{FABIANA CRISTINA SCHERER}

Doutoranda na linha de pesquisa em Atividade Física Relacionada à Saúde pelo Programa de PósGraduação Associado em Educação Física da Universidade Estadual de Londrina e Maringá UEL/UEM. Mestre em Atividade Física Relacionada à Saúde pela Universidade Federal de Santa Catarina - UFSC (2014), com Especialização em Atividade Física Direcionada à Promoção da Saúde pela Universidade Estadual do Oeste do Paraná - UNIOESTE (2007), com Graduação em Bacharelado em Educação Física - UNIOESTE (2007) e com Licenciatura Plena - UNIOESTE (2006). Tem experiência na área de Educação Física, com ênfase em: idosos, atividade física, exercício físico, qualidade de vida e processos e programa de promoção da atividade física. Participou recentemente como integrante dos projetos: Vida Ativa Melhorando a Saúde - VAMOS e ENVELHECIMENTO ATIVO - ETAPA II. 


\section{FABIANA SANTOS SILVA}

Graduada em Nutrição pela Universidade Potiguar em 2015, atuou como coordenadora da Política Municipal de Alimentação e Nutrição da Prefeitura Municipal de Mossoró (2017-2018) e atualmente é servidora pública na Estratégia de Saúde da Família. Atua na área da nutrição clínica e social.

\section{FABRÍCIO MIGUEL DOS SANTOS}

Graduando do oitavo período de psicologia pela Universidade Estadual da Paraíba - UEPB. Estudante bolsista do projeto de extensão "Escuta e Encaminhamento Psicológicos à Criança e ao Adolescente em Situação de Risco"; realizado na Casa dos Conselhos, Campina Grande - PB, no período de janeiro a dezembro de 2018

\section{FELIPE EDUARDO DA SILVA SOBRAL}

Médico veterinário pela Universidade Federal de Campina Grande (2007), Mestre em Sistema Agrosilvipastoril no Semi-Árido pela Universidade Federal de Campina Grande (2010). Desempenha atividades profissionais como médico veterinário autônomo e na Unidade de Controle Populacional de Cães e Gatos pela Prefeitura Municipal de João Pessoa (UCPCG/PMJP). Atualmente desempenha atividades de docência no curso de medicina veterinária da UniNassau João Pessoa. É avaliador e autor da revista Environmental Smoke. Trabalha com anatomia e morfologia animal, saúde pública e zooterapia.

\section{FERNANDA ALVES DA SILVA RIBEIRO}

Enfermeira Bacharela e Licenciada pela Universidade do Estado do Rio Grande do Norte. Mestre em Saúde e Sociedade pelo Programa de Pós-graduação em Saúde e Sociedade/UERN. Docente do Curso de Enfermagem da Universidade Potiguar, polo Caicó-RN.

\section{FLÁVIO MEDEIROS GUIMARÃES}

Possui graduação em Enfermagem pela Universidade Potiguar (2009), Pós Graduação em Terapia Intensiva 2015 e Enfermagem do Trabalho 2017, pela CENPEX. Atualmente é Chefe do Setor de Articulação de Redes Assistenciais da Secretaria Municipal de Saúde de Natal/RN e professor da FACULDADE DE CIÊNCIAS E TECNOLOGIA DE NATAL. Trabalhou como Enfermeiro/Técnico da Coordenação de Atenção a Saúde na Secretaria Municipal de Saúde de Parnamirim, Enfermeiro responsável técnico da Unidade Mista de Saúde - Maria Geracina de Oliveira, São Bento do Trairi/RN, do Hospital Municipal Dr Clóvis Avelino, Santana do Matos /RN, Coordenador da Atenção Básica do Município de Santana do Matos/RN. Enfermeiro do Hospital Severino Lopes Natal/RN.

\section{FRANCISCO JALISSON DE ALMEIDA E SILVA}

Especialista em Unidade de Terapia Intensiva e Urgência e Emergência pela Faculdade Metropolitana de Ciências e Tecnologia (FAMEC - 2014) . Enfermeiro, graduada pela Universidade Potiguar (2009). Coordenador de Estágios Práticos. Docente de nível superior e nível médio.

\section{GABRIELLA SOUZA DE AZEVEDO}

Bacharel em Enfermagem (2012) pela Universidade Potiguar de Natal Rio Grande do Norte. Especialista em Obstetrícia (2014) pela Faculdade Metropolitana de Ciências e Tecnologia (FAMEC). Atualmente Professora na Faculdade de Ciências e Tecnologia de Natal, do Grau técnico e Cfaz cursos e pós-graduação. Experiência como professora na Universidade Federal do Rio Grande do Norte (Técnico-PRONATEC), no Hospital e Maternidade Santa Terezinha (Tangará), Unifacex, Ctgás. 


\section{GERALDA JÉSSICA DE ARAÚJO SANTOS}

Bacharela e licenciada em Enfermagem pela Universidade do Estado do Rio Grande do Norte (UERN).

\section{GRAZIELLY DINIZ DUARTE}

Graduanda em medicina veterinária

\section{HOSANA BARROS CAPUXÚ}

Discente da Graduação em Medicina do UNIFIP - Centro Universitário

\section{IVANA CONCEIÇÃO PORTO MORAES}

Possui graduação em Serviço Social pela Universidade do Estado do Rio Grande do Norte (1992) e em Nutrição pela Universidade Potiguar- UNp (2014). Servidora Pública, atualmente é apoiadora do Programa Saúde na Escola e da Política de Alimentação na Secretaria Municipal de Saúde de Mossoró, atuando principalmente no seguinte tema: educação nutricional. Possui Especialização em Gestão da Clínica nas Regiões de Saúde pelo Hospital Sírio-Libanês, Brasil (2014), Especialização em Política Social na Área de Gerontologia Social (2005), Especialização em Pluralidade Cultural e Orientação Sexual

\section{ÍVINA ALBUQUERQUE DA SILVA}

Graduação concluída em Ciências Biológicas (Bacharelado) pela Universidade de Pernambuco. Atuação - Grande área da Biotecnologia. Experiencia em monitoramento e processamento de exames laboratoriais através dos equipamentos AU, DXI Unicell, Immulite, Architect e Cobas. Experiência em gestão de pessoas; Conhecimento nas normas ISO 9001, 14001 e 22000. Experiência também como representante comercial, oferecendo os serviços da empresa para clientes potenciais, acompanhando sempre o pós venda.

\section{JOÃO LUIS ALMEIDA DA SILVA}

Enfermeiro Graduado pela Universidade Federal do Rio Grande do Sul. Mestrado em Enfermagem pela Universidade Federal do Rio Grande do Sul. Doutorando em Ciências pela Universidade Federal de São Paulo. Professor Assistente do Depto. Ciências da Saúde da Universidade Estadual de Santa Cruz (UESC). Coordenador do Laboratório de Práticas Integrativas e Terapias Complementares do Núcleo de Ensino, Pesquisa e Extensão em Metodologias na Enfermagem (NEPEMENF). Experiência em Shiatsuterapia, Yogaterapia, Aromaterapia, Tai Chi Chuan estilo Yang, Lian Gong.

\section{JOSÉ ARTUR DE PAIVA VELOSO}

Orientador de graduação e pós-graduação lato senso na área de ciências da Reabilitação

\section{JOSIANE COSTA E SILVA}

Mestre em Recursos Naturais pela Universidade Federal de Campina Grande - UFCG. Docente do Curso de Bacharelado em Enfermagem da União de Ensino Superior de Campina Grande UNESC. 


\section{JOSILENE MARIZ DE BRITO}

Bacharela e licenciada em Enfermagem pela Universidade do Estado do Rio Grande do Norte (UERN). Enfermeira Plantonista do Hospital Regional do Seridó Telecila Freitas Fontes. Professora da Escola Técnica de Enfermagem Raimunda Nonata. Enfermeira voluntária no Hospital do Seridó atuando na área materno/infantil - Caicó.

\section{KÉZIA KATIANE MEDEIROS DA SILVA}

Doutoranda em Enfermagem pelo Programa de Pós-Graduação da Universidade Federal de São Paulo (Escola Paulista de Enfermagem/UNIFESP). Enfermeira, graduada (2012) pelo Centro Universitário do Rio Grande do Norte. Especialista em Unidade de Terapia Intensiva (2016) e Enfermagem do Trabalho (2019) pela Faculdade Metropolitana de Ciências e Tecnologia (FAMEC). Mestre em Enfermagem (2016) pela Universidade Federal do Rio Grande do Norte (UFRN). É membro dos grupos de pesquisa: Ações promocionais e de atenção a grupos humanos em Saúde Mental e Saúde Coletiva - UFRN; CALEIDOSCÓPIO: Laboratório de Pesquisa sobre Educação, Trabalho, Saúde e Enfermagem - UFRN e Grupo de Estudos e Pesquisas sobre Saúde do Trabalhador - UNIFESP.

\section{LARISSA PONTES CARVALHO GOMES}

Graduanda em psicologia pela Universidade Estadual da Paraíba (UEPB). Atualmente está concluindo o curso de formação em Ciência ABA pela FIP (Faculdades Integradas de Patos), trabalha como terapeuta ABA de crianças com autismo. Além disso, é extensionista bolsista do projeto "Serviço de Acolhimento psicológico a crianças e adolescentes em situação de risco". Tem experiência na área de autismo, saúde mental e desenvolvimento infantil.

\section{LHAIS CABRAL MARTINS}

Acadêmica de Psicologia na Universidade Estadual da Paraíba (UEPB). Atualmente desenvolve a atividade no projeto de extensão: SERVIÇO DE ACOLHIMENTO PSICOLÓGICO À CRIANÇA E AO ADOLESCENTE EM SITUAÇÃO DE RISCO. prestando atendimento psicológico na casa dos conselhos, localizado na cidade de Campina Grande-PB.

\section{LÍVIA DANTAS FRAGOSO}

Discente da Graduação em Medicina do UNIFIP - Centro Universitário

\section{LORENA BANDEIRA MELO DE SÁ}

Possui graduação em Psicologia pela Universidade Estadual da Paraíba (2011). Ênfase em Psicologia Clínica. É professora da Universidade Estadual da Paraíba e Centro Universitário Maurício de Nassau. Mestre em Ciências das Religiões pela Universidade Federal da Paraíba. Vice Coordenadora do Núcleo Viktor Frankl de Logoterapia da UEPB. é 'líder do grupo de pesquisa Sosein: estudos em Logoterapia da Uninassau e participa dos grupos de pesquisa em saúde mental Déjà Vu: Artes, Sonhos e Imagens, da UEPB e Nous: Espiritualidade e Sentido, da UFPB e é professora de Programas de Especialização na área de Logoterapia e Análise Existencial. É organizadora dos livros Da teoria à prática: a dimensão social da Logoterapia; e Logoterapia e Suicidio: a busca de sentido como prevenção ao vazio existencial.

\section{LUANA DE SOUSA PEREIRA}

Possui graduação em Enfermagem (2011) pela Faculdade de Enfermagem Nova Esperança FACENE, Especialista em Residência Multiprofissional em Atenção Básica/Saúde da Família e Comunidade pela Universidade do Estado do Rio Grande do Norte, UERN, Especialista em Saúde e Segurança do Trabalhador. Especialista em Enfermagem Clinica. Experiência na docência na faculdade FACENE. Atuou como Gerente Executiva da Atenção Básica na Prefeitura Municipal de Mossoró e como Supervisora em Saúde da Família na referida instituição. 


\section{LUCAS BRASIL FEITOSA}

Graduando em Psicologia pela Universidade Estadual da Paraíba (UEPB). Integrante do NINETS/UEPB (Núcleo de Investigações e Intervenções em Tecnologias Sociais) onde se busca problematizar a atuação de marcadores sociais de raça, gênero e sexualidade e sua interação com outros marcadores da diferença na produção de dinâmicas sociais do estado da Paraíba. Atualmente preside a Coletiva Gaia, organização empenhada em desenvolver estratégias pedagógicas articuladas a processos que permitam ampliar o acesso e permanência de pessoas, jovens ou não, a escola e a universidade, bem como a outros espaços da vida, atuando em varias frentes pela ampla defesa da cidadania e dos direitos humanos.

\section{LUCAS HENRIQUE DE BARROS PORTELA CAMPELO}

Tecnólogo em Gestão de Turismo pelo IFPE, campus Recife.

\section{LUCAS PEREIRA LUCENA}

Acadêmico de Psicologia na Universidade Estadual da Paraíba (UEPB). Atualmente, bolsista do Programa de Iniciação Científica (PIBIC) na qualidade de pesquisador do projeto: "A carta roubada e os desvios do inconsciente, em Freud e Lacan", orientado pelo Prof. Dr. Reginaldo Oliveira Silva.

\section{MARIA ANGÉLICA PALMEIRA DA ROCHA}

Graduada do Curso de Bacharelado em Enfermagem da Unesc Faculdades-FAC/CG. Técnico em Contabilidade. agiangelica@hotmail.com.

\section{MARIA DAS GRAÇAS SILVA}

Graduação em Farmácia pela Universidade Federal da Paraíba, mestrado em Produtos Naturais e Sintéticos Bioativos pela Universidade Federal da Paraíba

\section{MARIA DO ROSÁRIO DE FÁTIMA PADILHA}

Possui graduação em Nutrição pela Universidade Federal de Pernambuco (1979), mestrado em Nutrição pela Universidade Federal de Pernambuco (1996) e doutorado em Nutrição pela Universidade Federal de Pernambuco (2005) ambos na área de Ciência de Alimentos. Atualmente é Professor Associado do Curso de Bacharelado em Gastronomia do Departamento de Tecnologia Rural da Universidade Federal Rural de Pernambuco.Faz parte do Colegiado de Coordenação Didática (CCD) e da Comissão de Avaliação de Progressão Docentes (CAPD) do DTR/UFRPE. Tem experiência na área de Nutrição, com ênfase em Ciência dos Alimentos, atuando principalmente nos temas: Aproveitamento Integral de Alimentos, Frutas Nativas, Alimentação Não Usual, Plantas Alimentícias Não Convencionais

\section{MARIA JANINE PEREIRA FERNANDES}

Mestre em Saúde Pública e Gestão Hospitalar. Professora do Curso de Bacharelado em Enfermagem da Unesc Faculdades-FAC/CG.

\section{MARIA JOSELITA ALVES}

Enfermeira e especialista em Pediatria e Puericultura pela UEPB.

\section{MARIA ZÉLIA ARAUJO}

Mestre em Sociologia. Professora do Curso de Bacharelado em Enfermagem, Fisioterapia, Administração, Ciências Contábeis e Tecnólogo em Gestão Comercial, todos na Unesc FaculdadesFAC/CG. 


\section{MARIANA DOMINATO ABRAHÃO CURY}

Professora Assistente no Dep. de Projeto, Representação e Tecnologia da Faculdade de Arquitetura e Urbanismo da Universidade Federal de Juiz de Fora

\section{MILANE SALES DE SOUZA}

Graduada em Nutrição pela Universidade Federal da Paraíba(1998) com 21 anos de experiência em clínica. Formação e especialização em acupuntura pela Associação Brasileira de Acupuntura(2011) com 6 anos de atuação em práticas integrativas e complementares no SUS. Graduanda em Medicina Veterinária

\section{MILLENA CAROLINE GOMES RODRIGUES}

Graduanda do $8^{\circ}$ período no curso de Psicologia pela Universidade Estadual da Paraíba- UEPB. Aluna participante do Projeto Educacional do Trabalho em Saúde (Pet - Saúde Interprofissionalidade) do Ministério da Saúde.

\section{NÁDIA ROCELY SOUTO DE ALMEIDA LIMA}

Possui graduação em letras língua portuguesa pela Universidade Potiguar em 2002; graduada em enfermagem pelo Centro Universitário FACEX RN - 2012 Especialista em Preceptoria do SUS- 2012 pelo Sírio Libanês; Especialista em Qualidade em saúde e Segurança do Paciente Sírio Libanês 2015; Especialista em Educação Permanente em Saúde (2016) Especialista em Gestão de Desenvolvimento na Preceptoria e Programa de Residências Médicas e Multiprofissionais (2018/2019); Mestranda em Gerontologia (2018) Especializanda em Programas de Residências Médicas e Multiprofissionais 2019/2020. Atualmente coordena o setor de educação permanente e articulação ensino serviço na SMS de Natal; Docente da Faculdade de Ciências e Tecnologia de Natal - FACITEN (2014 e 2019). Possui experiência na área de assistência primária em saúde e hospitalar e em saúde coletiva. Atua principalmente em ministrar temas que facilitam a injeção na saúde pública com método paidéia metodologias ativas e inserção em saúde do Trabalhador do SUS na discussão da corresponsabilidade e gestão do trabalho e educação na saúde; Coordena o projeto Pet interprofissionalidade pelo Ministério da Saúde Secretaria Municipal de Saúde e UFRN ; Preceptora de discentes de saúde coletiva, enfermagem e gestão hospitalar; Membro da equipe de saúde do Trabalhador de Natal; Orientadora de trabalho de conclusão de curso TCC; Membro avaliadora de banca de TCC (2017/2019) Membro da comissão intergestora de ensino serviçosCIES; Membro da comissão de residência médica (COREMU) e Comissão de Residências Multiprofissionais (COREMU).

\section{NATHÁLIA DE AZEVEDO SOUZA}

Enfermeira graduada pela Universidade Estadual de Santa Cruz - UESC. Participou do Laboratório de Farmacologia Comportamental - LAFAC/UESC (2015-2016). Membro da diretoria da Liga Acadêmica de Enfermagem em Atenção Interprofissional em Urgências - LINTER/UESC (20162017). Participou do Núcleo de Estudo, Pesquisa e Extensão em Metodologias na Enfermagem, atuando no Laboratório de Práticas Integrativas e Terapias Complementares (2017-2018). Tem experiência na área de pesquisa científica, atuando principalmente nos seguintes temas: farmacologia comportamental, urgência e emergência, práticas integrativas e terapias complementares.

\section{NAYARA BATISTA MARQUES}

Graduando pelo Curso de medicina da Faculdade de Medicina Nova Esperança 


\section{NEIDE KAZUE SAKUGAWA SHINOHARA}

Graduação em Farmácia-bioquímica e Tecnologia em Gastronomia. Especialização em Bioética, Mestrado em Nutrição e Doutorado em Ciências Biológicas pela Universidade Federal de Pernambuco. Atualmente é professora Associado da Universidade Federal Rural de Pernambuco no Curso de Bacharelado em Gastronomia. Tem experiência na área de Ciência e Tecnologia dos Alimentos, Estudo de Ecossistemas, Políticas Ambientais e Culturais. Líder do Grupo de Pesquisa SAAIS/CNPq.

\section{RACHEL CAVALCANTI FONSECA}

Graduação em Fisioterapia pelo Centro Universitário de João Pessoa (2005) e mestrado em Ciências das Religiões pela Universidade Federal da Paraíba (2012)

\section{RAFAELA MARIA MARTINS QUEIROZ}

Graduanda em Medicina na Faculdade de Ciências Médicas da Paraíba - FCMPB. Integrante do projeto de extensão e pesquisa sobre Cuidados Paliativos no semestre 2019.1

\section{RITA DE CÁSSIA DANTAS DE FREITAS}

Graduação em Letras (Língua Portuguesa). Graduanda em Psicologia pela Universidade Estadual da Paraíba (UEPB). Atuou como docente no ensino fundamental e médio na rede púbica do Estado da Paraíba.

\section{RODRIGO PINHEIRO FERNANDES DE QUEIROGA}

Docente da graduação em Enfermagem da Universidade Federal de Campina Grande - UFCG

\section{SORAYA ABRANTES PINTO DE BRITO}

Graduanda em Medicina veterinária

\section{TÂNIA ROSANE BERTOLDO BENEDETTI}

Possui graduação em Educação Física pela Universidade Federal de Santa Maria (1986), mestrado em Educação Física pela Universidade Federal de Santa Catarina (1999), doutorado em Enfermagem pela Universidade Federal de Santa Catarina (2004) e pós doutorado pela University of Illinois at Urbana-Champaign EUA (2011). Estágio formação na universidade de Nebraska Medical Center EUA (2016). Atualmente é professor associada III da Universidade Federal de Santa Catarina. Tem experiência na área de Educação Física, com ênfase em Atividade Física Relacionado à Saúde, atuando principalmente nos seguintes temas: idosos, programas de atividade física e exercício físico e SUS. Bolsista produtividade do CNPq.

\section{THAINÁ CALÓ MAGALHÃES}

Enfermeira graduada pela Universidade Estadual de Santa Cruz - UESC. Participou do Núcleo de Estudo, Pesquisa e Extensão em Metodologias na Enfermagem, atuando no Laboratório de Práticas Integrativas e Terapias Complementares (2017-2018). Tem experiência na área de pesquisa científica, atuando em práticas integrativas e terapias complementares.

\section{TIAGO URIATÃ DE VASCONCELOS COSTA}

Graduando do $8^{\circ}$ período no curso de Psicologia pela Universidade Estadual da Paraíba- UEPB. Atuante no Programa saúde da família, no projeto "Escuta e Encaminhamento Psicológicos em usuários da UBS" 


\section{VANESSA SOUTO MAIOR}

Graduando do Curso de medicina da Faculdade de Ciências Médicas da Paraíba

\section{YANE SANTANA DE ALMEIDA}

Arquiteta, graduada pela Faculdade de Arquitetura e Urbanismo da Universidade Federal de Juiz de Fora/Minas Gerais.

\section{YNGRID MARIA TORRES FREIRE}

Discente da Graduação em Medicina do UNIFIP - Centro Universitário

\section{YRAGUACYARA SANTOS MASCARENHAS}

Bacharela e licenciada em Enfermagem pela Universidade do Estado do Rio Grande do Norte (UERN). 


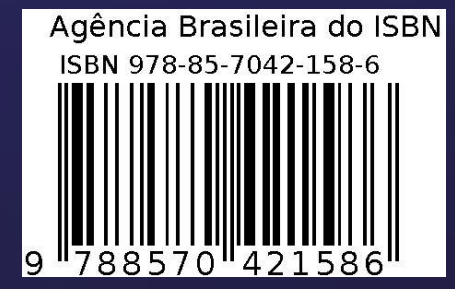

